\title{
Debating Europe : reflections on EU affairs in the public sphere.
}

Citation for published version (APA):

Bijsmans, P. H. M. G. (2011). Debating Europe : reflections on EU affairs in the public sphere. [Doctoral Thesis, Maastricht University]. Universitaire Pers Maastricht. https://doi.org/10.26481/dis.20110601pb

Document status and date:

Published: 01/01/2011

DOI:

$10.26481 / \mathrm{dis} .20110601 \mathrm{pb}$

Document Version:

Publisher's PDF, also known as Version of record

\section{Please check the document version of this publication:}

- A submitted manuscript is the version of the article upon submission and before peer-review. There can be important differences between the submitted version and the official published version of record.

People interested in the research are advised to contact the author for the final version of the publication, or visit the DOI to the publisher's website.

- The final author version and the galley proof are versions of the publication after peer review.

- The final published version features the final layout of the paper including the volume, issue and page numbers.

Link to publication

\footnotetext{
General rights rights.

- You may freely distribute the URL identifying the publication in the public portal. please follow below link for the End User Agreement:

www.umlib.nl/taverne-license

Take down policy

If you believe that this document breaches copyright please contact us at:

repository@maastrichtuniversity.nl

providing details and we will investigate your claim.
}

Copyright and moral rights for the publications made accessible in the public portal are retained by the authors and/or other copyright owners and it is a condition of accessing publications that users recognise and abide by the legal requirements associated with these

- Users may download and print one copy of any publication from the public portal for the purpose of private study or research.

- You may not further distribute the material or use it for any profit-making activity or commercial gain

If the publication is distributed under the terms of Article $25 \mathrm{fa}$ of the Dutch Copyright Act, indicated by the "Taverne" license above, 


\section{Debating Europe}

Reflections on EU Affairs in the Public Sphere 
(C) copyright Patrick Bijsmans, Maastricht 2011 Datawyse bv / Universitaire Pers Maastricht ISBN 978-94-6159-058-9 


\section{Debating Europe}

\section{Reflections on EU Affairs in the Public Sphere}

\section{PROEFSCHRIFT}

ter verkrijging van de graad van doctor aan de Universiteit Maastricht, op gezag van de Rector Magnificus, Prof mr. G.P.M.F. Mols

volgens het besluit van het College van Decanen,

in het openbaar te verdedigen

op woensdag 1 juni 2011 om 12.00 uur

door

Patrick Hendrik Matheus Gerardus Bijsmans

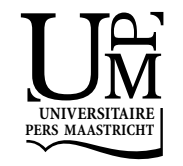




\section{Promotores:}

Prof. dr. C.Blom

Prof. dr. A.J.J. Nijhuis (Universiteit van Amsterdam)

\section{Beoordelingscommissie:}

Prof. dr. S. Vanhoonacker (voorzitter)

Prof. dr. T. Christiansen

Prof. dr. R. Koopmans (Vrije Universiteit Amsterdam)

Dr. C. Neuhold

Prof. dr. M. Shackleton 


\section{Contents}

$\begin{array}{ll}\text { Acknowledgements } & 9\end{array}$

List of Abbreviations

1 Introduction: The 'European Coffee House' 15

$\begin{array}{ll}\text { Democracy in the European Union } & 17\end{array}$

$\begin{array}{ll}\text { Europe's Public Deficit } & 19\end{array}$

Studying the European Public Sphere $\quad 22$

$\begin{array}{ll}\text { Research Design } & 27\end{array}$

$\begin{array}{ll}\text { Methodology } & 31\end{array}$

$\begin{array}{ll}\text { Outline of the Thesis } & 36\end{array}$

2 The Public Sphere: Questions of Standards 39

Democracy and the Public Sphere $\quad 41$

Political Actors, the Media and the Public: Constructing Public Spheres $\quad 45$

Political Actors $\quad 47$

The Media $\quad 48$

The Public $\quad 49$

The Contemporary Public Sphere $\quad 51$

The Demise of the Public Sphere? 51

Re-establishing the Public Sphere? 53

A European Public Sphere?

The Unfeasible European Public Sphere $\quad 57$

Four Critiques $\quad 59$

Manifestations of the European Public Sphere 63

The Elite European Public Sphere 64

Issue-Specific European Public Spheres 65

National Public Spheres and a Popular European Public Sphere 66 
3 EU Affairs in the Public Sphere: The Brussels Micro-Cosmos 71

The EU Institutions and the Communication Predicament 73

The National Tier: Governments, Parliaments and the Council 74

$\begin{array}{ll}\text { The Commission } & 77\end{array}$

The European Parliament $\quad 80$

'Bridging the Gap'? Transparency and Communication 82

Transparency: Necessary, but Sufficient? 83

Communicating Europe: 'Listening', 'Going Local' and 'Partnership' 86

The Response by the EP and the Member States 89

Communicating Europe: Some Critical Comments 92

The European Media and the Brussels Newsbeat 95

Pan-European Media and Press Reviews $\quad 95$

The Brussels Press Corps $\quad 97$

The Newsworthiness of EU Current Affairs $\quad 99$

Conclusion 101

4 National Public Spheres and the EU: Germany and The Netherlands $\quad 103$

Europe between Resemblances and Differences 104

Politics and Democracy in Germany and the Netherlands 105

Media and Political Communication in Germany and the Netherlands 109

Germany, the Netherlands and European Integration 113

$\begin{array}{ll}\text { Major Differences } & 118\end{array}$

The German Länder's Impact on Politics 118

Constitutions and Courts $\quad 120$

Conclusion 122

5 The Future of Europe: From Fischer to Failure 123

The Debate on the EU's Future: An Overview 124

The Findings: A General Overview 130

Considering the Numbers $\quad 131$

The Debate in the German Public Sphere 136

The Debate in the Dutch Public Sphere 138

The Three Dimensions 140

The Issue Dimension $\quad 141$

The Process Dimension $\quad 147$

The Actor Dimension $\quad 151$

Analysis 156

$\begin{array}{ll}\text { Conclusion } & 163\end{array}$

6 Ambient Air Quality: Tiny Particles, Major Consequences 165

EU Environmental Policy: A Concise Overview 166 
Clean Air For Europe $\quad 169$

The Findings: A General Overview 173

Considering the Numbers 174

The Debate in the German Public Sphere 177

The Debate in the Dutch Public Sphere 179

The Three Dimensions 182

The Issue Dimension 183

The Process Dimension 188

The Actor Dimension $\quad 194$

Analysis 200

$\begin{array}{ll}\text { Conclusion } & 207\end{array}$

7 Conclusion: A Public Sphere in the Making? 209

National Public Spheres and EU Affairs $\quad 210$

The Interaction Between National Public Spheres 212

Transnational Public Debates 215

Europe's Communicative Network: A Multifaceted Public Sphere 217

EU Democracy and the 'European Coffee House' 222

A Public Deficit? 226

$\begin{array}{lr}\text { Annex 1: Codebook } & 229\end{array}$

Annex 2: The Constructed Weeks 235

$\begin{array}{ll}\text { Interviews } & 237\end{array}$

$\begin{array}{lr}\text { References } & 239\end{array}$

$\begin{array}{lr}\text { Samenvatting } & 265\end{array}$

$\begin{array}{ll}\text { Curriculum Vitae } & 271\end{array}$ 



\section{Acknowledgements}

Writing a PhD dissertation is not an easy endeavour - nor should it be. Combining it with extra teaching duties and other administrative responsibilities does not help much either. Even so, I have rarely doubted whether I should have taken on this challenge. Looking back, it has certainly been extremely worthwhile and taught me many things which I will carry with me for the rest of my life. I would, however, not have been able to do this on my own, and am therefore grateful for the support and help of many people. First of all, I would like to thank my two supervisors, Tannelie Blom and Ton Nijhuis, for giving me the opportunity to do a PhD and for believing in my academic ability and supporting me throughout these years. I first met Tannelie as a student at the end of the 1990s and ever since I have benefited from his intellectual guidance and support, during formal and informal get-togethers. Whereas Tannelie acted as my day-to-day supervisor, Ton's was more a backseat role, but no less important; his erudite comments and feedback often helped me to see more clearly where my research was going.

I would also like to thank my colleagues and friends at Maastricht University's Faculty of Arts and Social Sciences, for feedback on my research, as well as for the many more pleasant social activities we engaged in. These include Cornelia, Elissaveta, Leen, Maaike, Martijn, Merel, Niki, Saskia, Sophie and Vivian, all of whom started to work on their own $\mathrm{PhD}$ research at about the same time as I did, and with whom I had many interesting discussions and great soup. A special thank you goes to Ludo, with whom I have had the pleasure of sharing an office for many years, and whose experience and ideas have been very inspiring, not just academically. I am also grateful to my fellow European Studies staff members, some of whom have become more than just colleagues: Aneta, Christine, Esther (\& Jeroen), Heidi, Karolina (\& Jost), Maarten, Mihaela, Paul (\& Tod), Petar and Sophie. Thanks also extend to my friends at the Faculty of Law, Mariolina and Michał (now representing the 
peoples of Europe in our nation's capital, Brussels). Not often mentioned are Jacqueline, Joke and Sabine, our wonderful secretaries, who have regularly been there to assist in making my life easier, though this thank you should probably be extended to all colleagues of the faculty's support staff (and in particular to Lucie and Sjoerd, who always let me finish first in the competitive runs we participate in). Finally, Johan has been very helpful in checking some of the more tedious parts of the manuscript, the list of abbreviations and the reference list.

I would, of course, also like to thank my friends outside of academia for lots of laughter, long nights and other much-needed distractions, in particular my longtime friends Björn, Ernesto, Ralph, Ronald and Sandrijn. My two paranymphs Paul and Stephan deserve special mentioning for all kinds of support in these last stages of the process and for their friendship in general. Paul has also read the manuscript for language errors, while at the same time providing me with further valuable feedback. My mum Annie and dad René, my sister Daniëlle and my brother-in-law Kai and my grandparents (who unfortunately did not live long enough to see this day) have been there for me along the way. Thanks also go to Rhea's family, in particular, Jos and Bert, Ruth and Rik and the kids and Roger and Kim and the kids. Finally, none of this would have ever been possible without Rhea, who I love very much. 


\section{List of Abbreviations}

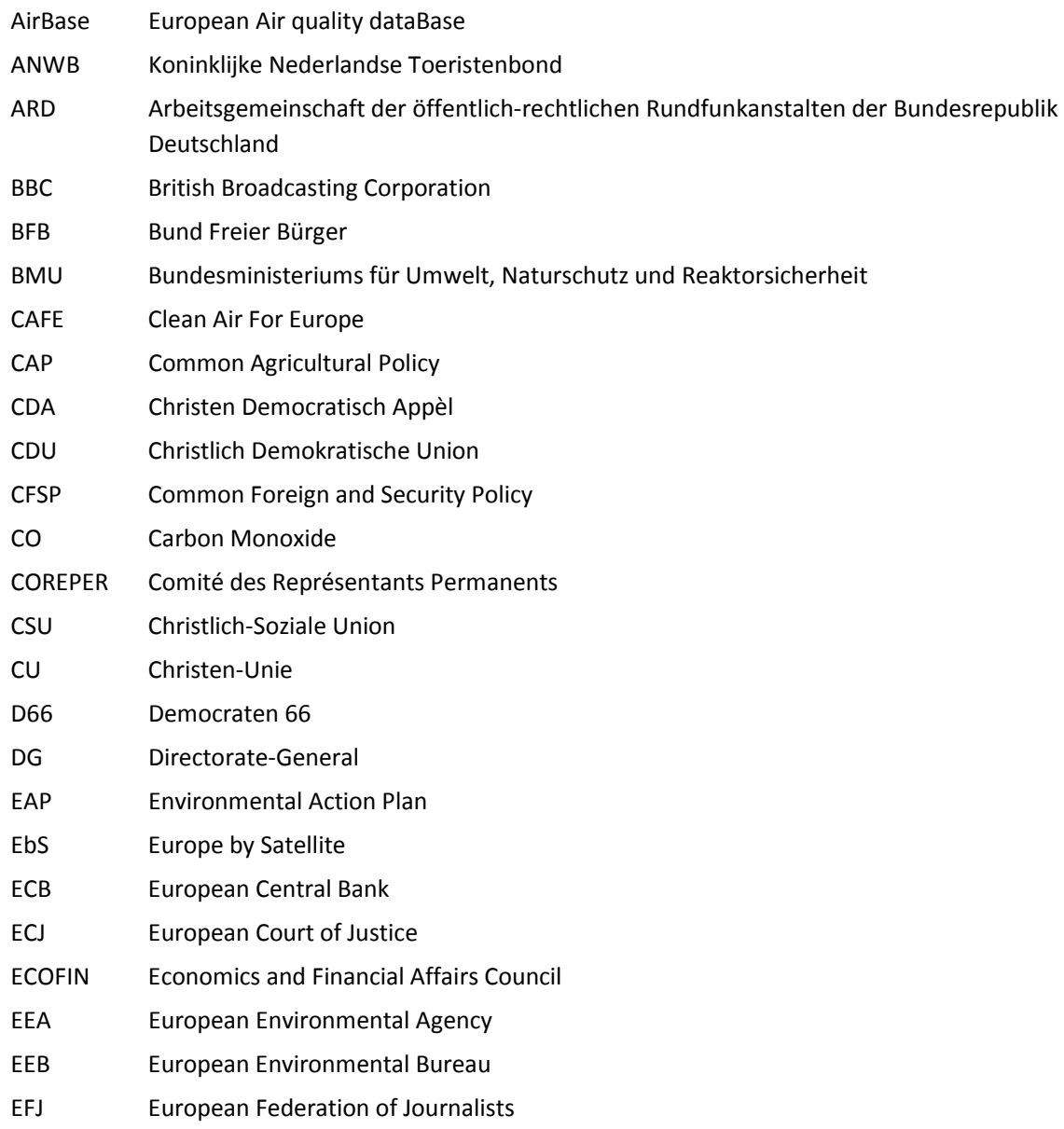


EIONET European Environment Information and Observation Network

EJC European Journalism Centre

EMU European Monetary Union

ENVI Committee on Environment, Public Health and Food Safety

EP European Parliament

EU European Union

EUROCLIO European Association of History Educators

FAZ Frankfurter Allgemeine Zeitung

FR Frankfurter Rundschau

FDP Freie Demokratische Partei

GG Grundgesetz

GMO Genetically Modified Organisms

GW Grondwet voor het Koninkrijk der Nederlanden

HR CFSP Secretary General/High Representative for the Common Foreign and Security Policy

IGC Intergovernmental Conference

IIA Inter-Institutional Agreement

LPF Lijst Pim Fortuyn

MEP Member of European Parliament

MP Member of Parliament

NATO North Atlantic Treaty Organisation

NGO Non-Governmental Organisation

NO2 Nitrogen Dioxide

NOx Nitrogen Oxide

NRC NRC Handelsblad

O3 Ozone

OJ Official Journal

PDS Partei des Demokratischen Sozialismus

PM Particulate Matter

PR Public Relations

PRINCE Priority Information Activities

PvdA Partij van de Arbeid

PVV Partij voor de Vrijheid

QMV Qualified Majority Voting

RIVM Rijksinstituut voor Volksgezondheid en Milieu

SEA Single European Act

SER Sociaal-Economische Raad

SO2 Sulphur Dioxide

SP Socialistische Partij

SPD Sozialdemokratische Partei Deutschlands

SGP Staatkundig Gereformeerde Partij

SZ Süddeutsche Zeitung 
TECE Treaty Establishing a Constitution for Europe

TEL De Telegraaf

TEU Treaty on European Union

TFEU Treaty on the Functioning of the European Union

UBA Umweltsbundesamt

UEAPME European Association of Craft, Small and Medium-Sized Enterprises

UN United Nations

UNICE Union of Industrial and Employers' Confederations in Europe

US United States

VK De Volkskrant

VROM Volkshuisvesting, Ruimtelijke Ordening en Milieubeheer

VVD Volkspartij voor Vrijheid en Democratie

WASG Wahlalternative Arbeit und Soziale Gerechtigkeit

WHO World Health Organisation

WTO World Trade Organisation

ZDF Zweites Deutsches Fernsehen 



\section{1}

\section{Introduction:}

\section{The 'European Coffee House'}

[T]here has never been a European coffee house, an 'agora', a place where Europeans can form their opinions, give birth to new ideas, and test their views. Which means that whoever wants their voice to be heard in the much-vaunted 'European Debate' will have to search hard: after half a century of European integration, still only a very small proportion of the national elites are actually taking part in that discussion. (Mak, 2005, p.55)

From the sixteenth to the nineteenth century coffee houses played a pivotal role in the development of democratic life and the emancipation of the citizenry in many European countries. They created an environment where people from different layers of society met and engaged in a variety of activities, ranging from playing games to the exchange of knowledge. Coffee houses provided an arena for open discussion between ordinary citizens and a platform for the emergence of political parties, movements and even modern journalism (Heise, 1987). The new 'critical publicness' that emerged in these venues was not just enacted through rational debate, but also by means of theatre, literature and other forms of expression (Kömeçoglu, 2005, p.11). As a result, coffee houses became increasingly associated with freedom of speech and political dissent.

Writing about coffee houses across the Ottoman Empire, Ugur Kömeçoglu $(2005$, p.8) notes that "coffee promoted the development of a novel civil experience based on a different kind of socialisation and a new civility." For the ruling political elites the emergence of coffee houses as sites for the advancement of this new, increasingly open political and social reality, constituted a threat. Many of them from the Ottoman Sultan Murat IV in the 1620s and 1630s, to the English King Charles II in the mid-1670s - tried to resist such new notions through the introduc- 
tion of tougher legislation and even attempted to close down coffee houses. They did not succeed, though. In fact, at the end of the eighteenth century coffee houses were at the centre of revolutionary events in France and in the British colonies in Northern America. In the Parisian coffee house Café de Foy, and the Merchants Coffee House in New York, drinking coffee was even considered to be an act of resistance (Heise, 1987, pp.171-3). In the words of Markman Ellis (2004, p.100), a new awareness of politics gradually emerged as

the coffee-houses continued to be emblematic locations for debate on public affairs by those outside the higher echelons of political life. Through such discussions and debates, a new notion emerged that there could be such a thing as an unofficial knowledge of affairs of state, that the common people had an interest in evaluating how they were governed.

In short, coffee houses played an important part in the advancement of democratic politics in which open debate and opinion formation about public affairs became an essential element. Jürgen Habermas assigned them a central role in his classic, 1962 account of the development and change of the public sphere: the arena for public debate on political, cultural and other issues. ${ }^{1}$ According to Habermas (1990, pp.968 ), coffee houses - and similar venues such as salons - made a threefold contribution to the development of the public sphere: everyone was considered equal regardless of such features as descent or profession; issues that had previously been excluded from broader discussion were now openly being questioned; and coffee houses and the discussions therein were, in principal, open to all.

Today all sorts of issues ranging from health policy to the arts are scrutinised in debates in the modern equivalents of the traditional coffee house, which include virtual venues, such as old and new media ${ }^{2}$, where people meet in time and hyperspace, and physical locations such as contemporary cafés where people come together face-to-face. Such debates can legitimate public policies and the politicians and officials who devise them. It is within this context that the Dutch author Geert Mak (2007, pp.823-4; cf. Mak, 2005), in his book on twentieth century European history, has argued that European democracy is flawed because of the absence of a 'European coffee house'. Mak presents the coffeehouse as a metaphor for the public sphere. His observation suggests two things: first, that democratic life in the European Union (EU) is imperfect and, second, that this shortcoming is linked to deficiencies within the European public sphere. This requires further explanation.

\footnotetext{
${ }^{1}$ As opposed to the private sphere, in which people may also discuss similar issues, but (relatively) free from social pressures. What is considered 'public' or 'private' may change over time (e.g. Sanders, 2009, pp.144-5; Staeheli \& Mitchell, 2004).

${ }^{2}$ Note that throughout this thesis 'media' will be used in the plural, in order to reflect the fact that there are different types of media which also display different ideas about their role in society, as well as offering different views towards societal issues.
} 


\section{Democracy in the European Union}

Democracies come in many forms and there are numerous different theoretical conceptions of this particular form of societal organisation (e.g. Held, 2006; Schmidt, 2000). Classical Greece was characterised by a form of direct democracy (however imperfect) that materialised in the agora. Contemporary politics is largely representative (e.g. Heywood, 2004, pp.224-5; Schmidt, 2000, p.355) and democracy has become associated with the nation-state. The development of the Westphalian state system promoted a belief that citizens were able to make sovereign and autonomous decisions within the clearly defined territory of the state, the latter being the sole source of legal obligations (Held, 2006, p.290; McGrew, 1997). The process of globalisation, defined by Anthony Giddens (1990, p.64) as "the intensification of worldwide social relations which link distant localities in such a way that local happenings are shaped by events occurring many miles away and vice versa", has questioned these beliefs. Global cultural, economic and legal flows have increased and international governance has become more important, with key decisions increasingly being made at a level that transcends the nation-state. Interest groups and other interested parties (such as sub-national governments) can even address regional and global authorities directly, thus bypassing national governments. Such developments have challenged established democratic procedures, and raised some concerns, because of a belief that the international level of decisionmaking is less transparent and democratic (e.g. Held, 2006, pp.290-304).

Hence, one of today's most prominent issues - both in academic and political debates - is how to democratise international governance. Prominent democracy theorists disagree as to whether international governance has the capacity to become democratic. For instance, Robert Dahl (1999) argues that international organisations cannot become democratic as it is hard to imagine people being able to exercise influence in such organisations when they are barely able to control (nor are very interested in) national foreign policies. Even if citizens were able to assert some degree of influence, the scale would probably be too immense, and citizens would be too far removed from international centres of decision-making. Others have explored new ways of enhancing legitimacy and accountability beyond the nation-state. David Held (1999; 2006, pp.304-11) introduces the idea of cosmopolitan democracy based on the internationalisation of democratic law, which allows for citizens to become part of multiple political communities at various levels. According to Held $(1999$, p.108) the establishment of bodies such as the United Nations (UN) and the EU, and the advancement of a transnational civil society might help "to create new forms of public life and new ways of debating regional and global issues." In other words, in contrast to Dahl, Held actually believes that international organisations can enhance democratic governance. 
Nowhere do the processes attributed to globalisation figure more prominently than in the EU. Originally the scope of this system of governance was limited to the economic sphere, yet over the years its competences have evolved. With the 1992 Treaty on European Union (TEU) ${ }^{3}$ European integration became a project that no longer only affected specific societal groups such as farmers, but also increasingly came to have an impact on the daily lives of other European citizens. Today Union decision-making applies to many different fields, ranging from environmental matters to security issues, and from food safety to judicial cooperation. Within this context the importance of ensuring the democratic legitimacy of the EU and its policies has become a prominent issue in political and scholarly debates.

For example, in its white paper on governance the European Commission (2001b, p.8, footnote 1) emphasised the importance of 'openness', 'participation', 'accountability', 'effectiveness' and 'coherence' for good governance, reflecting the importance of both effective problem-solving ('effectiveness' and 'coherence') and democratic legitimacy ('openness', 'participation' and 'accountability'). As it happens, this dual emphasis reflects a prominent dilemma in democratic societies, namely how to balance system effectiveness with citizen participation. In larger polities such as the EU this predicament is perhaps most pressing, as they are usually more distant from the citizen, despite the fact that they might be more apt to deal with cross-border matters in particular (Dahl, 1994; 1999, p.22). It is within this context that the term 'democratic deficit' has become one of the buzzwords in debates about the EU's democratic legitimacy. Definitions vary, but in short the alleged democratic deficit implies that Europeans have limited opportunities to (directly) influence EU affairs and hold European policymakers accountable, which, by implication, decreases the legitimacy of the Union and its policies (e.g. Chryssochoou, 2003; Follesdal \& Hix, 2005, pp.4-6; Kohler-Koch \& Rittberger, 2007b; McCormick, 2008, p.119; Newman, 2001).

References to this dilemma are not new. Back in 1979 the British scholar David Marquand (1979) phrased the term 'democratic deficit' in his appeal for an increase of powers of the European Parliament (EP), which should boost the European citizens' influence on legislation that had a growing effect on their lives. Throughout recent decades the debate on the democratic deficit has intensified, with many scholars discussing the EU's democratic legitimacy, its characteristics and the possible solutions to its presumed deficiencies (e.g. Arnull \& Wincott, 2002; Kohler-Koch \& Rittberger, 2007a; Lord, 1998; Warleigh, 2003). Some believe there is no real problem. For example, Giandomenico Majone (1998) stresses that the EU is a regulatory state which is actually better off having non-majoritarian standards of democracy. On a different note, Andrew Moravcsik (2002) claims that the involvement of both directly and indirectly elected representatives at all levels of the system of

\footnotetext{
${ }^{3}$ More commonly known as the Maastricht Treaty.
} 
European governance already creates a structure with sufficient checks and balances. Scholars like Arthur Benz (2006) disagree and argue that because of the involvement of so many different, often anonymous, actors and the complexity of the European system of governance, accountability and legitimacy are inherently flawed. In this context, Myrto Tsakatika (2008) argues that the EU suffers from a responsibility deficit, because of the difficulties in identifying responsible policymakers and holding them accountable. Others have criticised the EU for not even being able to live up to the criteria of democratic governance it sets for candidate countries (e.g. Zürn, 2000). ${ }^{4}$

By and large, a majority of scholars seems to agree that there is a problem, though they may not always agree on its extent. As for solutions, suggestions also vary. Originally it was thought that the strengthening of the EP, the EU's only directly elected institution (since 1979), would almost automatically lead to a democratisation of the Union (e.g. Marquand, 1979). But while steps in this direction have been taken during consecutive Intergovernmental Conferences (IGCS), the increased competences of the Parliament have not strengthened democracy. Some have even questioned the belief that a more influential role for the EP strengthens democracy, because the parliament lacks legitimacy due to low election turn-outs and the absence of a European demos (Blom, 2001, pp.34-5; Warleigh, 2003, pp.77ff). Other solutions tabled for dealing with the Union's democratic deficit include strengthening the involvement of organised civil society (e.g. De Schutter, 2002), enhancing the role of national parliaments (e.g. Norton, 1996) or increasing the emphasis on so-called 'diffuse control mechanisms' (e.g. Costa et al, 2003). Finally, some scholars have called for a more radical overhaul of the EU's institutional structure, including the establishment of sub-parliaments and the introduction of European-wide referendums ${ }^{5}$ (e.g. Schmitter, 2000).

\section{Europe's Public Deficit}

Notwithstanding the importance of the wider debate on the democratic deficit, it has been argued that the core problem of EU democracy is a European public deficit (e.g. Kantner, 2003, p.213; Machill, Beiler \& Fischer, 2006, pp.60-1). This assessment is based on the assumption that coverage of EU affairs in the mass media is rather limited and public debates on European policymaking are almost absent. The

\footnotetext{
${ }^{4}$ For concise overviews of arguments pro and con the democratic deficit, see: Kohler-Koch \& Rittberger, 2007b; Schmidt, 2000, pp.424-35.

${ }^{5}$ This thesis will use the plural 'referendums', instead of 'referenda'. According to the 2009 edition of the online Oxford English Dictionary the latter tends to imply a popular vote on a plurality of issues, whereas the former refers to plebiscites about a single issue, which is usually the case for EU-related referendums.
} 
extent of this deficit is as yet unclear. For example, previous studies have indicated that various EU policies receive attention in national public spheres (e.g. Bijsmans \& Altides, 2007, p.329). Cathleen Kantner (2006, p.155) even identified no less than 184 distinctive themes in her study of EU affairs reporting by 11 European newspapers and an American daily in 2000. Yet attention for many of these themes is often rather limited (see, also: Trenz, 2004, pp.303-5). Other scholars have also suggested that we might be more positive as regards the likelihood of a European public sphere emerging, but while developments do occur they are not evenly spread across Europe (e.g. Koopmans \& Pfetsch, 2006; Pfetsch, Adam \& Eschner, 2008; Risse, 2010, pp.157ff). However, several scholars have claimed that the public deficit represents a serious challenge to democracy. For example, in his book on democracy in the EU, Christopher Lord (1998) contends that one of the fundamental flaws of European-level decision-making is the general absence of an open exchange of opinions. Tsakatika (2008) argues that the lack of a European forum to discuss EU affairs exacerbates problems of accountability. In their assessment of the previously mentioned arguments of Majone and Moravcsik, Andreas Follesdal and Simon Hix $(2005$, p.22) maintain that "the lack of party competition and other lacunae concerning a political public sphere should make us more wary of Moravcsik's and Majone's optimistic conclusion."

As will be explained in Chapter 2, the public sphere - here defined as the 'space' that enables and stimulates public debate and opinion formation on important issues of public policymaking ${ }^{6},-$ is a necessary (but not sufficient) condition for democratic governance. It provides citizens with the opportunity to monitor the affairs of government, serves as a forum for discussing policy options and preferences, and offers a platform for opinion formation and holding those in office to account. Yet, public debates on EU affairs are said to be rare (Benz, 2006, p.109) and political parties tend to avoid discussing European politics, afraid that this will lead to internal divisions (Franklin, Van der Eijk \& Marsh, 1996, pp.368-73). Moreover, national Members of Parliament (MPs) are sometimes indifferent to what is going on in Brussels, and more preoccupied with issues that offer them the chance to attract media attention (cf. Raunio \& Wiberg, 2000). Usually these are not European issues, although the increase of EU competences has led to the penetration of the EU into many policy fields previously dealt with at the national level. In addition, real insight into European affairs is limited to a relatively small number of national politicians, mainly those who become members of EU affairs parliamentary committees, and in so doing develop a degree of expertise on particular EU matters.

Observations such as these suggest that there may not be a 'European coffee house', or at least that it has only developed to an inadequate degree. Hence, a

\footnotetext{
${ }^{6}$ Here the emphasis is on politics and policymaking, in contrast to Habermas' aforementioned emphasis on the public sphere as being engaged with other issues as well (see, also, below).
} 
'central precondition' for democratic governance (Fossum \& Schlesinger, 2007, p.1) may be absent. In addition, the EU can no longer count on a 'permissive consensus': its existence alone is not enough to maintain legitimacy, and the assumption that support for the integration project will gradually emerge can no longer be maintained (Wallace \& Smith, 1995). Europeans have become more critical, for example, with regard to issues such as Eastern Enlargement and the Services Directive concerning the free movement of services ${ }^{7}$, while at the same time they have certain expectations about what the EU should do.

On the whole, new policies and projects such as the Euro have increased the Union's visibility, yet the public has remained largely unaware of the ways in which various treaties and acts of legislation come about. Scholars have identified a knowledge deficit, meaning that most citizens have little awareness of the EU and its functioning (e.g. McCormick, 2008, p.123; Sinnott, 1997). For example, the European Convention that was set up to discuss the future of the integration project was designed in such a way as to promote more open discussion, yet most European citizens were unaware of its existence and its tasks (e.g. Lucarelli \& Radaelli, 2004, p.13). In addition, the twin challenges of transparency and openness in the EU concerning the availability of documents, but also the Union's seemingly complex institutional structure, the importance of informal negotiations, et cetera (e.g. Dyrberg, 2002) - form important obstacles to the dissemination of information on European policymaking, which, in turn, makes it difficult to discuss Union politics (e.g. Tsakatika, 2008). Such information is typically provided by the mass media, yet the supposed public deficit suggests that this is not always the case with regard to EU affairs.

The existence of the previously mentioned challenges has been acknowledged in Brussels. On 1 February 2006 the European Commission published its White Paper on a European Communication Policy. This document can be seen as a response to the rejection of the Treaty Establishing a Constitution for Europe (TECE) ${ }^{8}$ by Dutch and French citizens in 2005. But the white paper was also the latest document in a series that tried to address the problem of how to bring European citizens closer to the EU - or, in EU terminology, how to 'bridge the gap'. According to the Commission (2006a, p.4) this problem is partly rooted in "the inadequate development of a 'European public sphere' where the European debate can unfold." Moreover, the white paper argues that "Europe also needs to find its place in the existing national, regional and local 'public spheres' and the public discussion across Member States must be deepened" (ibid, p.5).

The European Commission, the EP and the Council of Ministers have launched several initiatives to try to open up the European political process, but as we will see

\footnotetext{
${ }^{7}$ Directive 2006/123/EC of the European Parliament and of the Council of 12 December 2006 on services in the internal market, OJ 2006, L 376/0036-0068.

${ }^{8}$ More commonly known as the European Constitution or the Constitutional Treaty.
} 
in Chapter 3, so far they have not been very successful. Even so, we may ask whether better communication by the European institutions or increased media attention to EU affairs will ever be able to engage Europeans (Fossum \& Trenz, 2006, pp.18-9; cf. Best, 2002, p.93), and whether it is possible to create a public sphere by top-down means, instead of bottom-up. Still, it is worth noting that Mark Franklin, Cees Van der Eijk and Michael Marsh (1996; cf. Van der Eijk \& Franklin, 2004, pp.47-50) have suggested that the European public would be receptive to the idea of debates on EU affairs, if only it received sufficient information. In addition, political parties and the media should make European policy the subject of open discussions. Other scholars have indeed suggested that the Union should become or is even becoming - more politicised (e.g. De Beus \& Mak, 2009; Papadopoulos \& Magnette, 2010; Risse, 2010, pp.172-3; Zürn, 2006), as for example illustrated by the gradual increase in protests against certain EU initiatives (cf. Della Porta \& Caiani, 2009; Imig \& Tarrow, 2001). In short, a 'European coffee house' could arguably develop, were there more information about EU affairs made available to open up 'Brussels' and make procedures more transparent, were European policymakers to engage with the public during policymaking, and were media coverage of EU affairs to increase.

\section{Studying the European Public Sphere}

The research community appears to agree that a homogeneous supranational public sphere is unlikely to develop due to the inherent diversity of Europe. Consequently, studies into this theme tend to highlight the potential contribution of national public spheres (see: Machill, Beiler \& Fischer, 2006; Trenz, 2003). Yet, although the need for a 'European coffee house' has increasingly become the focus of scholarly and political attention, our empirical knowledge remains quite modest (Gerhards, 2000, p.302; Hodess, 1997, p.216; Semetko, De Vreese and Peter, 2000, p.121). In an analysis of a number of previously published studies, Marcel Machill, Markus Beiler and Corinna Fischer (2006) present two observations which go some way to explain our modest empirical knowledge. The first observation concerns the lack of studies covering longer time periods. Most scholars discuss specific events and major political events - such as EP elections (e.g. Kevin, 2001), enlargement (e.g. Wimmel, 2005) or treaty changes (e.g. Packham \& Osterhoff, 2001) - or only focus on a short period. The second observation concerns the fact that there are hardly any large comparative studies that discuss various issues in more than three to five Member States, exceptions being, for example, Deirdre Kevin's Europe in the Media (2003) and the Europub-project (e.g. Adam, 2008; De Beus \& Mak, 2009; 
Koopmans \& Pfetsch, 2006). ${ }^{9}$ By and large the focus tends to be on the big three (Britain, France and Germany), whereas smaller Member States and the new Eastern European members have received little attention to date. ${ }^{10}$

Deficient resources certainly play a role in explaining both observations. These include language and time constraints, which play a key role in studies often based on labour-intensive content analyses. In addition, this method usually requires researchers to limit timeframes and sample material. Hence, research has focused on different cases studied in only a few countries over short periods of time and often applying different criteria and indicators (cf.: J-H. Meyer, 2004, p.221; Risse, 2010, pp.130-3). This has sometimes resulted in differing findings. For example, given that integration in Europe has deepened throughout the last decades, an increase of EU news coverage would be crucial from a normative perspective. Some studies have argued that Europe in general, and the EU in particular, are gradually receiving more attention in news coverage, not only as specific European issues, but also within the context of national issues, and compared to other international organisations. For example, Stephanie Sifft and her colleagues (Sifft et al, 2007; Brüggeman, Kleinen v. Königslöw \& Sifft, 2004) argue that EU affairs have become more visible in national quality newspapers, with attention for EU institutions having doubled between 1982 and 2003. Others, however, assert that events play an important role and that in general the EU is only 'marginally visible' (De Vreese, 2001, pp.298-9).

Regarding inconsistency, also open to question is whether or not the same topics are discussed with a broadly similar focus in the various national public spheres. This would be an important condition for the unfolding of European-wide public debates, because it increases the chances of communication between the various national public spheres (e.g. Eder \& Kantner, 2000; Kantner, 2006). Some scholars have identified similarities, both in timeframe and issues, and have signalled an impact of the EU's agenda on debates in national public spaces (e.g. Adam, 2008, pp.101-2; Díez Medrano, 2003). In this respect, it is important that various studies, such as those by Kantner (2006) and Marianne van de Steeg (2006), have concluded that there appears to be a general difference in the way EU affairs are discussed in European and non-European countries such as the United States (US). Even so, other scholars note that although the same issues might be discussed, national points of view dominate the debate and opinions are rarely being exchanged across borders (e.g. Gerhards, 2000; Sifft et al, 2007).

Despite such opposing findings, there are also findings which have been increasingly stressed by several studies. For example, Ruud Koopmans' assessment of the different actors who debate EU affairs is representative of most findings regarding this theme. Koopmans (2007) argues that executive actors such as ministers domi-

\footnotetext{
${ }^{9}$ http://europub.wz-berlin.de/Default.htm

${ }^{10}$ For an exception to the latter deficit, see: Illner, Čermák, Kosteleckŷ \& Stachová (2006).
} 
nate such debates, on average being responsible for almost $35 \%$ of all claims being made in national public debates. Legislatures and political parties play a more modest role and civil society actors are even less present, despite their eminent role in EU policymaking. ${ }^{11}$ Several studies also highlight that certain issues are more prominently discussed in some national public spheres than in others, and that generally the issue in question and the specific characteristics of a country also matter when it comes to the extent to and way in which EU affairs are being debated (e.g. Kantner, 2006; Koopmans \& Pfetsch, 2006; Pfetsch, 2008; Trenz, 2004, pp.303-7). Topics such as these will also be addressed in this study.

The focus on national public spheres is prominent in most of these aforementioned studies. Even so, some scholars have recently questioned the research community's emphasis on national public spheres, mainly because other less obvious contributions to the development of a European public sphere - such as Europe by Satellite (EbS) or speeches by Members of European Parliament (MEPs) - tend to be ignored (e.g. Baisnée, 2007b; Heikkilä, 2007). Nonetheless, the fact remains that, for the moment, national media rather than European media such as the European Voice and Euronews act as the principal sources of information about EU affairs for most European citizens (European Commission, 2005b, pp.80-83; Kevin, 2003, p.119; Sinnott, 1997, pp.14-5). This justifies the focus on national public spheres, even though it still leaves open the question of how they might play a role in fostering Europe-wide discussions (see, also, Chapter 2).

The emphasis on the possible contribution of national public spheres corresponds with a growing interest in national democratic structures and their potential value for democracy in the EU. It has always been clear that each Member State is characterised by its own political life, but for long this has only been of limited importance in the study of EU affairs. Instead, the two were studied separately. Today it is increasingly acknowledged that the continuous interaction between the European and the national (and subnational) levels of policymaking makes them mutually dependent. This also implies that the democratic deficit concerns the functioning of the EU itself, as well as that of its Member States (e.g. Outhwaite, 2008, pp.92-3). Or, as Christopher Lord and Erika Harris (2006, p.142) put it in their study on democracy in Europe, "for at least that large part of the new Europe that is part of the European Union it is no longer possible to evaluate the democratic performance of national democracies and that of the European Union institutions apart." ${ }^{\prime 12}$

While we should acknowledge the importance of national settings and the continuous interplay between politics on the European and national levels, we should also keep in mind the differences between the Member States, not just in terms of

\footnotetext{
${ }^{11}$ Yet, for a cautiously optimistic assessment of the role of organised civil society and social movements, see: Della Porta \& Caiani, 2006; Della Porta \& Caiani, 2009.

12 For a more detailed discussion of the relation between national and supranational democratic arrangements in the EU, see: Lord \& Harris, 2006, Chapter 4 and pp.142-50.
} 
policy preferences, but also regarding the ways in which democracy has been organised on the national level. In the words of Paul Taggart (2006, p.21), we should be careful not to stick to 'illusions of similarity'. Despite these differences (and despite their own weaknesses) national democratic institutions might be able to contribute to a European democracy, especially considering their more direct link with the citizens of the EU. All modern politics may be representative, but while people tend to be aware of important national institutions and politicians, they are often unaware of the EU and its political elite.

In line with this increased attention to the role of national democratic institutions in the democratic governance of the EU, it also makes sense to ask whether the existing domestic channels of communication can contribute to a European public sphere (cf. Vink, 2007). This study therefore sets out to examine whether national public spheres can advance the development of a transnational European arena for debate and opinion formation; one which transcends national borders and where contacts are forged at all levels and across borders, without replacing domestic institutions by a supranational construct (cf. Kaiser \& Starie, 2005). It particularly focuses on the information available on European affairs, as provided in those national arenas, and the way in which the policy process is reflected. In terms of societal importance, this research connects to the European public's call for a bigger say in, and more information about, EU policymaking, which has been identified in several national and European surveys (e.g. European Commission, 2005b, pp.22-3, 84-5). Scholars have stressed that democratic politics requires the availability of information about the political process in the public realm (e.g. Dahl, 1989). Given the limits of empirical insights to date, as well as continued questioning by scholars and practitioners about the likelihood, necessity and potential representation of a European public sphere, this issue merits further extensive research. Hence, this study seeks to contribute to improving our insights into, and understanding of, this issue. It centres on the following questions:

To what extent do national public spheres act as a forum for debates on, and provide information about, EU affairs? Do these national public spheres interact, and if so how? And can they establish a transnational European public sphere?

While used in the singular, it is important to bear in mind that public spheres come in several forms and may co-exist. Rather than being a single space, the public sphere consists of a network of several spaces (see Chapter 2). Although the public sphere refers to the wider 'scope of citizen interaction' (Crowley \& Giorgi, 2006, p.5), in today's modern, large-scale democracies the mass media play a key role in constituting arenas for debate, stimulating discussions and providing information on various issues. In other words, representation is not only a key element of democratic politics in general, but is also essential for the functioning of modern public 
spheres where political debate is represented through the media, and where actors tend to represent the viewpoints of a whole group of people (Barnett, 2004). As W. Lance Bennett and Robert M. Entman (2001, p.1) put it, "many polities have reached a point where governance, along with a host of related processes such as opinion formation, could not occur in their present form without various uses of media." Or, in the words of Brian McNair (2000, p.1): "Modern politics are largely mediated politics, experienced by the great majority of citizens at a remove, through their print and broadcast media of choice."

Hence, this study zooms in on the 'mediated' public sphere and the way in which the European policy process is represented in the media. Moreover, not only will it look at information about EU affairs, as provided in the public sphere, but it will discuss the prospect of interaction between the public spheres of the Member States. Interaction in this context refers to communicative exchanges, for example references to what the media say in other European countries or to politicians who address citizens in other Member States. It will be argued in Chapter 2 that national public spheres are not homogeneous spaces either. Even so, debates and opinions tend to converge on the national level, with newspapers, websites and radio and television channels implicitly and explicitly referring to each other; on the European (and the global) level such convergence has so far been less clear-cut.

Scholars do not necessarily agree whether or not such linkages between national public spheres are important for a transnational European public sphere. According to Kantner (2006; Eder \& Kantner, 2000) this is not the case: what is most important is that similar themes are discussed at the same time and that similar relevance is attached to them. A common European agenda provides enough ground for European citizens to formulate opinions on EU affairs (Kantner, 2006, p.148). Risse (2002; see, also, for example: Van de Steeg, 2002), however, has argued that a public sphere requires people to also talk to each other. He even argues that "it is almost impossible not to find a European public sphere" if we only focus on the criteria laid down by Kantner and others (Risse, 2002, p.5). Arguably, this is not always the case, as will also become clear throughout this study. Debates about EU affairs in national public spheres do not always occur simultaneously, nor is the focus of those debates always comparable. Whatever position one takes on this particular point, it is clear that any interaction between national public spheres will add an extra dimension to debates about EU affairs. In fact, in one of his most recent contributions Risse (2010) takes a more nuanced position, by arguing that European public spheres occur in different guises and that there may be different degrees of engagement of national public spheres with European policymaking.

At this point it is necessary to clarify a number of related concepts: 'public debate', 'public opinion', 'politics/political' and 'political communication'. 'Public debate' here refers to the exchange of opinions on public policymaking that takes place in the public sphere and, in so doing, shapes the public sphere. The result is 
the emergence of several public opinions as aggregations of private, individual opinions; the 'public opinion' tends to be the prevailing majority opinion, which may not be representative of the opinion of all people (McNair, 2003, p.19). At the centre of this study is the examination of the political public sphere. Although many topics are being discussed in public, ranging from biological views on human behaviour (e.g. Hellemans, 2007) to city-planning and architecture (e.g. Rooijendijk, 2005), the focus here is on political discussions about EU affairs. ${ }^{13}$ Political, or rather politics, concerns the affairs of government; policymaking in public bodies such as national parliaments and ministries or European Commission Directorates-General (DGs) and the Council of Ministers of the EU (cf. Heywood, 2004, pp.52-61). This focus on the political public sphere implies an important role for political communication. 'Political communication' consists of 'all political discourse' ${ }^{14}$ by both political (for example, politicians, trade union representatives) and non-political (for example, voters, journalists) actors (McNair, 2003, p.4; cf. Sanders, 2009, pp.17-9). All things considered, the 'European political public sphere' might thus be defined as the space that enables and stimulates public debate on EU current affairs and allows for the emergence of several European public opinions.

\section{Research Design}

So far, many empirical studies on the European public sphere have primarily taken a quantitative approach to the topic. Such studies can help answer the question of whether EU policymaking is being discussed and, if so, to what extent. This research will focus more on how it is being discussed and in particular on the information regarding the European policy process as conveyed in the public sphere, which implies the use of a predominantly qualitative approach. This is not to say that quantitative research on the mediated European public sphere is less valuable. It can certainly provide data about issues such as the extent of coverage over time. The qualitative aspect of EU news coverage has, however, been under-researched (e.g. Friends of Europe et al, 2004, p.29), despite the fact that the content of 'mediated' communication is important for democratic debates in the public arena (Negrine, 1996, p.21). ${ }^{15}$ In general, qualitative research can provide a more detailed insight into the research topic (Denzin \& Lincoln, 2003). Still, as qualitative and quantitative approaches do not exclude each other, some basic quantitative data will also be

\footnotetext{
13 In other words, other discussions that may be European in nature (for example, concerning Mohammad cartoons; e.g. Triandafyllidou, 2009), but which do not concern EU policies, will not be referred to in this study.

${ }^{14}$ Emphasis in the original.

${ }^{15}$ Note that qualitative, comparative studies of media systems and content are generally considered to be rare (Hallin \& Mancini, 2004, pp.16, 303).
} 
provided, in order to illustrate the qualitative analysis. Basic quantitative measurements

can offer a means to survey the whole corpus of data ordinarily lost in intensive, qualitative research. Instead of taking the researcher's word for it, the reader has a chance to gain a sense of the flavour of the data as a whole. In turn, researchers are able to test and to revise their generalizations, removing nagging doubts about the accuracy of their impressions about the data. (Silverman, 2001, p.37)

A qualitative research design presumes an extensive analysis of the material. This makes it impossible to study all media, all Member States and the entire affairs of the EU. This research will therefore focus on two topics, the debates on Europe's future and on EU air quality legislation, and the way in which they were both represented in newspapers in two Member States, Germany and the Netherlands. Quality newspapers in particular provide an overview of typical debates and often act as agenda-setters for other media and political actors and, as such, reach more people than just their own readers (Mautner, 2008, p.32). This is certainly the case in Germany and the Netherlands, where they continue to play a prominent role in the public sphere (Van der Eijk, 2000, p.329; Kaase, 2000, p.376; Pauw Sanders Zeilstra Van Spaendonck, 2004). In addition, newspapers are able to devote more attention to analysis, background information and discussion than most other media formats (cf. Bale, 2005, p.160).

At first sight television may seem to be a more obvious object of analysis as it is the most important source of information for many people, certainly with regard to European politics - in a 2005 Eurobarometer $70 \%$ of respondents listed television as an information source compared to $43 \%$ daily newspapers (European Commission, 2005b, p.80). Yet, while television is an easily accessible medium, with its content presented in small, easily-digestible features for the average viewer, the researcher is presented with the problem that television does not provide the most comprehensive overview of the information available in the public sphere. The Internet may also appear to be a prominent medium as it holds the promise of boosting citizens' active involvement (e.g. Weiler, 1997, pp.514-6). Yet, there remain important problems with this technology, including uneven access (within countries, but also between them) and an over-representation of extreme views (Downey \& Fenton, 2003; Savigny, 2002). These problems also play a role in the case of the EU (Cederman \& Kraus, 2005, pp.297ff.). On top of that, the Internet has not been used much so far by the general public as an information source on EU affairs (ibid, p.300), with just $22 \%$ of respondents mentioning it in the aforementioned Eurobarometer (European Commission, 2005b, pp.80-1). ${ }^{16}$

\footnotetext{
${ }^{16}$ It should be noted, though, that respondents aged between 15 and 24 make more use of the Internet as an information source than other age cohorts (European Commission, 2005b, p.81).
} 
Whereas the contributions of radio and the Internet to the European public sphere have barely been studied, television coverage has already been looked at quite extensively (cf. Machill, Beiler \& Fischer, 2006, pp.67-8). From those studies it appears, for example, that newspapers often devote more attention to European affairs than television broadcasters do, with public channels more engaged with such issues than commercial channels (e.g. De Vreese et al, 2006). In fact, the extent of EU coverage by quality newspapers surpasses that of other types of media and newspapers. ${ }^{17}$ For example, focusing on two separate weeks in 1999 Kevin (2003, p.55) found that the total number of European news stories published by quality newspapers was more than ten times as much as those published by public or private broadcasters. ${ }^{18}$ In sum, while a study of newspaper articles cannot offer a complete picture either of debates in the public sphere or of the information disseminated about EU affairs, it does offer the most comprehensive overview.

Since the focus of this research is on the ability of national public spheres to make EU politics public, it is important to emphasise that these arenas have their own characteristics and that the way in which issues are debated is influenced by social, cultural and political aspects (Curran, 1998, pp.90-1; Hallin \& Mancini, 2004, p.8; Pfetsch, 2004; cf. Newsom, 2007). As John Erik Fossum and Philip Schlesinger (2007, pp.7-8) note, one cannot 'bracket' the characteristics of, and differences between, national public spheres if one accepts that these spaces form an important building block for a European public sphere. Existing publications on this theme pay limited attention to such differences. In order to reach any meaningful conclusions, further detailed inquiry is necessary. ${ }^{19}$ Practically speaking, however, it is impossible to cover all Member States. Therefore, this research focuses on two countries, namely Germany and the Netherlands, countries which are very similar in terms of their political cultures, public spheres and approaches towards European integration. By focussing on two seemingly similar countries we are more likely to get a better insight into how EU affairs are being debated in national public spheres. It may also be easier to locate and explain differences that do occur. In contrast, focussing on two different countries would make it more problematic to single out reasons behind potential differences (cf. B.G. Peters, 1998). The differences and similarities help us to explore whether or not national public debates contribute to a

\footnotetext{
${ }^{17}$ Note, however, that this does not mean that the style of coverage of EU affairs necessarily diverges greatly between different types of media. For example, Barbara Pfetsch (2008, p.31; Pfetsch, Adam, Eschner, 2008, p.477) has observed that differences between quality, tabloid and regional newspapers are less pronounced than may be expected.

${ }^{18}$ Note that these figures do not just concern EU affairs, but also other European issues, including culture and sports.

${ }^{19}$ Ruud Koopmans, Friedhelm Neidhardt and Barbara Pfetsch (2000) provide a more detailed overview of the evolution of the Dutch, German and Swiss public spheres, but with the aim of mapping possible trajectories for the development of a European public sphere.
} 
transnational European public sphere; in other words, whether interaction between national public spheres is occuring.

Germany and the Netherlands are both countries in which coalition, consensus and corporatist arrangements play a prominent role in politics. Both have been identified as consensus democracies. Germany has been dubbed the 'grand coalition state' (Schmidt, 2003; 2008); the Netherlands is a classic example of a consensus democracy (e.g. Timmermans \& Andeweg, 2003). In terms of their media systems, the two countries have been grouped under the 'Democratic Corporatist Model', characterised by a tradition of political parallelism and consensus politics, as well as limited state power, mass circulation of the press and journalistic professionalism (Hallin \& Mancini, 2004; Weibull, 2007). In addition, these countries were among the six founding fathers of the EU and, until the turn of the century, attitudes towards the integration project were predominantly positive. However, scepticism about the EU has become more prominent in Germany and the Netherlands, which can be partly explained by the introduction of the Euro in 2002 and the unprecedented Eastern Enlargement in 2004 (Busch \& Knelangen, 2004; Harmsen, 2004).

Six newspapers have been selected for a more detailed study: the Dutch newspapers De Telegraaf (TEL), NRC Handelsblad (NRC) and de Volkskrant (VK), and the German newspapers Frankfurter Allgemeine Zeitung (FAZ), Süddeutsche Zeitung (SZ) and Frankfurter Rundschau (FR). This selection was based upon the way in which national newspapers have been characterised in terms of a political left-right continuum. ${ }^{20}$ By choosing newspapers on the basis of such a continuum we may find a more comprehensive spectrum of positions and opinions 'floating around' in the public sphere. The focus of this study will not be so much on the individual newspapers, though, but rather on presenting an overview of the debates in each country. Distinctive features of individual newspapers' reporting will, however, be presented too.

De Telegraaf is the largest Dutch newspaper and has a centre-right profile. It devotes relatively more space to life-style issues and entertainment than to political news. NRC Handelsblad is considered to be closest to what in international circles is understood as a 'quality newspaper' and it has a very influential op-ed (opinion and editorial) section. Until the 1960s it mainly attracted voters from the liberal VVD party, but its readership has become more diversified (Scholten \& Kleinnijenhuis, 1999, p.86). Formerly a Catholic newspaper, de Volkskrant has now established itself as a centre-left newspaper. Like NRC Handelsblad, it has an important op-ed

\footnotetext{
${ }^{20}$ Continuums such as these represent a simplification of reality (e.g. Bale, 2005, pp.106-10; Heywood, 2002, pp.252-3). Political ideas and beliefs are not static, but they evolve, and differences between certain ideological positions may not always be so straightforward. Yet, in general terms, left-wing ideas include an emphasis on greater societal equality and state involvement, whereas right-wing views embrace the freedom of the individual and the market.
} 
section. Frankfurter Allgemeine Zeitung is usually depicted as a centre-right newspaper, Süddeutsche Zeitung as a centre newspaper and Frankfurter Rundschau as a centre-left daily (Eilders, 2002, p.29).

To illustrate the way in which European affairs are discussed in national public spheres and to find out if and how these arenas intersect, two cases will be studied in more detail: debates on the future of Europe, and about EU air quality legislation. The time frames for both are roughly similar, covering the period from 2000 to 2005. Focussing on a recent, yet contained, time-period means the cases are highly relevant, while at the same time allowing the researcher enough distance to analyse them properly and place them in their wider context. The two cases represent different aspects of European Union affairs. The debate on the future of Europe is concerned with a 'history-making decision' which could change the EU's procedures and institutional structure (Peterson \& Bomberg, 1999) - it is a debate about Brussels. In contrast, the air quality issue represents a more technical topic which does not alter the Union as such - this debate concerns legislation that originates from Brussels. Studies on the European public sphere tend to focus on major political issues and events, whereas the reflection of day-to-day policymaking and ordinary policies in the public sphere has been largely overlooked. By taking two different case studies - researched during roughly similar time frames - one can study whether the different nature of the issues shapes their representation in the public sphere (cf. Koopmans \& Pfetsch, 2006, pp.120-1). Although one may instinctively expect large differences, some preliminary research has also identified similarities, such as the virtual absence of public debate preceding decision-making (Bijsmans \& Altides, 2007).

\section{Methodology}

The selected newspapers are considered to be the 'texts' that reflect debates in the public sphere. They will be studied by means of a qualitative content analysis. Content analysis is a systematic form of reading texts which allows the researcher to make broader inferences about specified issues and topics (Krippendorff, 2004; Wester, 2006). A qualitative content analysis emphasises the importance of 'good descriptive information' (Altheide, 1996, pp.15-7), which is required to find out how EU affairs are being discussed in the public sphere. Such an interpretive strategy will yield valuable information about the issues and actors that figure in the European public sphere and the ways in which EU affairs are represented in the latter -what may be called the 'political sociology' of the European public sphere (cf. Crowley \& Giorgi, 2006; Rumford, 2002). Not only does such an approach provide an insight into the information circulated about EU affairs, as represented in the mass media, but it also offers an opportunity to compare that information to the actual policy 
process, in order to identify possible differences between the timing and content of the actual process, and the way in which the issues were covered by the media.

In both cases certain key words have been used to find relevant articles, overviews of which will be presented in the relevant chapters. Moreover, articles not only had to refer to the debate on the future of the EU, and respectively, the Union's air quality policy, but also had to contain information regarding the policy process and an opinion, act or other type of statement relating to the process or the policy itself. ${ }^{21}$ The online newspaper database Lexis-Nexis was used to search the Dutch newspapers. The German newspapers were no longer (fully) available in this database, as a result of which different digital databases had to be used: Factiva for Süddeutsche Zeitung, GENIOS-wiso for Frankfurter Rundschau and the Frankfurter Allgemeine Zeitung's own CD-ROM archives. ${ }^{22}$ All these databases employ Boolean logic and specific commands ${ }^{23}$, allowing for the use of similar search strategies and key words in a practical and less time-consuming manner than traditional paper archives.

More information about the involved procedures can be found in the relevant chapters and in the codebook (Annex 1). Nevertheless, it should be noted that any attempt to make a viable and reliable selection may result in some potentially interesting data being excluded from the sample. For instance, by aiming at articles which refer to the EU or EU policy, one excludes articles which may refer to EU policy, though without explicitly identifying the policy as such. It may be argued that such articles constitute a specific category of references to EU policy, which illustrate that European affairs may have penetrated the national public spheres to a more extensive extent than usually assumed. However, finding all these articles would be practically unfeasible - how would we be able to identify all of them? In addition to this, while the selection of articles was based on carefully constructed lists of key words, we can not rule out the possibility of certain relevant articles not being found. For example, they may have been written using a slightly different terminology or they may no longer be available due to publication rights. Nevertheless, Fred Wester, Alexander Pleijter and Karsten Renckstorf (2006, p. 205) have argued that this is only a minor problem in the case of a qualitative approach, because the omission of a few press articles will normally not distort the general picture that emerges from the empirical analysis of the selected articles.

\footnotetext{
${ }^{21}$ The policy process has been approached as consisting of five stages, being agenda-setting, policyshaping, decision-making, implementation and evaluation (e.g. Versluis, Van Keulen \& Stephenson, 2011).

${ }^{22}$ Articles for which certain information was missing or unclear were cross-checked in other databases (when available).

${ }^{23}$ For example, each search contained the term 'eu!' or, in case of Factiva, 'eu'/'eur*'. The exclamation mark and the asterisk command imply that the databases look for any word beginning with 'eu' or, respectively, 'eur'.
} 
It is assumed that the different nature of the cases will affect the style of media coverage. Therefore different selection techniques were applied to collect representative sets of articles. Exploratory searches for articles regarding EU air quality legislation showed that this case was clearly less prominent in the six newspapers and, therefore, all eligible articles have been selected. This method is known as 'relevance sampling' (e.g. Krippendorff, 2004, p.118-20). In contrast, similar queries revealed that the debate on the future of Europe was discussed in thousands of articles and therefore a more focussed selection was necessary. One option would have been to take a random sample of articles, but this would not have taken into account the fact that newspaper coverage of current affairs displays differences between and within ordinary weeks. For example, on some days newspapers devote more time to sports. Also, special events (such as European Council meetings) may draw more attention than ongoing affairs (Wester, 2006, p.21). Therefore a technique called 'constructed week sampling' has been employed. This sampling method, an example of stratified random sampling (e.g. Burnham et al, 2008, p.104), involves the construction of weeks: the researcher gathers all Mondays and randomly selects one and repeats this for every other day of the week. ${ }^{24}$ Statistical analysis has shown that for studies covering a period of about five years the construction of one week for each half year will provide a reliable overview of newspaper content (see: Lacy et al, 2001; Riffe, Aust \& Lacy, 1993). The constructed weeks can be found in Annex 2.

The collected newspaper articles have been studied using a set of qualitative indicators concerned with the information distributed in media content. In this respect, Dennis McQuail (1992, pp.205ff.) stresses the importance of 'factualness', 'accuracy' and 'completeness'. Factualness is concerned with the 'reliability of reporting' and the 'degree of informativeness', which relate, respectively, to the need to cover the facts and to the number of facts that need to be offered to understand the news. Accuracy refers to the 'quality of media reports' in terms of the prevention of errors when covering those facts. Completeness stands for the incorporation of a 'full range of information' in media reporting with regard to a particular story, as well as in terms of all essential stories. In other words, these three interrelated criteria concern the extent to which media reporting covers the facts, whether these facts are accurately depicted, and to what degree the media provide a complete picture. ${ }^{25}$ For the sake of this research the three criteria introduced by McQuail have been translated into workable variables by applying and adapting the three content-related dimensions introduced by Christoph Meyer (1999; cf.

\footnotetext{
${ }^{24}$ Note that since most of the studied newspapers do not have a Sunday edition, articles have only been selected for Monday to Saturday.

${ }^{25}$ It should be noted that an incomplete picture of an issue will not necessarily prevent people from forming an opinion. Moreover, a rich and exhaustive body of information is not always available for every issue in national discourses.
} 
Bijsmans \& Altides, 2007). These are the issue, process and responsibility dimensions (see Box 1).

First, the issue dimension refers to the content of the topic as represented in the public sphere, focussing on its background and importance and on the reason why the EU is involved. Second, the process dimension is concerned with the phases in the policy process, including the institutions involved and the procedures followed. This dimension provides insights into the previous, current and future stages of the development of the issue, which can help determine which opportunities there are to influence the policy process. Third, the responsibility dimension refers to the national, transnational, supranational and non-EU actors figuring in public debates and their respective views and preferences. The three dimensions cover important information for formulating an opinion, by disclosing the nature of policies, the steps in the policy process, the various preferences and responsible policymakers.

Box 1: The Three Content Dimensions

\begin{tabular}{|c|c|c|}
\hline & Questions & Indicators \\
\hline \multirow[t]{4}{*}{ Issue Dimension } & Which issues are at stake? & $\begin{array}{l}\text { A reference to certain policy measures } \\
\text { decisions or problems. }\end{array}$ \\
\hline & What is the background/context? & $\begin{array}{l}\text { Developments and causes to which the } \\
\text { issue is linked. }\end{array}$ \\
\hline & What role should the EU play? & $\begin{array}{l}\text { Arguments regarding the question } \\
\text { whether or not the EU should be involvec } \\
\text { in a policy domain. }\end{array}$ \\
\hline & What is the relevance of the policy? & $\begin{array}{l}\text { Benefits for consumers, companies, e } \\
\text { cetera. }\end{array}$ \\
\hline \multirow[t]{4}{*}{ Process Dimension } & $\begin{array}{l}\text { What was the state of affairs in the } \\
\text { past? }\end{array}$ & $\begin{array}{l}\text { Previous legislation, no legislation, pro- } \\
\text { posals, EP deliberations, et cetera. }\end{array}$ \\
\hline & What is the current state of affairs? & $\begin{array}{l}\text { New legislations, Council and/or } \\
\text { decisions, Commission proposals, imple- } \\
\text { mentation and enforcement. }\end{array}$ \\
\hline & What will happen next? & $\begin{array}{l}\text { Decisions, proposals, implementation } \\
\text { enforcement, et cetera. }\end{array}$ \\
\hline & How is the policy process shaped? & $\begin{array}{l}\text { QMV, unanimity, co-decision, right o } \\
\text { initiative, et cetera - who decides. }\end{array}$ \\
\hline \multirow[t]{2}{*}{ Actor Dimension } & Who acts in the public sphere? & $\begin{array}{l}\text { Domestic actors, transnational actors } \\
\text { supranational actors and non-EU actors. }\end{array}$ \\
\hline & $\begin{array}{l}\text { What are their actions, responsibilities } \\
\text { and positions? }\end{array}$ & $\begin{array}{l}\text { Initiating, deciding on or refuting o } \\
\text { supporting legislation, stimulating de- } \\
\text { bate, calling for protest, et cetera. }\end{array}$ \\
\hline
\end{tabular}


Studying these three dimensions can help provide an answer to the first research question by providing an insight into the information available in the public sphere. It is also useful when seeking to answer the second and third research questions concerning the coverage of debates that take place in other national public spheres, and the exchange of information and opinions across borders. The issue dimension is concerned with the background of the topic and, as such, might refer to debates in other European countries, or in and between the EU institutions. The process dimension can also refer to, for example, the ratification of treaties or the transposition of EU legislation in other Member States, as well as to what is going on in the 'Brussels micro-cosmos'. The responsibility dimension can provide information about the different actors participating in the debates. In short, the three dimensions are used as analytical tools for the study of the European public sphere. Together they serve as an instrument for sorting and then interpreting textual information.

Some scholars have attempted to provide a structure for analysing debates in the European public spheres by employing the Europeanisation approach (e.g. Grundmann, 1999; C. Meyer, 2005; Packham \& Osterhoff, 2001; Schlesinger, 1995). As Tanja Börzel and Thomas Risse (2003, p.60) explain, domestic processes of 'public discourses' - which belong to what they have called the 'politics' dimension - can change as a result of Europeanisation. Yet, like many other studies which employ a Europeanisation framework (see: Eising, 2003; Featherstone, 2003), definitions and operationalisations offered by studies about the European public sphere tend to remain rather vague and imprecise; there is no clear 'scale' to measure the degree of Europeanisation (Machill, Beiler \& Fischer, 2006, p.79). Furthermore, while more elaborate approaches (e.g. Brüggemann, Kleinen-v. Königslöw, \& Sifft, 2004; Koopmans \& Erbe, 2004) at first sight seem to offer promise, they turn out to be impractical due to the many different forms of Europeanisation that can be envisaged beyond the ones proposed by these studies. Rather than presenting an eloquent framework, the Europeanisation approach might actually result in a much more complex presentation of results.

The Conclusion of this study will present several possible manifestations of the European public sphere and diffusion of EU affairs into national public spheres. As will be discussed in Chapter 2, a three-pronged distinction can be made between a supranational, elite European public sphere, issue-specific public spheres and overlapping national public spheres. However, as will be addressed in the conclusion, the findings of this study suggest that we should consider several other manifestations, in particular concerning the ways in which Europe figures in national public spheres, and the ways in which these national public spheres interact. Moreover, even if EU affairs are regularly discussed in national public spheres, which themselves do not necessarily interact, we might still be able to discern differences and similarities regarding the ways in which the EU figures in the national media. 
Finally, the analysis of newspapers will never be able to present a full picture of the way in which EU affairs are debated in the public sphere. Nevertheless, as was argued before, newspapers do offer the most comprehensive insight into public debates. Even so, in order to construct a more thorough image, the study of press articles has been accompanied by references to other material, including primary documents from the EU institutions. Also, qualitative interviews have been conducted with representatives of the media, EU institutions and other relevant people. Their insights have been used to obtain a better overview of several issues. In an attempt to collect as much valuable information as possible, these interviews have been approached as conversations between interviewer and interviewee (Mason, 2002). While this may suggest an unstructured approach, all interviews have been conducted on the basis of an interview guide containing areas, topics and questions (Weiss, 1994, pp.45-51). Employing more than one method and using several sources of information increase the chances of being able to draw reliable (and viable) conclusions (e.g. B.G. Peters, 1998, pp.97-103; Wester, 2006, p.36).

\section{Outline of the Thesis}

As has been pointed out already, studies regarding the European public sphere have sometimes drawn contradictory conclusions, which might in itself indicate that there is still a lack of knowledge about the European public sphere. It may also signal, however, that what we have learned so far has actually emerged from different approaches to the study of the European public sphere, and which may therein account for opposing perspectives. Little is known about changes in EU news reporting over time, so what is required is data on the long-term coverage of EU affairs, preferably collected in as many Member States as possible. The qualitative nature of the current study obviously cannot live up to this completely. Although it does include a temporal component, the focus will only be on two Member States. Even so, by means of a qualitative approach, the two cases will confirm some of the findings put forward by other studies, but also raise new questions. One thing that will become clear is the similarities and differences between debates in Germany and the Netherlands. Other studies have also revealed differences as regards the extent to, and ways in which, the EU is covered and discussed in the Member States (Machill, Beiler and Fischer, 2006). Such differences will certainly play a role in the advent of transnational public debates - the question of to what extent this is problematic will be returned to at a later stage.

The outline of the rest of this thesis is as follows. The next chapter will provide a more elaborate discussion of the public sphere and the connected theoretical debates, followed by an analysis of the debates concerning the European public sphere. Chapter 3 will then continue with a more concrete description of this Euro- 
pean arena, concentrating on the way in which political actors such as the EU institutions communicate, and on the way in which EU affairs are covered by the media. Chapter 4 will then take a step back and return to the potential role of national public spheres by focussing on the key features of politics, the public sphere and attitudes towards European integration in Germany and the Netherlands. Chapter 5 will commence with the empirical research and present the first case: the debate on the future of Europe. This chapter will show how some exchange of opinions across national borders does occur, but it will also reveal shortcomings concerning the timing of the public debates and the representation of the policy process and the allocation of responsibilities in national public spheres. Chapter 6 will discuss the debate on EU air quality legislation. In contrast to the debate on the EU's future, this regulatory policy debate was predominantly national in focus, yet it too was characterised by shortcomings concerning the timing and information about the policy process and the responsible actors. Both empirical chapters will start with an introduction to the case in question. The findings will be analysed in light of the discussions in Chapters 2, 3 and 4. Chapter 6 will be followed by a conclusion that reflects on these findings, and examines the promise (or otherwise) of the 'European coffee house' and its different manifestations. Several different forms of engagement with European affairs within national public spheres will be presented, ranging from purely national discussions to a truly transnational European public sphere. Depending on the issue at hand, but also on, for example, the phase in the policy process, the materialisation of the European public sphere may differ. Overall, this study will present some cautiously optimistic conclusions regarding the potential contribution of national public spheres to the enhancement of a transnational European public sphere. It will be argued that the public deficit is not so much related to quantitative shortcomings as it is to qualitative ones. 



\section{The Public Sphere:}

\section{Questions of Standards}

Although the term 'public sphere' is widely used nowadays, its meaning is not clearcut. Research into this notion and its attributes has been of a theoretical and empirical nature; several disciplines have dealt with the subject, including philosophy and political science. Moreover, even though it has been the theme of many academic publications, the term 'public sphere' has not always figured prominently itself. Other more or less similar terms have been used, including 'the public at large', the 'public space' and the 'public domain' (Agacinski, 2001; Hohendahl et al, 2000, p.7). Hans Kleinstüber (2001, p.96) argues that the notion of public sphere is a 'recent construction', emanating from the translation of Jürgen Habermas' work on the public sphere, in particular his Strukturwandel der Öffentlichkeit (1962). Peter Uwe Hohendahl et al (2000) confirm this line of reasoning, showing that the concept was non-existent in eighteenth and nineteenth century English, whereas the use of the German equivalent 'Öffentlichkeit' dates back to the eighteenth century. As a result, the concept also carries with it certain cultural connotations. In fact, ever since its first use in German, die Öffentlichkeit has been an important issue in both public and academic debates in Germany, to some extent making it a particularly German theme, which is exemplified by the prominence of feuilletons in Germany's quality newspapers (ibid; Kleinstüber, 2001).

Issues related to the public sphere (such as its development or the role of mass media) have become prominent in other countries too (e.g McNair, 2000; Van Vree, 2000). Conceptual differentiations remain, though. For example, whereas the term 'public sphere' implies some kind of space, 'Öffentlichkeit' implies a kind of actorness. The Dutch translation, 'openbaarheid', appears to be more appropriate. At the same time the use of this Dutch term tends more towards the spatial connotations 
attached to 'public sphere'. The English 'public sphere' could be translated as 'publieke ruimte' or 'openbare ruimte' in Dutch. This would again be confusing, because these terms are generally used to denote public spaces such as streets and parks. According to Kleinstüber (2001) 'openness' presents a better, English translation. He (ibid, pp.98-9; cf. Calhoun, 1992) adds that Habermas himself barely considered the cultural differences attached to the term 'public sphere', which no doubt explains part of the conceptual confusion.

By looking at some definitions of the public sphere we can acquire a better sense of its modern connotations. Although such definitions are abundant, some core values can be extracted by examining only a few. For example, according to McQuail $(1992$, p.2) the public sphere refers to "the channels and networks of mass communication and to the time and space reserved in the media for attention to matters of general public concern." McNair (2003, pp.20-1) defines this space as "the communicative institutions of a society, through which facts and opinions circulate and by means of which a common stock of knowledge is built as the basis for collective political action". For John Keane $(1995, p .8)$ the public sphere is

\begin{abstract}
a particular type of spatial relationship between two or more people, usually connected by a certain means of communication (television, radio, satellite, fax, telephone, etc.), in which non-violent controversies erupt, for a brief or more extended period of time, concerning the power relations operating within their given milieu or interaction and / or within the wider milieux of social and political structures within which the disputants are situated.
\end{abstract}

All three definitions refer to two particular aspects of the public sphere. The first is that it is a space for discussing social and political matters that affect the citizenry. The second is that these discussions are predominantly relayed through communication media, signifying the public sphere's representative function, as already mentioned in the introduction. In earlier times the public sphere was often a more manifest place, as was the case with the Greek agora. Such places still exist today, for example in the guise of parliaments, but most exchanges of opinion now occur in a metaphorical space (cf. Sanders, 2009, p.143), a 'nonvisible network of positions' (Hénaff \& Strong, 2001, p.228). As John Hartley (1992, p.35) explains:

[I]n classical Greece and Rome, assuming you were a free man - rather than a woman, slave, or foreigner - you could walk into the agora or forum and participate in daily life directly, as a voter, a jurist, a consumer, or as an audience of oratory in the service of public affairs. (...) But nowadays there is no physical public domain, and politics is not 'of the populace'. Contemporary politics is representative in both 
senses of the term; citizens are represented by a chosen few, and politics is represented to the public via the various media of communication. ${ }^{26}$

This chapter will provide an overview of some of the theoretical questions that play a role in discussions about the public sphere. It will start with a discussion of a number of more general issues. It will examine why public spheres are so important for democracy and how these arenas are formed in the interaction between political actors, the media and citizens. Some have claimed that this interaction has changed over time - and not for the good. Hence, the subsequent section will consider the ongoing debate on the functioning of the public sphere and will argue that changes to the public sphere are not as negative as often suggested, and even had some important positive effects. The chapter next turns to the issues and questions concerning the European public sphere, by asking whether there is any potential for such a space at all. Having answered that question positively, the remainder of the chapter will then explore potential manifestations of a European public sphere.

\section{Democracy and the Public Sphere}

When discussing democracy, most people stress the importance of equality, freedom and justice. They typically emphasise a desire to influence decision-making and hold policy-makers accountable (cf. Swift, 2006, pp.179ff). Opportunities for citizen participation constitute an important feature of a well-functioning democracy. The most obvious articulations are voting, or standing as a candidate in elections; other manifestations include protesting or signing petitions. Accordingly, while modern democracy is predominantly representative in nature, citizen involvement should not necessarily be restricted to voting. On the contrary, it should be possible to raise concerns and voice opinions at regular intervals. As Tim Bale $(2005$, p.183) aptly puts it,

it would be a very 'thin' conception of democracy indeed that supposed citizens would - or, indeed, should - be content between elections to leave things to the politicians and the bureaucrats. After all, the policies initiated and implemented between those elections will rarely suit everyone and may even be seen as unfair by some people.

Ideally, public opinion should influence policymaking and government policy should reflect the public's will. Debate should also be open to all citizens and all issues. Public deliberations between citizens and their representatives may function as a mechanism for legitimating public policy: the exchange of views can foster agree-

\footnotetext{
${ }^{26}$ Emphasis in original.
} 
ments and create an understanding of political choices and their possible alternatives, as well as identify responsible policymakers and hold them accountable.

This does, however, require that debates take place at the right time, for example, ahead of decision-making, if the aim is to influence outcomes, because otherwise a temporal mismatch between debates in political bodies such as parliaments and those in the public sphere is likely to occur. In addition, the media may have certain ideas about which elements of the policy process should be covered and which should not, and these ideas may not correspond to those held by political actors. This may result in a content-related mismatch between, on the one hand, the debates in institutions and, on the other hand, the representation of these debates in the media. Both disparities may act as an obstacle for citizens wanting to gather information and form an opinion about certain issues (Barnett, 2004, pp.188-9; Eilders et al, 2004, p.221; T. Meyer, 2001, p.566). This already suggests that the ideal depiction of the public sphere sketched above is not necessarily even given at the national level (cf. Van de Steeg, 2002, p.506; 2003, p.177). Policymaking does not always figure in the public sphere and even when it does, it may not be easily traceable by citizens. The significance of such a space, however, is that it has the potential to bring policymaking into the open, increasing the possibility to influence the policy process and hold political actors accountable.

One of the most prominent readings on the public sphere is Strukturwandel der Öffentlichkeit (1990) by Jürgen Habermas. In this book, first published in 1962, Habermas discussed the importance of a well-established public sphere (Öffentlichkeit) as a necessary element of a democratic polity, and its development (Wandel) over time. He understood this public sphere as a space for free and un-coerced debate on important questions to do with the social order, one that enables discussion of countless different topics, many of them non-political. Despite certain important omissions (e.g. Calhoun, 1992), Habermas' treatise on the public sphere is still referred to widely. Yet, Habermas was certainly not the first to stress the importance of public debates. In Ancient Greek democracy the public sphere manifested itself in the agora: the market place that offered a platform for all kinds of political and non-political discussions (Agacinski, 2001). The significance of public deliberations was also stressed by Enlightenment philosophers such as Voltaire and Immanuel Kant and, in the nineteenth century, by liberals such as John Stuart Mill and Jeremy Bentham. Kant, for example, stressed the 'public usage of reason' as a guiding principle for all legal orders. The English philosopher Bentham coined the concept of the 'public opinion tribunal' to emphasise the importance of public debates for democratic governing (see: Hohendahl et al, 2000). In the $20^{\text {th }}$ century scholars such as John Rawls (1997) and Hannah Arendt (see, Benhabib, 1992) have also discussed the value of a well-functioning public sphere for democratic polities.

Theories of deliberative democracy are now often seen as providing the most detailed accounts of the role of public debates and the public sphere in democratic 
societies. Adherents of these theories, including Habermas (1996), stress the importance of open, un-coerced debate based upon reasoned arguments. They believe that the quality of decision-making could be improved by introducing open-ended and continuous deliberation at all levels. Likewise, they advocate all citizens being able to take part in these deliberations and their contributions being given equal weight, provided they are rational and altruistic (e.g. Held, 2006, pp.231-8). Seyla Benhabib (1996), for example, explains that deliberative processes are instrumental in improving the quality and rationality of decision-making by providing new information, helping to formulate coherent preferences and forcing reflexivity in terms of arguments as the latter should appear sound and convincing.

Theories of deliberative democracy have been criticised for their overly idealistic emphasis on consensus and rational debate, and at the same time, their neglect of power relations and inequalities (see: Held, 2006, pp.238-46). Recent contributions have tried to tackle such criticism by arguing that majoritarian views can and should be incorporated, and by stressing the fact that deliberation should be an ongoing process during which observations and opinions can change - the majoritarian position just reflects mainstream opinion at a given time (Lafont, 2006; cf. Gutmann \& Thompson, 1996). Critics of deliberative democracy have also pointed out that an ideal type of rational discourse, as anticipated by deliberative theory, is not omnipresent. People communicate not only on the basis of facts, but taking on board beliefs or opinions that are not necessarily based on solid proof. In fact, although Rawls (1997) originally asserted that such 'nonpublic reasons' should be excluded from the debate, he later argued that they might be admissible, because they may be required to settle certain issues. ${ }^{27} \mathrm{~A}$ final criticism concerns the main platforms of the public sphere - the media - which do not constitute a 'level playing field' as deliberative democracy would have it, meaning that some have easier access to the public sphere than others, which in turn leads to inequalities. This is one reason why people and groups outside (and inside) the mainstream may need to resort to strategic or even emotional discourse (e.g. Delicath \& Deluca, 2003; McKee, 2005; Pröpper \& Witteveen, 1995).

The importance of public spheres has not been acknowledged by deliberative democracy theorists alone, even if they appear to be the most outspoken of scholars. In fact, the public sphere features as an element within almost all theories of democracy, although the particular focus and emphasis tend to vary (Beierwaltes, 2002). For example, adherents of elite theories of democracy have framed democracy as a competitive struggle for power in which the input of citizens is limited to the occasional selection of a professional political class that has to run the country. Even though one of the premises of these theories is that most people are poorly

\footnotetext{
${ }^{27}$ The example Rawls (1997) uses, is the financing of education. Should it apply only to public schools or also to religiously inspired schools? It might be necessary for the leaders of opposing groups to explain their views referring to what he calls their 'background culture'.
} 
informed and emotional (Held, 2006, p.157), theorists such as Anthony Downs assumed that they were more or less fully informed about possible choices and their consequences (Schmidt, 2000, p.214). Hence, a public sphere is needed, if only to provide the information on the basis of which citizens can better make choices.

In contrast to elite models, theories of participatory democracy demand an encompassing public sphere. While it is acknowledged that a degree of representation is required in modern, large-scale societies, citizen involvement is seen as a key determinant for the democratic political process, because participation will decrease alienation from power, increase concern for collective problems and create an active and informed citizenry. In the perfect participatory democracy, political communication flows continuously between the represented and their representatives and, similar to deliberative democracy, opinions are formed in an open exchange of arguments and information. The main difference between participatory and deliberative democracy is that the latter also stresses the quality of the political process, not just the importance of participation (Held, 2006, pp.209-16; Schmidt, 2000, p.254).

Theories of democracy thus stress the importance of information and debate for legitimate governance. As Arthur Benz and Yannis Papadopoulos (2006, p.5) explain, "the democratic legitimacy of a polity and of particular policies requires a circular relationship between decision-makers and the citizenry." One of the conditions for this circular relationship to take shape is the "stability of communication between represented and representatives' (ibid, p.6). Citizens need to be able to discuss and voice their opinion in order for the political process to be seen as legitimate. Of vital importance in this respect is the availability of information about this political process and, consequently, the unfolding of democratic politics in a public arena (McNair, 2003, pp.18-9). In the words of Dahl (1989, pp.111-2), citizens should be able to acquire an 'enlightened understanding' about matters of public interest. In terms of legitimacy of, and trust in, the political process, it is important that political actors take debates and opinions into account when formulating policies. The public sphere thus forms a space between state and private sphere that empowers civil society - the independent organisations and groups that represent individual citizens (Heywood, 2004, p.41) - and enables discussions in which different views and judgements can be formulated free from state or market intervention (Eder, 2000, p.175; Imhof, 2003, pp.193-4). ${ }^{28}$

\footnotetext{
${ }^{28}$ The relationship between civil society and public spheres is prominent in many writings. Some have argued that the public sphere is a particular manifestation of a civil society (e.g. Edwards, 2004). Others have argued that a public sphere is an important precondition for the development of civil society (e.g. Calhoun, 1993).
} 


\section{Political Actors, the Media and the Public: Constructing Public Spheres}

According to Andreas Beierwaltes (2002, pp.42-56) communication in modern democracies is made up of three essential structural dimensions. Publicity refers to the communication from political actors to citizens. The former want to inform the latter about the policy process, the political choices that have been made and the actors' role therein, in order to gain approval (and possibly get re-elected). Responsiveness entails the feedback from citizens, which political actors supposedly use to make decisions. Finally, discursiveness refers to the ability of the people to 'talk' to each other; to put forward and discuss different views and arguments, in order to formulate a more broadly shared public opinion. In today's mass society the media play a key role in all three dimensions, as the principle arenas for public debates, sources of information and channels for communication (Figure 1), hence their important representative function.

Figure 1: Three Dimensions of Communication

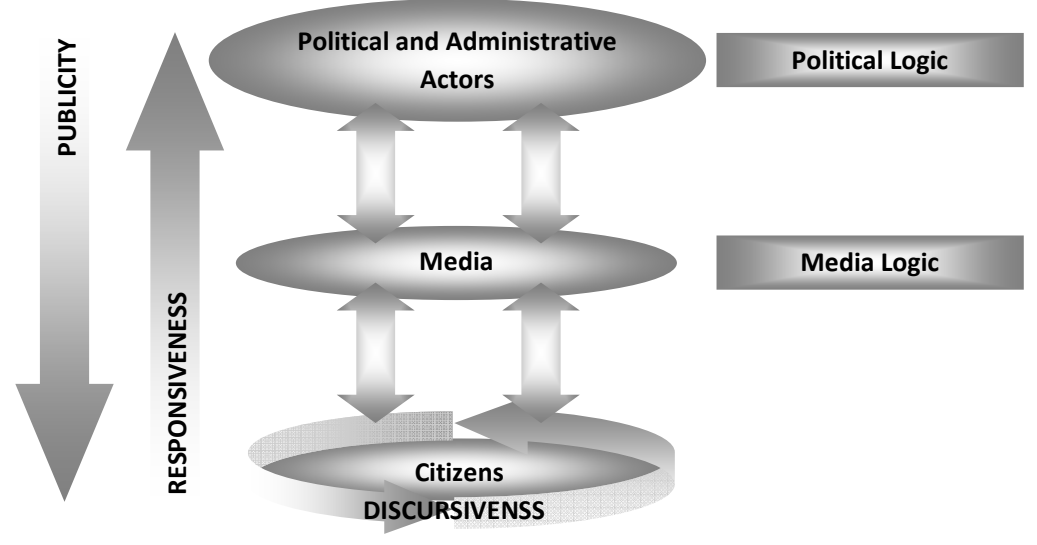

Based on Beierwaltes (2002)

However, the media and political actors have their own ideas when it comes to communication. There is a constant tension between, on the one hand, political logic, based upon the need to communicate the background and results of policies as fully as possible in an attempt to gather citizen support, and, on the other hand, media logic, defined by an interest in attractive, clear stories and not the long, intricate process of policymaking. Even so, journalists and politicians are partners in a 'tense tango' (Sanders, 2009, p.38); they are mutually dependent - the former providing the means to go public and the latter supplying the ingredients for interesting stories. This study will reflect upon both logics: in this chapter by discussing the interaction between political actors, the media and the public in the public sphere, 
and by looking at current debates on the (European) public sphere; in the next chapter, by exploring the ways in which EU actors attempt to go public and the ways in which the media approach EU affairs. The two empirical chapters will focus on the representation of debates and communication efforts in the media, providing insights into publicity and, to a lesser extent, discursiveness. Since responsiveness requires a different research design and methodology, this dimension will not feature in detail.

If the public sphere is constructed through the communicative interaction between political actors, media and the public (Beierwaltes, 2002; Neidhardt, 1994; McNair, 2003), this implies that the public sphere is by no means a static space. Rather, it is a constantly changing one, as each public conversation can foster its own particular 'nonvisible network of positions' through the interaction of different actors. The modern public sphere refers to many different forms of expression, ranging from street protests to petitions. Nevertheless, even though the public space may not be the same as the media, it is within the media that different groups can really engage in debates in today's mass society (McKee, 2005, pp.5-6; McNair, 2003, p.21). Yet, manifest places such as parliaments or courts are still important arenas for debates. In this respect a distinction has been made between weak publics, mainly concerned with opinion formation, and strong publics, focused on both opinion formation and decision-making (Fraser, 1992, p.134; Habermas, 1996, Chapters 4 and 7). The latter includes parliaments, the former generally refers to public spheres as represented by the media. It may be argued that the interaction between such strong and weak publics is vital for Benz and Papadopoulos' 'circular relationship' between representatives and represented, and thus forms an important prerequisite for democracy.

The media form an intrinsic part of a well-functioning democracy, as they enable us to follow and study public debates. They help to make the 'nonvisible network of positions' visible (both to the citizen and the researcher). Still, we should be careful not to focus exclusively on the media, because, as Ralph Negrine (1996) asserts, alterations in the way in which politics is communicated are also linked to broader changes in politics and society. These include secularisation and increased electoral volatility, but also legislative issues such as libel laws and technological advances, such as the development of the internet (e.g. Balvanes, Donald \& Shoesmith, 2009, Chapter 2; Street, 2001, pp.103ff). In addition, developments at both the national and supranational level have transformed the nature of government (Kjær, 2004). For example, independent agencies have been established in various fields. These agencies cannot be held accountable easily, yet their decisions often have an impact on the life and well-being of citizens. Also, the internationalisation of politics has created new arenas of decision-making - EU policymaking is but one example - that do not always operate openly due to their complex and multi-layered nature. This means that political communication has become impor- 
tant at various levels and between an array of actors, all of whom ultimately need public support in democratic societies. Therefore it is essential to have a more detailed look at the interaction between political actors, the media and the public.

\section{Political Actors}

Political actors, including political parties and governments, but also social movements and business interests, seek to shape the policymaking process and are the main communicators of messages in the public sphere. In a democratic polity parties and politicians need to convince citizens of the soundness of their preferences and interests, yet, as electoral volatility and voter dealignment have increased, they have found it difficult to build upon a more or less stable electorate. As a result, reaching out to the citizen is ever more complex. For example, few citizens attend parliamentary sessions, and party manifestos are rarely read (Street, 2001, p.1934). Hence, political actors try to influence the media and gain publicity by adopting a range of strategies (e.g. Sanders, 2009, pp.89, 192-3). Christiane Eilders et al (2004, p.222) distinguish between three options. First, political actors may try to set the agenda by, for example, providing journalists with newsworthy information through press releases, and by staging so-called pseudo-events such as press conferences to anticipate media logic. ${ }^{29}$ Second, they may also decide to cut the agenda by bypassing critical journalists and trying to avoid certain information becoming public in order to prevent debates. Third, political actors may attempt to become personally associated with other newsworthy events as a way of boosting their own visibility, which Eilders et al call agenda surfing.

Governments and political parties employ consultants and media experts in order to monitor the media, determine audience preferences, create a beneficial image and devise effective communication strategies to reach and convince the citizenry (e.g. Sanders, 2009, pp.88-90). They actively promote their ideas and try to gain media coverage and manage the way in which they are represented by the media, for instance by trying to satisfy the needs of the media while at the same time keeping their core message intact (for example through press releases). Logos and slogans are designed to increase visibility. Nevertheless, only a small amount of such communications is actually picked up by the media to enter the public sphere. Therefore, advertisement through ads and commercials is crucial too, although it has one major drawback: everyone realises it is not impartial and hence allegations of propaganda are not uncommon.

Another challenge concerns the consistency and coherence of communication efforts, as uncoordinated and divided messages may damage the credibility and legitimacy of the political actors (Von Alemann \& Marschall, 2002, pp.23, 26-28;

\footnotetext{
${ }^{29}$ This use of agenda-setting should not be mistaken for discussions about the media's impact on their audiences, which also often refer to agenda-setting (see: Negrine \& Stanyer, 2007, Section 5).
} 
McNair, 2003, pp.135, 152). Political organisations typically accommodate various preferences and priorities and, hence, do not constitute homogeneous organisations. For example, within any single government different ministries, departments and agencies might compete with one another, and are influenced by individual (yet collective) institutional cultures and ideologies.

Civil society actors play a particular role as communicators, providing different opinions and information. On the one hand they are able to act as intermediaries between citizens and political actors (Nanz \& Steffek, 2004, p.323). Membership of and identification with political parties may have declined, but participation in, and membership of, civil society organisations has increased (e.g. Bale, 2005, pp.123-9, 140-3; Dalton, 1999). On the other hand, civil society actors are regularly disadvantaged because of a lack of resources available to be used to try and influence the public agenda by 'making news', certainly when compared to established political actors such as parties, but also in contrast to business interests (e.g. McNair, 2003, pp.163ff). Nevertheless, despite their relative competitive disadvantage, civil society actors can - in theory - form a useful alternative source of information for journalists and citizens. Such actors employ different strategies to win the backing of citizens and influence policymakers, including direct access to the latter, but also other forms of engagement such as media strategies (Sanders, 2009, pp.109-10). These include press releases, but also so-called 'image events' - "staged acts of protest designed for media dissemination" (Delicath \& Deluca, 2003, p.315). Strategies may often be devised by various interests in a concerted effort to advocate policies (e.g. Ansell, Maxwell and Sicurelli, 2006).

\section{The Media}

The media form the principle fora for public debates and have been called 'the connective tissue of democracy' (Mughan \& Gunther, 2000, p.1). The media fulfil three broad functions in the public spaces of democratic polities (Van Cuilenburg, 1993, p.321). The first is the information-function, which states they should provide citizens with information about the formulation, implementation and enforcement of public policy. The second function is the expression-function. This implies that the media ought to reflect trends and opinions in society, thus informing political actors about societal preferences. The criticism-function is the last function. As Eilders (2000, p.182) explains, the media are not just transmitters of political messages: "They take an active role in the political process by selecting and structuring information, assigning relevance, interpreting and evaluating the stream of events continuously taking place." The media produce their own statements and viewpoints by providing commentary through for example editorials and by supplying background information. As such the media can criticise government policy. Taken together, 
these media functions provide society with the possibility to debate, influence and criticise political deliberations and policymaking.

Journalists often rely on established sources for news stories, since these sources are typically better apt to communicate on the basis of newsworthiness. The media try to provide the public with unique news, but simultaneously 'keep an eye' on their competitors to make sure that no 'hot' items are missed (e.g. Brants, 2002a, pp.96-7). Incidents and events - which may or may not be intentionally staged - are arguably important when it comes to covering national and international affairs, for time pressure and deficient resources do not always allow for proactive and in-depth journalism (Negrine, 1996, pp.170-4; Street, 2001, p.18). The media have to make a selection; they determine which issues are covered and which are not; they cannot report everything. Still, in this respect they are constrained by commercial and political factors (Negrine, 1996; Street, 2001). The public can influence the selection of issues ('stories') - if citizens do not accept the style or content of coverage, they are free to buy another newspaper or switch channels (Curran, 1998, p.92; Palmer, 1998, p.377)..$^{30}$

In addition, the media's leeway in selecting news stories and setting the agenda is limited by political actors who typically provide the material for interesting stories. For instance, although 'spin doctors' are often depicted as the villains of political communication due to their persistent efforts to manage the news, journalists do acknowledge their importance as sources (Street, 2001, p.149). Journalists must take account of the terms and preferences (and content) of the political actors, who can always choose to approach another outlet. This does not always present a good strategy, because there are always a few key media that tend to be more influential than others - be it in terms of readership, as sources for other media outlets, or as reliable information for politicians themselves.

\section{The Public}

Citizens form the public (or audience) of political communication. Yet the public itself has become increasingly diversified and heterogeneous during the last four to five decades. Changing preferences among the public have introduced new issues into the political sphere, such as the state of the environment and human rights. In fact, it makes more sense to talk about different publics (see below). For most people the media are the main sources of information about political issues (McNair, 2003 , p.23). They use a variety of media to inform themselves about, and get involved in, politics and current affairs; as such, the mainstream media tend to reflect public opinions. ${ }^{31}$ Moreover, people can also participate in debates in the public

\footnotetext{
${ }^{30}$ Even so, there still is the question how the media can be held accountable (e.g. Bardoel \& d'Haenens, 2004).

${ }^{31}$ As explained in Chapter 1, there is no such thing as the public opinion, just a majority opinion.
} 
sphere, voicing their opinions through letters in the press, phone-ins on radio and television programmes, protest, et cetera (cf. responsiveness). What opinions people actually have, tends to be studied by means of surveys, focus groups and so on. Despite their potential shortcomings (for example, leading questions or sociallydesirable answers), such tools are often seen as a 'holy grail', which is hard to ignore for politicians and journalists (e.g. Sanders, 2009, p.154).

While the media may reflect public opinions, they do not create them, as opinion formation often takes place through informal, private channels. People try to make sense of the world based upon their understanding of similar issues, personal experiences, other information, and so on. They talk to their family, friends and colleagues and as a result their views are not only shaped by the media, but also by these personal interactions (Livingstone, 2003a; McNair, 2003, p.4; Negrine, 1996, pp.128-9; Newsom, 2007, pp.5-7). This particular aspect of discursiveness materialises in the private sphere. Therefore, 'everyday talk' in such informal settings is often a stepping stone for public deliberations in the media as well as in formal institutions such as parliaments (Mansbridge, 1999; cf. Staeheli \& Mitchell, 2004). Even so, while citizens may have the right to be informed about the political process and may well discuss politics at regular intervals, some choose to ignore politics altogether. One is not obliged to take part in the political process (Gurevitch \& Blumler, 1990, p.271; cf. Negrine, 1996, p.8; Sanders, 2009, p.161). The majority tends to adopt a more passive approach, by either supporting or rejecting a certain view or by adopting a neutral position (Negrine, 1996, p.127; Neidhardt, 1994, p.23), whereas a more active approach is likely where people consider the need to intervene in the policy process - if they feel particularly affected by a policy, or when they anticipate something is going wrong (Verhoeven, 2004, pp.69-70).

Despite the fact that people place the information provided by the media (and other sources, such as politicians themselves) within their own framework of understanding, there has been, and still is, intensive debate about what the actual impact of the media on the public sphere and public opinion is. Do the media determine what we think, or only what we think about? Do they reinforce existing opinions or shape new ones? This tricky issue has not been resolved, partly because findings have been of a contradictory nature (e.g. Cumberbatch, 1998; Negrine \& Stanyer, 2007, Section 5); it will not be the focus of this study.

To conclude, political actors, citizens and media are engaged in a more or less continuous exchange of information and opinions, directly (by contacting your MP for example) and indirectly (through the media), but also by voting or tuning into a specific radio programme. By doing so, together they shape the public sphere, the representation of political debates and the topics covered in it. This is reflected in Figure 2, which displays both direct interaction between citizens and political actors, as well as mediated interaction via the media. The actual characteristics of the pub- 
lic sphere may change depending on the issue, with different actors, different publics and even different media (re)constituting spaces for debate.

Figure 2: Constructing Public Spheres

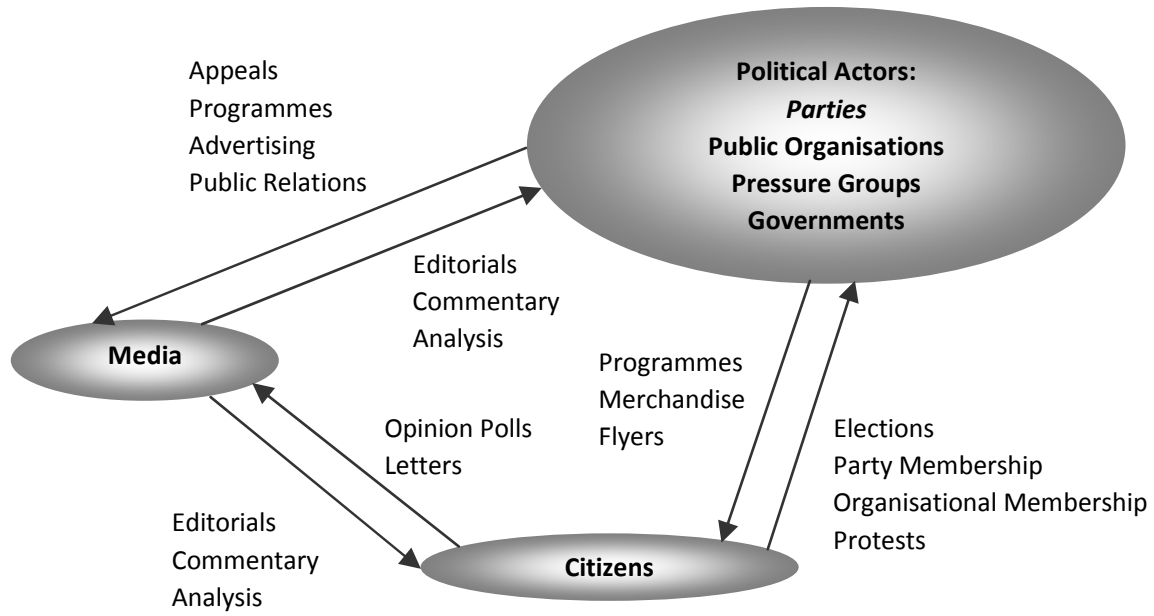

Based on McNair (2003, p.6); the examples of ways of exchange of opinions are non-exhaustive.

\section{The Contemporary Public Sphere}

The functioning of the public sphere and interaction between political actors, the media and citizens has long been subject to scrutiny. ${ }^{32}$ Needless to say, there are different views on the effects of broader societal developments on the interplay between democracy and the public sphere (e.g. Blumler \& Kavanagh, 1999). For some, the value of discourse and debate for democratic life is at risk due to the supposed demise of the public sphere. Others, however, argue for a strengthening of democracy owing to the gradual opening up of the public sphere.

\section{The Demise of the Public Sphere?}

In their book The Crisis of Public Communication, Jay Blumler and Michael Gurevitch $(1995$, p.203) argue that changes in society in general, and political communication systems in particular, have resulted in a political communication process that "tends to strain against, rather than with the grain of citizenship." Marcel Hénaff and Tracy B. Strong (2001, p.27) claim that in today's public sphere of over-information and the blending of public and private, democracy "loses its rationality. Images replace

\footnotetext{
${ }^{32}$ It already figured in for example the work of Alexis de Tocqueville (Imhof, 1996, p.5).
} 
arguments. Debates are turned into games. The show never stops." According to these and other critics, the way in which politics figure in contemporary public spheres may degenerate, rather than advance, the development of an 'enlightened understanding', as stressed by Dahl (1989). The most prominent lines of reasoning regarding the demise of the public sphere concern commercial pressure on the media, the professionalisation of political communication and the fragmentation of the public.

The performance of the mass media has been evaluated rather critically by scholars and politicians. The media have frequently been accused of not being willing or able to live up to the three functions described above. Such criticism has also been aired by journalists themselves. For example, Dutch journalist Joris Luyendijk (2006), writing about his experiences as a correspondent in the Middle East, explains how a journalist's opportunities to produce unbiased and informative news are restricted by deadlines, uninformed editors, professional spokespersons and dictatorial regimes in many of the region's countries. Luyendijk adds that reporters are partly to blame themselves since they do not appear to try to circumvent these obstacles. ${ }^{33}$ British journalist Nick Davies writes about similar challenges in his Flat Earth News (2008) and links them to economic pressures. Like Luyendijk, Davies notes that many journalists seem to conform to these new circumstances.

Explanations of these challenges vary, but usually the commercialisation of the media is indeed put forward as an important reason. From this perspective, fierce competition between numerous media outlets has led to an over-emphasis on entertainment and human-interest stories at the expense of news, public affairs and reporting on international politics. When the media do report on political affairs, they are often said to be 'dumbing down' the reports. In other words, they focus on events, 'sound bites', et cetera, possibly to the detriment of more thorough information and serious debate about national and international politics. Elections are framed as a 'horse race', with a prominent focus on (charismatic) individual politicians instead of their parties' programme, which supposedly leads to a more cynical stance towards politics among citizens (Street, 2001, pp.36ff). In this context, the term 'Americanisation' is often mentioned. It emphasises the centrality of television, a focus on events and the importance of marketing and professionalisation in political communication (e.g. Hallin \& Mancini, 2004, pp.254-9; Hardy, 2008, pp.119-22; Negrine, 1996, pp.149-53).

The latter trend - the professionalisation of political communication - refers to the ways in which political actors engage in the public sphere. In his book on political communication in Britain, Bob Franklin (2004, p.24) claims that this country "has become a media democracy in which politicians and politics are packaged for media

\footnotetext{
${ }^{33}$ Luyendijk's book has been translated in a number of languages. In the Netherlands it triggered a broader debate about journalism (e.g. Van Hoogstraten \& Jinek, 2008).
} 
marketing and public consumption." Political actors and their advisors try to 'spin' the news in such a way that it is beneficial for them, while sometimes concealing underlying motives, complexities and conflicts of interest (Bennett \& Manheim, 2001). For example, the diaries of Alastair Campbell, the spin doctor of former British Prime-Minister Tony Blair, are full of references to media coverage and opinion polls, to selling policies and sticking to the message (Campbell \& Stott, 2007). Sometimes political leaders have close ties with media outlets or own important outlets themselves, such as Italian Prime Minister Silvio Berlsuconi. But 'media moguls' such as Rupert Murdoch also attempt to influence politics (e.g. Hardy, 2008, pp.108-14). For some scholars, political parties have even been transformed into campaign organisations and campaigning has become an ongoing occupation (e.g. Sanders, 2009, 76-7). This shift can be explained by the fact that politicians have to compete for the attention and votes of a citizenry which is, to a large extent, disconnected from political parties. Moreover, they also have to compete with other (non)political issues.

A final criticism concerning the functioning of modern public spheres concerns the supposed fragmentation of the public. Today's societies are characterised by a surplus of information (Van Cuilenburg, 1993, p.319). Citizens read different newspapers, watch different television channels and visit different websites. The proliferation of different media outlets has resulted in a fragmented and heterogeneous public. There is simply 'too much choice' (McKee, 2005, p.140) and citizens tend to be no longer able to process and assess the available information. Moreover, marketing techniques such as segmentation and targeting have come to play a prominent role in the political game, as a result of which communication is no longer aimed at the wider public but at individuals belonging to certain groups (Gandy, 2001). On top of this, as was noted already, citizens may decide to abstain from politics altogether. Therefore the 'public' in the 'public sphere' may not even represent all citizens. As a result, people are detached from each other and one can no longer detect a shared process of will formation. Consequently, some critics argue that if we are to preserve democracy we should try to recreate a single, unitary public sphere. For this to take place common media are needed, such as public broadcasting systems (cf. Curran, 2000; Garnham, 1992).

\section{Re-establishing the Public Sphere?}

Developments such as the aforementioned ones are not one-sided, nor are their effects straightforward or even irreversible (e.g. Hallin \& Mancini, 2004, pp.251ff; Hardy, 2008, p.231). Hence, the criticism outlined in the previous section is not shared by everyone. The conception of the public sphere as used in such accounts is said to amount to a static and unitary or homogeneous space - a singular, national entity. From this conception it is a small step towards a pessimistic assessment of 
the current state of the public sphere. Other evaluations of the public sphere offer a different and on the whole more optimistic perspective, which rests on two broad claims. First, there has never really been one, homogeneous public, but rather several publics. The public sphere is a dynamic and pluralistic entity, which consists of many intersecting spaces and countless media outlets. Citizens are media consumers and have become much more able to use, reflect upon and reject different types of information. This also makes it increasingly difficult for political actors wanting to set the agenda and 'spin' political affairs (e.g. Sanders, 2009, pp.61-2). Second, there have always been people who were excluded from the public sphere, so the past should not be idealised. In fact, the modern media are more accessible than their predecessors (e.g. McKee, 2005, p.87).

Regarding the heterogeneity of the public sphere, Kurt Imhof (1996, pp.12-4) notes that besides the general public sphere there are special public spaces (such as with regard to science and the arts) and autonomous spaces where marginalised groups or subcultures develop alternative accounts about society and politics. Nancy Fraser (1992, p.123) has called the latter spaces 'subaltern counterpublics'. Such 'counterpublics' have always existed, effectively creating opportunities for a broader group of people who might otherwise not be able to raise their voice to speak out (cf. McKee, 2005, p.171). In addition, the increased importance of global issues and international organisations has resulted in the development of public spheres on the global level, which remain linked to national public spheres and other non-national and even sometimes borderless arenas (e.g. Nanz \& Steffek, 2004). Karen Sanders $(2009$, p.139) refers to the possibility that new, international political arenas may result in the rise of 'transnational publics'.

Spaces for deliberation and citizen action are formed anew in every debate as different actors and media engage in front of an ever-changing public. There are no monopolistic points of view, because there are always counter opinions and other actors, at least in democratic societies - which does not exclude the existence of majority opinions. New actors appear on the stage, offering new opinions and, in so doing, new public spaces are established. These different arenas do not exist in isolation, but are inter-connected. The media address similar issues, keep tabs on each other and cross-reference each other, while politicians try to attract the attention of several media at once, and citizens use different media outlets and types to keep informed. As Charles Taylor (1995, p.186) explains

although the media are multiple, as well as the exchanges that take place in them, these are deemed to be in principle intercommunicating. The discussion we're watching on television now takes account of what was said in the newspaper this morning, which in turn reports on the radio debate yesterday, and so on.

John Keane (1995, pp.8-16; 1998, pp.169-78; 2003, pp.166-74) argues along corresponding lines when he writes about 'a multiplicity of networked spaces of commu- 
nication'. He introduces a three-fold distinction between different, but inter-related levels of public spheres: micro-public spheres located at the sub-state level, mesopublic spheres at the nation-state level, and macro-public spheres at the supranational or global level.

The second point which should direct towards a more optimistic evaluation of modern public spheres is that the ideal public sphere of the 'good old days' was an elite arena, whereas its current manifestation has been popularised (Keane, 1995, p.18). The bourgeois public sphere only existed in its ideal form in a limited, elite setting and authorities have always tried to influence it. In contrast to what Habermas (1990) has claimed, communication in the public sphere was actually never fully rational. For instance, Kömeçoglu (2005, pp.11-12) shows that cultural expressions such as games and story-telling also contributed to debates in the Ottoman public sphere and made it more accessible to various social strata. In fact, while some have claimed a deterioration of political news through the growing importance of entertainment and human interest, others welcome these developments. John Street (2001, pp.74-5; cf. Delli Carpini \& Williams, 2001) notes that the boundary between politics and entertainment is not as clear as it is frequently presented. Often entertainment such as soap operas or protest songs serves a political purpose, promoting solidarity, and emphasising or criticising certain norms and values. Gurevitch and Blumler (1990, pp.273-4) emphasise that dramatising events or using sports-concepts to cover politics does not have to be explained in negative terms. We could even argue that by excluding such colourful and less serious expressions from societal debates, people are actually prohibited access to the public sphere, which contradicts one of the basic premises formulated by Habermas and others, namely its open character. Instead, these techniques can mobilise citizens and get them interested in politics (cf. McNair, 2003, p.223; Street, 2001, p.204).

In sum, potentially negative developments regarding the public sphere have also been accompanied by positive changes, implying that a more nuanced outlook is possible. Thus, Alan McKee (2005, p.19) writes that "changes to the public sphere are a good thing" as "they make it easier for people from different backgrounds to access the public sphere". Of course, less attentive and more calculating media and political actors may still constitute potential risks for the democratic potential of public spheres. Yet, just as political debate seems to have become more open, the information available to citizens has increased and, as a result, democratic accountability may have been strengthened (cf. McNair, 2000; 2003).

\section{A European Public Sphere?}

As was already noted in the Introduction, this study focuses on political discussions about EU affairs and therefore pays no particular attention to other possible Euro- 
pean-wide discussions. EU governance is largely based on representative democracy, for example through the direct election of the EP, but also the indirect election of the members of the Council of Ministers. The Ministers are appointed following national elections (or even directly elected in some countries) and as such indirectly represent their citizens in the Council. Yet the need for a stronger deliberative element is widely acknowledged, meaning that representative channels should be complemented by other forms of democratic involvement (cf. Curtin, 1997, p.55).

As Christopher Lord (1998, p.129) explains "the EU has developed an elaborate system of deliberation at elite level (...) however, the public is scarcely involved at all." ${ }^{34}$ Here we can once again refer to the aforementioned distinction between weak - or 'general' (e.g. Eriksen, 2007; Eriksen \& Fossum, 2002) - and strong publics, with the latter being quite developed, in the guise of, for example, the EP, comitology and the Convention which prepared the Constitutional Treaty. The challenge is to bolster weak publics by extending debates about EU affairs in such a way that the European citizens become more aware of, and involved in, European governance; in other words, the inclusiveness of debates needs to be improved (e.g. Auberger \& Iszkowski, 2007; Curtin, 2006). Of course, discussions concerning the EU and its policies do take place, but many important issues go unnoticed. Political decisions taken at the EU level may be mentioned in the media, but little real discussion precedes them (Sifft et al, 2007, p.149; Teschner 2000, p.81; Wimmel 2005, p.473).

Right now the European public sphere seems to be hampered by a number of obstacles, including the domestic focus of most national media and the seemingly inadequate communication efforts by the European institutions (see Chapter 3 ). We can draw two tentative conclusions from this: First, a European public sphere is never going to evolve, because the European political process is difficult to grasp (cf. Dahl, 1999) and national positions dominate. European-wide discourses about EU affairs are therefore unimaginable. Nonetheless, global and European affairs are being discussed in the public sphere at regular intervals while the relative secrecy of international politics has lessened (McNair, 2003, pp.14-15, 187-8; Sanders, 2009, pp.134-40; Shaw, 2000; cf. Newsom, 2007). Both domestic and foreign audiences are targeted in an attempt to gain support and legitimacy for policy choices. At the same time the public regularly raises its voice about international affairs, such as in 2003 when protest against the invasion of Iraq led by the US was widespread (see, also: Renfordt, 2007). It is therefore increasingly difficult to support Dahl's previously mentioned argument that citizens are not involved in international politics.

Hence a second possible conclusion: we should consider where the EU is coming from. It is a relatively young political entity, certainly when compared to most of its Member States. Moreover, European integration only really proliferated with the

\footnotetext{
${ }^{34}$ Emphasis in the original.
} 
1992 Maastricht Treaty, precisely at the time when public disapproval came to play a more dominant role. Before that time, a supposed 'permissive consensus' and low media coverage basically ruled out the politicisation of European affairs (Wallace \& Smith, 1995). Hence, a democratic European political process needs time to mature. As Charles Tilly (1995, p.385) has noted "sites of democracy always display the sign 'UNDER CONSTRUCTION'”, meaning that democratic political systems are in constant development. In other words, from the onset there does not appear to be a reason to refute the possibility of a European public sphere altogether. Nevertheless, some important challenges have been identified.

\section{The Unfeasible European Public Sphere}

Critical reflections about the possibility of a European public sphere tend to be related to broader ideas about European culture, language, history, citizenship and so on, and to the broader discussions about public spheres discussed in the previous section. The central propositions of the critics are summed up by Peter Graff Kielmannsegg (2003, p.58), who states that "Europa, auch das engere Westeuropa, ist keine Kommunikationsgemeinschaft, kaum eine Erinnerungsgemeinschaft und nur sehr begrenzt eine Erfahrungsgemeinschaft." He argues that Europeans do not share a common communication infrastructure and language. They lack shared memories and experiences which are necessary to allow for a meaningful exchange of opinions. National communities, traditions and identities persist, a continental community is missing - fragmentation prevails. Therefore Kielmannsegg asserts that the development of a European public sphere is unlikely.

The EU contains twenty-seven Member States and as many national public spaces, each based on specific cultural characteristics. Political communication is still largely defined by these national characteristics (Negrine, 1996, p.168; Sanders, 2009, p.127; Schlesinger, 1995, p.12). The Member States, as Marcel Machill (1998, p.429) notes, are political-culturally unified, whereas Europe is not. This, so it is argued, makes it extremely difficult, even impossible to transfer domestic experiences to the European level and foster an exchange of perceptions and preferences between national publics. When EU affairs are discussed at all it is only within national public spheres. Yet, to really establish a European deliberative space these need to interact and political discourse needs to transcend national borders (Tsakatika, 2008, pp.73, 76-7; cf. Curtin, 1997, pp.56-7). Coalitions need to form across borders and arguments should not be based on national preferences and views, but on a European perspective (e.g. Gerhards, 2000, p.293).

In line with this, it has been argued that we cannot expect a European public sphere to emerge without the existence of common European media, parties and language. In his discussion of the necessity and likelihood of a European constitution, Dieter Grimm (1995) claims that the democratisation of the EU cannot solely 
rely on a parliamentarisation of the institutional framework, but requires the establishment of European mediatory structures, such as associations, movements, parties and media. Although these structures are by no means perfectly developed at the national level, they are almost completely absent at the European level. A European communication system, Grimm contends, would require pan-European media, but their advance is unlikely. Moreover:

A Europeanised communications system ought not to be confused with increased reporting on European topics in national media. These are directed at a national public and remain attached to national viewpoints and communication habits. They can accordingly not create any European public nor establish any European discourse. (Grimm, 1995, pp.294-5)

The absence of a common language is considered to be especially important in this respect. It is evident that a shared language does not exist, despite the fact that most of the day-to-day business in Brussels is based on only two languages: French and, increasingly, English. Most European citizens are only able to communicate in one or two languages, with English as the most likely candidate for the second language. Nevertheless, they feel less comfortable with communicating in a foreign language. ${ }^{35}$ Moreover, different understandings of terms result in different interpretations, which can complicate discussions, even at the political level (e.g. Rose, 2008). According to Philip Schlesinger (1995, pp.26-7), if a kind of common European news agenda does emerge, this is still an important stumbling block, because "even a multilingual rendition of a single given European news agenda is more likely to be diversely 'domesticated' within each distinctive national or language context (...) than it is likely to reorientate audiences towards a common European perspective." ${ }^{36}$ In other words, different interpretations, as well as the constant need to translate, would not allow for any dynamic transnational debates. Even were it so, national perspectives would dominate (cf. Sifft et al, 2007, p.137).

The absence of a shared identity and common experiences also creates hurdles for communication between Europeans. There have been various initiatives to shape some kind of 'Europeaness', often under the lofty banner of 'Unity in Diversity'. They range from the introductions of symbols such as the European flag to more concrete projects, like the appointment of European Cities of Culture (e.g. Laffan, 1996; Llobera, 2001; Sassatelli, 2002). Yet, national allegiances remain and the corresponding historical and cultural experiences still shape the lives of most Europeans. What is more, Anthony Smith (1992, p.62) argues that national identities are much stronger than the idea of European identity, because they are

\footnotetext{
${ }^{35}$ Scholars have even discussed the need to establish one European language (read: English) in order to stimulate democratic exchanges in the EU (e.g. Krause, 2008).

${ }^{36}$ Emphasis in the original.
} 
vivid, accessible, well established, long popularized, and still widely believed, in broad outline at least. In each of these respects, 'Europe' is deficient both as idea and as process. Above all, it lacks a pre-modern past - a 'prehistory' which can provide it with emotional sustenance and historical depth.

In fact, there are different conceptions of what 'Europe' actually entails. For example, Europe can be viewed as a geographical, political, cultural and/or historical entity (Davies, 1997, 7-16; Llobera, 2001, pp.179-80.). This problem is exemplified by the ongoing, often emotional discussions about the question of whether Turkey is a European country or not, and about the general fuzziness of Europe's geographical borders. Moreover, there are different - and sometimes highly conflicting - ideas about what kind of political community Europe should be, ranging from federal blueprints to intergovernmental accounts (e.g. Parsons, 2009). In sum, diversity in Europe negates the emergence of common frames of reference and, hence, transnational public debates will not be possible.

\section{Four Critiques}

The arguments outlined above partly rest on the belief that a European public sphere would only be possible were it to take the guise of a national-type public sphere, with European intermediary organisations, a common culture and a shared identity. Such a single, uniform European public sphere is not very likely to develop, certainly not in the near future (cf. Wessler, 2004). Yet, we have already seen that homogeneous spaces do not even exist at the national level. So on what assumptions are the sceptics' views based? Four kinds of critique have been brought forward, concerning historical outlooks, observations of contemporary Europe, theoretical arguments and normative assumptions.

The first critique, of a historical nature, is represented by Hartmut Kaelble (2002; cf. J-H. Meyer, 2004). He argues that in many ways there has always been a European public sphere, such as the one existing at the time of the Republic of Letters (the transnational intellectual community of the $17^{\text {th }} / 18^{\text {th }}$ century), or during debates on the future of Europe after the two World Wars - after all, Europeans share common historical experiences, including these battles and the Cold War. Kaelble (ibid, p.19-22) also identifies a number of developments which would suggest a European public sphere is in the making, namely the centuries old political and philosophical debates on Europe's future, the growing interest for European topics among experts, the rise of a European civil society, the increased of European symbols, the fact that Europe increasingly figures as a topic in elections and referendums and the rising coverage of European topics in the national media.

The first two developments mentioned by Kaelble are most convincing, considering the frequent reform of the EU treaties (e.g. Christiansen \& Reh, 2009), the ongoing debate about Europe's geographical reach (e.g. McCormick, 2008, pp.32- 
6), the huge amount of publications on the EU and the increase of European Studies bachelor and master degree programmes. Though the establishment of Brussels as a hub for various organised interests is evident, the supposed development of a European civil society is a more controversial issue (e.g. Greenwood, 2007). Kaelble's reference to the latter two developments is least convincing, because EU affairs do not seem to figure prominently in national politics and media attention for it is still considered by most accounts to be moderate. In addition, he has been criticised for an all too easy use of the term 'European public sphere', one he attributes to developments which did not always result in the establishment of public spheres (J-H. Meyer, 2004, pp.217-8).

While some of Kaelble's assumptions may be criticised, the broader notion of the existence of a shared European history has become widely endorsed. True, not all events in history have been felt equally across the whole continent, yet major episodes such as the Thirty Years War (1618-1648) and the Age of Enlightenment (much of the $18^{\text {th }}$ century) have had a widespread impact. The importance of this, besides being mentioned in the European institutional discourse, is also exemplified in other ways. European history teachers united as members of the European Association of History Educators (EUROCLIO) have been able to develop mutual agendas in which Europe has become a 'routine' subject, while national histories are increasingly being situated in the broader history of the continent, despite different national accents (Soysal, 2002). Furthermore, exhibitions have been organised that adopt a European approach to history ${ }^{37}$ and the topic is the subject of several ambitious books in which the authors seek to paint a comprehensive picture of the continent as a whole, treating Europe as a single entity (e.g. Davies, 1997; Mak, 2007). Like nation-states, Europe even has its own myths, such as with respect to the European 'founding fathers' - Jean Monnet, Robert Schuman and others (e.g. Shore, 2000, pp. 48, 58-9).

The second objection to the pessimists' account of the European public sphere is of a more practical nature and refers to today's Europe. It has been declared that Europeans do share a common identity, based on shared values such as human rights, democracy and the rule of law, whose foundations can be found in Roman Law, Judeo-Christian traditions and the ideas of the Enlightenment. For example, the Constitutional Treaty's preamble referred to "the cultural, religious and humanist inheritance of Europe, from which have developed the universal values of the inviolable and inalienable rights of the human person, freedom, democracy, equality and rule of law. ${ }^{38}$ A strong counter-argument to this is that many of these values are not specifically European, but rather Western and, in some cases, even

\footnotetext{
${ }^{37}$ Such as the exhibition It's Our History! which took place from 26 October 2007 until 12 May 2008 in the gallery Tour \& Taxis in Brussels. It was organised by the Museum of Europe. See: http://www.expoeuropa.be

${ }^{38}$ Treaty Establishing a Constitution for Europe, OJ 2004, C310.
} 
universal - at least in principal (cf. Delanty \& Rumford, 2005). Nevertheless, they do play a role in today's Europe and are often referred to in internal affairs (e.g. the EU's Charter of Fundamental Rights ${ }^{39}$ ) and external affairs (e.g. the European Security Strategy (European Council, 2003)).

A more substantial shared element of modern Europe has been put forward by Klaus Eder and Cathleen Kantner (2000, pp.323-5), namely the development of a common European system of law (cf. Llobera, 2001, p.178). Since the early decades of European integration there has been a steady increase in regulations, directives, and other forms of legislation. Also, the Treaty framework has evolved rapidly (especially during the last two and half decades), increasing the responsibilities of the EU. The legal order that has evolved as a consequence of these developments binds the Member States closer together. Eder and Kantner (2000, p.324) argue that this legal order stimulates political actors to discuss public policy options in a way that is understandable to their partners, which is particularly important if they are to have any hope of convincing them of their own preferences. Although the attention for EU affairs is still moderate, some of these discussions do take place in public, which might promote synchronised public debates across the continent. We may add that the EU has become synonymous with Europe and that many countries outside the Union are eager to join this legal order. As Thomas Risse (2009, p.154) explains, this means that EU membership has an effect on the identities of both members and non-members, to such an extent that "the EU has achieved identity hegemony in Europe."

The third critique is of a theoretical nature. The sceptics adhere to a largely static, non-changing perception of community and identity. Yet, in many ways these have been, and still are, in a process of constant (re)construction. The nation-state is an 'imagined community' (Anderson, 1983), and it created the nation, not the other way around (E. Gellner, 1983). Like the nation, 'Europe' is an ever-changing idea based upon, at times, contradictory discourses which, in addition, are often the result of a dialectical relationship between European self-images and those constructed of 'others' (Stråth, 2002). Moreover, identities do not exclude each other. People usually have multiple identities, as consumers, as parents or children, as inhabitants of a town, region, and state - even of Europe. In this respect the phrase 'Unity in Diversity' does make sense: different identities and commonalities overlap and exist side by side. Identities change and even disappear, and therefore, there is no reason to reject the possibility of an evolving European identity.

Craig Calhoun (2003; cf. Delanty \& Rumford, 2005, Chapter 3; Risse, 2010, pp.120-5) contends that the legitimacy of the EU does not even require a 'thick' European identity. Other kinds of social integration are possible, since identity and interests are not given, but are formed through collective action in the public

\footnotetext{
${ }^{39}$ Charter of Fundamental Rights of the European Union, OJ 2000, C364/1-22.
} 
sphere. Calhoun (2003, p.252) argues that this already helps to create a kind of solidarity and social integration: "With regard to Europe, this means that mutual engagement in public life need not depend on prior cultural similarity or compatible interests." Linked to Calhoun's conception of changing identities is the belief that borders are not unchangeable and impermeable. Instead, as Chris Rumford (2006, p.132) explains, European borders, like identities, "are periodically dissolved, constructed afresh, shifted, reconstituted." They are not "cast in stone" (Berezin, 2003, p.10). This does not mean that borders such as national boundaries no longer matter - they will remain important for democratic life - but they are sometimes permeable at and at other times more rigid (Rumford, 2006, p.135). Borders will continue to play a role in social and political life, but European spaces are of a "nonexclusive nature" and "can be simultaneously local, national, European and global." (ibid, p.137). As will be argued here, this also applies to the engagement of national public spheres with EU affairs.

A fourth objection concerns a normative problem. Claiming that a European public sphere only comes into being when discussions are based on European perspectives and arguments denies the possibility for a debate when domestic concerns are brought into play. This goes against a basic proposition of democracy: the idea that debates should, in principal, be open to all arguments. In fact, diverse national preferences indicate the existence of communication and do not necessarily indicate that a common problem has not been identified or that shared references are impossible (Eder \& Kantner, 2000, p.308; Kantner, 2003, p.218; Kantner, 2006, p.148). One might even ask whether it really is a bad thing that debates on EU affairs often proceed along national lines. Maybe this is not problematic - it might in fact be an important step towards creating an awareness of European politics among citizens (Voltmer \& Eilders, 2003, pp.189-90), which makes sense considering the EU's relatively young age. ${ }^{40}$ Of course, this could lead to a more critical and even sceptical citizenry but, at the same time, this could also turn out to be a 'healthy' phenomenon for EU democracy (e.g. De Beus \& Mak, 2009, p.31; Milner, 2000). ${ }^{41}$

Accordingly, a more nuanced view with respect to the fragmentary nature of the European public sphere is possible. Risse (2002; 2010, pp.112-3, 146) makes a useful distinction between fragmentation, polarisation and heterogeneity. The latter is necessary for any public debate; different opinions are common to modern,

\footnotetext{
${ }^{40}$ In this respect it is also important that 'Europe' is not only the topic of current affairs media, but also figures in other programmes, media formats and so on. As a matter of fact, European integration has already been discussed on for example MTV and at music festivals. See, for example, the website of Coolpolitics, an organisation which tries to stimulate participation and debate among young people: http://www.coolpolitics.nl/

${ }^{41}$ Silke Adam (2009) takes a more cautious position regarding the potential positive impact of euroscepticism, arguing that a purely negative opinion will have detrimental effects.
} 
pluralist democratic societies and fuel debates. Polarisation might be more problematic in a situation where people no longer engage with the views of their opponents, but just ignore them. Fragmentation, however, means that different spaces exist in isolation from one another. Risse therefore argues that a transnational European debate needs some kind of linkage between, and reflection on, the perspectives and views presented across the different Member States. Such linkages occur when references are made to debates in these countries, when representatives of the European institutions are given a voice in the national public spheres, or when actors from other Member States are able to present their arguments. In other words, national public spheres should not just simultaneously reflect on the same issues, they should also interact with each other. As mentioned before, this latter criterion is not equally valued by all scholars (e.g. Kantner, 2006, pp.147-9) and Risse (2010) seems to have adopted a more nuanced position himself. We will later see that interaction between national public spheres is not uncommon, even though it may not always occur.

Language does not have to be a problem; it is common to translate international and foreign news into local languages (cf. Newsom, 2007; Shaw, 2000). Hence, the insistence on a common media system is also peculiar as this is even absent at the national level; an array of media outlets operate in most Member States. As explained above, this does not mean that national public debates cannot exist as these micro-public spheres are interlinked. There is no special reason why this could not occur on the transnational level (which is not the same as arguing that it will occur - some of the most important obstacles will be addressed in the next chapter). Ultimately, what is most important is that citizens become aware of the important issues and different positions in the debate (Eder \& Kantner, 2000, pp.312-3). In today's European societies the media play a formative role, covering international developments and (through translation) presenting them in a language understandable to the majority of people. They 'amplify' and 'condense' debates between the different actors and stakeholders (Van de Steeg, 2002, p.507; 2003, p.179). Press reviews are just one example of the ways in which opinions might cross borders (e.g. Erbe, 2005; Scherer \& Vesper, 2004).

\section{Manifestations of the European Public Sphere}

Eder (2000) has identified two shortcomings of the more sceptical perspectives on the European public sphere. The first is the theoretical emphasis on national borders, which is illustrated by the weight attributed to a people with a common language, shared history and predefined identity and traditions, and the existence of clearly identifiable intermediary organisations, such as mass media and political parties. Communication which transcends these national borders is virtually impos- 
sible. This theoretical shortcoming is also reflected in the second limitation, which is of a more empirical nature - namely, that the indicators one tends to draw upon to test these theoretical assumptions can only yield one finding: that a transnational public sphere is nonexistent given the absence of shared culture, language and identity (cf. Baisnée, 2007b, p.496). Eder (2000, p.172) argues that there is enough empirical evidence to suggest that there is communication beyond borders in Europe, which includes different actors, media and publics (cf. Eder \& Kantner, 2000, pp.317-22). Therefore, we should not depart from an understanding of the public sphere being based upon static and predefined notions of identity, history or language, but rather, from a notion that assumes the presence or absence of communication through an ever-changing, multi-dimensional public sphere. Elsewhere Eder, together with Hans-Jörg Trenz, argues that a European public sphere is gradually evolving due to the European institutions' efforts to communicate with citizens, who are themselves often critical of the EU's performance, as is regularly recorded by opinion polls (Trenz \& Eder, 2004).

In other words, despite some clear indications that there is potential for a transnational space in which to debate, a European public sphere is unlikely to develop in a manner consistent with 'traditional' national public spheres. One difference concerns the fact that the EU functions differently to most of its Member States, which has consequences for any European public sphere. For example, complex and long procedures tend to stifle attempts to politicise EU politics (see, also, Chapter 3). Another difference is the absence of nationhood due to the existence of at least 27 different publics. Considering that national public spheres are also heterogeneous, diversity in Europe does not have to be an obstacle per se. Following this line of argument, the question we should ask is not whether a European public sphere is likely to evolve at all, but rather what it would look like (cf. Barnett, 2004, pp.193-4). Eder (2000, p.176; 2003, pp.94-5) argues that it is likely to exist in various manifestations and will be quite different from national public spheres. Trenz (2003, pp.162-3; cf. Voltmer \& Eilders, 2003, pp.175-9) distinguishes between three specific appearances: an elite European public sphere, functional spaces and a popular, mediated public sphere. Based on national public spheres, the latter seems to offer the best opportunities for more inclusive European debates.

\section{The Elite European Public Sphere}

On the European level there is a public sphere, based upon media such as the European Voice, Financial Times, Euronews and Euractiv.com. Some of these media "selfconsciously address a European (...) elite audience conceived as composed of political and economic decision-makers, the preferred language being English" (Schlesinger, 1999, p.272). Policy-makers, civil servants and representatives of organised interests all follow the news in order to keep up with the latest develop- 
ments in the EU. They also use these European media to air opinions and interests. For example, a Dutch correspondent based in Brussels once wrote that many consider the Financial Times to be the Commision's 'official organ' (Lanting, 2005).

Arguably, these European media outlets constitute in themselves an elite public sphere: they are predominantly used by a small group of insiders, including academics, politicians, journalists, students and other professionally-engaged people (Schlesinger, 1999; cf. Kevin, 2003, p.40). Language acts as an important obstacle to making direct contact with the 'ordinary' European citizen, as most of these outlets publish their news in only a few languages (principally English, sometimes French and German). Stories are written with a particular, highly-educated, well-informed readership in mind. Consequently, these media form selective discussion platforms for Brussels 'insiders'. They (unintentionally) exclude the large majority of the European citizenry and are unable to constitute a truly democratic, mass public sphere (Trenz, 2003, p.162).

The exclusive character of this European public sphere should however not lead to the conclusion that it is unimportant. For one, pan-European media can play a role as agenda-setters and transmitters of issues, information and debates to the national public spheres. For example, the Financial Times is read by many editors of national newspapers, so 'leaking' information to this European newspaper can result in the information being picked up by national media (Balčytienè et al, 2007, p.158; Lanting, 2005). Another example concerns the EP's own web-TV channel, EuroparlTV, which was not set up purely to attract viewers from all over Europe, but also to act as a source of information for other journalists, in particular those who do not always possess the means to go to Brussels (Shackleton, 2007). Furthermore, the European public sphere provides an opportunity for EU policymakers and stakeholders to exchange views, become more knowledgeable and to get to know each other. This can stimulate informed discussions and promote more optimal solutions.

\section{Issue-Specific European Public Spheres}

One of the main characteristics of modern governance is the development of sectoral differentiation and the appearance of 'policy communities' and 'issue networks', which bring together policy-makers and organised interests with the aim of discussing problems, squaring differences and developing solutions that exist within a particular field. Policy communities tend to be rather closed and stable, whereas issue networks are usually more loosely organised (e.g. Peterson, 2009, pp.108-9). The importance of networks can also be observed in EU governance. The Common Agricultural Policy (CAP) is a typical example of a field in which policy communities are important, whereas environmental policy is partly characterised by the existence of issue networks (Nugent, 2006, p.575). 
In the light of this development it is possible to discern the existence of specific public spheres, linked to different networks, for example with regard to the CAP (e.g. Eder, Hellmann \& Trenz, 1998). We have already seen that the occurrence of such specialised arenas is not unusual within national settings; these functional spaces even exist at the global level, for example with regard to World Trade Organisation (WTO) (Nanz \& Steffek, 2004, pp.319-20). They are constituted by conferences, journals and so on, with a specific focus on the issue or policy-field in question. In the field of EU agricultural policy, examples include Agra Europe ${ }^{42}$ and the European Review of Agricultural Economics ${ }^{43}$. Like the elite public sphere described above, these issue-specific public spheres lack a certain public resonance because they only involve those directly affected by the policy in question, and thus have difficulty connecting to the wider citizenry. Still, they play a role in bringing together those people most affected by specific policies and they too can act as agenda-setters and sources of information for national media and, in so doing, influence the public agenda.

In this context it is important to note that the European institutions - especially the Commission and the EP - are quite open to interest groups and eagerly make use of their expertise. Although these interest groups may not always directly involve citizens in EU affairs, they do contribute to democratic legitimacy in other ways. For one, some interests may be more affected by EU decisions than others. These differences may be reflected in the degree of interest group mobilisation and their (efforts to secure) participation in functional public spheres (Baisnée, 2007b, pp.500-1). ${ }^{44}$ Also, by bringing in information and expertise, interest groups can increase the quality of representation. Moreover, their involvement can provide a more continuous link between society and government, which partly compensates for the low electoral connection in the EU. One might add that interest groups often cut across national frontiers, identifying common problems, focussing attention towards EU decision-making and stimulating shared interests, for example concerning consumer affairs or environmental issues (Lord, 1998, p.76; McCormick, 2008, pp.138-40).

\section{National Public Spheres and a Popular European Public Sphere}

We have just seen that the EU already incorporates deliberative elements in the form of a supranational space consisting of officials, scholars, and so on, as well as in the form of issue-specific spaces formed around policy networks and issue com-

\footnotetext{
${ }^{42}$ http://www.agra-net.com/portal2/home.jsp?template=productpage\&pubid=ag002\#

${ }^{43}$ http://erae.oxfordjournals.org/

${ }^{44}$ One could imagine that the same observation might apply to the EU members. For example, developments on the African continent may be of more interest to its former colonisers than to the other Member States.
} 
munities. Despite their potential importance for setting agendas, informing other media and bringing together interested parties, these European and issue-specific public spheres only play an indirect role in promoting broader public debates. Instead, a popular public sphere based on national print, broadcast and electronic media might be able to play a bigger role - after all, most people do not use panEuropean media, but national media, as the principal sources of information about EU affairs. As Stephan Russ-Mohl (2003, p.205) explains:

Looking at the readership or audience, all European publications and programs are simply irrelevant. The field of political information is clearly dominated by national newspapers and magazines, networks and talk shows. Media products are mass products. And masses of people are, unfortunately, not cosmopolitan, polyglot Europeans. They are Swedes, Russians, Poles, French, Italians, Swiss, and Germans.

For the time being a popular European public sphere will therefore depend on the national public spheres of the Member States of the EU. Here people feel most secure and 'at home'; they are more familiar with the characteristics of national public spheres. Hence, overlapping national public spheres might be able to constitute platforms for European wide debates (cf. Schlesinger \& Kevin, 2000). ${ }^{45}$ As we will see later, there is reason to believe that, together, these national spaces might be able to foster a transnational space for debate and opinion formation. This is compatible with the fact that even modern national public spheres are not homogenous, but based upon different subnational spaces and counter publics, as shown above. The mass media still provide a platform to discuss current affairs (political, cultural, et cetera) in the heterogeneous national public spheres (Eder \& Kantner, 2000, pp.314-5), even in countries such as Switzerland which harbour different linguistic communities (e.g. Kriesi, 1994).

It can thus be argued that national public spheres may be able to play an important role in linking the European political process with the citizens, first, by fostering vertical connections between national publics and European political actors and, second, by stimulating horizontal interaction between Europeans (cf. Kunelius \& Heikkilä, 2007, p.67). The elite space and the issue-specific public spheres also play their own part by acting as points of reference for national media, as intermediaries between the national media and European institutions, and as meeting places for policymakers and stakeholders. Given their more detailed and focussed accounts of EU affairs, they may be the first to disclose issues, set the agenda and frame the problem. By disseminating information and connecting to other media they have a similar role to play in the public space as the various national media.

It is now possible to draw a tentative, multifaceted and dynamic multi-level picture of the European public sphere as consisting of at least three different forums:

\footnotetext{
${ }^{45}$ For a similar argument with regard to a global public sphere, see: Nanz \& Steffek, 2004, p.322.
} 
an elite European space, various functional spaces, and twenty-seven national spaces. In other words, this European public sphere is not just an intermediary between state and society, but forms a dynamic space that connects political actors, media and public through different levels of communication (cf. Eder \& Kantner, 2000, p.329). Figure 3 provides a graphical representation of this 'communicative network', focusing on the two national public spheres that are the subject of this study. The vertical arrows represent exchanges between the different levels of the network; the horizontal ones between the different spaces on a single level. The arrows in this figure only connect the various public spheres, but the latter are of course also in contact with the different levels of decision-making in the EU. The picture therefore represents a simplified version. Sub-national spaces and the global public sphere are left unaccounted for, but naturally play a role as well. In addition, Figure 3 does not take into account the presence of possible European counterpublics (e.g. Della Porta \& Caiani, 2009; Wimmer, 2005). Moreover, this graphical representation of the European public sphere cannot account for the fact that debates can vary according to factors such as topic, Member State and phase in the policy process, as will become clear in the upcoming chapters.

Figure 3: The European Communicative Network

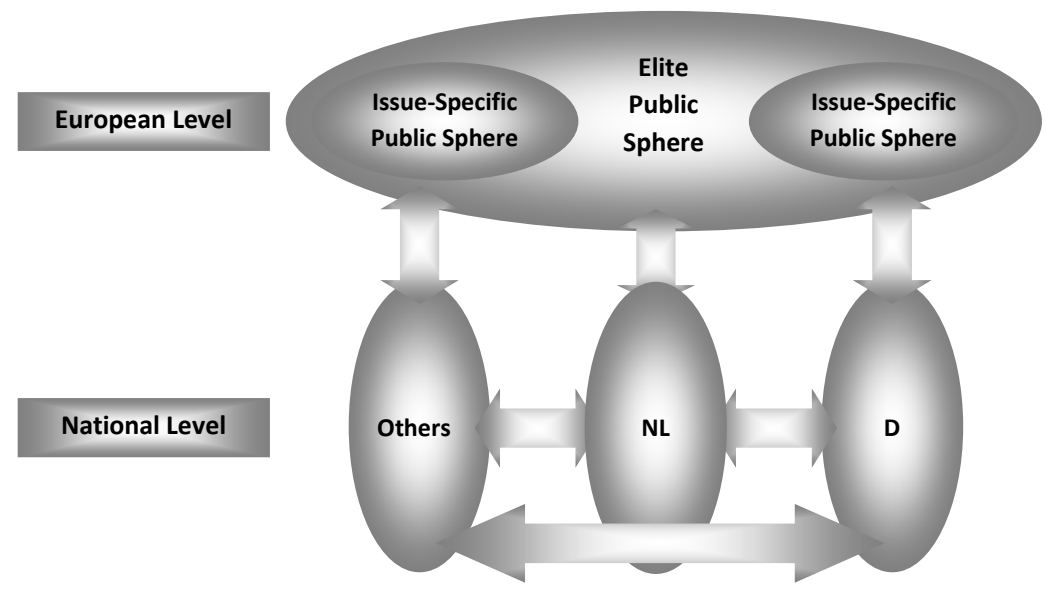

\section{Conclusion}

This chapter discussed several issues: firstly, the importance of public spheres for democracies; secondly, the interaction between political actors, citizens and the media in fostering public spheres; thirdly, the debates about the condition of modern public spheres; and fourthly, the likelihood of the development of a European 
public sphere. The debate about the latter has - in some ways - developed along similar lines as the one about modern public spheres. Issues such as fragmentation and commercialisation play a role too and conceptions of the (European) public sphere are often based on similar ideas.

Traditional conceptions of the public sphere and European public sphere were criticised, in particular, by presenting an account that combines elements from two relevant theoretical perspectives. First, the account emphasises liberal-pluralistic views of power relations in the public sphere, and stresses the existence of multiple media and political actors, the importance of personal experiences for the processing of information, and the increased accessibility of the public sphere and disclosure of political information resulting from broader social changes (cf. Street, 2001, pp.236-48). Second, this is combined with a social constructivist account of how identities and debates are shaped through social interaction and communication. From this perspective, agents and structures shape and influence each other; the European public sphere is regenerated based on the topics and actors involved. Moreover, the way in which actors interact, or the way in which a topic is discussed, is also determined by previous and parallel materialisations of the public sphere (cf. Delanty \& Rumford, 2005, pp.12-20; Risse, 2009, p.150; Rosamond, 2000, pp.1714). These two perspectives suggest that the development of a European public sphere - transnational or otherwise - should not be excluded per se. Instead we should consider what it would one day look like.

Where scholars such as Grimm and Tsakatika have argued that the discussion of EU affairs in national public spheres does not entail the development of a European public sphere due to the dominance of national perspectives, others, including Eder and Kantner, have argued that such discussions - and the resulting national preferences - actually designate the development of communication. Even a purely national debate might increase awareness of the EU, which may be a first step in the development of a more elaborate European communicative network. Even so, scholars such as Risse and Wimmel have argued that a transnational space only occurs when arguments and actors cross national borders and when this interaction includes reactions to opinions from actors in other Member States. This suggests that there may be different ways of conceptualising the role of national public spheres in strengthening European democracies.

Hence, the issues that have been addressed in this chapter lead on to some tantalising questions about the very nature of an arena for debating EU affairs and the potential contribution of national public spheres to the democratisation of EU policymaking. One of the aims of this study is to find out whether the tentative image of the European communicative network, as sketched out in the last section, provides a good representation of the European public sphere. Can national public spheres create a transnational arena? If so, what would it look like? If not, which hurdles prevent this development and could they be overcome? Based on the discussion 
above, one might question the need for European perspectives - in other words, are national perspectives on EU affairs adequate and sufficient? A purely national debate may be problematic in terms of a transnational space, but does that mean that it cannot stimulate democratic exchanges on EU affairs? And related to this point, what kind of public sphere should we conceive of when debates are purely national, but nonetheless take place simultaneously and concern the same policies? Arguably, since Member States attach different political weight to particular issues (and hence may or may not have a heightened interest), public spheres may only come into being on in some countries. It is not inconceivable that on some issue related to EU affairs, such as the need to protect certain regional products, a debate only takes place in a single country. This also implies that the particular manifestation of the European public sphere is likely to depend on the issue being discussed, as has been suggested in existing studies (e.g. Adam, 2008; Koopmans \& Pfetsch, 2006; Van de Steeg, 2006; Wessler, 2004).

Issues and questions such as these will resurface throughout the subsequent chapters, starting with Chapter 3 which will examine the influence of the EU's institutional setting and the Brussels micro-cosmos - perhaps an (elite) European public sphere in its own right - on transnational debates, and the way journalists approach EU affairs. As we will see, obstacles to reporting on European policies and developing a transnational public sphere are closely related to the political logic of the institutions and the media logic of national outlets. 


\section{EU Affairs in the Public Sphere: The Brussels Micro-Cosmos}

According to John Gaffney (1999) debates about Europe are shaped by both the EU's institutional setting and the various national politico-cultural frameworks. The latter will be the topic of Chapter 4. This chapter will discuss the bearing of the Brussels micro-cosmos on (transnational) debates. Like the national public spheres, the European public sphere is constituted by the interaction between actors, media and public. Yet, its manifestation is even more complex. The public is a multinational public, consisting of 27 national publics. In addition, there are media outlets that specifically focus on EU politics, including dedicated websites, television channels and weeklies. The national media play a prominent role in fostering a European public sphere at the popular level. Their correspondents in Brussels are the main interlocutors between the EU and the national publics. Much of the interaction between political actors and journalists engaged in EU affairs takes place in the European neighbourhood around Rond Point Schuman, a stone's throw from the main institutions. Hence being there in person is important for both journalists and political actors.

Many political actors play a part in the policy process and the related debates, including EU institutions, national and sub-national governments and various (transnational) organised interests. Most have offices in Brussels to promote their interests. NGOs stage protests against EU affairs and resort to institutionalised action, in national capitals and in Brussels (e.g. Ansell, Maxwell \& Sicurelli, 2006; Imig \& Tarrow, 2001). National actors may choose to try to engage in debates in other national public spheres, in issue-specific spaces or in the elite European space.

The policy process in Brussels tends to be different and sometimes more complex compared to what most people are used to. There is no clear government- 
opposition dichotomy and the system of 'checks and balances' works differently from that in most Member States, requiring robust majorities, compromises and deals. Power and influence are diffused across many different actors and between different levels, obscuring responsibilities to such an extent that the EU sometimes appears to some as though it were one single body. Relations between the judiciary, legislator and executive, while not always that straightforward at the national level (Hering \& Kiiver, 2009, pp.21-3), are even more complex in the EU, where, for example, the Commission and the Council combine legislative and executive roles. Some have even argued that in terms of democracy the EU tends to resemble American pluralism, instead of the parliamentary democracy known in most European states (Coultrap, 1999). Certainly, the way in which the EU is governed will also affect the development of a European public sphere (cf. Giorgi, Crowley and Ney, 2001) - as we will see later, those complexities tend to be disregarded in national public spheres, with responsibilities and procedures remaining unclear and, hence, with information about EU affairs incomplete or even skewed.

Jürgen Gerhards (2000, pp.297-9) identified three possible causes for the deficient development of the European public sphere. First, the efforts of the EU's institutions to play a role in the public arena are limited: the Commission suffers from internal divisions and its image as a bureaucratic monster; the EP, despite having gained power throughout the last two decades, is still seen as a weak institution; and the Council and the European Council for their part are mainly interested in national gains. Second, the EU's newsworthiness is limited: 'Brussels' is perceived as being too complex and a place where consensus dominates; and there is hardly any room for drama and personalisation during the policy process. Third, EU correspondents are mainly nationally-orientated in their outlook (and thus reporting), and there is little room for investigative journalism (often due to a lack of resources).

This chapter will show that that these structural problems do indeed affect European public debates, and possibly act as serious hurdles for the development of a transnational European public sphere, although their impact may differ according to, for example, the issue involved. The chapter begins with a section on the communication machinery of the institutions, which has expanded in the last few years. Thereafter, recent attempts to increase transparency and streamline communication will be discussed. Transparency is important for democratic governance, but it needs to be complemented publicity in order to be noticed in public spheres. The final section discusses the role of the Brussels-based media in creating a transnational public space. It will question why, despite the Brussels press corps being one of the biggest in the world, EU news items feature disproportionately low in the national media. 


\section{The EU Institutions and the Communication Predicament}

As explained in the introduction, there is a widespread belief that the EU institutions need to (re)gain legitimacy. One strategy in this respect is to enter the public arena and foster support for policies and actions (Eder, 2003, p.96). The institutions, Member States and other stakeholders all try to gain media attention to promote their individual take on EU affairs. As one public relations (PR) practitioner explained, for many interest groups the traditional distinction between public affairs and PR has become blurred (Interview 4). The institutions employ channels, methods and strategies which are often similar to those used within national settings (Kopper et al, 2007, p.81; see, also, Chapter 2). So far, publications that reported on the institutions' communication policy predominantly focussed on the Commission, while the EP and the Council were largely ignored. In the last couple of years this seems to have been changing.

The focus here will be on the three main institutions/actors in the European policy process, the Commission, the EP and the Council (including Member States governments and parliaments). Until recently these actors did not put any special efforts into communicating with the public and the national media. The heated debates at the time of drafting the Maastricht Treaty and the difficult ratification process acted as a wake-up call, signalling the end of the 'permissive consensus', especially given the Danish rejection of the TEU in June 1992 and the narrow French approval in September 1992 (C. Meyer, 1999, p.624; Tumber, 1995, p.511). Nevertheless, almost 10 years later Neil Gavin (2001, p.302) still questioned the EU's attempts to improve communication efforts, stating that "there is a distinct failure on the part of the EU to acknowledge the imperatives of modern political communication" (cf. De Vreese, 2003, p.6). One EP official said that all those involved in communicating the affairs of the institutions are 'gifted amateurs' (Interview 1). A Commission official made similar remarks and said it feels like being 'Alice in Wonderland' (Interview 10).

Still, currently the European institutions act as the main engineers of the European political arena. Although they may not always succeed in engaging the broader public in discussions, they certainly are responsible for forging the various issuespecific public spheres and the elite public sphere. Generally, the Council of Ministers and the European Council represent the national angle and act as a link between the European level and the national level, whereas the Commission and EP represent the European perspective (Jopp \& Kleine, 2004). With ongoing debates about the EU's democratic deficit and increased scepticism among European citizens - as evidenced by the Dutch and French rejection of the Constitutional Treaty in 2005, and Irish rejection of the Lisbon Treaty in 2008 - the importance of political communication and of openness and transparency has only increased. 


\section{The National Tier: Governments, Parliaments and the Council}

National governments have always taken an ambiguous position with regard to actively communicating EU affairs. As initiators and beneficiaries of European integration one would expect them to take a positive approach, focussing on the benefits of this process. Yet, as Birza (2000, p.120) illustrates in the Dutch case, most citizens used to consider integration a good thing (cf. the permissive consensus) and therefore governments generally felt no need to actively pursue a communication policy. In countries where citizens were (and are) more sceptical, EU communication is tricky, as the British New Labour party experienced after winning the 1997 general election (Anderson \& Weymouth, 1999, pp.158-9). In addition, for domestic reasons a more negative account of what happens in Brussels also makes sense, for example in case of unpopular decisions which have been adopted at the European level, regularly in an attempt to circumvent domestic opposition. In other words, national governments may have strategic reasons to decide what to communicate and whether or not to communicate regarding European affairs at all (e.g. Adam, 2007, pp.413-4, 423; De Beus \& Mak, 2009, p.90).

The Member States can communicate via the machinery of the (European) Council, above all during the legislative process. Within this institution's General Secretariat, DG F ('Press, Communication, Protocol') is responsible for communication, information and transparency, and for contacts with the public and interinstitutional relations in the field of communication. It includes a Press Service, which offers various facilities to the press and the Member States and organises special arrangements during meetings of the European Council. Moreover, it provides journalists with background and information notes as well as press communiqués. The Press Service tries to stay in the background. It does not have an opinion, but serves the institution and the Member States, the latter having their own opinions and spokespersons (Interview 13; Interview 14). DG F's Public Information Unit deals with public access to Council documents and, before the Lisbon Treaty came into force, DG F also supplied a spokesperson for the Secretary General/High Representative for the Common Foreign and Security Policy (HR CFSP) (HayesRenshaw \& Wallace, 2006, pp.126-7).

Within the Council framework, the Presidency and the HR CFSP have so far played an important role in making EU affairs more visible, both to European citizens and external partners. The HR CFSP has been significant in terms of external representation on the world stage. The establishment of this position by the Amsterdam Treaty may not have created the single European phone-number Henry Kissinger was supposedly enquiring about, but the appointment of Javier Solana certainly increased the public profile of EU foreign policy (e.g. Keukeleire \& MacNaughtan, 2008, pp.79-81). Due to his active approach and strong personality, Solana was able to generate considerable media attention. 
The Presidency is responsible for many tasks, including organising and chairing meetings during its six months term, acting as a mediator and representing the Council. The visibility of this role has gradually increased and the need to provide some kind of public spectacle has resulted in, for example, the introduction of Presidency logos and websites in the 1990s. Many things have been said and written about the strengths and weaknesses of the Presidency (e.g. Hayes-Renshaw \& Wallace, 2006, pp.154-7), but in terms of information and communication the rotation system offers the opportunity to increase awareness about EU affairs at home because it generates much public attention. Some have therefore argued that this task is ideally suited to bring the EU and its citizens closer together (e.g. De Vreese, 2003, pp.29-32; see, also, Boomgaarden et al, 2010, p.p.518). Related to this, a country also has the chance to make itself - particularly its cultural heritage and assets that may draw visitors - known to other EU members and their citizens, thus creating consciousness and promoting exchange of ideas, norms and values.

Both the position of the HR CFSP and that of the Presidency have changed with the Lisbon Treaty. Whether or not Solana's successor, Catherine Ashton, will be able to create a pronounced public profile is still too early to predict, but so far her increased powers do not seem to have been matched by a strong media image. Ashton's position is somewhat ambiguous: being the new High Representative of the Union for Foreign Affairs and Security Policy and Commission Vice-President she has to navigate her way around the interests of the Council and the Commission. ${ }^{46}$ The profile of the rotating Presidency seems to have decreased with the establishment of the new post of European Council President. Even though the actual impact of the appointment of Herman 'Haiku' van Rompuy remains unclear, he has taken over some of the more high-profile functions that used to be performed by the rotating Presidency, including chairing the meetings of the European Council. Ben Crum (2009) writes that the personalisation of the Presidency may increase the chances for democratic control, but that much depends on the personality of the new President, on the way in which he carves out this new role and on his interaction with the EP. One might add that these factors will also affect the President's public profile.

Despite the presence of various communication channels in the Council, ministers and EU leaders tend to make use of their own facilities, in particular in the context of Council meetings when national media are targeted in order to present the national point of view, and to discuss the results of the meetings from a national perspective (Gerhards, 2000, p.298). The focus on national points of view makes it more difficult to present a coherent picture, yet it is also a reflection of the fact that the EU is made up of Member States and citizens with different and wide-ranging preferences.

\footnotetext{
${ }^{46}$ Her spokesperson is provided by the Commission.
} 
National parliaments have so far only been weakly engaged in communicating Europe. Their statements and positions are usually of a general nature, providing governments with enough room for manoeuvre during meetings in Brussels. Also, European policies are typically only scrutinised after agreement has been reached and legislation has been implemented. As a result, national parliaments do not establish a stable connection between national arenas and European politics (Benz, 2006, pp.106-7). ${ }^{47}$ National political parties often only attach minimal importance to European issues in their (electoral) programmes and domestic elections do not usually focus on EU affairs. Moreover, even though a more critical attitude has evolved, even in traditionally more pro-European countries such as Germany and the Netherlands (see Chapter 4), political parties tend to agree on the basic premise of the integration process. Debate is therefore limited with political parties playing a secondary role in the European public sphere (Piepenschneider, 2004).

Because of growing scepticism among European citizens, national governments have taken steps to communicate more actively, individually and within the Council, but there are a number of difficulties. An obstacle that tends to be overlooked is Member States' often opposing interests; they are caught in the dilemma that they have to accommodate the wishes and needs of their citizens at home and of their colleagues in the Council (Benz, 2003, p.162; Lord, 1998, p.31). Dealings between the institutions necessitate a common approach, but relations with the 27 national electorates at home require ministers to be able to communicate policymaking outcomes with a view to the implications for the individual Member State. One Council Secretariat source noted that during press conferences what ministers regularly say differs from what they said during the meetings (Interview 14).

Governments have difficulty 'selling' an EU that they at times choose to blame when policies do not turn out as planned or when they have been 'forced' to adopt unpopular policies. As Mitchell Smith (2000, p.170) explains, "the myth of a grasping, bureaucratic, centralising, unaccountable 'Europe' embodied in the European Commission can be extremely useful in domestic politics." By blaming 'Europe', national politicians add to the already ambiguous view people have regarding responsibilities in the Union, and tend to do so without explaining their own role in the legislative process, which actually combines executive and legislative duties (e.g. Kevin, 2003, p.124; C. Meyer, 1999, pp.633-4; Sneijder, 2008, pp.101-2; Stabenow, 2004, p.232; Tumber, 1995, p.511). In fact, they emphasise distinctions between institutions and Member States that may have had little bearing on negotiations and decision-making in Brussels, which is traditionally geared towards consensus.

\footnotetext{
${ }^{47}$ There are some exceptions to this, for example the Danish Parliament. Its European affairs committee, the Europaudvalget, has the power to formulate binding positions for the ministers negotiating in Brussels (Raunio \& Wiberg, 2000). The Lisbon Treaty (Title II, Art. 12, TEU) contains new provisions for the role of national parliaments in policy-making which could potentially increase their engagement in EU affairs and stimulate cross-border debates between them.
} 
The challenges resulting from the 'blame game' were even acknowledged by officials from the Council General Secretariat (Interview 14). Communication experts have accused the Member States of a 'lack of cooperation' in getting the EU's message across (Friends of Europe et al, 2004, pp.21-2).

The fact that EU issues have to be communicated to 27 national public spheres also complicates communication efforts and, consequently, the possible development of transnational debates. By almost exclusively addressing their national publics the governments act as intermediaries, reporting back to their national 'constituents'. Yet, they also uphold the moderate exchange of opinions between national spaces. In addition, as we will see later, some Member States invest more in communicating and informing their citizens than others.

\section{The Commission}

The Commission has always been an important source of information about EU affairs (Baisnée, 2004, p.136; Stabenow, 2004, p.234). It is the only institution to organise a daily press briefing where new policies or actions are introduced, and other affairs and events discussed. This press briefing has been called the beating heart of EU news' (Baisnée, 2007a, p.32). Journalists go there to learn about Commission policies and positions, but also to meet each other and exchange information. A spokesperson from one of the permanent representations in Brussels explained that, additionally, spokespersons and PR officers from other institutions as well as various stakeholders, attend the briefings in order to keep up with what's going on and to contribute their own views and interests (Interview 15). While the Commission may still be able to set the agenda, it is certainly not the sole communicator.

DG Communication is responsible for daily press briefings, the Europa-website and the Representations in the Member States, which disseminate and collect information. Since early 2010 this DG has fallen under the responsibility of Commission Vice-President and Commissioner for Justice, Fundamental Rights and Citizenship, Viviane Reding. The Berlaymont building also houses media facilities such as television studios. In addition, maintaining regular contact between the Commission, national and regional political elites, and policy experts is important, as is the relative prominence of Commissioners in their home countries - as such they form a link with the national arena.

Scholarly analysis of the Commission's communication efforts before the Maastricht wake-up call paints a mixed picture. It ranges from a friendly interaction between civil servants and journalists (Baisnée, 2004), to a reluctant and even hostile attitude on the part of Commission officials (C. Meyer, 1999, p.624). Despite these different conceptions of the Commission's efforts in the pre-Maastricht period, few would disagree that it has stepped up its communication efforts in recent years. 
This has resulted in a number of important papers, including the previously mentioned white paper on communication (European Commission, 2006a). ${ }^{48}$ Meanwhile, the Commission's work in this field has become more professional, partly as a reaction to the arrival of a new breed of more critical journalists in Brussels during the 1990s (see below). The Prodi Commission (1999-2004) rethought the institution's communication strategy and its relationship with the media, with the aim of improving the management of information flows. Generally, the intention was to create a communication culture and to encourage the development of a clear and coordinated message (Anderson \& Price, 2008; Baisnée, 2004, pp.148-150). Attempts have also been made to improve the content of information and the style of communication by employing staff with a communications background and improving the quality of the spokespersons. The first ever concours in this field was organised a couple of years ago. In addiction, several web-based initiatives such as EUTube $^{49}$ have been set up to increase the number of communication channels and bring diversity in terms of content, style and target audience.

In a critical evaluation of the reforms initiated by the Prodi Commission, Peter Anderson \& John Price (2008) argue that despite some improvements in recruitment policy, organisational structure and the coordination of media relations, a number of important weaknesses remain. They include a lack of resources, poorly coordinated communication and an over-emphasis on the Brussels-based press. Some of these issues have been addressed by the first Barroso Commission (20042009) in its Action Plan (European Commission, 2005a), which will be discussed below. Yet the rate of change has been gradual, due in some part to the slow emergence of a communication culture (e.g. C. Meyer, 2009, pp.1059-60).

Despite the Commission's efforts to create a more coherent and clear picture of its position to the outside world, there are a number of factors which complicate these efforts. First, the arrival of more critical journalists in Brussels has made it more difficult for the EU institutions to set the agenda and work on enhancing their image. In particular, the Commission representations have been unsuccessful in some of their main tasks, including distributing information and liaising with the press. This may be explained by limited resources and an inability to explain complex issues in simple words. For example, the former head of the European Commission Representation in the United Kingdom, Jim Dougal (2003), complained that he met difficulties in the UK, 'correcting' the British view on Europe.

Another complication is the institution's 'divided information structure' (Morgan, 1995, pp.329-31) and the frequent differences of opinion between Commissioners, DGs (and units), et cetera (Friends of Europe et al, 2004, p.27; cf. Nugent, 2006, p.166), which is, admittedly, also characteristic of most national governments.

\footnotetext{
${ }^{48}$ A more detailed discussion of these documents will follow in the next section on transparency and communication.

${ }^{49}$ http://www.youtube.com/user/eutube
} 
Andy Smith (2007, p.235) notes that "the College is an arena for political competition within which practices of information and communication are jealously guarded resources for advancing ideological preferences, national or sectoral interests and personal careers." One of the working groups involved with the drafting of the 2001 white paper on governance (European Commission, 2001b) also addressed the 'divided information structure':

\begin{abstract}
Although all DGs have had a head of unit for information since 1993, the quality of performance is variable. Budgets are very different sizes and not apparently allocated according to any common criteria. Web pages for which the DGs are responsible also vary widely in quality. Planning and coordination between the Press and Communication Service and the DGs needs strengthening. Most of it is ad hoc and too little is devoted to developing common programmes over 6 or 12 month periods. (Group 1a, 2001, p.17)
\end{abstract}

This challenge also plays a role in the Commission's current efforts to enhance its communication policy (see below), because other DGs need to be convinced of the need to do so, which is not always easy. Two Commission officials explained that some DGs - such as Budget and Energy - are more open to this than others - such as Competition and Internal Market (Interview 10; Interview 12).

A final problem is that the Commission has to constantly shift between the position of 'responsible political actor' and 'neutral bureaucratic agent' (Foret, 2004, p.163; cf. Kopper et al, 2007, pp.106-9; C. Meyer, 2009). These conflicting stances result in conflicting demands on its communication efforts. On the one hand, the Commission acts as initiator of legislation, trying to draft proposals that are supported by the Council and the Parliament, and a mediator between different interests, which requires it to take an unbiased position. In other words, the institutional setting and the accompanying rules and expectations predispose it to act in a diplomatic manner (cf. A. Smith, 2007). Communication in this case does not refer to conflicts or various opinions and perspectives, but is often concerned with technocratic matters and presenting results, which limits the potential to stimulate broader public discussions (Jopp \& Kleine, 2004, p.255). For example, while spokespersons may try to write press releases in a clear and eloquent way, revisions by the legal staff often have the opposite effect (Balčytienè et al, 2007, p.155; Kopper et al, 2007, p.103).

On the other hand, the Commission sometimes presents itself as more than just a bureaucratic apparatus (Dinan, 1999, pp.234-5). Some of its responsibilities, such as monitoring Member State compliance with EU law, do encourage it to take a more assertive and, at times, outspoken position. Even its role as policy architect endows the Commission with a political dimension, with governments, various interest groups, social movements, and so on, all trying to influence its work. As a result it has to present how and why it has adopted a certain position in order to 
legitimate it. This has also led to more public attention to the Commission's work, which requires it to be even more concerned with its stature (Christiansen, 2008, p.57; Lord, 1998, p.82).

\section{The European Parliament}

The EP is the only directly elected body in the EU and has figured prominently in debates about the democratic deficit (e.g. Benz, 2003; Moravcsik, 2002). Unlike the Council and the Commission, it convenes in public, which applies to plenary sessions and most committee meetings. Moreover, through special events and activities such as prizes and exhibitions, own-initiative reports, and invitations to various political and religious leaders to address the parliament, the EP actively tries to raise its profile (Corbett, Jacobs and Shackleton, 2007). Within Parliament the idea prevails that it is much better situated to stimulate open debates than the other institutions, and that overall its approach to communication is much less hierarchical compared to the Commission's (Shackleton, 2007, p.8).

Compared to the Council and the Commission, the Parliament has received little attention in the public sphere, which is partly explained by its perceived lack of powers and allegedly weak communication policy (Morgan, 1999; Warleigh, 2003, p.87). Nevertheless, the EP has been keen on formulating a proper communication policy. It triggered the first attempts to 'go public' in the late 1980s and early 1990s, following increased worries about declining voting participation in the European elections (Brüggemann, 2005, pp.65, 67). Moreover, Ulrike Liebert (2007, p.262) notes that despite the obstacles the Parliament has to deal with (see below), we should also reflect on its contribution as the only directly elected, supranational parliament, because "the EP fosters publicity and transparency in a range of activity spheres of the Union that otherwise would go completely unnoticed by the public." This is particularly the case in those policy fields where majority voting is the rule and where national parliaments do not have a strong role to play or lack a good oversight. With the Lisbon Treaty the number of policies to which this applies has increased.

Party groups and MEPs naturally play a prominent role in communicating parliamentary activities. They are able to communicate with their respective constituencies in their voters' native tongue. This eases the language problem. Although the press office is the official institutional press service, the MEPs are effectively 'the real spokespersons' (Interview 3; Interview 5). The party groups structure relations between MEPs and national politicians (Corbett, Jacobs \& Shackleton, 2007, pp.326-7). Moreover, they represent the ideological differences in the EP and, as such, convey the various positions within parliament. The 2009 elections were the first in which the parliament's own campaign emphasised these differences and 
positions clearly, instead of just positing that Europe (or the EP) 'is good for you' (Interview 3; Interview 5). ${ }^{50}$

The Parliament's DG Communication is responsible for relations with the press, the distribution of information to the public and management of the Documentation Service (Anderson \& McLeod, 2004; Corbett, Jacobs \& Shackleton, 2007, pp.197-8). It takes care of visitors, deals with requests for information and manages the institution's website, as well as running information offices in the national capitals. DG Communication provides regular background notes, daily news bulletins and other documents to inform journalists about current EP affairs, while maintaining a neutral position.

Like the Council and the Commission, the Parliament supports the work of journalists, for example, by offering audiovisual facilities. The Parliament has also set up an internet television channel called Europar/TV, which operates in all official EU languages. ${ }^{51}$ This channel, which falls under the responsibility of DG Communication, was inspired by the various channels set up by national parliaments and is aimed towards providing live and recorded broadcasts of parliamentary sessions, as well as background information about the EP and ongoing affairs. Programmes may be watched directly, but are also available for use by regional and local broadcasters (Shackleton, 2007). The Parliament has been further experimenting with different ways to use the internet for communication with the European public, such as the 'Citizens' Agora'. ${ }^{52}$

Despite the Parliament's public procedures and efforts to increase its own communication strategy, as well as that of the EU as a whole, so far it has only been moderately successful in presenting its role in European governance. This will also become apparent in the empirical chapters that follow later. Public awareness of what it does is low and many European citizens consider it a weak institution (the knowledge gap); hence, they "do not think that enough is at stake in European elections to warrant going to the polls" (Corbett, Jacobs and Shackleton, 2007, p.340). Generally, EP-elections do not focus on European issues or European policies, but on national issues: above all they are 'national contests' (Nugent, 2006, p.260). The European issues that do play a role usually do so because of domestic political disagreements, not because of disputes in Brussels (Franklin, Van der Eijk, Marsh, 1996, p.368). In addition, voter turnout is low (just above $43 \%$ in 2009) as many voters consider EP-elections to be unimportant. This is a challenge for the EP, because elections are very prominent events for democratic assemblies and generate considerable media attention.

\footnotetext{
${ }^{50}$ See, also: The Secretary General. Note for the Attention of the Members of the Bureau. An Information and Communication Strategy for the 2009 European Elections, D (2007) 33625.

${ }^{51}$ http://www.europarltv.europa.eu/

52 For more information, see: http://forum.agora.europarl.europa.eu/jiveforums/category.jspa?category $I D=9$
} 
Like the Commission, the EP is characterised by internal differences and fragmentation which can complicate communication. MEPs, spokespersons, party groups and national delegations seek to spread their own distinct messages. The EP consists of several political groups (currently seven) and 27 nationalities with different positions on policy issues. Yet, when the press office needs to present parliamentary decisions, coherent information is not always easy to produce (Morgan, 1999, p.13). In addition, the press office has to be careful to ensure that information is balanced, because it should not present the views of just one party group (Interview 3; Interview 5).

In addition, opinions differ as to the extent to which the EP and its secretariat should be actively involved in communication. Given the divergent opinions among MEPs, the development of EuroparlTV provides an interesting example because its features can be quite controversial. As one involved official explained, there has been disagreement over the degree of editorial independence and the need to balance the visibility of the different groups, but also over seemingly trivial details such as the position of the EuroparITV hyperlink on the EP website - whether it appears above or below the links to political groups (Interview 11).

Moreover, not all MEPs seem to be willing and/or able to play a role in communicating the EU (Anderson \& McLeod, 2004). To be able to communicate their message effectively, even the most confident and articulate of MEPs need first to overcome a widespread impression (perceived to be) held by much of the audience that MEPs are in fact second-rate or retired national politicians, mainly preoccupied with filling their own pockets. Now that the Lisbon Treaty has come into force the EP has become more important in prominent policy fields, such as the budget, the CAP and justice and home affairs. This might increase the EP's visibility, since MEPs will speak out on more policy matters, though the absence of a clear government-opposition distinction at the EU level perhaps limits the extent to which political opinions may actually diverge, and downplays the potential for controversy - something that usually manages to attract media interest.

\section{'Bridging the Gap'? Transparency and Communication}

Besides specific institutional attempts to improve communication efforts, there are also a number of other policies that directly or indirectly affect the opportunities for transnational debate in the EU, including media and cultural policies (e.g. Terzis, 2008; Ward, 2004). Over the years, transparency, openness and communication have become particularly important in the growth and evolution of the EU. Linked to ideas of democratic and effective governance, these notions have often been presented as values central to the Union's legitimacy. The subsequent develop- 
ments in transparency and communication policies therefore deserve more detailed exploration.

Transparency: Necessary, but Sufficient?

Transparency covers many different issues, including the simplification of treaties and the closed nature of comitology, though public access to documents has been the main focus of attention (Dyrberg, 2002; cf. Best, 2002). Many European politicians believed that the growing public scepticism about European integration in the wake of 'Maastricht' was the result of a lack of information. Ensuring a more transparent conduct of EU affairs was seen as a way of solving this problem (Dyrberg, 2002, p.82; Lodge, 1994, p.360).

The Maastricht Treaty first referred to transparency in Declaration 17 on public access to information, but real practical steps were only taken at the Birmingham and Edinburgh European Council meetings in 1992. Against the background of the troubled ratification process, the Commission was asked by the EU leaders to work out the transparency provisions of the Maastricht Treaty, which eventually resulted in the 'Code of Conduct concerning Public Access to Council and Commission Documents'. ${ }^{53}$ This document set out the principles regarding access to documents, including cases in which the institutions were allowed to refuse to make documents available. The Amsterdam Treaty introduced the formulation that decisions should be taken 'as openly as possible' (Art. 1 TEU) and included a new provision on the access to documents (Art. 255 EC). Regulation No. 1049/2001, which reflected the new 'Amsterdam' provisions, became effective of 3 December 2001 (and is currently in the process of being reviewed). ${ }^{54}$ It determines the scope of transparency, which in principle applies to all documents drawn up and received by the Commission, Parliament, Council and various EU agencies. ${ }^{55}$ It also stipulates that sensitive private and public interests, including security issues, should be protected, meaning that differential treatment applies. The Lisbon Treaty has restated the importance of transparency and openness, further stressing that the Union shall conduct its work 'as openly and as closely as possible to the citizen' (Title II, Art. 10-3, TEU), asserting that the Council will 'meet in public when it deliberates and votes on a draft legislative act' (Title III, Art. 16-8, TEU) and, in the Charter of Fundamental Rights, declared legally binding following Declaration 1 attached to the Treaty, introducing the right of access to documents for all Union citizens.

\footnotetext{
${ }^{53}$ Code of Conduct concerning Public Access to Council and Commission Documents (93/730/EC), OJ 1993, L340/41-42.

${ }^{54}$ Regulation (EC) No 1049/2001 of the European Parliament and of the Council of 30 May 2001 regarding Public Access to European Parliament, Council and Commission Documents. OJ 2001, L145/43-48.

${ }^{55}$ Other EU bodies were invited to adapt their procedures as well.
} 
Officials in the Council Secretariat contend that the Council has significantly improved its record on transparency (Interview 14). Still, quite a few national governments tend to be reluctant when it comes to improving EU transparency (Lodge, 1994, p.346; Tumber, 1995, p.518). In contrast, the Commission (e.g. Baisnée, 2004, p.136; Nugent, 2006, p.341) and the EP (e.g. Corbett, Jacobs and Shackleton, 2007, pp.331ff; Kevin, 2007, p.199) are regarded as highly accessible. Throughout the years the Council has been slow to adopt new rules of procedure, take steps to improve access to documents, and open up its meetings, owing perhaps to divergent perspectives among the Member States. The Scandinavian countries and the Netherlands have been most in favour of opening up Council activities, but the majority of national governments have generally stressed secrecy and confidentiality, at the expense of transparency and openness (Gargarella, 2000; Peers, 2002, pp.12, 24). ${ }^{56}$ For example, due to such differences of opinion, the decision on Regulation No. 1049/2001 was seriously delayed (Dinan, 2002, pp.39-41).

The controversial nature of transparency is illustrated by the fact that, throughout the years, many cases have been brought before the European Ombudsman and the Courts (see, respectively: Harden, 2002; Naômé, 2002); the institutions have often been obliged to become less restrictive (Peers, 2002, pp.19-23). One of the most infamous cases was the Guardian case, the first instance where EU judges would give an interpretation on the transparency procedures, as set up by the 1993 code. $^{57}$ In February 1994 John Carvel, European affairs reporter for British newspaper The Guardian, filed a request for the disclosure of a number of documents concerning meetings of the Justice Council and the Agriculture Council. Referring to the confidentiality of procedures the Council rejected the request. Carvel and The Guardian, supported by the EP, Denmark and the Netherlands, brought the case before the Court of First Instance, which on 19 October 1995 ruled against the Council's decision. While this was a clear victory for those promoting more transparency, it would still take another eight months for the documents to be released (Naômé, 2002, pp.150-2, 183-4).

In 2005 the Commission launched new proposals under the heading of the 'European Transparency Initiative', which sought to go beyond the transparency of the institutions themselves by focussing mainly on the transparency of interest representation. This initiative resulted in the creation of a voluntary register for interest groups and a related code of conduct (European Commission, 2008c). The

\footnotetext{
${ }^{56}$ The so-called 'Solana Decision' of 27 July 2000 is illustrative in this respect as it limited the access to documents following developments with regard to EU military and security cooperation. The EP and some Member States challenged this decision before the Court. Regulation No. 1049/2001 eventually revoked and replaced the 'Solana Decision'. See: Decision of the Secretary-General of the Council/High Representative for Common Foreign and Security Policy of 27 July 2000 on measures for the protection of classified information applicable to the General Secretariat of the Council. OJ 2000, C239/1-5.

${ }^{57}$ Case T-194/94, John Carvel and Guardian Newspapers Ltd v Council of the European Union
} 
voluntary nature of the register has been criticised. ${ }^{58}$ The Council too has taken new steps in order to increase transparency, by opening up Council meetings to the general public. Following several heated debates the Member States agreed to open up all 'deliberations on legislative acts to be adopted by co-decision', as well as to publish 'the votes and the explanation of votes by Council Members'. But: "The Council or COREPER may decide in individual cases that a given deliberation should not be open to the public" (European Council, 2006, p.23).

In sum, despite improvements the Member States retain the right to limit access to certain documents. Moreover, the fact that many issues are discussed and often even decided at lower levels (in COREPER or in the many working groups) means that even substantial steps towards transparency in the Council do not automatically lead to a more open policy process (Gargarella, 2000, pp.198, 201). ${ }^{59}$ This is even more so in second and third pillar negotiations, where the other EU institutions have little or no involvement (Curtin, 2007). Then again, transparency is not always possible or favourable. It might, for example, result in more negotiations in informal settings, thus producing the opposite effect (cf. Meijer, Grimmelikhuijsen \& Brandsma, 2009). Moreover, some institutions, such as the European Central Bank (ECB), have been set up to function more or less independently of the political process. Their effective conduct could arguably be threatened if they are forced to operate more transparently (e.g. Best, 2002, p.116).

More importantly, although a more open and transparent EU may be generally desirable from the perspective of democratic governance, some have argued that it will not necessarily result in increased awareness. For example, Juliet Lodge (1994, p.364) argues that "attention is drawn to bureaucratic procedures and administrative rather than political and substantive differences among the various Member States." A similar argument is made by Paul Magnette (2003) who argues that what is needed is not only more transparency, but also overviews of the different positions during the policymaking process. Thorsten Hüller (2007) contends that we should distinguish between two kinds of openness: the first is transparency, in other words, the availability of information; the second is publicity, meaning awareness of the availability of this information. ${ }^{60}$ Hüller argues that transparency alone is not enough to increase the democratic legitimacy of a polity and that publicity is essential in most situations. In essence, increasing transparency does not necessarily mean EU citizens are better informed about EU policymaking. Elites and practitioners know where to look for information, yet the ultimate 'stakeholders', the citi-

\footnotetext{
${ }^{58}$ See: http://www.euractiv.com/en/pa/transparency-initiative/article-140650

${ }^{59}$ Fiona Hayes-Renshaw and Helen Wallace $(2006$, p.77) estimate that some $85 \%$ of all issues are agreed upon before the ministers meet in the Council, even though many issues move up and down the hierarchy.

${ }^{60}$ Note that Hüller's use of the word 'publicity' differs from Beierwaltes' use, as introduced in the previous chapter.
} 
zens, do not (Curtin, 2006, p.148). As mentioned before, citizens are more dependent on mass media to gather information. Therefore, transparency is a 'necessary, but in itself insufficient' condition for improving the EU's accountability and legitimacy (Dyrberg, 2002, p.96).

\section{Communicating Europe: 'Listening', 'Going Local' and 'Partnership'}

In the early 1990s transparency was presented as the solution to the problem of increased scepticism among European citizens. Yet, citizens also need to be aware of the information distributed, which itself depends on a clear and focussed communication policy. However, for a long time the Union was characterised by what Christoph Meyer (1999) has dubbed the 'communication deficit'. Lately, communication seems to have become a new catchword in EU governance, with a particular focus on three principles: 'listening', 'going local' and 'partnership'. The Commission emphasises that communication is not a one-way stream, but entails a two-way process requiring one to listen to citizens and engage them in dialogue. The EU should 'go local', by connecting to the issues citizens are concerned about; issues which often have a national or sub-national dimension, even though the corresponding policy might originate at the European level. Accordingly, the institutions, Member States and other stakeholders, such as media and organised interests, should cooperate when communicating EU affairs; since all parties are involved in policymaking, they would together benefit from a more democratic, citizen-centred approach.

Previously, the importance of communication was not completely ignored. During the 1990s various steps were taken to improve information and communication, for example through the establishment of the PRINCE (Priority Information Activities) programme in $1995^{61}$ and the creation of so-called 'Houses of Europe', accommodating the representations of Commission's and Parliament's information offices in the Member States. Some of the terminology used at the time was quite similar to that being used today. For instance, a 1994 paper (European Commission, 1994) noted an 'information deficit', which was considered part of the wider democratic deficit. It called for information and communication to become an intrinsic part of every policy. Proposals to achieve this included efforts to increase cooperation between relevant actors, decentralisation by means of the Commission offices in the Member States, and a reorganisation of then DG X (Information, Communication, Culture and Audiovisual Media).

The 2001 white paper on governance drafted by the Prodi Commission noted that the EU institutions and Member States should communicate more actively

\footnotetext{
${ }^{61}$ The PRINCE programme aims to foster cooperation between institutions, Member States and organised civil society and was considered to be rather successful at the time of the launch of the Euro (Brüggemann, 2005, p.67; Friends of Europe et al, 2004, p.27).
} 
what the EU does and that they should do so using understandable language. This should help to "create a transnational "space" where citizens from different countries can discuss what they perceive as being the important challenges for the Union" (European Commission, 2001, pp.11-12). The governance paper did not specify any details, though, despite the fact that a more thorough analysis had been prepared by one of the working groups involved in the preparatory work (Group 1a, 2001). A 2002 Commission paper provided a number of recommendations such as the need for shared responsibility for and greater coherence of communication efforts. It emphasised the importance of devising a fundamentally new approach based on 'genuine dialogue' (European Commission, 2002, p.10), yet many of the proposals seemed to be aimed at convincing citizens of the EU's success, rather than stimulating any real debate (cf. Brüggemann, 2005, p.68).

Despite these previous efforts, and notwithstanding various initiatives by other institutions, communication seems only to have really gained importance with the appointment of the Barroso Commission in 2004. With respect to the Commission, Andy Smith (2007, p.233) even argues that "[f]rom at least 1958 to 1999, responsibility for communication within the College was a task that no Commissioner wanted." In fact, many of the aforementioned initiatives of the mid-1990s did not receive enough support. What sets out the latest initiatives is the fact that communication has become a policy in its own right and, for the first time ever, a Commissioner for Communication Strategy was appointed in the person of Margot Wallström. Moreover, this renewed emphasis on communication has been endorsed by the EP and Member States.

Wallström and her staff produced a number of papers, notably the Action Plan (2005a), Plan-D (2005e), the White Paper on a European Communication Policy (2006a), Communicating Europe in Partnership (2007a) and Debate Europe (2008b). The core observation in all papers is that there is a gap between the EU and its citizens, which needs to be bridged in order to increase the democratic legitimacy of the Union and its policies. The lack of European debates is considered to be a key issue. It would seem that people are ill-informed and would be receptive to more and better information about Union affairs from national governments and the media. In order to stimulate the development of a European public sphere, EU policies should, so the Commission argues, be made more understandable. This might improve the accountability and legitimacy of the institutions by giving European citizens a certain ownership over EU policies and their outcomes.

The Commission encourages institutions and policy stakeholders not just to provide information, but to actively communicate the EU's conduct to its citizens, and better connect with national, regional and local audiences by appearing sympathetic to their concerns. They are also encouraged to connect with journalists not based in Brussels, for example, with regional media or through Commission Representations in the Member States. Partnership with other actors is presented as an 
important prerequisite for good communication, although individual initiatives should still be possible.

The 2005 Action Plan is mostly concerned with the Commission's own efforts in the field of information and communication. It identifies existing shortcomings, especially the fragmentation of the institution's communication activities (see above), poor staffing in terms of quality and quantity, the inadequate consideration of the needs of European citizens and the poor implementation of previously agreed objectives (cf. Anderson \& Price, 2008). The Commission writes that it should 'put its own house in order', because earlier reforms such as those proposed in the previously mentioned 2002 paper were seen to be inadequate (European Commission, 2005a, p.2). Proposed reforms include providing communication training for Commission staff and integrating communication into the policy process.

Plan-D for Democracy, Dialogue and Debate was a reaction to the 'no'-votes in France and the Netherlands, and the European Council's subsequent call for a 'period of reflection' (European Commission, 2005e). It was presented as part of a more encompassing development towards better EU communication, which included the Action Plan and the forthcoming 2006 white paper on communication. The Commission's aim was to incite a broad debate that would continue beyond the reflection period. The document stresses the importance of ending the "blamegame' (ibid, p.3) and notes that Member States themselves are primarily responsible for organising national debates. The Commission and other institutions can only support or facilitate such endeavours. The White Paper on a European Communication Policy establishes communication as an 'EU policy in its own right' (European Commission, 2006a, p.4) and identifies the media as key players. Communicating Europe in Partnership makes a number of practical propositions, some of which seem to have been inspired by the Parliament's comments - discussed below (European Commission, 2007a). Debate Europe presented further proposals and was accompanied by a website that is, however, no longer active (European Commission 2008b). ${ }^{62}$

Whereas Plan-D is still mostly concerned with suggesting some general recommendations to the Member States (for example, to structure national debates as soon as possible), subsequent documents list more concrete projects and ideas. These include focussing on new media technologies, setting communication priorities, developing so-called 'European Public Spaces' in the Houses of Europe (intended to host debates, exhibitions, and so on), cooperating with regional authorities (for example through their offices in Brussels), establishing management partnerships between the Commission and individual Member States, and drafting an Inter-Institutional Agreement (IIA). Europe should be given a 'human face' (European Commission, 2006a, p.9).

\footnotetext{
${ }^{62}$ http://ec.europa.eu/archives/debateeurope/index_en.htm
} 
The Commission's 2006 white paper on communication was welcomed by the Parliament and the Member States. On previous occasions, the EP had made suggestions for improving the EU's policy in this field, but argued that the Commission had only marginally taken these suggestions into account. ${ }^{63}$ The EP criticised the Commission and the Member States for not translating ideas into practical proposals. It welcomed the European Council's call for a period of reflection, but noted the absence of clear methods or goals, as well as a lack of political will to foster dialogue (European Parliament, 2005). Thus, the EP's position regarding a European communication policy has been rather critical. One EP official called Wallström's ideas 'mere platitudes' (Interview 5).

In general, the EP keeps on pushing for practical steps. The report on the period of reflection mentions a few, such as the organisation of Parliamentary Forums, while at the same time encouraging other actors at all levels to get involved (European Parliament, 2005). The Parliament's opinion on the Commission's communication white paper is reflected in the report drafted by rapporteur Luis HerreroTejedor (European Parliament, 2006). The report welcomes the Commission's initiative, especially its emphasis on the idea of communication as a two-way process. However, the EP seems once more somewhat anxious about the practicalities of carrying it out, stressing that communication should not just be about the final stages of the policymaking process, but should also focus on the evolution of decisions' (ibid, p.7), arguably aware that participation and dialogue is most effective when encouraged from the early stages of the policy process.

The EP has since lamented the fact that many of the suggestions in the 2006 white paper, which were positive in theory, have not accompanied by ideas of how to implement them in practice. It also questions the Commission's emphasis on new media and calls for more attention for the role of inter alia quality newspapers. Furthermore, the Parliament believes that the decrease of funds for exchange programmes such as Erasmus contradicts the new faith in communication, as such programmes actually "accentuate the European dimension and facilitate the establishment of transnational networks" (ibid, p.7). Such programmes have been successful in the past and could be adapted in such a way as to take into account communication. The EP calls on the Commission to draw up an Inter-Institutional Agreement to establish common principles, guidelines and priorities for communication by the institutions, but also notes that their autonomy should be respected. ${ }^{64}$

\footnotetext{
${ }^{63}$ See the EP communication policy fact sheet:

http://www.europarl.europa.eu/parliament/expert/displayFtu.do?language=en\&id=74\&ftuld=FTU_4.17. 7.html

${ }^{64}$ For the EP EuroparITV would fall within its own remits, but the Commission at first expressed its doubts and asked why it was not involved (Shackleton, 2007, p.8).
} 
In sum, the Parliament "doubted that the Commission really knew how to listen, it [the EP; PB] insisted on its own autonomy and it resisted the idea of a structure that could be easily portrayed as a tool of propaganda" (Shackleton, 2007, p.7).

The Member States initiated the 'period of reflection' at the summit of EU leaders on 16 and 17 June 2005, stating that it should be used

to enable a broad debate to take place in each of our countries, involving citizens, civil society, social partners, national parliaments and political parties. This debate, designed to generate interest, which is already under way in many Member States, must be intensified and broadened. The European institutions will also have to make their contribution, with the Commission playing a special role in this regard. ${ }^{65}$

The European Council asserted that various actors should contribute to this debate and the Commission was awarded a distinct role. The latter's Plan-D was a response to this call.

At various occasions since then EU leaders have made references to the importance of improving Europe's information and communication policies. For example, the European Council conclusions of June 2006 contain a separate subsection called 'Europe Listens' in which the contributions to the 'period of reflection' made by the Member States and the EU institutions are welcomed. Moreover, it is noted that the EU remains committed to becoming 'more democratic, transparent and effective' (European Council, 2006, p.2). At the June 2007 European Council meeting the EU leaders placed greater emphasis on the need for an effective information and communication policy, based on the objective of involving European citizens in a 'permanent dialogue', especially in the run up to the IGC and with the ratification process for the Lisbon Treaty in mind (European Council, 2007, p.2).

The contributions made through the (European) Council remained largely rhetorical and practical proposals were almost absent. Some Member States took individual initiatives though - sometimes reflecting the ideas aired by the Commission. Plan-D noted that Member States should try to learn from each other's experiences. An evaluation of Plan-D written for the European Council (European Commission, 2006b) and an information note from Commissioner Wallström for the Commission (European Commission, 2006c) observed what had been done so far. As for national initiatives, the Commission welcomed efforts made by a number of Member States including Germany, Hungary and Ireland, but also mentioned that others should and could do more, thus suggesting that there was some reluctance on the part of a number of governments. Wallström's information note made a case for concentrating on a number of EU priorities.

\footnotetext{
${ }^{65}$ Declaration by the Heads of State or Government of the Member States of the European Union on the Ratification of the Treaty Establishing a Constitution for Europe, SN 117/05, Brussels 18 June 2005.
} 
The Council also conducted its own investigation into trends and tendencies in the information and communication policies of the Member States (Council of the European Union, 2006a; Council of the European Union, 2006b). The results showed that Member States attach most importance to the use of audiovisual media and acknowledge that people's interest in policy/political issues is determined by national agendas. This also means that conveying a key message may be quite difficult. In addition, while Member States are prepared to work together with the institutions, they emphasise the importance of 'voluntary participation' (Council of the European Union, 2006b, p.9), which in itself may imply an inherent reluctance to commit.

Some Member States have indeed gone further than others. At the end of 2007 the Dutch government presented its own European communication policy. ${ }^{66}$ The document seemed to be inspired by the Commission's invitation to translate the EU's approach into a national strategy and explicitly referred to the efforts made by the Commission. It also incorporated the three core principles, 'listening', 'going local' and 'partnership'. The importance of dialogue and debate with citizens was stressed, something that was to be promoted in local settings, such as cafés and sport clubs. The document called upon various interests to participate in the debate. An official at the Dutch Ministry of Foreign Affairs argued that the similarities between the Commission's ideas and those of the Dutch government were not intentional, though they were not completely coincidental either: there is a constant interaction between Brussels and The Hague, but no specific attuning of positions (Interview 8). The Commission's plans were seen as an attempt to set up new structures deemed unnecessary by national government (ibid; Interview 15). Following the Netherlands' rejection of the Constitutional Treaty (see Chapter 5), the Dutch government and parliament stressed the need for better communication and more debate, but without much success (Wolinetz, 2008, pp.188, 196). Hence, it remains to be seen whether a communication policy will make a difference.

The German government was the first to devise a management partnership with the Commission in 2005. One of its outcomes was 'Aktion Europa', a partnership between the Ministry of Foreign Affairs and the offices of the Commission and EP in Germany. ${ }^{67}$ Local and regional governments as well as organised interests were invited to contribute to this programme, which aimed at promoting dialogue with the German citizens. Various projects were set up, including trainings for editors of high school newspapers, an exhibition and simulation games on EU decisionmaking. According to the Commission (2007a, p.14) the management partnership with Germany proved successful; other Member States subsequently signalled an interest in concluding a similar partnership.

\footnotetext{
${ }^{66}$ Tweede Kamer, vergaderjaar 2007-2008, 31 202, nr. 9 herdruk.

${ }^{67}$ http://www.aktion-europa.de/
} 
A final example concerns the Irish 'National Forum on Europe ${ }^{68}$, which both the Commission and the Dutch government presented as a good example of how to organise a public debate on Europe. The Forum was set up after the Irish 'no' vote on the Nice Treaty on 7 June 2001. It was to promote an EU debate among Irish citizens. After the 'yes' vote on 19 October 2002 the Forum was not abolished but remains as the country's main EU discussion platform. Despite positive evaluations by the Dutch government and the Commission, research suggests that the Forum merely broadened the scope of elite involvement whereas the impact on popular participation was modest (O'Brennan, 2004).

\section{Communicating Europe: Some Critical Comments}

All in all, the Commission has in recent years made some important proposals to flesh out a European communication policy, with a gradual transition from lofty ideas to practical propositions. Its observation that communication entails more than just providing information is important. Also, acknowledging that political communication is mostly a national affair, has rightfully resulted in a more focussed approach towards gaining media attention at national and sub-national levels. The attempt to structure the Union's message by, for example, trying to agree on certain joint priorities, might certainly be helpful in this respect. Whether this active stance will be continued under Commissioner Reding is yet to be seen; after Reding took op her post in February 2010, she indicated that communication will remain 'a strategic priority $^{\prime 69}$. Some former Brussels-based journalists have argued that Wallström's influence has been crucial and that she will be missed (Interview 6; Interview 7). Others are more positive and noted that the need to communicate better is now widely acknowledged (Interview 8; Interview 10).

Even so, it remains to be seen whether a joint EU communication strategy will work in practice. Even Commission spokespersons are not always convinced that new ideas will be effective and, like journalists, they point at the challenges posed by the amount and complexity of information, the long policymaking process, cultural differences and the absence of well-known personalities (Balčytienè et al, 2007, p.161; Kevin, 2007, p.201; Leppik et al, 2007, pp.70-3). Such issues were also raised by several respondents during the interviews, journalists as well as officials. $A$ fully-fledged critical analysis of the initiatives of the institutions goes beyond the scope of this study (see, for example: Bijsmans, 2009; Kurpas, Brüggemann and Meyer, 2006), but a few key concerns can be raised.

A first major concern relates to the question who communicates, in particular when it comes to joining forces to communicate Europe. It should not be forgotten

\footnotetext{
${ }^{68}$ http://www.forumoneurope.ie/

${ }^{69}$ Communicating Europe begins at home, says Reding, EurActiv.com, 15 February 2010. Available Online: http://www.euractiv.com/en/priorities/communicating-europe-begins-home-says-reding
} 
that while citizens may have difficulties distinguishing between the institutions, these actually have distinct roles and diverging interests in EU governance, complicating attempts to harmonise communication. ${ }^{70}$ One EP official argued that the Parliament is a 'political body', whereas the Commission is mostly an 'executive body', which means their messages will be different in style and content (Interview 5). Such differences were raised by several interviewees, even by a Commission official (Interview 10). On the level of expectation and intent, this difference is reflected in the institutions' own documents on European communication, which exhibit diverging ideas about who should communicate. The Member States see a special role for the Commission, while the Commission regards the Member States as the main responsible actors; the EP considers itself the most suited to communicate with citizens.

On a practical level, an EP press officer noted that the press services of the EP and the Commission "usually do not cooperate on how to present individual dossiers, but only in cases of broader communication matters" (Interview 3). Officials in the Council Secretariat emphasise the fact that there are no treaty provisions regarding a European communication policy. Hence, only practical day-to-day cooperation is possible, not a fully fledged EU strategy with a budget (Interview 14). A good illustration is the failure of the Inter-Institutional Agreement. The Commission did present a first proposal, which made a case for selecting communication priorities that would be laid down in a common annual work plan. It included two objectives for EU communication: firstly, free access to 'fair and diverse information'; and secondly, the right to let one's voice be heard and to engage actively in public debates (European Commission, 2007b, p.3). The efforts were to be assessed in an annual debate in the EP and by the Inter-Institutional Group on Information ${ }^{71}$ that would play a leading role in European communication. Yet, as one Commission official explained, political and procedural issues immediately posed problems. Some Member States were against the idea of a framework that would be imposed on them, including Germany - somewhat surprising in light of its management partnership. Moreover, initially the Council's desire not to involve the EP caused tension. Meanwhile, the Commission had to navigate between the positions of the other two institutions (Interview 12). In the end, the institutions settled for a less forceful political declaration on 'Communicating Europe in Partnership'. ${ }^{72}$

A second issue concerns what will be communicated. EU communication should not just be about celebrating integration, but should focus on presenting current

\footnotetext{
${ }^{70}$ In the communication white paper the Commission did not seem to take this into account, but Communicating Europe in Partnership appears to be more practical, probably as a reaction to the objections raised by the Parliament (European Commission, 2007a, p.13).

${ }^{71}$ This body was set up in 2002 and brings together representatives from the Commission, the Council and the EP to discuss information and communication matters.

${ }^{72}$ Communicating Europe in Partnership, OJ 2008, C13/3-4.
} 
affairs: issues, positions, et cetera (cf. De Vreese, 2003, p.23). One Finnish journalist who used to work in Brussels said the following:

There is so much, I wouldn't use the word propaganda, but official EU information, and there is clearly a very strong need for, let's say, objective information. (...) To me as a journalist you should always try and show not only the positive sides but with every policy there are also challenges. (Interview 7)

Nevertheless, both Plan-D and the 2006 white paper on communication seem to emphasise the importance of communicating the success of European policies. For example, Plan-D argues that debates should focus on 'the capacity of Europe to generate growth and create more jobs' and on 'previous achievements and the concrete benefits brought to them [the citizens; PB] in their daily lives by the Union' (European Commission, 2005e, p.5). It is perfectly understandable that the Commission, or any policymaking institution, would want to showcase and defend the 'fruits of its labours', that is, the results of more than 50 years of integration. Yet, one might imagine communication being more effective if accompanied by objective information about policy choices that would enable citizens to form their own opinions as to if and how issues could be tackled on the European level. Otherwise communication efforts may trigger a counter reaction with the Union being accused of propaganda. This will most probably lead to a more sceptic public, rejecting the institutions attempts to engage in dialogue. ${ }^{73}$

There is a danger of EU communication being considered propaganda, particularly given the distinctly 'top-down' impression it gives, wanting to 'create' a European public sphere and outlining communication priorities. As explained in the previous chapter, public spheres emerge in the interaction between citizens, media and political actors. They cannot be created unilaterally by the Commission, because the issues also have to be picked up by the media and need to be deemed important by European citizens. As such, communication can only rely on priorities if these are linked to the concerns of those citizens. The debate on the future of Europe, as discussed in Chapter 5, was a prime example of how issues can go relatively unnoticed in public spheres, despite the efforts made by national and European politicians to stimulate debate (see, also: De Beus \& Mak, 2009, pp.53-6).

This also raises the question of who will be on the receiving end of communication. Even if communication is aimed at European citizens, there is still no guarantee that they will actually listen and engage in dialogue. As noted in the previous chapter, people can feel overburdened by information, but they can also be genuinely uninterested and, as such, the EU institutions need to devise different communication strategies. Not all information will be aimed at citizens; many stakeholders are

\footnotetext{
${ }^{73}$ The EP's paper on the period of reflection was also not entirely devoid of overly optimistic language, above all regarding the need to get the Constitution ratified (European Parliament, 2005).
} 
actually seeking more specialised, technical information. Such dialogues may take place outside the wider public realm, inside issue-specific public spheres, which does not necessarily constitute a problem.

Commission documents do not offer clear clues as to how the institution should listen to Europeans. Opinion polls and the internet are regularly mentioned as useful tools to communicate with the public. However, opinion polls do not always offer valuable information, nor do they always set the stage for debates (e.g. Munnichs, 2000). Citizens may not be enticed to visit an EU website to take part in debates. Even when citizens are stimulated to participate in online forums, this does not necessarily lead to discussion, but may simply remain an alternative way to register opinion. This has been illustrated by Elizabeth Monaghan (2008), who studied the influence of interest organisations on the debate on the future of Europe. The website that accompanied these discussions did not lead to much discussion and little seems to have been done with the opinions of the various organisations. One of Monaghan's respondents said the following:

When the Laeken conclusions came out and they said there was going to be a forum for civil society we got quite excited about that and then we got pretty dispirited when we found out it would amount to a website. (ibid, p.25)

\section{The European Media and the Brussels Newsbeat}

Any communication effort on the side of the EU institutions still requires resonance in the media. Their role in European integration has not been a prominent research topic until quite recently. Nevertheless, it is possible to discuss some more general aspects of the way in which the media engage with Europe. This section addresses three issues. First it zooms in on the pan-European mass media and their role in the public sphere. This is followed by an overview of the functioning of the Brussels press corps. Finally, the consequences of news values for the (in)visibility of EU current affairs are discussed.

\section{Pan-European Media and Press Reviews}

There have been numerous attempts by private and public bodies to establish panEuropean media with the aim of opening up and monitoring EU decision-making. Many of these attempts have failed, such as 'Europe's national newspaper' The European and the French magazine L'Européen (e.g. Neveu, 2002). Other newspapers and magazines have been more successful, including The Economist, European Voice and Financial Times. There have also been attempts to set up European televi- 
sion channels. Some have survived, including Eurosport, Arte and Euronews. ${ }^{74}$ Others have failed, such as the attempt to set up a pan-European channel (Europa TV) in the mid-1980s. Finally, the development of the Internet has resulted in the creation of a number of EU-news portals, such as EurActiv.com, EUobserver.com and web-TV channel EUX.tv.

Representatives of the pan-European media keenly stress their importance in making Europe more transparent. EurActiv.com's former editor-in-chief Willy de Backer (2002) once claimed his medium to be a free and neutral platform for debate that tried to deliver information in a 'time-saving, transparent and efficient' format. Former European Voice chief editor Dennis Abbott (2002, p.244) has stated that the weekly newspaper aims "to promote informal debate, openness and progress in the European Union." Indeed, the pan-European media might act as sources for national media, as might press reviews such as euro/topics ${ }^{75}$ and signandsight.com ${ }^{76}$, as well as national and international news agencies and organisations such as Project Syndicate, which tries to foster stronger ties between newspapers from various countries around the world and circulate commentaries from experts. They may not be able to reach a wide audience, but can be intermediaries between different public spheres and act as sources for other (national) media (e.g. Erbe, 2005).

Another example concerns the Financial Times, which Christiane Grefe (2001) calls the only newspaper that is able to forge a European public sphere. Yet, she also notes how it only reaches an elite audience. Even so, it is often named as an important source for other media outlets. The spokesperson of one EU permanent representation noted that while $80 \%$ of his work was aimed at the national media, the rest dealt with important international media, in particular the Financial Times: if something is in there, other (national) media are likely to pick it up too (Interview 15).

Technological progress (for example satellite, cable and digital television) and changes in policy and regulation (an increasingly free European media market) could stimulate the development of pan-European media. Yet, commercial and cultural obstacles remain (McQuail, 2001, p.219). As noted in the previous chapter, political communication is mostly a national affair and there is a perceived disinterest of citizens in European politics. This makes a channel such as Euronews less commercially viable than, for example, Eurosport. As Andrea Esser (2002) explains, European television has become more transnational due to cooperation between national channels, the development of common financing and formats, the establishment of transnational media organisations and even the launch of transnational channels.

\footnotetext{
${ }^{74}$ Euronews considers itself to be the 'European answer to CNN' (Machill, 1998, p.429). It currently receives a yearly subsidy of $€ 5$ million from the Commission.

${ }^{75}$ Provided by the German Federal Agency for Civic Education (Bundeszentrale für politische Bildung): http://www.eurotopics.net/en/presseschau/aktuell.html

${ }^{76}$ http://www.signandsight.com/
} 
Yet, the latter are generally only successful when having adopted a 'local approach' (ibid, p.21).

Some initiatives are hybrids, presenting European media formats based on national production. In 2008 the European Radio Network (Euranet) was launched. ${ }^{77}$ This project is being developed by a consortium of national broadcasters, some of whom are already familiar with operating internationally. Euranet is an independent broadcaster, although it is partly funded by the Commission. It airs programmes with a European perspective on political issues, culture and society. By 2012 all official EU languages should be used in its programming. A similar project concerns PRESSEUROP.EU, launched by the Commission and an international consortium of newspapers in $2009 .{ }^{78}$ It will gradually expand with the aim of covering Europe's main stories in all official EU languages; there are also plans for a television network. Such projects may be more successful in stimulating transnational debates than real pan-European media because, though they present European perspectives, they do so in domestic languages, making it easier for people to tune in.

\section{The Brussels Press Corps}

Baisnée (2002, p.109) calls the Brussels press corps "a specific and limited social group with its own history, practices and customs." These journalists generally work in relative isolation from their colleagues and editors at home. They often meet each other, both in formal and informal settings. Cooperation is important to gain different perspectives on issues and events (Kevin, 2007, p.198; Mancini et al, 2007, pp.118-22). They can also benefit from various organisations that offer knowledge and support, such as Journalists @ Your Service, the European Federation of Journalists (EFJ) and the European Journalism Centre (EJC). Yet, national professional and political cultures still matter. This is, for example, illustrated by the fact that investigative journalism on the European level is still an exception and information is not always shared (C. Meyer, 2003). The arrival of more sceptical journalists, both owing to the accession of some 'more reluctant' Member States and increased scepticism among European citizens, can sometimes further complicate cooperation. The original Brussels-based journalists were not interested in scandals and scoops, but presented a more factual overview of EU affairs. Some newcomers tend to emphasise conflicts and scandals (Baisnée, 2002). Baisnée (ibid, p.116) argues there is no such thing as 'Eurojournalism', but Kevin (2007, pp.202-3) takes a more nuanced position, pointing out that while national angles and cultures are still important, trends such as cooperation between journalists and their presence in the Brussels micro-cosmos also contribute to a common culture.

\footnotetext{
${ }^{77}$ http://www.euranet.eu/

${ }^{78}$ http://www.presseurop.eu/
} 
Journalists in Brussels often consider the European institutions' communication strategies as rather weak (Gleissner \& De Vreese, 2005, p.227). Yet, correspondents also appreciate the institutions' relative openness compared to that of national bodies and governments and to other foreign correspondents' posts (Baisnée, 2002, p.114; Baisnée, 2004, p.137; Morgan, 1995, p.328). For example, as mentioned previously, the Commission has long been a very important source of information for the Brussels press corps, due to its dominant 'information position'. Yet, while the Commission's daily press briefing may still be important, spokespersons and representatives of other institutions and actors also use the occasion to inform the press. National sources (in other words, fellow nationals) have always been very dominant too and they still are (Leppik et al, 2007, p.70; Morgan, 1995, p.328). Other information sources that have become more important include fellow journalists and spokespersons of social movements and business organisations. As a result, competition between the various sources has increased with the result that it has become more difficult for the Commission to set the agenda. For journalists such a variety of sources presents new opportunities to cover EU politics.

This variety of sources does, however, also pose problems. Journalists have to filter a huge outpouring of information on a daily basis, including press releases, position papers, legislation, and so on (Leppik et al, 2007, p.68; Sneijder, 2008, p.100). This is how a Finnish journalist, formerly based in Brussels put it:

The problem for the journalists is the vast amount of information that's poured over you, to find what is most interesting each day. (...) You just sort of make you're own agenda. (...) It's always a compromise. But the defining factor is whether it's interesting to the viewers and listeners and readers in my country. That's what you measure everything with. (Interview 7)

Country/nationality is a 'defining factor'. It constitutes a basic characteristic when it comes to the work of correspondents in Brussels. The national political, cultural and journalistic context to a large extent determines their focus (Gavin, 2001, p.303; Gleissner \& De Vreese, 2005, p.228-9; Leppik et al, 2007, p.66; Morgan, 1995, p.331-3). Moreover, home-based editors are generally not always interested in EU news, nor are they well-informed about what actually goes on in Brussels (Interview 2; Leppik et al, 2007, pp.65, 67; Sneijder, 2008, p.101). They tend to be willing only to print EU articles when coverage is nationalised. The fact that the European polity and its affairs are often considerably different from the national situation, and are consequently often perceived as intransparent and incomprehensible, has to be taken into account in coverage aimed at the domestic public. ${ }^{79}$

\footnotetext{
${ }^{79}$ While it is often contended, certainly by editors 'back home', that most citizens are not interested in European affairs, some take a different view. For example, former Brussels-based BBC Europe Editor Mark Mardell (2005) believes people are interested in what happens in Europe, simply because they
} 
What makes the work of EU reporters even more challenging is that they often have to be experts in many policy fields (Gleissner \& De Vreese, 2005, p.230), ${ }^{80}$ focussing on events and issues ranging from highly politicised issues such as the budget, to very detailed and technocratic issues such as rules on admitting GMOcrops. ${ }^{81}$ In addition, it is common practice for Brussels-based journalists to also be responsible for non-EU topics, mostly Belgian news and NATO (North Atlantic Treaty Organisation) politics (Morgan, 1995, pp.324-5) and, in some cases, even current affairs in Luxembourg and the Netherlands. Such 'complications' interfere with the development of a steady, in-depth coverage of European current affairs.

There used to be more than 1,000 accredited journalists in the European capital, but at the moment there are approximately $900 .{ }^{82}$ While this may signal a decline in the attention to, or importance of, EU affairs, home-based journalists are also increasingly expected to refer to EU affairs, for their domestic policy/issue area may be one in which Union policies play an important role (cf. Kevin, 2003, pp.1267). Dutch EU correspondent Paul Sneijder (2008, pp.104-5) argues that this should become commonplace in order for one to properly reflect the close connection between national and European politics. Yet, according to an Italian journalist in Brussels, a problem in this respect might be that most of these journalists have little knowledge or a meagre awareness of the details and technicalities of EU politics (Interview 2).

\section{The Newsworthiness of EU Current Affairs}

The criteria that make a European story relevant or appealing are said to be similar in the Member States and based on the same elements as those applied to national news (Mancini et al, 2007, p.129; McQuail, 2001, p.224). Important selection criteria are for example 'closeness', 'clarity' and 'negativity' (McQuail, 2000, pp.340-2; Palmer, 1998). One prominent hurdle for EU news has long been its interpretation as foreign news, as international news. This is still illustrated by the fact that it often appears in newspaper sections such as 'foreign news', 'world news' and in a few cases 'Europe' (Kevin, 2003, p.64). Foreign affairs have long been seen as the pre-

\footnotetext{
frequently go to various countries for holidays, bachelor parties, formal occasions, and so on. He also contests the claim that people are not interested in politics, because why then are British and American politics so omnipresent in the news?

${ }^{80}$ In contrast, generally news organisations have tended towards specialisation, meaning that a journalist's core field of reporting depends on his experience in, and knowledge of, a certain topic. The multidimensionality of issues such as European affairs does however pose a problem and more general journalistic experience may therefore become more important (Negrine, 1996, pp.78ff).

${ }^{81}$ See also the interview with FAZ correspondent Michael Stabenow on German EU-portal europa-digital: http://www.europa-digital.de/aktuell/dossier/oeffentlichkeit/stabenow.shtml \& http://www.europadigital.de/aktuell/dossier/oeffentlichkeit/stabenow2.shtml

${ }^{82}$ Brussels press corps shaken by declining numbers, EUobserver.com, 18 March 2010. Available Online: http://euobserver.com/9/29717
} 
rogative of diplomacy, not of publicity (or democracy, for that matter). Although in general the media and politics are to a large extent dependent on each other, in the case of international relations "neither side is quite so sure." (P.M. Taylor, 1997, p.57) Political actors sometimes want to safeguard the secretive conduct of foreign affairs, which means the media are not able to fully expose what happens. But the latter are also hindered by high costs, a lack of expertise and a perceived lack of public interest.

As was noted in Chapter 2, international issues have become subject to political communication and increasingly figure in debates in the public sphere. One can argue that in the EU this issue is more important than in any other field of international relations since Union politics is generally regarded as having an undeniable impact on the daily life of European citizens. Although it may still be presented as foreign news, EU politics has a clear and indisputable impact on national, regional and local affairs - it even makes sense to see it as domestic news (e.g. Interview 15; Sneijder, 2008, pp.105-7). The media have acknowledged the increasing impact of EU politics. As Morgan (1995, p.338) explains, "Union news is no longer foreign news within member countries but has been nationalized and treated accordingly." ${ }^{83}$ Still, a Brussels-based correspondent may write a story he deems worthwhile, but the final decision - as to whether to run with the story, and if so, how lies with the editors at the national headquarters. The different logics mentioned in Chapter 2, as well as the mismatch between the national and the European realities, play a key role in this respect (Kopper et al, 2007, p.106).

EU news has to compete with all sorts of other news items, both national and international and political and non-political (Morgan, 1999, p.6). A problem in this respect is that EU current affairs are typically seen as unspectacular or incomprehensible (Kevin, 2003, pp.122-4; Machill, 1998, p.430). The nitty-gritty work of EU policymaking, often of a specialised (even technocratic) nature, is not very transparent and straightforward; it corresponds little with national politics. Brussels is less politicised than Washington: "Everyone is part of the solution, there is no conflict here" (Interview 4). Journalists have criticised the use of jargon and absence of compelling images and strong personalities (Kopper et al, 2007). There are few wellknown European politicians, which complicates efforts to personalise and put a face to Union affairs. As Michael Stabenow (2004, p.235), a Brussels-based correspondent for Frankfurter Allgemeine Zeitung, writes, "Romano Prodi is nicht Wouter Bos und, noch weniger, Pim Fortuyn." In other words, one cannot compare the personality and media presence of European politicians with those of prominent national politicians.

Despite this, EU institutions have become more important, and the distinction between European politics and national politics is becoming more blurred. Even so,

\footnotetext{
${ }^{83}$ Emphasis added.
} 
it is generally believed that nationalised news coverage remains the main selection criterion (Gleissner \& De Vreese, 2005, p.228; Mancini et al, 2007, pp.131-3) and will probably remain so for the foreseeable future (McQuail, 2001, p.225). ${ }^{84}$ Yet, we may argue that this enhances the 'closeness' and 'clarity' of news otherwise too distant and unclear for most citizens. 'Negativity' is reflected in the media's tendency to adopt a predominantly negative view on EU affairs and by an emphasis on conflicts and crises (Gleissner \& De Vreese, 2005, p.224; Mancini et al, 2007, p.1334; Semetko, De Vreese \& Peter, 2000, p.130). ${ }^{85}$

\section{Conclusion}

Several interviewees stressed the importance of showing how the EU affects daily life. National elements can be useful in this respect because they might more easily be picked up by national media. While this was acknowledged by several interviewees, some also warned of European perspectives being shut out in national reporting, and of opportunities for Member States governments to blame Brussels or take the credit for policy successes. Interviewees also noticed the problem that the regular policy process often goes unnoticed, with both politicians and citizens feigning surprise when new EU legislation needs to be implemented. The position of the Member States, seen to be one of a general unwillingness to assume their responsibilities and explain their own role, was again raised in this context. The complex nature of some policies also makes it difficult to reach out to citizens. One way to solve this would be to allow for more drama, conflict and personalisation - in other words, a politicisation of EU affairs. Finally, several respondents noted the overkill of information, which requires journalists to select astutely, and political actors to communicate better.

What is clear is that the three obstacles identified by Gerhards (2000) do indeed pose a problem for the emergence of transnational debates. For one, the main EU actors do not always appear to be willing and able to stimulate communication and present information in such a way as to enable public debate. Divisions and differences of opinion play a role within the EU institutions, as well as between them. Political questions affect communication efforts especially since there are also other institutional policies and obligations involved. While this is actually a prerequisite for public debate, it also suggests that a common EU communication policy is hard to imagine. Still, in recent years the institutions have reformed their communication

\footnotetext{
${ }^{84}$ However, based on an analysis of claims made in German newspapers, Ruud Koopmans and Barbara Pfetsch (2006) argue that when compared to other actors, the media themselves are most open to European affairs and perspectives, as well as to perspectives from other Member States.

${ }^{85}$ Note that a negative tone is not limited to EU news, but is quite common in the coverage of national politics as well (De Vreese, 2003, p.19).
} 
machinery and new initiatives have been presented to improve information and communication policies. Whether these reforms and initiatives will allow the Commission, Parliament and Council to play a more prominent role in public debates has still to be seen, especially since the plans presented by the Commission contain a number of problematic assumptions and propositions.

Meanwhile, the apparent lack of newsworthiness of EU affairs poses another obstacle to the advent of European-wide debates. Certain pan-European media do consider events in Brussels to be important, but these are just 'village publications' (Interview 3 ) scarcely able to reach out to the majority of citizens. For most national media the supposedly technical nature of EU politics and the absence of controversy at the European level recurrently make it an unrewarding topic. The EU's distinctive institutional set-up and procedures seems to have evident effects on its possible appearance in the public arena and should therefore be taken into account when exploring the European public sphere. The two case studies that follow in Chapters 5 and 6 reveal that the responsibilities and procedures related to European policymaking, as reflected in national public spheres, remain ambiguous. This issue will also be taken up again in the Conclusion.

When 'Europe hits home' (Börzel \& Risse, 2000), things change, however. Put differently, when European policies become controversial at the national level, journalists and editors become more interested (see, also: Sifft et al, 2007, p.141). Yet, as pointed out in the previous chapters, this often only happens after decisions have been made, and hence, democratic influence and control through a public debate hampered. In addition, the way in which EU affairs are debated in national public spheres may not be in line with actual developments in Brussels, as will become clear in the two empirical chapters. In any case, national circumstances certainly have a strong impact on transnational public debate, as discussed in the next chapter. 


\section{National Public Spheres and the EU: Germany and The Netherlands}

The potential of a transnational European public sphere is partly determined by relations and events in the Brussels micro-cosmos, as established in the previous chapter. Even so, as we have seen in Chapters 1 and 2, national public spheres remain the principal components of a European public sphere. In fact, it is within these national settings that the most intense and inclusive political debates take place (Gaffney, 1999). To be able to shed more light on the different national traditions of debating converge, we should not only focus on a country's position with regard to Europe, but examine the media coverage of politics in general as well as the characteristics of national politics. This is important because, even when debates on European issues do cross national boundaries, they still take place in national settings (notably, the national media).

This chapter will therefore provide an overview of the national public spheres of Germany and the Netherlands. The issues that will be discussed here will return both implicitly and explicitly in the two case studies. Despite some clear differences between these countries as regards history and size, they share many important characteristics in terms of media and politics and their position towards the development of the EU. Notwithstanding these similarities, two differences bear a particular significance, namely the important role of the Länder in German politics, versus the relative unimportance of the Dutch provinces, and the importance of the German Grundgesetz (Basic Law; GG), judicial review and the Bundesverfassungsgericht (Federal Constitutional Court), versus the prohibition of judicial review in the Netherlands and the modest status of the Dutch Constitution (Grondwet voor het Koninkrijk der Nederlanden, GW). Each which will be discussed separately. 


\section{Europe between Resemblances and Differences}

In his introduction to a well-known comparative volume about European politics, Josep M. Colomer $(2008$, p.7) writes that studying politics in Europe is a worthwhile and rewarding endeavour due the presence of a sizeable set of countries which have undergone largely similar cultural and socio-economical experiences. This allows for rigorous analysis of political institutions. Tim Bale (2005), in his book on European politics, outlines some of these more general developments that European countries have experienced in the recent past and are currently going through. These range from the shift from government to governance in academic terminology, to Europe's ageing population. In political terms increasing voter volatility is an important development, whereas in media terms, the presumed change in focus from content to personalities is often highlighted. Some of these tendencies have been mentioned in the previous chapters: including the impact of globalisation and European integration on the nature of the political process and the way in which the media function; the increase of national and international information and communication channels and efforts; the rise in the number of political actors and the intensification of competition between them; the increased interdependence between journalists and political actors; and the diversification and fragmentation of audiences, which have by and large become more critical about the political process even though they still support democracy.

Despite these and other more general trends, Bale recurrently notes that differences remain between European countries, for example, due to cultural particularities and national traditions. As he writes:

\footnotetext{
Europe may be coming together literally as well as figuratively in the guise and under the umbrella of the EU. As a result, it is already more than simply the sum of its parts. But, at the beginning of the twenty-first century, the contrasts and contradictions between those parts - contrasts and contradictions that emerged over hundreds and thousands of years of often overlapping development - are not disappearing quite as fast as we might think. (Bale, 2005, p.2)
}

When viewing Europe from the perspective of the present study, national issues and concerns, as well as domestic media, are still significant for the communication of politics. The persistence of national cultures and their own peculiarities may explain particular appearances of the public sphere (e.g. Curran, 1998, pp.90-1; McQuail, 2001; Negrine, 1996, p.168; cf. Newsom, 2007). There has certainly been no standardisation of political communication. As Barbara Pfetsch (2004, p.345) and Daniel C. Hallin and Paolo Mancini (2004, pp.8, 62) explain, structural and cultural circumstances determine the interaction between media and political actors in the public sphere. Such national particularities are visible in all areas, for example in the political arena, in the media and in society. Still, some countries have more in com- 
mon than others. As explained briefly in the introduction, Germany and the Netherlands display a number of similar features in terms of politics, media and the public sphere, as well as with regard to their stance towards Europe.

\section{Politics and Democracy in Germany and the Netherlands}

When analysing their political features, Germany and the Netherlands have both been described in terms of Arend Lijphart's consensus model of democracy (e.g. Keman, 2008; Schmidt, 2008). Consensus systems are usually characterised by multi-party systems and proportionality. Power is shared between different groups and institutions (Lijphart, 1999). The German state is characterised by vertical decentralisation between federal, regional and local levels, and by horizontal decentralisation between the various federal institutions. The need to negotiate and cooperate is important due to the importance of coalitions, the relations between Bund and Länder, the participation of organised interests in policymaking and the influence of various autonomous institutions such as the Bundesverfassungsgericht (Korte, 2001, pp.523-6). The Dutch political process is shaped by broad agreements, consensus, behind-the-scene negotiations and coalitions, which are meant to accommodate the wishes of political minorities (Andeweg \& Irwin, 2002, pp.17-20). The period of pillarisation (verzuiling), lasting from approximately 1917 until halfway through the 1960s, represents the apex of Dutch consensus politics. ${ }^{86}$ Yet, even during the 1960s and 1970s, during the period of de-pillarisation and polarisation, and later phases of more manifest political competition, a consensual approach has been at the centre of Dutch politics. Cabinet-formation as well as day-to-day politics still requires coalitions.

Germany and the Netherlands are characterised by a multiparty system based on proportionate representation. The Dutch electoral system is based on party lists in a nation-wide district (Andeweg \& Irwin, 2002, pp.73-77). German citizens have two votes: one for a party list and one for a district candidate (Schmidt, 2008, p.63). In Germany smaller parties face a significant electoral threshold of five percent (which has been in effect since 1953), in contrast to the Netherlands where parliament normally includes many smaller parties. Post-war German politics has been dominated by the Christian Democratic CDU (and its Bavarian sister party, the CSU) and the Social Democratic SPD, Germany's oldest political party. Smaller parties have been less influential, although the liberal FDP especially has often been instrumental for the formation of coalitions. Bündnis 90/Die Grünen (the Greens) emerged from several social movements in the late 1970s and 1980s, first entering parliament in 1983. Die Linke (the Left Party), a merger of the former Communist party PDS and the protest party WASG, has gained considerable popularity as a

\footnotetext{
${ }^{86}$ During this period Dutch society was divided in four societal pillars (Catholics, Protestants, Socialists and Liberals) which had an impact on most aspects of society (e.g. Andeweg \& Irwin, 2002, pp.21-6).
} 
protest party, especially in the Eastern part of the country (Olsen, 2007; Green et al, 2008, p.80). Extremist parties have scarcely benefitted from protest votes, despite the sporadic success of extreme right parties in some communities and Länder (Glaab \& Kießling, 2001, pp.576-7). ${ }^{87}$ The limited influence of smaller parties is partly to be explained by the success of the bigger parties and minor differences between them (Ismayr, 2003, p.465; Saalfeld, 2003, pp.33-4, 37). ${ }^{88}$

The CDA (Christian Democrats), PvdA (Social Democrats) and VVD (Liberals) have been the leading Dutch political parties since the end of World War II, although their dominance has declined since the 1960s. In addition a number of smaller parties have come to play a lasting role in Dutch politics: D66 (Social Liberals), GroenLinks (Greens), SP (Socialist) and the two smaller religious groups CU and SGP. In recent years new parties have entered the political scene, typically characterised by more radical views and populist tactics (Keman, 2008, p.215). Some newcomers, such as Pim Fortuyn's populist-conservative party the LPF, only managed to last a short time. ${ }^{89}$ Geert Wilders' PVV currently enjoys particular success. According to André Krouwel and Paul Lucardie (2008), the PVV's success can partly be explained by the fact that so far there has not been a real conservative and nationalist party in the Netherlands, while there seems to be room for such a party. An extremely low electoral threshold of about $0.6 \%$ and a system of proportional representation explain why so many parties are represented in parliament (Andeweg \& Irwin, 2002, p.62). Moreover, party splits and mergers have been numerous due to internal differences.

Both countries tend to be ruled by coalition governments based on collegial cabinets responsible to and dependent on parliament (Saalfeld, 2003; Timmermans \& Andeweg, 2003). German governments have always been coalition governments, with the exception of four brief phases of single-party government which were the result of temporary circumstances, not strategic choices. Historically single-party governments have been considered volatile and inefficient. Post-election coalition agreements $^{90}$ form the basis of coalitions and, together with the Chancellor's inaugural government speech, serve as a reference point for the government's working programme (Saalfeld, 2003). While informal arrangements often define day-to-day relations between government and coalition parties, opposition parties in the Bundestag have to resort to formal opportunities for controlling government and

\footnotetext{
${ }^{87}$ Frank Decker and Florian Hartleb (2007) suggest that left-wing populist parties generally stand a better chance of challenging the establishment than right-wing parties, as the latter are commonly placed within the context of Germany's troubled past, whereas the former's past is less stigmatised, even that of the PDS.

${ }^{88}$ Both CDU/CSU and SPD have always presented themselves as Volkspartei (e.g. Green et al, 2008, p.77).

${ }^{89}$ André Krouwel and Paul Lucardie (2008) explain that this does not necessarily imply that their impact is modest, as they may have a more lasting impact on the programmes of established political parties and on political discourse in general.

${ }^{90}$ Pre-election coalition pacts are not unusual.
} 
maintain some degree of influence (Ismayr, 2003, pp.453, 461). Yet, since the majority in the Bundesrat is often different from that in the federal government cooperation and compromise between government and opposition is often crucial. Germany has therefore been dubbed the 'grand coalition state' (Schmidt, 2003; 2008).

Dutch politicians have also been reluctant to consider the option of minority governments (Timmermans \& Andeweg 2003, p.363). Coalitions are usually based on coalition agreements, which set out the major policy guidelines. Although not legally binding, coalition agreements do foster strong links between the government and the coalition parties in parliament. Most legislation originates from the cabinet and is accepted by parliament - the latter is mainly pre-occupied with controlling the government and adjusting initiatives (Keman, 2008, pp.229, 231). This seems to make it more difficult for opposition parties to influence policymaking, but they do actually have a say, for example in the drafting of legislation in parliamentary committees. Consequently, opposition parties regularly vote in favour of government legislation (Andeweg \& Irwin, 2002, p.136).

Constitutional changes require at least a two-thirds majority in the parliaments of both countries (and even two readings intervened by elections in the Netherlands). Nonetheless, the German Bundesrat has a much more important role in policymaking than the Dutch Eerste Kamer. Colomer $(2008$, p.11) lists the Netherlands as 'weak bicameral' and Andeweg and Irwin (2002, pp.123-4) argue that the Dutch Eerste Kamer is 'secondary in importance', mainly because it is unelected and largely focuses on the quality of legislation. It cannot amend legislation, just approve or reject it, though threatening with a veto sometimes helps to convince the Tweede Kamer to amend a piece of law (Lepszy, 2003, p.360). The role of the Bundesrat will be discussed in more detail in the section on the Länder.

The role of the German President is largely ceremonial, as is that of the Dutch queen or king (even though (s)he is a member of government). The Chancellor can play an important role in decision-making because of her/his authority to determine the general guidelines of both internal and external policies - the so-called Richtlinienkompetenz (Art.65 GG). However, this competence has rarely been used. Ministerial autonomy, entrenched in the same article in the Basic Law, also acts as a restraint. Being a primus inter pares in a collegiate cabinet, the Dutch Prime Minister has less power to determine policies, though informally the Prime Minister's influence has increased due to the need for more coordination and for carrying out her/his external role (for example, as a member of the European Council). Ministers in both countries have considerable freedom to act and are largely responsible for their own policies, even though cabinet decisions are taken on a collegial basis. This can act as a restraint on policymaking, for example, when determining positions regarding EU policy.

Corporatist arrangements also advance Dutch and German consensus politics. Organised interests play an important role in German politics (Schmidt, 2008, p.78). 
There is regular contact with office holders at all levels of the German polity and during all phases of the policymaking process. In some cases it is even obligatory to formally invite organised interests to the table (Ismayr, 2003, 471), whereas in certain fields (such as health policy) these interests may even be responsible for certain aspects of implementation (Green et al, 2008, p.65). Organised interests play a key role in many fields and at many levels of Dutch politics too (Andeweg \& Irwin, 2002, pp.139-48; Keman, 2008, pp.234-5). Their involvement is both informal and formal (for example through the Social Economic Council, SER). The so-called polder model has become famous inside and outside the Netherlands, even though it has not always been perceived as a blessing due to the, at times, slow policy process and apparent inability to pursue real reforms (e.g. Hendriks, 2001).

Like citizens in most Western countries (e.g. Dalton, 1999), the engagement of Dutch and German citizens in politics often depends on the issue at hand, the context and so on. They are selectively engaged in politics, often adopting a re-active instead of pro-active stance (Glaab \& Kießling, 2001; Verhoeven, 2004). Voter turnout in national elections has long been around $80 \%$ in Germany, but dropped to $70.8 \%$ in $2009 .{ }^{91}$ In the Netherlands there was a steady decrease in turnout between 1986-1998, but the elections in 2002, 2003 and 2006 showed an increase again (around $80 \%$ ), followed by a decrease to $75.4 \%$ in $2010 . .^{92}$ In both countries the number of floating voters has increased as ideology, class and religion have become less important and party membership decreased. Traditional parties and interest organisations such as unions have lost support, while support for nontraditional participation and new social movements has increased.

A continued association with the former Socialist regime, dissatisfaction with their economic situation, discontent about government performance and occasional claims that a new constitution should have been drawn up, have led Eastern Germans to be, on the whole, less positive about democratic government in Germany (Gabriel, 2007; cf. Glaab \& Kießling, 2001; Green et al, 2008, pp.47-54). Dutch citizens widely support democracy and their interest in politics has increased (Verhoeven, 2004; cf. Aarts \& Thomassen, 2000). Nonetheless, political 'satisfaction' has decreased in both countries. It has been suggested that more direct democratic instruments such as referendums might help to increase citizens' ownership of the political process. Such instruments have actually been introduced at lower administrative level, but not on the national level. Opponents in Germany often refer to ways in which the Nazi and GDR regimes used referendums to legitimise their rule (Glaab \& Kießling, 2001, pp.582-85; Schmidt, 2003, pp.176-7). Many Dutch politicians, despite being worried about the consequences of the citizen-politics gap, have so far been rather hesitant to introduce reforms and have emphasised the

\footnotetext{
${ }^{91}$ Information available on the website of the Federal Returning Officer (Der Bundeswahlleiter): http://www.bundeswahlleiter.de

${ }^{92}$ Information available on the website of the Electoral Council (Kiesraad): http://www.kiesraad.nl
} 
importance of representative democracy (Andeweg and Irwin, 2002, p.216; p.46; Keman, 2008, p.241)..$^{93}$

\section{Media and Political Communication in Germany and the Netherlands}

The role of the media and political communication in Germany and the Netherlands can be explored in terms of the three media system models developed by Hallin and Mancini (2004). These models are not only based on certain media characteristics, but also on an analysis of political elements that principally apply to Western Europe and North America. ${ }^{94}$ The 'Polarised Pluralist Model' is applicable to the countries in southern Europe, including France (cf. Papathanassopoulos, 2007). It is characterised by rather strong ideological diversity, the instrumentalisation of the media by political actors, and less autonomy and professionalisation among journalists (which tends to result in advocacy journalism). Print media circulation in these countries is generally low, whereas broadcast media play a dominant role.

The countries grouped under the 'Liberal Model' (such as the United Kingdom) are characterised by moderate pluralism and a predominantly majoritarian political system. Press freedom developed early and mass circulation of the press used to be high, though today it is usually lower than in 'Democratic Corporatist' countries. The professionalisation of journalists also developed early; political parallelism - the intensity of links between media and politics - is low and journalists tend to be quite autonomous (cf. Hallin \& Mancini, 2007).

Germany and the Netherlands have been grouped under the 'Democratic Corporatist Model' (cf. Weibull, 2007). Countries in this model combine a tradition of political parallelism with the mass circulation of press and journalistic professionalism. For example, the first Dutch and German unions for journalists were formed in 1894 and 1895, respectively. Political parallelism has largely vanished in Democratic Corporatist countries, but certain political orientations can still be observed, though they "are manifested more in patterns of selection and emphasis in news reporting than in explicit commentary" (Hallin \& Mancini, 2004, p.183). Back when Dutch society was 'pillarised' many newspapers and almost all broadcasting media acted as a forum for one of the pillars, but the end of pillarisation saw the end of the pillarised media system. ${ }^{95}$ Nowadays, Dutch newspapers do not usually adopt an outright position towards political parties, though they emphasise different issues and

\footnotetext{
${ }^{93}$ In the Netherlands a temporary law on consultative, corrective referendums was introduced in 2000. Only a couple of weeks after this temporary law expired (1 January 2005), the First Chamber, on 25 January 2005, approved a temporary law for a referendum on the TECE. Despite mounting pressure, Germany did not organise a referendum on this new treaty (see Chapter 5).

${ }^{94}$ While acknowledging the limitations resulting from this geographical bias, Hallin and Mancini (2004, pp.305-6) do provide some tentative suggestions about the usefulness of the three models for other regions. For a discussion concerning the post-Communist European countries, see: Jakubowicz, 2007.

${ }^{95}$ De Telegraaf was one of the few newspapers that were not attached to a pillar.
} 
sometimes tend to be slightly more positive towards those parties closer to their own affiliation (Van der Eijk, 2000, pp.319-320, 329). Today's German newspapers have never been clearly linked to any political party, because after World War II the Allies wanted to avoid the development of a party press (Kaase, 2000, p.376). They do, however, reflect certain ideologies and as such represent different voices (cf. Eilders, 2000; 2002).

Most German newspapers are either locally or regionally distributed, the main exceptions being the quality newspapers Frankfurter Allgemeine Zeitung, Frankfurter Rundschau, Süddeutsche Zeitung, Tageszeitung and Die Welt, as well as the tabloid Bild-Zeitung, Germany's biggest newspaper (Kleinsteuber \& Thomass, 2007, p.112). In 2009 there were ten nationally distributed (überregionale) newspapers and some 333 local and regional newspapers. ${ }^{96}$ In the Netherlands there are eight national newspapers (Algemeen Dagblad, De Telegraaf, de Volkskrant, Nederlands Dagblad, NRC Handelsblad, nrc.next, Reformatorisch Dagblad and Trouw) and more than 30 regional titles. In some provinces (the Province of Limburg, for example) the market is dominated by regional newspapers. In other Dutch regions, notably the urbanised area in the west (commonly referred to as the Randstad), the national dailies attract most readers (Bakker \& Vasterman, 2007, p. 146). There are tabloids and Sunday newspapers in Germany, but not in the Netherlands. More specialised newspapers make up part of the newspaper market in both countries, such as business newspapers Het Financieele Dagblad (Netherlands) and Handelsblatt and Financial Times Deutschland (both in Germany).

Subscriptions play an important role in both newspaper markets. Newspapers are still widely read and, as was already explained in Chapter 1, play an important role in political and public debates in Germany and the Netherlands. Even so, circulation has generally declined. In a bid to regain and increase market shares, newspaper publishers have introduced many new initiatives, including monthly and weekly magazines, special discounts for subscribers, new formats, layouts and elaborate websites (e.g. Bakker \& Vasterman, 2007, p. 146; Pross, 2000, pp.261-2, 289-93). Accordingly, in 2007 the Frankfurter Rundschau adopted the tabloid format. The Netherlands even saw the introduction of a new newspaper in 2006, the relatively successful NRC Handelsblad spin-off nrc.next.

Democratic Corporatist countries are also characterised by a custom of limited state power, but with occasional instances of active state intervention in the media market - for instance, an early development of press freedom on the one hand (in 1874 in Germany, in 1815 in the Netherlands), a specific organisation of public broadcasting which incorporates the various social and political groups on the other. With regard to the latter, the Dutch and German systems are quite similar,

\footnotetext{
96 The Federation of German Newspaper Publishers (Bundesverband Deutscher Zeitungsverleger), http://www.bdzv.de/schaubilder+M56127951a3c.html (Retrieved 28 June 2010).
} 
despite different ways of organising public broadcasting (Hallin \& Mancini, 2004, pp.166-8).

The post-war public broadcasting system in Germany was modelled after the British Broadcasting Corporation (BBC), but with authority almost completely in the hands of the Länder. This has resulted in a variety of different media laws (Kleinsteuber \& Thomass, 2007, pp.114-6), even though the freedom of the media and freedom of expression are enshrined in the Basic Law (Art. 5 GG). ${ }^{97}$ The broadcasters have a legal duty to present a balanced coverage of society and politics. The regional associations have been cooperating in the first network, ARD (Arbeitsgemeinschaft der öffentlich-rechtlichen Rundfunkanstalten der Bundesrepublik Deutschland), since 1950 and in the ZDF (Zweites Deutsches Fernsehen), the second network, since 1961. Since 1981 commercial broadcasters have been welcomed, but they too need to work within the regulations set by the Länder. In the Netherlands the public broadcasting system used to be based on pillarised organisations, but it became more open with the end of pillarisation. The introduction of commercial television at the end of the 1980s was the most decisive point in this development (Van der Eijk, 2000, pp.304-13). Many of the original public broadcasting organisations still exist and new ones have been set up. What distinguishes the Dutch system from other European public broadcasting systems is that the organisations are independent, meaning that the government is not allowed to intervene in programming (Bakker \& Vasterman, 2007, p.148).

Max Kaase $(2000$, pp.384-7, 395) notes that research has suggested that the German mass media have played an important role in the evolution of German democracy and coming to terms with its past after World War II. For example, many high-profile debates about Germany's past, such as the Historikerstreit ${ }^{98}$ and the debate about Daniel Goldhagen's controversial book Hitler's Willing Executioners $(1996)^{99}$, to a large extent took place in the media, and newspapers in particular (Pross, 2000, pp.255-7). The media have also played a part in strengthening trust in the country's democratic processes and institutions, fostering interest in politics and making politics more accessible to the average citizen. Interestingly, whereas the Dutch media system - in particular the broadcasting organisations - was one of the most pillarised sectors in society, the media themselves - especially television played a key role in ending pillarisation by introducing audiences to other issues, ideas, and so on (Van der Eijk, 2000). While the media in both countries tend towards accentuating different political points of view, the legal requirement to pre-

\footnotetext{
${ }^{97}$ Art. $7 \mathrm{GW}$.

${ }^{98}$ The 'Historian's Dispute' principally concerned the question how to interpret the Holocaust. Prominent historians and philosophers such as Jürgen Habermas were involved in this debate, which took place from 1986 to 1989 (see, for example: Green et al, 2008, pp.15-6).

${ }^{99}$ Goldhagen argued that ordinary Germans were aware of, and actively took part in, the holocaust, which was in line with the country's political culture.
} 
sent balanced coverage, as well as a more general feeling of responsibility for democratic politics since World War II, mean that the German media are less likely to pay disproportionate attention to just one party or political leader (Hallin \& Mancini, 2004, p.163; Ismayr, 2003, pp. 473-4; Kleinnijenhuis \& Oegema, 1995, p.189).

The Dutch and Germans make extensive use of the abundance of media channels and formats; they listen to the radio, watch television and read newspapers and internet penetration has rapidly increased (Bakker \& Vasterman, 2007, pp.14650; Kaase, 2000, p.381; Kleinsteuber \& Thomass, 2007, pp.112-8). ${ }^{100}$ Yet, despite the apparent diversity in titles and viewpoints, media concentration has regularly been named as a major threat to the media's role in democracy. Considering the presence of a number of big media firms in Germany, including the Axel Springer Group (print media) and ProSiebenSat.1Media AG (broadcast media), this is not entirely surprising. Until recently, four of the seven Dutch national dailies (Algemeen Dagblad, de Volkskrant, NRC Handelsblad and Trouw) were part of one publishing company, PCM.

A strong form of segmentation of society is an important characteristic of Democratic Corporatist countries. Consensus politics has therefore always played an important role, with the segmented media stressing differences between groups, while simultaneously providing a platform for the political bargaining process (Hallin \& Mancini, 2004, p.188). This is also apparent in Germany and the Netherlands, where political communication is generally shaped by the characteristics of politics, such as the need to form coalitions and the important role of political parties, but also by the existence of public broadcast media. Dutch political parties have to pursue what Hans Keman (2008, p.219; cf. Van der Eijk, 2000, p.330) has called a 'dual strategy'. On the one hand, it is important to explain why one party differs from the other; on the other hand, political parties must be prepared to form coalitions. Both government formation and day-to-day policymaking require parties to cooperate in order to establish a parliamentary majority - too critical a message about other parties might hinder these processes (cf. Andeweg \& Irwin, 2002, p.87). The same applies to German political parties, which have to generate political support and legitimacy within society and within the party, while informing other parties about their political positions (Pfetsch, 2001). Accordingly, negative campaigning occurs little during Dutch and German election (Holtz-Bacha, 2002, p.50; Van Praag \& Brants, 2000, p.254). The resulting communication strategies apply not only during election campaigns, but also in day-to-day political communication.

As in most democratic societies, regular news coverage is very important as it generates relatively inexpensive publicity, which tends to be seen as mostly un-

\footnotetext{
${ }^{100}$ Winand Gellner and Gerd Strohmeier (2002) assert that even in terms of media exposure we should be aware of the existence of a 'double German public', which may partly explain different political attitudes in the eastern part of Germany.
} 
prejudiced, in particular when compared to, for example, party manifestos. Dutch and German political actors (parties, but also organised interests) have professionalised their communication machinery in an attempt to adjust to the demands of the modern mediatised society and to the looser ties between citizens, parties and other organisations. Some have offered a critical evaluation of such shifts (e.g. Falter, 2002; Munnichs, 2000); others opt for a more nuanced account (e.g. Brants, 2002a; Meyer, 2001). Although parties have to compete with each other over media attention, and despite the competition between the various media, German election campaigns on the whole remain oriented towards issues and the parties' problem-solving capacities, not towards persons (Ismayr, 2003, p.463; Kaase, 2000, pp.394-5; Schoenbach, 1996). In the Netherlands interpretation of the news and entertainment values have come to play an important role, but factual information is still important. The public seems to value content and facts above conflicts or personalities (e.g. Brants, 2002a, pp.94-6; Brants, 2002b).

\section{Germany, the Netherlands and European Integration}

Both the Grundgesetz (Art. 24 GG) and the Dutch Constitution (Art. 92 GW) explicitly allow for the transfer of powers to international organisations; the German Basic Law even includes a specific article devoted to the EU (Art. 23 GG). Fostering a coherent European policy is difficult for both countries due to ministerial autonomy (e.g. Hoetjes, 2003; Maurer, 2003), but this problem is much more serious in Germany following the important role of the Länder in the policy process and may even result in Germany abstaining from voting in the Council if there is no agreement on a common position on time. The Länder's views on the EU will be discussed in more detail later. In terms of their approach to European integration Germany and the Netherlands have long been able to build on broad political and public support, but both political parties and citizens have, as discussed earlier, become more critical.

The process of European integration has played a central role in answering the 'German Question' - concerning Germany's place in Europe (e.g. Green et al, 2008, pp.6-7; Pritchard, 1996). It allowed Germany to recover from both World Wars, to regain trust from its neighbours, and to reunify after the collapse of the Berlin Wall (Green et al, 2008, pp.24-7; Roberts, 2000, pp.168-9). The deterioration of EastWest relations after 1945 was accompanied by an increasing awareness among the Western countries that a rearmed and economically prosperous West-Germany would be in their interest. Ever since, Germany has played a pivotal role in the integration process, frequently together with France. This was, for example, evident in debates on the EU's institutional development (see, also, Chapter 5).

For the Dutch, European integration also had practical benefits and was not necessarily supported out of idealism. During the Cold War the Netherlands supported economic integration, but sought to avoid political integration. In the fields 
of security and defence policy the focus was actually on the North Atlantic Treaty Organisation (NATO) and the US. European integration and cooperation were mainly seen as ways towards strengthening an open Dutch economy. Supranational institution building was supported, but primarily as a tool to curb the power of the big Member States (notably France and Germany). As such it was a way to protect national interest (Andeweg \& Irwin, 2002, p.199; Van der Harst, 2003). Reluctance towards European political co-operation in such fields as external relations has somewhat waned, but is still alive in other policy fields, most notably regarding social affairs (Hoetjes, 2003, pp.318-9). The fear of a Franco-German leadership has decreased, but ensuring a more effective Commission and a more influential EP are still central to Dutch policy on Europe.

European integration has long been an uncontroversial issue in Germany and the Netherlands where public support for EU membership remains considerable (Busch \& Knelangen, 2004, p.95; Wennekers, 2009). Even so, support for EU membership and further integration has steadily decreased (Janssen, 2001, pp.124-39) and during the 1990s scepticism about the EU and its policies became more prominent. The introduction of the Euro in 2002 and the unprecedented Eastern Enlargement in 2004 were particularly contentious, respectively because of the expectation that the Euro would lead to higher prices and due to the fear of an influx of cheap labour from the East after new Member States joined (Busch \& Knelangen, 2004; Harmsen, 2004). In addition, in Germany the Deutsche Mark was always an important symbol of stability, low inflation and economic prosperity; the prospective loss of the D-Mark seriously dampened enthusiasm for the EU (Teschner, 2000, pp.70-71). ${ }^{101}$

European integration has always been an elite project in both countries and differences between political parties have always been minimal, something that has long prevented the issue from entering the public arena. Even so, these very elites have also started to raise questions. A more sceptical attitude seems to be on the rise in the Netherlands because, although a founding member of the EEC, it is now part of a much larger EU 'club' (resulting in a loss of influence) ${ }^{102}$. Moreover, the integration project, itself an experiment in regional integration, is arguably losing its supranationalist dimension, overshadowed by a more intergovernmentalist ap-

\footnotetext{
${ }^{101}$ After the Berlin Wall had come down Chancellor Helmut Kohl pledged that the united Germany would be a 'European Germany'. The advancement of the Economic and Monetary Union (EMU) played a key role in his approach, despite only moderate domestic support (Paterson, 2003, p.219). It is commonly agreed that on its inception the European Central Bank (ECB) was modelled after the German Bundesbank (e.g. Dinan, 1999, pp.129, 137-8, 462; McCormick, 2008, p.159). Dutch and German politicians have generally been supportive of stringent criteria and a strong and independent ECB, even though Chancellor Schröder deviated from this.

102 The infamous 'Black Monday' of 30 September 1991, when an ambitious Dutch draft TEU was rejected (see, for example: Dinan, 1999, p.145), is often used to illustrate this point. During subsequent IGCs the respective governments took a more cautious and matter-of-fact position.
} 
proach to cooperation. Additionally, the relatively high contribution to the EU'S budget has become one of the main points of dissent (Van der Harst, 2003, p.144; Soetendorp \& Hanf, 1998, pp.48-9). Consequently, since the Maastricht Treaty the Dutch national interest is increasingly emphasised in the national media (Hoetjes, 2003, p.318).

Former VVD-leader and European Commissioner for the Internal Market Frits Bolkestein was the first to air a more critical voice in the 1990s, by emphasising subsidiarity and a limited European project, raising questions about the relationship between integration and the Dutch national interest (Harmsen, 2004, pp.103-9). Initially, Bolkestein was heavily criticised, but towards the end of the 1990s a more critical view vis-à-vis Europe became anchored in elite discourse (Van der Harst, 2003, pp.143-4). The VVD continued on the path laid out by Bolkestein, for example by rejecting the 2004 'big bang' enlargement in favour of a country-by-country approach (Harmsen, 2004, pp.110-114). To the left of the political spectrum, the SP criticises the EU for being a neo-liberal, undemocratic project. Geert Wilders' PVV is the most outspoken Eurosceptic party, calling among other things to abolish the EP and block Turkey's membership bid. Though to a lesser extent, critical opinions have also been voiced by parties such as the CDA and PvdA, whereas D66 and GroenLinks are now seen as the most pro-European parties.

The CDU has been the most enthusiastic supporter of European integration, while sister party CSU became less supportive from the 1990s (Paterson, 1996). Initially the SPD was very reluctant about European integration, but it changed position during the 1950s, when German unification seemed further away than ever, at a time when the party transformed itself from an anti-capitalist working class party into a moderate centre-left Volkspartei (Moeller, 1996; Schmidt, 2008, p.66). The FDP has been quite pro-European since the 1970s whereas, of the established parties, the Greens have always been the most critical, especially with regard to the Union's perceived democratic deficit and supposedly weak environmental credentials of EU policy (Rüdig, 1996, pp.260-6; Teschner, 2000, p.75). Anti-EU parties and sceptical, one-issue parties such as the Bund Freier Bürger (BFB) ${ }^{103}$ have not been able to gain broad support (Busch \& Knelangen, 2004, p.90; Sturm \& Pehle, 2001, pp.137-8). However, Die Linke has so far been more successful with $6.1 \%$ of the votes in the 2004 European elections and $7.5 \%$ in 2009. ${ }^{104}$

German political parties have increasingly been paying attention to the 'normalisation' of Germany's position in Europe and the attainment of national inter-

\footnotetext{
${ }^{103}$ This party was set up by a former head of the Commission's Single Market Division, Manfred Brunner. Its main agenda point was opposition against the EMU. The party ceased to exist in 2000 (Busch \& Knelangen, 2004, p.90; Teschner, 2000, p.73).

${ }^{104}$ Information available on the website of the Federal Returning Officer (Der Bundeswahlleiter): http://www.bundeswahlleiter.de/de/europawahlen/EU_BUND_09/ergebnisse/bundesergebnisse/index. html
} 
ests. This was most apparent during the two Red-Green governments (1998-2005), with Chancellor Gerhard Schröder's rhetoric clearly differing from that of his predecessors due to his sensitivity for short-term domestic politics and his preference for dealing with the other big Member States (Paterson, 2003, p.217; cf. Nijhuis \& Blom, 2002). In contrast, Angela Merkel has so far paid more attention to the small and the Central and Eastern European Member States, trying to reposition Germany as a 'consensus-builder' (Green et al, 2008, p.147; Marhold, 2006), for example, with regard to treaty reform and the EU's budget. Andreas Maurer (2003, p.117) argues that, above all, there has been a change of tone, from a rather idealistic to more pragmatic approach; overall, continuity prevails in Germany's policy on European integration.

In both countries the increased level of criticism has not been matched by a more pro-active parliamentary engagement in EU affairs. This can be explained partly by the long-lasting and positive general attitude towards European integration, and the widespread belief that the EP was to become the core democratic institution when it came to EU affairs (Maurer, 2003, p.128; Van Schendelen, 1996, pp.60-1). The parliaments' internal organisation also played a role, their chambers unable to deal with the information overload and the particular pace of the European policy process (e.g. Saalfeld, 1996; Van Schendelen, 1996). With the advance of the Single European Act (SEA) and the TEU, the parliaments in both countries did try to take a more active stance. Nonetheless, the Bundesrat's engagement with European affairs has been called 'reactive' (Sturm \& Pehle, 2001, p.85), whereas the Bundestag, in particular, remains quite passive (Sprungk, 2007). The latter's influence is usually limited to the transposition and implementation phase of EU decision-making (Rometsch, 1996, p.81). The involvement of the Dutch parliament also remains weak, with debates typically focussing on implementation issues, not on the actual content of Commission proposals and EU policies (Hoetjes, 2001, p.347; Hoetjes, 2003, p.326). In line with its general responsibilities, the Dutch First Chamber mostly focuses on legal issues, whereas political discussion is left to the Second Chamber (Hoetjes, 2001). Parliamentary debates about EU affairs rarely reach the public (Hoetjes, 2001, pp. 355-6; Saalfeld, 1996, p.32). The air quality case described in Chapter 6 will testify to this limited and mostly belated involvement of national parliaments. The recently ratified Lisbon Treaty (Title II, Art. 12, TEU) gives a more prominent role to national parliaments while the accompanying ruling of the Bundesverfassungsgericht explicitly called for a stronger role of the German parliament ${ }^{105}$, though whether this will change anything remains to be seen.

Although they feature more regularly, EU policies do certainly not always figure in the Dutch and German public spheres, not even at times of treaty reform (Beuter, 1994; Beuter, 2002; Engel, 2006; Den Hartog, 1994; Langendoen \& Pijpers, 2002;

\footnotetext{
${ }^{105}$ See: http://www.bundesverfassungsgericht.de/pressemitteilungen/bvg09-072.html
} 
Luitwieler \& Pijpers, 2006). ${ }^{106}$ As is the case in most other EU Member States EP elections predominantly focus on national issues (Oppenhuis, 1996; Schmitt, 1996); in national election campaigns European affairs has not been an important issue either (Harmsen, 2004, p.124; Sprungk, 2007, p.152). Furthermore, in Germany 'Europe' is a "highly consensual issue in media discourse" with all newspapers tending to support supranationalism and cooperation (Voltmer \& Eilders, 2003, p.191), while in the Netherlands the media have generally only paid moderate attention to developments in 'Brussels' (Bardoel, 2002, p.368; De Beus \& Mak, 2009; Van der Eijk, 2000, p.339).

The attention paid to European affairs in the Dutch media has been even less than in the German media (e.g. De Beus \& Mak, 2009). Kevin (2003) maintains that German media provide more coverage about European news than media in other countries (see, also: Machill, Beiler and Fischer, 2006, pp.70-1). While 'European news' in her study refers to more than just EU news, Kevin's case study on the 1999 European elections shows that only French media devoted more attention to the elections than German media. The number of news items about these elections in the Dutch media was less than a third of those in the German media (see, also: Kevin, 2001). As Pfetsch and her colleagues show, when it comes to newspaper commentary German dailies devote more attention to EU affairs than Dutch dailies. In the latter more than $56 \%$ of commentaries takes a purely national scope, compared to just 47\% in German newspaper commentaries (Pfetsch, 2008, pp.28-9; Pfetsch, Adam \& Eschner, 2008, p.473).

Overall, in line with what was discussed in the previous chapter, coverage of EU affairs often tends to be limited in both countries, and the way in which it figures in national public spheres seems to be dependent on a policy's impact on domestic politics. In addition, correspondents also struggle with the issues identified in Chapter 3 (e.g. De Beus \& Mak, 2009, Chapter 4 and pp.136-7). FAZ-correspondent Michael Stabenow (2004, p.231) claims that there are important issues which do not receive coverage at all. Paul Sneijder (2008), the Brussels-based correspondent of Dutch public broadcaster NOS, writes that both politicians and journalists should live up to their responsibilities and bring Europe to the spotlight, because EU policies are becoming ever more important for the daily lives of the European citizens. $^{107}$

\footnotetext{
${ }^{106}$ Beuter (2002, p.117) does however suggest that the German public's lukewarm stance towards the Euro did influence a more modest German agenda during the Amsterdam IGC.

${ }^{107}$ Some years ago the moderate coverage of 'Europe' by the Dutch media triggered a debate in the professional journal De Journalist ('The Journalist'). Journalists agreed that the Dutch media should include more 'foreign' opinions, but they disagreed whether or not this was possible, language being seen as the main barrier (Freijser, 2002; Jansen van Galen, 2001; Scheffer, 2001).
} 


\section{Major Differences}

Notwithstanding the important resemblances between Germany and the Netherlands discussed before, there are two very clear and significant differences between the two countries. They concern the division of powers between the different levels of government, and the importance attached to the role of the constitution. These differences require a more detailed discussion, especially since the following chapters will reveal how the strong role of the German Länder, in particular, has influenced the debate on the future of Europe and EU air quality legislation.

\section{The German Länder's Impact on Politics}

The first major difference between Germany and the Netherlands concerns the role of sub-national administrations. Germany's federal system assigns extensive powers to the Länder, whereas the Dutch provinces only have very limited weight (Andeweg \& Irwin, 2002, pp.161-3). The Länder are important players in the German political system and since they existed before the Bund they provided its very foundation. When the Grundgesetz had to be adopted in 1949, it was the Länder which had to do so, and by at least a two-thirds majority. Moreover, each Land has a separate constitution, parliament and government. The judiciary does however form an integrated, country-wide system (Heringa \& Kiiver, 2009, pp.58, 61-2). The division of competences between the various levels is enshrined in the Basic Law. In case of conflicts between the federal level and the Länder, the Constitutional Court can be asked to settle the issue.

Through the Bundesrat, which consists of members of the regional governments, the Länder occupy a key position in the policy process. Constitutional changes require the endorsement of a two-thirds majority in both Bundestag and Bundesrat. Moreover, federal legislation that has an effect on the interests of the Länder needs to be approved by the Bundesrat; beyond that, it still possesses a qualified veto with respect to controversial legislation. ${ }^{108}$ In policy areas such as environment, education and the media, the Länder enjoy exclusive competences (Roberts, 2000, pp.101-2), although their influence goes well beyond these areas. Until the recent federal reforms, some 50-60 percent of federal legislation required the approval of the Bundesrat (Schmidt, 2003, pp.57-8). Though set up to represent the long term interests of the Länder, and meant to refrain from party politics, this chamber sometimes acts as a venue for party political battles (Ismayr, 2003, p.455).

There have been many proposals to reform the federal system because some believe it prevents effective decision-making and necessary reforms, for example, with regard to the welfare state - the so-called Reformstau (Roberts, 2000, pp.108-

\footnotetext{
${ }^{108}$ For more information, see: Schmidt, 2003, p.58.
} 
9). In 2003 discussions began about reforming the federal system, eventually resulting in a reform package in 2006. Among other things this included reducing the number of laws that need consent by the Bundesrat to about 35 percent, while returning some competences to the Länder (Green et al, 2008, pp.66-72; Heringa \& Kiiver, 2009, pp.89-90; Moore, Jacoby \& Gunlicks, 2008; cf. Roberts, 2000, pp.1089).

In an attempt to defend their prerogatives, the Länder have increasingly become more active with regard to European integration, both at the European level and the national level (Maurer, 2003, pp.131-6). Their role in EU policymaking has gradually been extended since the 1986 SEA, and was addressed in more detail during the TEU negotiations as well as in the subsequent change of Article 23 of the Basic Law, which formally incorporated the role of the Länder in Germany's European policymaking (Hrbek, 1999). In addition, the Länder have stepped up their dayto-day approach of EU affairs: first, their Europe Ministers regularly meet in the socalled Europaministerkonferenz which, among other things, is responsible for coordinating policies with respect to the EU and the federal government; second, they have appointed a common representative (the Länderbeobachter) who is responsible for collecting information and keeping an eye on the day-to-day affairs in the European and national institutions; and third, they have established their own representative offices in Brussels (the Ländervertretungen). Such initiatives have not always gone down well with the federal government or with officials in the German Permanent Representation (e.g. Escher, 1998, p.58; Jeffery, 1997b, p.199).

During the negotiations on the Maastricht Treaty the Länder more or less successfully lobbied for a subsidiarity clause, a Committee of the Regions, and the right to sit in on Council meetings which concern regional competences (Jeffery, 1997a, p.66). The German Basic Law now endows the Bundesrat with the right to appoint a representative to speak for Germany in the Council of Ministers when the exclusive competences of the Länder are at stake (Art. 23-6 GG). The Länder also had a profound influence on the German positions during the negotiations for the Amsterdam and Nice Treaties, as well as the TECE (Beuter, 2002; Engel, 2006; Hrbek, 2003). Furthermore, they have regularly protested against European legislation, for example during the 1980s when the Länder successfully argued that the federal government had acted in an unconstitutional manner by agreeing with the Television Without Frontiers Directive ${ }^{109}$ (see: Herdegen, 1995). Charlie Jeffery (2004) argues that over the years the Länder have become more defensive by emphasising their national competences, instead of enhancing their role on the European level. Yet, while they may have regularly voiced their opposition against new Union competences, they have never been willing to reject new treaties.

\footnotetext{
${ }^{109}$ Council Directive of 3 October 1989 on the coordination of certain provisions laid down by law, regulation or administrative action in Member States concerning the pursuit of television broadcasting activities (89/552/EEC), OJ 1989, L298/23-30.
} 
Relations between the different administrative levels in the Netherlands and the involvement of Dutch sub-national levels in EU affairs clearly differ from the German situation. The Netherlands is a unitary state whose history may be traced back to 1579, when the erstwhile sovereign Northern provinces first agreed to work together in the Union of Utrecht. At that time the provinces were in control, the Republic of the Seven United Provinces mainly being a 'loose confederacy' (Andeweg \& Irwin, 2002, p.10). It was only during the times of Napoleon (17951813) that a centralised country was created. Today, regional governments in the Netherlands have far less influence than their German counterparts and mostly have an administrative role.

The Dutch provinces are mainly responsible for spatial planning, risk assessment and the coordination of municipal policies, as well as for the implementation of several policies (Neelen, Rutgers \& Tuurenhout, 2003, pp.89-90). Their most prominent impact on Dutch politics is that the directly-elected regional representatives determine the composition of the Eerste Kamer. Andeweg and Irwin (2002, p.161) call the once highly influential provinces 'the most impotent of the three layers of government'. In contrast, they label the municipalities the main benefactors of decentralisation - despite the fact that decentralisation has so far only partly materialised (Keman, 2008, pp.236-7) - and their association VNG as one of the most influential interest organisations (Andeweg \& Irwin, 2002, pp.163-8; cf. Heringa \& Kiiver, 2009, pp.65-6). The provinces and municipalities are not very involved in EU affairs, with the exception of their administrations. The bigger cities and provinces have their own representations in Brussels, where they lobby for EU (financial) support in several fields (Hoetjes, 2003, pp.327-9). These representations include the Huis van de Nederlandse Provincies (House of the Dutch Provinces) ${ }^{110}$ and the joined representation of the four biggest Dutch cities Amsterdam, Den Haag, Rotterdam and Utrecht (the G4). ${ }^{111}$

\section{Constitutions and Courts}

A second major difference between Germany and the Netherlands concerns the importance attached to the role of the constitution. The Grundgesetz for Western Germany was drafted by a Parliamentary Council and adopted in 1949 (Green et al, 2008, pp.23-4; Roberts, 2000, p.12). It would later become the constitution for the unified German state. The Dutch constitution dates back to 1814 , but has been changed a number of times since - the most substantial revisions taking place in 1848 and 1983 (Heringa \& Kiiver, 2009, p.43).

Schmidt (2003, pp.9ff) emphasises the importance of the Basic Law and the judiciary in Germany while Martin Schermaier (2006, p.273) argues that, due to the

\footnotetext{
${ }^{110}$ http://www.nl-prov.be/

${ }^{111}$ http://www.grotevier.nl/g4/g4europa/index.html
} 
country's history, "[l]aw, rules and the enforcement of rules play a greater role in German daily life than in other European countries". Indeed, the Bundesbank may have ceded power to the ECB, but the Karlsruhe-based Bundesverfassungsgericht remains a key player in German politics, for example, through dispute settlement and judicial review (Green et al, 2008, pp.62-4; Heringa \& Kiiver, 2009, pp.157-9; Ismayr, 2003, p.475; Schermaier, 2006, p.273). All administrative and legal acts have to conform with the Basic Law. The Bundesverfassungsgericht is independent from any political institution. Generally, its duty is to uphold the constitutional order and mediate where there is conflict between the different institutions and levels of government, and between the individual and the state. Other powers include the involvement in potential impeachment procedures against the President (e.g. Schmidt, 2008, pp.82-4).

Whereas the German Constitutional Court has the right to carry out constitutional review of legislation and uses it actively, this is impossible in the Netherlands (Art.120 GW). The Netherlands does not, strictly speaking, have a constitutional court. It is one of the 'very few' countries which does not allow for judicial review (Heringa \& Kiiver, 2009, p.23). Currently there is a debate concerning the need to amend this situation. Even if judicial review is made possible, it will probably not lead to the establishment of a constitutional court, but be handled by the normal courts (Smits, 2006, p.494). The Dutch judiciary has become more active (Andeweg \& Irwin, 2002, pp.154-8; Keman, 2008, p.238). Nevertheless, the Dutch reality is still very far removed from the German one. For example, the Dutch do not display much enthusiasm for the Dutch Constitution, which does not hold the same symbolic importance as the German Grundgesetz (e.g. Ter Horst, 2008).

In both countries national laws can be assessed against EU legislation and treaties, but different legal systems also affect the way in which the two countries deal with EU treaties and legislation. The Netherlands has a 'monist' system in which ratified treaties are grosso modo automatically treated as part of the national legal order. Yet, Germany adheres to a 'dualist' system which distinguishes between two separate legal orders and necessitates the transposition of treaties into national law (Heringa \& Kiiver, 2009, p.149). Even though the ECJ has determined that EU legislation has 'direct effect' and 'supremacy' over national law, the Bundesverfassungsgericht has been reluctant to accept this unconditionally, and issued a number of important rulings concerning European laws and treaties, for example, regarding the Maastricht Treaty and, most recently, the Lisbon Treaty (ibid, p.159-60; Herdegen, 1994; Schmidt, 2003, pp.126-7). However, in the Netherlands, parts of the Dutch Constitution have even been annulled owing to the development of EU legislation (Andeweg \& Irwin, 2002, p.158). The Dutch Council of State (Raad van State), the government's most important advisory body, does have an Administrative Jurisdiction Division that has ruled on a number of cases regarding the EU and its policies, for example, on the admissibility of a referendum on the TECE, or on the inter- 
pretation of EU air quality legislation (cf. Lepszy, 2003, pp.351, 359, 379). Once again, this Dutch legal division comes no way close to wielding the same powers that the German Constitutional Court enjoys.

\section{Conclusion}

This chapter provided an overview of political processes, media environments and the stance towards European integration in Germany and the Netherlands. In many respects these countries share important characteristics: first, the Netherlands has been called a classic example of a consociational democracy (e.g. Andeweg \& Irwin, 2002), a democracy in which social divisions are overcome by involving all important societal groups, whereas Schmidt (2008, p. 90) has described Germany as 'a consociational democracy German style'; second, the media environment in both countries is characterised by important national dailies and an enduring role for public broadcasting, while being shaped by consensus-style politics - the latter has a lasting effect on the style of political communication; and third, regarding European integration, Dutch and German citizens and political actors have become more critical in recent years, often looking out for the national interest. This does not seem to have triggered national public debates, however.

Yet, there will always be cultural differences, even between countries that have many characteristics in common (e.g. Livingstone, 2003b). The two most important distinctions between Germany and the Netherlands concern the role of the Länder versus those of the Dutch provinces, and the importance attached to the German Basic Law and constitutional review vis-à-vis the situation in the Netherlands.

Together with the two previous chapters, this chapter has provided the basis for the upcoming empirical chapters analysing the debate on Europe's future and on clean air policies in the EU. As we will see, some of the elements discussed in this chapter have a more pronounced effect on debates about EU affairs in the various public spheres than others. 


\section{The Future of Europe: From Fischer to Failure}

European integration has always been a process of small steps without a clear end goal, just a reference to an 'ever closer union'. This process has been shaped by internal and external circumstances and events. Existing politico-institutional structures have been adapted to the new reality of having to decide upon legislation with six, 12, 15, 25, 27, and in the future, perhaps even more than 30 Member States. At the same time, the changing international economic and political environment has stimulated new projects such as Economic and Monetary Union (EMU) and the Common Foreign and Security Policy (CFSP). The accompanying treaty changes have on each occasion been preceded by intensive discussions and negotiations between the Member States (e.g. Christiansen \& Reh, 2009, pp.51ff; Parsons, 2009).

There have been calls for a more explicit end goal for the integration process (e.g. Grimm, 1995; Habermas, 1995). One of the most prominent contributions in this respect was German Minister of Foreign Affairs Joschka Fischer's May 2000 Humboldt speech, which triggered responses from many other European politicians. The discussions that followed, along with dissatisfaction about the Nice Treaty, eventually resulted in a decision by the European leaders at the 2001 Laeken Summit to set up a Convention that was to debate the EU's future and to draft proposals for a new treaty that would subsequently be discussed by the Member States during an Intergovernmental Conference (IGC). This process resulted in the Treaty Establishing a Constitution for Europe (TECE). ${ }^{112}$ The Dutch 'nee' and the French 'non' in the first half of 2005 proved to be the nails in the coffin of Europe's Constitutional Treaty, although most of the text was eventually revived with the Lisbon Treaty.

${ }^{112}$ Treaty Establishing a Constitution for Europe, OJ 2004, C310. 
The debate on the future of Europe was effectively a debate about Brussels and the way it functions. The aim was to restructure the EU's procedural and institutional arrangements and, as such, the result would be a 'history-making decision' (Peterson \& Bomberg, 1999). The TECE would have had important implications for the governance of the Union, increasing the scope of Union competences and the use of the so-called 'Community method', by which all three major institutions (Commission, Council and Parliament) engage in policymaking. The first informal interventions by Fischer and others were openly discussed and the formal discussions that followed were also intended to be as open as possible in an attempt to include the European citizens. In other words, we could say that the aim was to stimulate interaction between the weak and strong publics (the latter in the guise of the Convention and later the IGC). Sonja Lucarelli and Claudio Radaelli (2004, p.4) argue that this particular round of treaty reform had the potential to create a public sphere that would involve domestic publics and politics in the decision-making process, and promote deliberative, participatory governance.

This chapter zooms in on the debate on the future of Europe in the Dutch and German public spheres. It starts with an overview of the policy process, from Fischer's speech in 2000 to the rejection of the TECE by the Dutch and the French in 2005. This overview also includes references to Dutch and German reflections and positions. This is followed, first, by the presentation of the empirical findings and, second, by a discussion. It will become clear that European affairs are discussed in national public spheres and that there is reference to events and debates in other countries. The latter should, however, not always be equated with interaction in terms of actors reacting to each others statements across borders, but rather with observing what goes on elsewhere. In addition, this chapter will reveal two important qualitative shortcomings, concerning the timing of public debates and the representation of the European policy process in national public spheres.

\section{The Debate on the EU's Future: An Overview}

Though he was by no means the first to call for a more explicit finalite for the integration process, it was German Minister of Foreign Affairs Joschka Fischer's influential speech at the Humboldt University which triggered a European-wide debate (Becker \& Leiße, 2005, pp.56-7; Christiansen \& Reh, 2009, p.233). Contrary to the aforementioned step-by-step process, Fischer (2000) argued for a final settlement of the integration process along the lines of a federation of nation-states with an unmistakable trias politica and a two-chamber parliament. A European constitution could lay the basis for this renewed European polity. Not surprisingly, his speech triggered responses from other politicians, including French President Jacques Chirac, who focussed on the central role of the sovereign nation-state, and British 
Prime Minister Tony Blair, who argued that the EU should become a superpower, but not a super state. ${ }^{113}$ The Länder and the Bundestag supported a broad debate on the future of the EU and another treaty revision. The initial Dutch reactions were reluctant; the Dutch Minister of Foreign Affairs, Jozias Van Aartsen, called the ideas of his German counterpart 'unrealistic' (Luitwieler \& Pijpers, 2006, p.242). Nevertheless, the Netherlands did eventually support a new, more comprehensive treaty reform and promoted the Convention-method as the most suitable means to engage in this process.

Fischer delivered his speech at a time when the 2000 IGC was already underway. This IGC had a rather narrow agenda, only focussing on the so-called 'Amsterdam left-overs' - the extension of majority voting, the re-weighting of votes and the question of Commission size - as well as the issue of 'flexible integration', which would allow some Member States to integrate at a faster pace. Fischer's 'pre-Nice launch of the post-Nice debate' (Dinan, 2002, p.29) went well beyond these issues, but did not affect the agenda of the ongoing negotiations. Ultimately, the results of the Nice Treaty were widely perceived as modest and, in some aspects (most notably the new QMV rules), overly complex. Doubts were raised about whether this treaty actually prepared the EU for enlargement, as it was set out to do in the first place. ${ }^{114}$ This mood was eloquently summarised by liberal MEP Andrew Duff (2001), who wrote that the EU had moved 'from Amsterdam left-overs to Nice hangovers'. The Member States did not appear particularly enthusiastic themselves and called for a "deeper and wider debate about the future of the European Union", with another IGC scheduled for 2004. ${ }^{115}$

It was widely believed that deliberations about a new treaty should no longer be restricted to diplomatic circles, but opened up to a broader set of participants and to the European public (Becker \& Leiße, 2005, p.172; Christiansen \& Reh, 2009, p.237; Gray, 2000). It was eventually agreed during the Laeken European Council in December 2001 that a Convention comparable to the one that drafted for the EU Charter of Fundamental Rights should discuss the Union's main challenges. The 'Convention on the Future of Europe' was to focus on three broad issues, namely closing the gap between citizens and institutions, preparing the EU for further enlargement, and strengthening Europe's global role. The agenda was left relatively open, as was the intended outcome which, it was felt, could take the form of a list of options or even a comprehensive draft treaty (Allen, 2004, p.22).

\footnotetext{
${ }^{113}$ For a synopsis of some of the main contributions to the debate, see: Becker \& Leiße, 2005, pp.56-66; Norman, 2003, pp.11-16.

${ }^{114}$ For a discussion of the 2000 IGC and its results, see, for example: Galloway, 2001.

${ }^{115}$ See declaration 23 on the EU's future attached to the Nice Treaty: Treaty of Nice amending the Treaty on European Union, the Treaties Establishing the European Communities and Certain Related Acts, OJ 2001, C80, at pp.85-6.
} 
The rationale behind the choice for the Convention was that it might stimulate open and free discussion between all interested and affected parties. It clearly differed from the traditional IGC format in that participants were not limited to representatives of Member States governments, but included national and European parliamentarians, observers from a number of other EU institutions, and envoys from the candidate members. Meetings took place in public and most documents were made available through the Internet. Organised interests could participate in the discussions via an online Forum and in the early stages of the process they were also invited to hearings. Furthermore, a Youth Convention met from 9-12 July 2002, presenting a final report on 12 July. Finally, the European institutions and the Member States took several initiatives to stimulate debate, such as the information campaigns and web forums organised by the Bundestag and Bundesrat in advance of the Convention's start (Sprungk, 2007, pp.147-8).

The Convention's proceedings took place at a time when intra-European and international affairs were in turmoil, most forcefully illustrated by controversy over the war against Iraq and the EU's Stability and Growth Pact - the political accord between the countries of the Eurozone, based on the criteria set out by the Maastricht Treaty. Notwithstanding the squabbles between the European leaders about these and other issues, the work within the Convention continued. Initial expectations were quite modest, but it soon became clear that the participants had more ambitious plans to draft an EU Constitution (Allen, 2004, p.22; Dinan, 2003, pp.278; Nugent, 2006, p.118). As the Convention proceeded and became more momentous, some countries (including Germany) even decided to send their Ministers of Foreign Affairs to the Convention (Dinan, 2003, p.35; Dinan, 2004, p.32). At the outset Dutch Minister Van Aartsen had referred to the Convention as merely a 'vrijblijvende praatclub' (a talking shop without obligations; quoted in Van der Kolk \& Aarts, 2005, p.12), but this attitude changed when it became clear that Giscard d'Estaing and many other convention members harboured greater ambitions.

Dutch priorities included the safeguarding of the Community method, the increase of discipline, transparency and control with regard to the EU budget, the promotion of efficiency and coherence in the Union's external relations (but on a largely intergovernmental basis), and the further communautarisation of cooperation in matters of justice and home affairs, with the exception of issues pertaining to criminal law. Germany proposed a 'competence catalogue' but this was considered too rigid by Dutch politicians (e.g. Pelkmans et al, 2003; Wolinetz, 2008, p.184). The German government's main priorities were to improve the efficiency, transparency and democratic nature of the EU by, for example, strengthening the role of the Commission and the Parliament, having the Commission president elected by the $E P$, reforming and extending QMV and creating a clearer division of competences (e.g. Möller, 2008, p.147; Norman, 2004). Together with France, Germany presented a number of influential papers to the Convention, including one on institu- 
tional reforms on 15 January $2003 .{ }^{116}$ The latter included proposals for a long-term President of the European Council, the election of the Commission President by the EP and the establishment of the post of an EU Minister of Foreign Affairs, as well as an extension of QMV in the field of foreign and security policy. Some of the FrancoGerman proposals were rejected almost immediately by many of the smaller Member States. For example, countries such as the Netherlands feared that the establishment of a long-term President for the European Council would increase its influence at the expense of the Commission, which would in turn harm the Community method (Norman, 2003, pp.179-84).

The Convention presented its final document - the Treaty Establishing a Constitution for Europe - in July 2003. It was endorsed by most participants, though some drafted a dissenting opinion (The European Convention, 2003, Annex 3). Despite broad support for the TECE among the conventioneers, several governments wanted to reopen certain provisions during the forthcoming IGC. The main stumbling block turned out to be the new QMV-provisions, which were vehemently opposed by the Polish and Spanish governments. ${ }^{117}$ Both favoured sticking to the agreement reached in Nice, since this would bring their voting weight up to almost equal that of Britain, France, Germany and Italy. In the end a new Spanish government meant room to manoeuvre for a compromise, and alone the Polish government could no longer uphold its opposition. ${ }^{118}$ The final document was approved during the European Council of 17 and 18 June 2004 and signed by the heads of state and government during an official ceremony in Rome on 29 October of the same year. ${ }^{119}$

The TECE would, to a large extent, uphold the existing treaty framework, of which the part on the first pillar had already been dubbed 'constitutional' by the European Court of Justice (ECJ) (e.g. Hoffmann \& Shaw, 2004, pp.626, 630-1). Nevertheless, observers noted that terms such as 'constitution' were bound to raise objections and create unease as they were likely to be associated with the idea of 'stateness' (Dinan, 2004, p.39; Galloway, 2001, p.163). Neil Nugent (2006, p.125) writes that the TECE consequently attracted more attention than any previous treaty, but this also complicated the ratification process. It soon became clear that several governments would organise a referendum to ratify the treaty, although

\footnotetext{
${ }^{116}$ Contribution Submitted by Mr Dominique de Villepin and Mr Joschka Fischer, Members of the Convention. (CONV 489/03)

${ }^{117}$ The Convention proposed a double majority representing at least $50 \%$ of the Member States and $60 \%$ of the citizens of the EU.

${ }^{118}$ A new double majority was set at a minimum of 55\% of the Member States (consisting of at least 15 countries) and $65 \%$ of the Union's population.

${ }^{119}$ See Dinan $(2004 ; 2005)$ for an account of the negotiations between the Member States.
} 
factors other than the Constitution often played a role in these decisions, especially domestic politics (see: Qvortrup, 2006). ${ }^{120}$

Despite some minor points of criticism, there was broad support for the TECE among Germany's political elite (e.g. Hrbek, 2003; Möller, 2008, p.149). What did become somewhat controversial was the exact procedure that would be followed to ratify the new treaty. There were calls from several politicians - including CSU and FDP politicians, as well as some Greens - for a referendum, following similar debates in other Member States. This option was rejected by the government. As noted in the previous chapter, referendums are not legally possible at the federal level. Fear of a negative outcome no doubt also played a role (Möller, 2008, p.151; cf. Eberl, 2004). Opinion polls showed increasing opposition among German citizens, especially after the negative referendums in France and the Netherlands. The work of the Convention and the ratification of the TECE were never accompanied by a wider public debate in Germany (Möller, 2008, p.150; Sprungk, 2007, p.152).

In the Netherlands the TECE was to be the subject of a referendum, despite objections by the government and notwithstanding broad political support for the new treaty (Wolinetz, 2008, pp.185-6). The MPs that had presented the referendum proposal expected that it would increase citizen involvement, foster support for the EU and stimulate a public debate about the Constitution and European integration in general. $^{121}$

None of the political parties had any experience of organising a referendum campaign, but the 'yes' camp (which included most major parties, including CDA, D66, the Greens, PvdA and VVD) ${ }^{122}$ was clearly less able to present a united front and only became involved in the campaign in late April. The 'no' camp included both populist left-wing (notably the SP) and right-wing (in particular VVD-renegate Geert Wilders) parties, which expressed a common aversion to what they saw as a centralised and undemocratic European super state. By wasting no time in starting their campaigns they were able to set the agenda. The 'yes' campaign became a complete disaster when government ministers painted several gloomy scenarios in case the Dutch rejected the TECE (Harmsen, 2005, pp.4-8; Lucardie, 2005). According to Leonard Besselink (2006, p.349), a contribution to the debate by Joschka Fischer on

\footnotetext{
${ }^{120}$ Referendums were announced by the Czech Republic, Denmark, France, Ireland, Luxembourg, the Netherlands, Poland, Portugal, Spain and the United Kingdom.

121 Tweede Kamer, vergaderjaar 2002-2003, 28 885, nr. 1-3. One could argue, as Jos de Beus and Jeannette Mak (2009, p.90) for example do, that strategically this was not a logical decision since there was always a chance that public debate would result in a rejection of the treaty. In their view, normative considerations played a decisive role during the political discussions leading up to the decision to organise a referendum (cf. Adam, 2007, pp.413-4, 423).

122 The 'yes' campaign was supported by some of the main interest organisations, including business associations VNO-NCW and MKB and the workers' union FNV. Most Dutch media - including De Telegraaf, de Volkskrant and NRC Handelsblad - supported the TECE, the main exception being centre-right magazine Elsevier, which took a stance against the TECE on its cover page of 16 April 2005.
} 
Dutch television on 22 May "made more impression and political sense than any politician in The Hague was able to foster."

The first country to ratify the TECE was Lithuania, its parliament approving the new treaty on 11 November 2004. The first referendum took place in Spain. Voter turnout was low (42.3\%), but support for the new treaty was overwhelming with $76.7 \%$ of the Spanish voters approving it. The Bundestag ratified the treaty on 12 May 2005 and the Bundesrat on 27 May. ${ }^{123}$ The referendums in France and the Netherlands took place on 29 May 2005 and 1 June 2005 respectively. Although initial support for the TECE appeared to be strong in both countries, the 'no' camp quickly gained ground (Keohane, 2005; Qvortrup 2006, pp.91-3). For different reasons (e.g. Taggart, 2006) citizens of both countries eventually rejected the treaty: $54.9 \%$ of the French voters (turnout $69.7 \%$ ) and $61.5 \%$ of the Dutch voters (turnout $63.3 \%$ ) voted against it. By that time ten other Member States had already ratified the treaty. Despite the increase in criticism on the EU and its policies, as set out in the previous chapter, the Dutch rejection still came as a surprise. Opinion polls regarding the outcome of the referendum attached different importance to specific issues (for example, the Turkish membership bid), but some explanations figured prominently in all surveys, namely the loss of political control, the supposedly unfair Dutch contribution to the EU budget, and the absence of information about the EU in general, and the TECE in particular (Besselink, 2006). Interviewees in Brussels and The Hague argued that the Dutch government's reluctance towards EU communication contributed to the TECE's rejection (Interview 5; Interview 9; Interview 10). ${ }^{124}$

As explained in Chapter 3, after the TECE was rejected by the Dutch and the French, EU leaders initiated a 'period of reflection' in order to promote a debate about the future of the EU and the new treaty; subsequently the Commission presented its Plan- $D$. Although the European Constitution itself did not survive, most of the text was eventually revived with the draft Lisbon Treaty in 2007, which eventually came into force at the end of 2009 , after yet another thorny ratification process.

Box 2: The Future of Europe - Key Moments

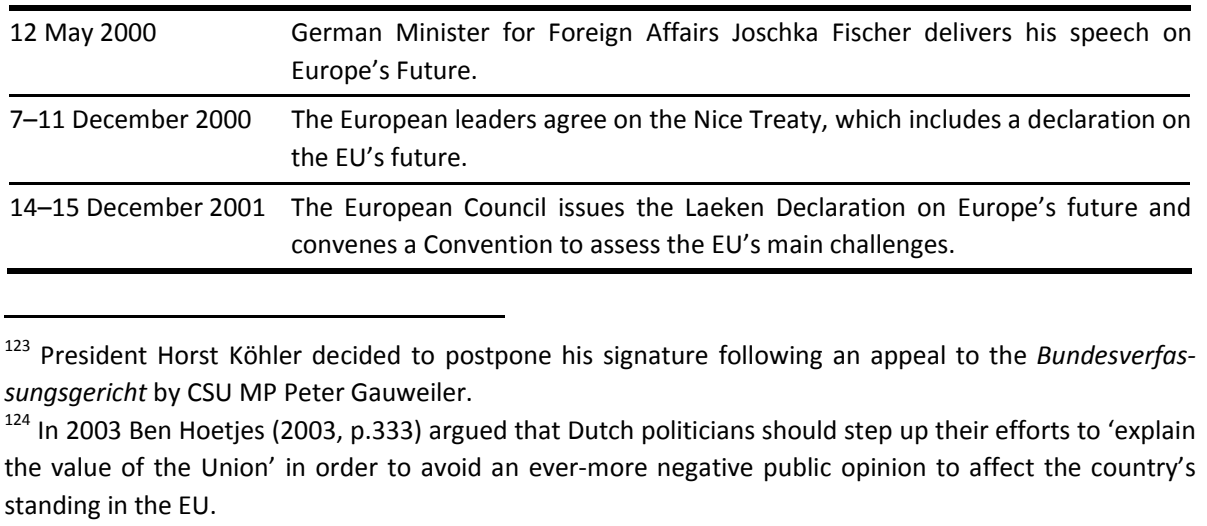




\begin{tabular}{ll}
\hline 28 February 2002 & The Convention opens its proceedings. \\
\hline 19-20 June 2003 & $\begin{array}{l}\text { The Convention's chair Valéry Giscard d'Estaing presents a first draft TECE to } \\
\text { the Thessaloniki European Council. }\end{array}$ \\
\hline 18 July 2003 & The final draft of the Constitution is presented to the Italian Presidency. \\
\hline 4 October 2003 & The IGC is opened. \\
\hline 12-13 December 2003 & The European Council fails to agree on a new treaty. \\
\hline 17-18 June 2004 & The European Council agrees on the TECE. \\
\hline 29 October 2004 & Official signature ceremony in Rome. \\
\hline 29 May 2005 & The French vote against the TECE. \\
\hline 1 June 2005 & The Dutch also reject the TECE. \\
\hline 16-17 June 2005 & $\begin{array}{l}\text { The European Council agrees on a 'period of reflection' to enable a 'broad } \\
\text { debate' about how to proceed. }\end{array}$ \\
\hline
\end{tabular}

\section{The Findings: A General Overview}

In order to present a first overview of the debates in the Dutch and German public spheres this section presents some basic quantitative data and sketches how the debate on Europe's future featured in respectively the German and the Dutch newspapers, all articles taken together. As was already mentioned, the timeframe for this case is over five years, from January 2000 to June 2005, spanning the period from Fischer's Humboldt speech on 12 May 2000 that effectively kicked off the debate, to the European Council meeting of 16 and 17 June 2005 when EU leaders opted for a 'period of reflection'. This period does not cover later considerations about the reasons behind the failure of the TECE, nor does it include the re-launch of the treaty reform process that eventually resulted in the Lisbon Treaty. It covers a process that essentially closed with the June 2005 European Council and was only re-launched by the German EU Presidency in the first half of 2007. The 'no' vote on the Nice Treaty (and the IGC that preceded it) took place during this timeframe, which is important given the accompanying declaration on Europe's future.

Since preliminary explorations showed that thousands of press articles had been dedicated to the debate on the EU's future, a more focussed selection method was used: 'constructed week sampling'. ${ }^{125}$ The articles were gathered using a number of search terms (Box 3). Articles had to refer to the debate about the EU's future and had to include information regarding the policy process and an opinion, act or other type of statement related to it. Some articles could be dismissed right away; others were less straightforward. ${ }^{126}$ Throughout the process some search terms became more prominent than others. For example, whereas 'Nice' was still men-

\footnotetext{
${ }^{125}$ The constructed weeks can be found in Annex 2 .

${ }^{126}$ See the Codebook in Annex 1 for more information
} 
tioned throughout 2000 and 2001, it slowly faded away, while 'constitution' became ever-more important. Other search terms mostly repeated previous results, especially 'verklaring'/'Erklärung'. This suggests that the set of search terms was solid enough to limit the chances of articles being left out.

Box 3: Search terms

\begin{tabular}{lll}
\hline Dutch & English & German \\
\hline Grondwet/Constitutie & Constitution & $\begin{array}{l}\text { Grundgesetz/Konstitution/Verfas- } \\
\text { sung }\end{array}$ \\
\hline Conventie & Convention & Konvent \\
\hline Verklaring & Declaration & Erklärung \\
\hline Toekomst & Future & Zukunft \\
\hline Laken & Laeken & Laeken \\
\hline Nice & Nice & Nizza \\
\hline Voorstel & Proposal & Vorschlag \\
\hline Referendum & Referendum & Referendum/Volksabstimmung \\
\hline Hervorming & Reform & Reform \\
\hline Verdrag & Treaty & Vertrag \\
\hline
\end{tabular}

\section{Considering the Numbers}

In order to better understand the complete set of articles, it is worthwhile having a brief look at a general overview of the number of articles analysed per newspaper, as well as per year. Given the sampling method used for this case study, the chapter seeks to present a reliable snapshot of the debate about Europe's future.

Table 1: Number of Articles per Newspaper and per Year

\begin{tabular}{lccccccc}
\hline & FAZ & FR & SZ & NRC & TEL & VK & Total \\
\hline $\mathbf{2 0 0 0}$ & 30 & 6 & 11 & 9 & 3 & 4 & $\mathbf{6 3}$ \\
\hline $\mathbf{2 0 0 1}$ & 24 & 9 & 9 & 2 & 2 & 2 & $\mathbf{4 8}$ \\
\hline $\mathbf{2 0 0 2}$ & 12 & 6 & 10 & 1 & 1 & 3 & $\mathbf{3 3}$ \\
\hline $\mathbf{2 0 0 3}$ & 29 & 7 & 22 & 17 & 4 & 8 & $\mathbf{8 7}$ \\
\hline $\mathbf{2 0 0 4}$ & 20 & 13 & 15 & 9 & 2 & 8 & $\mathbf{6 7}$ \\
\hline $\mathbf{2 0 0 5 *}$ & 24 & 7 & 9 & 15 & 4 & 9 & $\mathbf{6 8}$ \\
\hline Total & $\mathbf{1 3 9}$ & $\mathbf{4 8}$ & $\mathbf{7 6}$ & $\mathbf{5 3}$ & $\mathbf{1 6}$ & $\mathbf{3 4}$ & $\mathbf{3 6 6}$ \\
\hline
\end{tabular}

* Note that the articles from 2005 only represent half a year.

Table 1 presents the number of articles per newspaper and per year. What is clear from the outset is that during the selected weeks Frankfurter Allgemeine Zeitung 
devoted considerably more attention to the debate on Europe's future than the other five newspapers, whereas De Telegraaf in particular seems to have been less disposed to report on the debate. Overall the selected German newspapers provided most coverage, as can also be seen from Figure 4. This graphical representation of the total numbers of articles per newspaper suggests that NRC Handelsblad was the only Dutch newspaper which devoted similar attention to the issue, at least vis-à-vis the Frankfurter Rundschau and Süddeutsche Zeitung.

Figure 4: Annual and Total Number of Articles per Newspaper

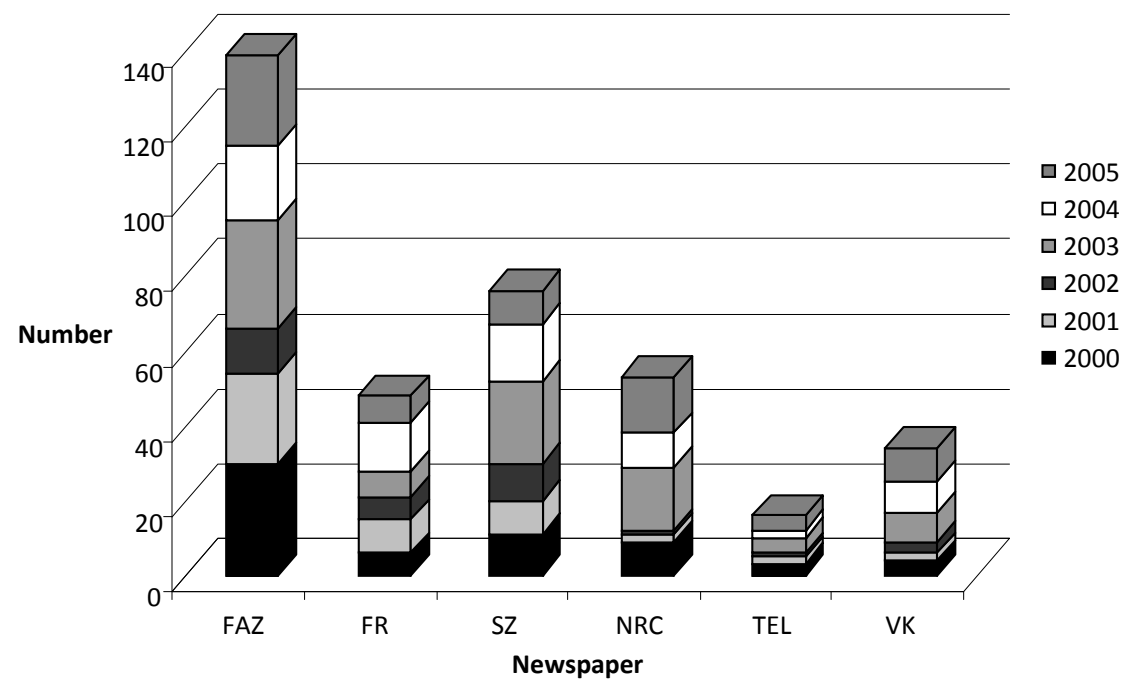

The Dutch newspapers seem to have paid less attention to the debate about Europe's future. This is in line with the observation that the Dutch media generally appear to cover EU affairs less than their German counterparts (see Chapter 4). Of course, to be able to really draw conclusions concerning this particular case, we would have to compare the figures presented above to those concerning other Member States. Such figures are not available based on the same selection method and general methodology and other types of studies do not always present data which allows for clear conclusions. For example, Silke Adam (2007; 2008) studied the debates about the TECE in France and Germany, and so did Regina Vetters, Erik Jentges and Hans-Jörg Trenz (2009). While both studies employed the method of claims analysis, the selection of articles focussed on different timeframes. In this case, both studies seem to suggest that the TECE was almost equally prominent in France and Germany, although French engagement with the ratification process appears to have been higher than in Germany, at least during parts of the 20042005 period. 
Commentators have noted that the intensity of the debate in the Netherlands was very modest compared to in France (Qvortrup, 2006, p.92). This may be explained by the fact that, from the start, the issue was more controversial in France than in the Netherlands. At first the French socialists - and Prime Minister Lionel Jospin in particular - were reluctant to engage in the debate and critical of Chirac's proposals, which were seen as interfering with the French EU Presidency in the second half of 2000. Later, the Socialists were divided over whether or not to support the TECE. As we will see later, the debate going on in France was reported in the Dutch and German public spheres.

Compared to Dutch newspapers, the German dailies were more engaged with the debate. One important reason for this may be that Germany's chief politicians, Minister of Foreign Affairs Fischer (Greens) and Chancellor Schröder (SPD), played an important role in triggering the debate and setting the agenda. Another reason may be the special role of the Basic Law in the German consciousness, a point raised in the previous chapter. This may explain the enthusiasm for - or, in more moderate terms, the positive attitude towards - the idea of a European constitution (at least among politicians), but also the seemingly elaborate attention paid to it in German newspapers.

Another explanation could be that the German papers have more correspondents in Brussels, which makes it easier to acquire the necessary information. Yet, Dutch newspapers are also relatively well represented, plus they also send journalists from the national HQ to Brussels (e.g. Kevin, 2003, p.127). Moreover, journalists in Brussels cooperate on a daily basis to find their way through the surplus of information, and to gain the most important facts and figures, which somewhat lessens the challenge of tracking down the right information (Kevin, 2007).

Even if we argued that German newspapers provide more detailed coverage of political affairs in general, the question would remain whether they consider EU affairs to be interesting enough to cover in a detailed way. Moreover, this does not explain why Frankfurter Rundschau had less coverage than NRC Handelsblad, or why the debate was over-represented in Frankfurter Allgemeine Zeitung. That the latter covered the debate to such an extent may be owing to the fact that it is regularly targeted by key spokespersons in Brussels and is a source for other media in Germany, even other Member States. It should be noted, however, that the same has been claimed of Süddeutsche Zeitung (Balčytienè et al, 2007, pp.157-8; Interview 15).

While Figure 4 provides data about the total coverage of the debate on the EU's future during the constructed weeks, Figure 5 is interesting in terms of the actual policy process and its representation in the media, because it focuses on the coverage per year. Though the Convention drafted many of its conclusions during the (plenary) sessions in 2003, hearings engaging various interests and stakeholders, and many important discussions in 2002, largely determined the direction for the 
rest of the process (Becker \& Leiße, 2005; Norman, 2003). Yet, judging from Figure 5 the year 2002 seems to have been the least important in terms of actual coverage by the six newspapers. Even Frankfurter Allgemeine Zeitung showed a clear decrease in attention. This seemingly moderate attention for the Convention's work (compared to the IGC and the ratification period) has also been observed, first, by Vetters, Jentges and Trenz (2009, pp.417-8) in their study of media debates in France and Germany between December 2001 and August 2005, but which paid special attention to the ratification process in 2004 and 2005; and, second, by Hajo Boomgaarden et al (2010, p.516) in their study of exogenous events relating to EU news coverage.

Figure 5: Annual Number of Articles per Newspaper

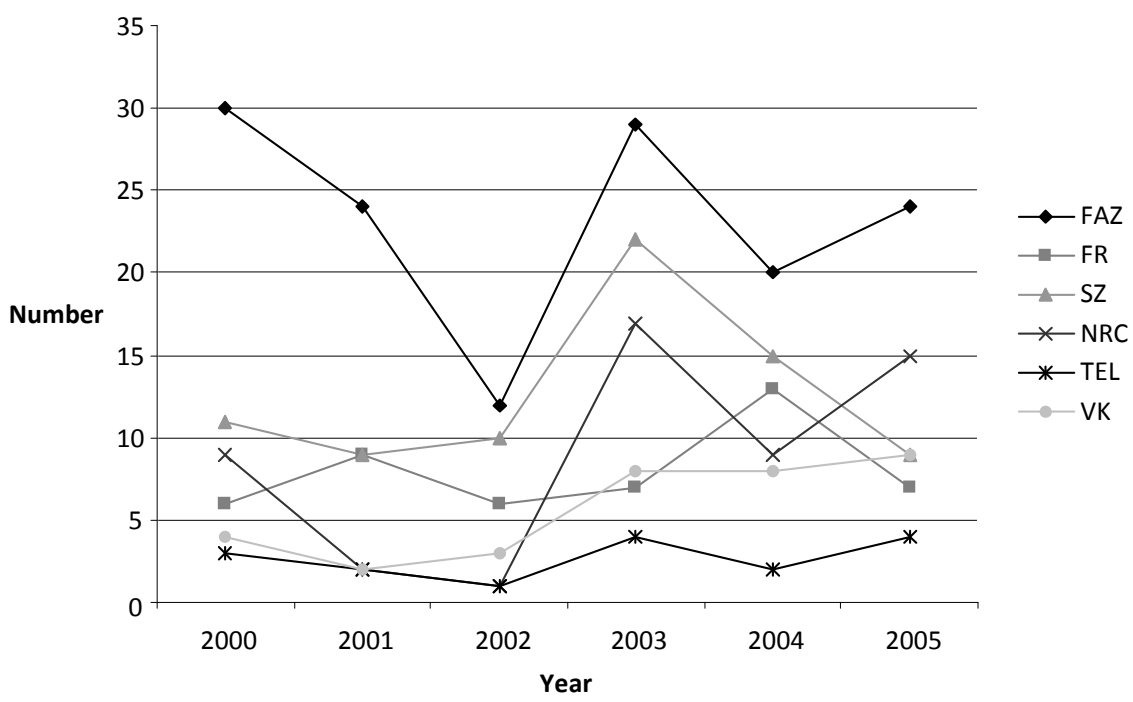

In 2003, the year in which the IGC started, but during which the Member States failed to reach an agreement on the TECE, the number of articles increased again. The year, or rather, half-year, during which the treaty was rejected by the Dutch and French also showed an increase in coverage, if mostly in the Netherlands. This can probably be explained by the attention paid to the Dutch referendum. In fact, other studies regarding newspaper coverage in the Netherlands (Kleinnijenhuis, Takens \& Van Atteveldt, 2005, p.126), in France and Germany (Vetters, Jentges \& Trenz, 2009), and in France and a number of other Member States (Gaisbauer, 2009), also suggest that the referendums resulted in an increase in media coverage, even in Member States that did not hold a referendum (cf. Boomgaarden et al, 2010 , p.516). A rough search for articles concerning some of the events outlined in Box 2 also suggested that key moments received more attention, ranging from just a couple of articles regarding Fischer's speech ( 3 in the Dutch papers, 19 in the Ger- 
man ones) to hundreds of articles on the referendums in France and the Netherlands in both public spheres (398 in the Dutch papers, 286 in the German ones). ${ }^{127}$ In their study of news coverage of the Constitutional Treaty, Martin Gleissner and Claes de Vreese (2005, p.237) also argue that key political events played an important role.

How may we explain the seemingly limited attention to the work of the Convention? Thomas Christiansen and Christine Reh (2009, pp.241-2) note that the Convention did not at first appear to be that different to earlier reflection groups. It was

making proposals to an IGC which was itself to have the final word on any treaty change. Unsuspecting observers in the member states might therefore have been forgiven if they were to consider this new body as nothing more than a 'talking shop', and one which was unlikely to produce much of substance given its diverse membership.

Yet, they also note that the Convention almost immediately considered itself a 'Constitutional Assembly' (p.78), as already noted above. There are other indications that the Convention perceived itself to be increasingly influential. For example, Peter Norman $(2003$, p.51) refers to the rising numbers of advisors, lobbyists, diplomats, officials and others (including journalists) who came to populate the corridors of Brussels' institutions. He also notes an early move towards a document not proposing various options for reform, but one single proposal in the guise of a Constitutional Treaty (ibid, p.56). Peter Becker and Olaf Leiße (2005, p.89) highlight the dynamic and uplifting atmosphere during the Convention's opening session on 28 February 2002, when conventioneers displayed their delight at being able to take part in shaping Europe's future: "Alle Beteiligten schienen sich zu freuen, an etwas Neuem zu partizipieren, ausgewählt worden zu sein, die Zukunft Europas mitgestalten zu können." That many people were unaware of the existence and tasks of the Convention (e.g. Lucarelli \& Radaelli, 2004, p.13) might be explained by the moderate attention paid to this body in the national public spheres.

Coverage of the process seems to have only increased when the Member States stepped in. Apparently the negotiations in the IGC (though not represented in an elaborate way either) were valued as more important. As a result, much of the debate and drafting process actually took place outside the public limelight, even though the various meetings in the Convention were open to the public. The wider public debate (if any) took place mostly at the time of ratification, not during the drafting of the document itself. The time lag between the agreement on the TECE

\footnotetext{
${ }^{127}$ This rough search focused on the weeks around the key moments, for example 9-15 May in case of Fischer's speech and 26 May-4 June in case of the Dutch and French referendums. Articles were searched using some more specific search terms than the ones mentioned in Box 3 (e.g. 'Fischer'). The results of the searches were not tidied up according to the criteria used for the constructed weeks, nor were the articles read closely. The rough numbers merely serve as an indication.
} 
and the actual referendum debates in, consecutively, Spain, France, the Netherlands and Luxembourg, is another illustration of such a mismatch in timing. Consequently, we may question the extent to which the process was actually more democratic than for previous treaty revisions.

\section{The Debate in the German Public Sphere}

Of the German newspapers, Frankfurter Rundschau appears to have paid the least attention to the future of Europe, whereas Frankfurter Allgemeine Zeitung clearly provides most coverage. Together, all three newspapers presented insights into the debate, referring to various issues and actors. They suggest that Germany was engaged in the debate from day one onwards. On 16 June 2000 Süddeutsche Zeitung wrote that the debate initiated by Fischer seemed to be really taking off, with Fischer identified as the main initiator of the debate; subsequent reactions from other politicians did not go unnoticed either. These included responses from EU leaders (for example, Luxembourg's Prime Minister Jean-Claude Juncker), (former) Commission members (for instance, former President Jacques Delors) and the German opposition (such as CDU MP Wolfgang Schäuble). In Frankfurter Allgemeine Zeitung in particular we find many references to what newspapers in other Member States wrote about the debate, both in the initial phases and during the Convention negotiations and the IGC. German politicians were seen as being generally supportive of the idea to draft a European Constitution. Even opposition parties applauded Fischer's call for a debate about Europe's finalité (see, also: Vetters, Jentgens \& Trenz, 2009, p.419). CDU MP Wolfgang Schäuble (FAZ 08.06.00) argued that this debate should not be postponed until after the Nice IGC, but should start as soon as possible. In fact, Frankfurter Allgemeine Zeitung (04.12.01) noted that the position of CDU/CSU was similar to that of the SPD on important issues, such as the extension of majority voting in the Council, the election of the Commission President by the EP and budgetary rights for Council and EP.

The German newspapers wrote that the Nice Treaty was widely perceived as being inadequate to allow an enlarged Union to function, hence the Member States' decision to set up a Convention led by Giscard d'Estaing. The dailies explained that the Convention would draft proposals for reform, to be subsequently discussed by the Member States in a new IGC. On the occasion of the ratification of the Nice Treaty by the Bundestag on 18 October 2001 most speakers looked ahead, towards the upcoming Convention and the ensuing reform process. The mood was exemplified by FDP MP Haussmann who called the Nice Treaty the worst European treaty ever to have been put forward for ratification (FAZ 19.10.01; FR 19.10.01). According to the newspapers, the debates in the Convention focussed on a number of topics, in particular, the division of competences, the tasks of the EU and the power balance between the institutions (e.g. FAZ 11.12.2002). We also read about the 
hearings of civil society organisations and the gathering of the Youth Convention. On Thursday 31 October 2002 Frankfurter Rundschau even presented the full skeleton of the first draft of the Constitution.

Generally, although all six newspapers conveyed the image that the debate about the EU's future was controversial in many Member States - such as Britain and France, but also the Czech Republic and the Netherlands - the reader almost gets the impression that it was not at all controversial in Germany, which is partly true, as we have seen above. Still, it was acknowledged that the Convention's job would be a challenging one. For example, Süddeutsche Zeitung (19.10.01) referred to Commission President Romano Prodi who believed that the most important issues might be discussed elsewhere. Frankfurter Allgemeine Zeitung (02.03.02) referred to Swiss newspaper Neue Zürcher Zeitung which wrote that national interests would no doubt be decisive, because the Convention could propose, but the EU leaders would ultimately decide. Moreover, reluctance concerning the whole idea of a European Constitution was not exclusive to the Netherlands (see below), but also surfaced in Germany. For example, in a commentary in Süddeutsche Zeitung (22.09.00) the author suggested that, instead of projecting visions about Europe's future, European politicians should focus on tackling current issues such as rising oil prices.

The topics discussed in the newspapers included the introduction of a European Council President, the extension and reform of majority voting, the division of competences, a possible reference to Christianity, the EU Minister of Foreign Affairs, defence cooperation and the role of the Euro-group and the ECB. It was noted that these reforms are necessary for EU enlargement, but other issues were linked to the debate too, including the war against terrorism and the rifts over Iraq. According to Carina Sprungk and Sabine Von Oppeln (2005), the German debate covered broader issues, in particular the democratic nature of the EU, and its external borders. The first issue particularly focussed on the apparent loss of influence by the Bundestag and the Länder parliaments, the second on Turkey's possible membership of the EU. These issues did surface in all articles, but where they did it was typically in more general terms, such as the need to decrease the gap between the EU institutions and the citizens, and prepare the Union for enlargement (though the Turkish membership bid did not go unnoticed either; e.g. FR 27.04.05). Not surprisingly, one of the most prominent issues was the division of institutional competences.

In the newspaper articles analysed, France and Germany emerged as the main advocates of the draft Constitution, supporting its adoption without changes. Poland and Spain were the main opponents, their discontent mainly being concerned with the new QMV procedures. The newspapers explained that the election of a new Spanish government offered a way out of the deadlock that emerged after the EU leaders failed to agree on the Constitution in late 2003. After the EU leaders reached agreement in mid-2004, the ratification process received particular atten- 
tion in the newspapers, especially regarding the issue of prospective British and French referendums. Frankfurter Allgemeine Zeitung (29.01.2005) noted that not only were EU citizens barely aware of the Convention, they also knew little about the contents of the Constitution. Immediately after Tony Blair's announcement in April 2004, the British referendum was identified as a considerable challenge to ratification. The French referendum was not initially seen as being problematic. The newspapers also note that some German parties (notably CSU and FDP) also called for a referendum, but the government disagreed, as did the CDU. The Dutch referendum was not discussed, but this impression may be due to the selection.

The newspapers identified Lithuania as the first country to ratify the Constitution following parliamentary approval. Social reforms had a negative impact on the French vote. Schröder directly intervened in the French debate by calling upon the French to vote 'yes', expressing his hope that early approval by the Bundestag would set an example - an editorial in Süddeutsche Zeitung (27.04.2005) commented that he should feel lucky there was to be no German referendum. Possible ways out of the deadlock that followed the rejection of the Constitution were mentioned too, in particular, the proposal by new French Prime Minister Dominique De Villepin for a Franco-German Union. Other reflections included those of Albrecht Fürst zu Castell-Castell, who argued that the rejection of the Constitution was no surprise since it did not refer to God, hence it was not blessed (FAZ 10.06.05).

\section{The Debate in the Dutch Public Sphere}

Taken together the Dutch newspapers presented a fairly good overview of the debate, yet there were clear differences between the three dailies. De Telegraaf seems to have paid the least attention to it and only presented a rather incomplete picture of the process; even the Dutch position was not clear. In de Volkskrant we read more about issues and process, though the positions of different actors were not always clear. Compared to the other two newspapers NRC Handelsblad was much more detailed in reporting how the discussions were evolving.

Whereas the debate about Europe's future seems to have been picked up immediately in the German papers, the Dutch newspapers seem to suggest that the debate was initially looked at with some disdain in the Netherlands. On 8 June 2000 De Telegraaf noted that it did not yet appear to be time for a more comprehensive debate about Europe's future, while NRC Handelsblad did acknowledge its importance (e.g. NRC 16.06.00). Even so, initial proposals to reform the EU (and the subsequent reactions) from prominent (inter)national politics came to the fore, including those made by Fischer, Chirac, Blair (together with Spanish Prime Minister Aznar), Belgian Prime Minister Verhofstadt and the Dutch State-Secretary for European Affairs, Dick Benschop (e.g. NRC 16.06.2000; TEL 08.06.00). The Dutch seemed sceptical about the whole idea. Still, the unsatisfactory Nice Treaty and the Irish 'no' 
to the latter were seen as challenges: more needed to be done to prepare for enlargement.

The newspapers explained that a Convention of 105 politicians from the Member States, the accession states and the institutions, led by former French President Valéry Giscard d'Estaing, had been set up to consider new proposals for reform. The core issue seemed to be whether the Member States wanted 'more or less Europe' (VK 02.03.02). Notwithstanding the mention of a Convention set up to draft plans to reform the Union, in order to prepare it for enlargement, we learn less about what actually went on in this forum and which topics were discussed, than in the German newspapers. Topics that were mentioned include: plans to allow for more majority voting; more intensive cooperation by smaller groups in foreign and defence policy; the possible establishment of a European Minister of Foreign Affairs; the proposed reference to Europe's alleged Judeo-Christian tradition; and the weighting of the votes in the Council of Ministers. Poland and Spain were the main opponents of a reweighting of the votes, but it was not explained why exactly (NRC 19.11.03; VK 21.04.04). It was also not always clear where the Dutch parties stood on these issues.

Even after the Convention had been established and started its work, there remained a certain lack of enthusiasm in the Dutch media debate. This was forcefully reflected by an article by Brussels-correspondent Geert-Jan Bogaerts in de Volkskrant of 31 October 2002. Entitled 'Europe's unimaginable constitution will become reality after all' ${ }^{128}$ the article commented on Giscard's presentation of the draft skeleton of the future Constitution and provided an overview of some of the more controversial issues, by pointing at the different positions of the three big Member States and the Netherlands. It noted that the Dutch government had replaced its representative and that Germany had even sent Fischer - and argued that this signalled Germany's only recent engagement, which was certainly not the impression conveyed in the German debate ${ }^{129}$ - which should be seen as a signal that the debate about the EU's future was a relevant exercise after all. Bogaerts wrote:

Just the mere fact that the idea of a Europe-wide 'constitution' is now seriously being discussed and will probably also be realised, was unimaginable at the beginning of the Convention in February. ${ }^{130}$

\footnotetext{
${ }^{128}$ 'Europa's ondenkbare grondwet komt er toch.' (Own translation.)

${ }^{129}$ Bogaert's assertion also contrasts with those of one well-informed observer of the Convention's procedures, Norman (2003, pp.155-6), who has argued that German representatives played an important role in the Convention. Other scholars do however assert that the German government initially also underestimated the Convention's impact (Möller, 2008, p.148; Peters, 2004, pp. 282-3).

${ }^{130}$ Alleen al het feit dat het idee van een Europawijde 'grondwet' nu serieus wordt besproken en waarschijnlijk ook wordt gerealiseerd, was aan het begin van de Conventie, in februari, ondenkbaar. (Own translation.)
} 
Throughout the debate other issues became increasingly intertwined with the reform discussion, especially the clash over the Stability and Growth Pact. Dutch Finance Minister Zalm was noted to have expressed concerns that a dismantling of the pact also questioned the value of a new European Constitution and might increase the anti-European mood in the Netherlands with potentially negative consequences for a possible referendum (e.g. NRC 19.11.03; TEL 25.11.2003). The opening up of the European market to Chinese textiles was identified as an important issue in the French debate (NRC 27.04.05; VK 27.04.05).

Dutch newspapers wrote how EU leaders had failed to agree on the Constitution at the end of 2003 and that the Irish Presidency had been working hard to foster agreement in the first half of 2004. At about the same time, several Member States announced that they would be organising referendums on the new treaty. Germany would opt for the parliamentary route and Lithuania was the first country to ratify the constitution, after parliamentary approval; the Dutch and the French would organise a referendum. Tony Blair's announcement of a British referendum on 20 April 2004 was perceived as a serious blow to the chances of ratifying the Constitution as all Member States would have to agree. Besides the British, NRC Handelsblad (27.04.2005) identified the Czechs as potential no-voters. In the run up to the Dutch and French referendums de Volkskrant's Brussels-based correspondent Bert Lanting (VK 27.04.2005) even noted that the European Commission had become more reluctant to propose new legislation, in order to avoid a negative effect on the referendums.

After the 'no' votes in France and the Netherlands, the EU appeared to have found itself in a crisis. The 'yes' campaign was criticised and various solutions were proposed, including a 'Europe lite' (VK 10.06.2005) and a proposal to split up the treaty (NRC 10.06.2005). U2 singer Bono was quoted to have said that there were more pressing problems to be solved, such as hunger in Africa (TEL 10.06.05; VK 10.06.2005).

\section{The Three Dimensions}

In both country cases the debate about the future of Europe, as it appeared in the public spheres, represented a partial mismatch with the actual discussions in the established fora, especially the Convention. For one, this is illustrated by the moderate attention paid to the discussions in 2002, the year in which the Convention did much of the groundwork, and some of the key innovations were introduced, even sometimes fiercely debated. Next to this temporal mismatch, the previous section also hinted at a content-related mismatch, in terms of the development of the process, involved actors and rationale behind the whole exercise. 
The following sections offer a more detailed analysis and discussion of the debate as reported in the newspapers, by focussing on the three content dimensions. Judging from the previous analysis of the Dutch and German debates, one might be tempted to assume that the German press was more detailed across all dimensions, but closer examination may well reveal this not to be the case.

\section{The Issue Dimension}

All six papers provided information about issues linked to the debate, and their background, sometimes directly, sometimes by means of an actor in the debate either directly, for example, through opinion pieces, or indirectly by the paper referring to statements expressed by an actor. In contrast, Table 2 shows that the relevance of yet another treaty reform, and need for a new treaty, were mentioned infrequently and actually in less than half the articles, whereas discussions about the role of the EU were limited to specific policies, such as foreign affairs, or specific issues, such as whether or not to include a reference to Europe's supposedly JudeoChristian heritage. These sporadic references to the role the EU does or should play mostly occurred ahead of the actual ratification process; in other words, before the Member States agreed on the TECE. Thereafter, the rationale behind the new treaty became more important, though without being referred to continuously. Overall, there seems to have been little discussion about the need to introduce a new treaty, to reform existing policies, or to even introduce new ones. The reform process was virtually presented as a fait accompli, not as something open for discussion.

Table 2: The Issue Dimension in Figures

\begin{tabular}{lcccc}
\hline & $\begin{array}{c}\text { Which issues are at } \\
\text { stake? }\end{array}$ & $\begin{array}{c}\text { What is the back- } \\
\text { ground/ context? }\end{array}$ & $\begin{array}{c}\text { What role should the } \\
\text { EU play? }\end{array}$ & $\begin{array}{c}\text { What is the relevance } \\
\text { of the policy? }\end{array}$ \\
\hline FAZ (139) & 139 & 139 & 25 & 45 \\
\hline FR (48) & 48 & 48 & 11 & 18 \\
\hline SZ (76) & 76 & 76 & 12 & 31 \\
\hline NRC (53) & 53 & 53 & 9 & 26 \\
\hline TEL (16) & 16 & 16 & 2 & 7 \\
\hline VK (34) & 34 & 34 & 6 & 13 \\
\hline
\end{tabular}

NB This table simply records whether information appears in an article at all. In a few cases an article contains more than one piece of information.

The debate about Europe's future was discussed in articles which were first and foremost concerned with this topic, but it also regularly appeared as a secondary issue in articles about EU-related issues, such as the Danish 'no' to the Euro, and even sporadically in articles about very different issues like the impact of rules set by the WTO on culture (FAZ 14.02.03), or rights and justice in Germany (SZ 
19.08.03). In the case of NRC Handelsblad about half the articles did not provide a focussed discussion of the debate, but referred to it in another way. This means that the background against which the debate about Europe's future was mentioned may have actually been something unrelated altogether.

Even though EU news is usually not abundant, these kinds of article nonetheless suggest the importance of the EU in general, and the debate about its future in particular, was recognised. It also shows that the debate certainly was not seen as taking place in a void and vice versa; the debate was seen to have an effect on other issues as well. This was also recognised explicitly in an article about the controversy over the Stability and Growth Pact in De Telegraaf of 18 October 2003. Here it was observed that as 'months of tough negotiations' on the Constitution still laid ahead other issues had become important and political bargaining had become more significant:

Zeker nu de komende maanden hard onderhandeld moet worden over de Europese grondwet zijn andere kwesties ineens weer stukken belangrijker en wordt er politiek volop gedeald.

The importance of other issues, events, and developments, however, went beyond the mere acknowledgement that the debate on the Union's future was not taking place in isolation. They were also raised to question the whole constitutional exercise. This was most prominent with regard to the war against Iraq and the discussions about the Stability and Growth Pact. The war in Iraq was a recurring issue in both debates, dividing the Member States as well as the accession countries. Consequently, Europe's inability to act on the international stage was considered to be a problem and it was doubted whether the novelties suggested by the Convention and included in the TECE would actually make a difference (e.g. SZ 05.09.03; VK 17.02.03). NRC Handelsblad (17.02.03) reported that even prominent conventioneers such as Convention vice-President and former Belgian Prime Minister, Jean-Luc Dehaene, were unconvinced. He was quoted as saying that institutions could only create the means to draft a common policy, but what was really required was political will:

\footnotetext{
“Een politieke wil kan niet door decreten ontstaan. Wij kunnen hoogstens structuren, instellingen opzetten, die het mogelijk maken om een gemeenschappelijk buitenlands beleid te voeren als de politieke wil bestaat."
}

In the Dutch debate the breach of the Stability and Growth Pact by France and Germany and the subsequent half-hearted response by the European Commission and most other Member States were seen as highly problematic for the future of the integration project. This issue surfaced in the German newspapers, but was not really linked to the overall importance and credibility of the debate about Europe's 
future, except in Frankfurter Allgemeine Zeitung (e.g. FAZ 05.03.03). In reality the debate over the Stability and Growth Pact was formally unrelated to the debate about the new treaty. Agreement to adapt the pact was negotiated in the Economics and Financial Affairs Council (ECOFIN) and agreed by the European Council in March 2005 (Nugent, 2006, pp.364-5). Nevertheless, in the Dutch public sphere both issues were considered to be intimately tied together: would it make sense to approve a new round of treaty reform if existing accords could be violated without any consequences (e.g. NRC 19.11.2003; TEL 25.11.2003; VK 19.11.2003)? As mentioned in the previous chapter, the Dutch and Germans were always in favour of stringent EMU criteria, but Chancellor Schröder deviated from this position. This may explain why the issue seems to have been less sensitive in the German debate about the EU's future.

EU enlargement was an important reoccurring theme in both public spheres. It was generally felt that the existing rules and procedures would not allow for efficient and effective decision-making in a larger EU (e.g. FAZ 03.07.00; FR 16.06.01; NRC 18.12.03; SZ 05.09.03; TEL 10.09.01; VK 02.03.02). It was commonly noted that the EU needed to be reformed to cope with future challenges, especially the 2004 enlargement that was set to significantly increase the number of Member States. Despite the fact that the rationale behind the whole exercise was rarely mentioned, the prospect of a Union of more than 25 Member States was typically raised in both public spheres as the reason behind a new round of treaty reform. Previous revisions (and in particular the Nice Treaty) were considered inadequate for preparing the Union for this challenge. Still, not always was it explained what the consequences of not reforming the Union would be. Generally, it was assumed that it would render the EU ungovernable, but was this really the case, and why? This question was discussed in academic circles (e.g. Best, Christiansen \& Settembri, 2008; Wallace, 2007) but did not return to appear in the public debates.

Several articles concerned the imperative for EU reform, in order to improve effectiveness, but also to raise its democratic profile. The perceived distance between the EU and its citizens was a theme that occurred implicitly and explicitly in both public spheres. It was most apparent in articles about the Danish rejection of the Euro and the Irish rejection of the Nice Treaty, events presented as the expression of a more widespread feeling of uncertainty about the EU. In the press it wasn't initially really a prominent theme, despite the occasional statement that a new treaty was needed to make the EU more democratic by: for example, Verhofstadt argued for a bi-cameral parliamentary system (e.g. NRC 22.09.00), and Juncker claimed that the debate about the future of the EU should not only be about a reform of institutions and procedures, but about the inclusion of the citizens in the policy process, and properly conveying what the EU is all about (FAZ 17.05.01). As soon as the Member States began to announce their referendums, the citizen-EU gap became increasingly apparent, with recognition in the newspapers that the 
referendums might result in a rejection of the new treaty (e.g. VK 28.06.04) - a more detailed discussion of this will follow below.

EU leaders were discredited for not taking legitimacy problems seriously enough. The main exception was Irish Prime Minister, Bertie Ahern, who framed the Irish 'no' to the Nice Treaty as a wider problem. In its coverage of the Irish rejection of the Nice and the subsequent EU Summit in Gothenburg, Frankfurter Rundschau (16.06.01) provided a clear illustration of this assessment. Its correspondent wrote that even though Ahern had tried to convey to his colleagues that the 'no' was not merely a marketing disaster, but an accurate reflection of the way citizens felt about the Union, other EU leaders did not want to listen to his message:

\begin{abstract}
Bertie Ahern gab sich zwar große Mühe, seinen Kollegen begreiflich zu machen, dass nicht nur Politschlamperei und unfähiges Marketing zum Abstimmungsdesaster geführt haben. Sondern dass dabei auch Ängste vor der Großorganisation EU, Unsicherheiten und die große Distanz zwischen dem Volk und der EU eine wichtige Rolle spielten. Dinge also, die nicht spezifisch irisch sind. Aber diese für einen amtierenden Politiker ungewöhnlich tiefen Einsichten, die der traumatischen Erfahrung des gescheiterten Referendums zu verdanken sind, trafen weitgehend auf taube Ohren.
\end{abstract}

Ahern's position may not have been taken onboard by his peers, but it did figure in the Dutch and German debates about the Irish rejection of the Nice Treaty. De Telegraaf (16.06.01) was the most outspoken, referring to a lack of trust - the result of decisions 'plotted' in Brussels that lacked transparency. The apparent gap between the European institutions and citizens was generally recognised; this could not simply be solved by better communication efforts, or even greater transparency. In fact, a commentary in Frankfurter Allgemeine Zeitung (16.06.01) warned that more transparency might have an adverse effect - transparency could mean citizens became more aware of the loss of national sovereignty that European integration entailed. ${ }^{131}$ As argued in the previous chapter, more transparency and communication may indeed not necessarily solve the EU's legitimacy problems.

When considering the attention paid to debates in other Member States, it becomes clear that the French debate was prominent in both the Dutch and German public sphere. As noted previously, the French socialists were initially reluctant to take part in the debate and eventually were even divided about how best to assess the TECE. Reactions to President Chirac's vision on Europe were cautious; various members of the socialist government noted that its commitment lay with successfully concluding the ongoing Nice IGC (SZ 03.07.00; TEL 03.07.00). As the discussion about the new treaty progressed and a new centre-right government came to power, the Socialists became divided over whether or not to support the European

\footnotetext{
${ }^{131}$ Incidentally, the idea that a new treaty might make the EU more democratic is never raised as a reason for reform in the selected FAZ-articles.
} 
Constitution, with some prominent party members promoting a positive stance and others a negative one (e.g. FR 01.12.04). In the run up to the French referendum on 29 May 2005, various issues were identified as being important, including the maiden flight of Airbus' A380 plane (a positive example of European cooperation; NRC 27.04.05) and the opening up of the European textile markets to Chinese goods (an example of Europe's neo-liberal policy which causes job losses in France: FAZ 27.04.05; VK 27.04.05).

In the press articles sampled, German attention to the Dutch referendum was nonexistent, as was Dutch attention to the German ratification debate and the option of a referendum. Fischer's contribution to the debate was acknowledged in the Netherlands (but not in de selected articles from de Volkskrant). NRC Handelsblad (13.05.03) even referred to the premature discussions in Germany about Fischer's possible move to Brussels to become Europe's first Foreign Affairs Minister (FAZ 13.05.03; FR 13.05.03; SZ 13.05.03).

Other topics taken up in both public spheres, in the context of the debate on Europe's future, were the Danish 'no' to the Euro (28 September 2000), the Irish rejection of the Nice Treaty (7 June 2001) and Tony Blair's U-turn on the British referendum (20 April 2004). There were also several distinct 'national' topics, such as the previously mentioned Stability and Growth Pact and the Kompetenzkatalog. In Germany, the division of competences between EU and Member States occurred regularly, whereas in the Netherlands it hardly ever occurred (for an exception, see: NRC 22.09.00). The division of competences between the institutions has long been an important topic in the German debate, in particular for the Länder (Hrbek, 2001, p.108; Hrbek, 2003; Jeffery, 2004), playing an important role in the run up to the Nice IGC (FR 08.06.00) and throughout the discussions about the new European Constitution. Now it was felt that the moment had arrived to really push forward on this issue (e.g. FAZ 04.12.2001; FR 13.07.2002; SZ 13.05.03).

Beyond the common topics and distinctly 'national' topics discussed, various issues were reported on in just one of the public spheres, while certain issues were only dealt with in one newspaper. Besides, the degree to which many topics were discussed varied greatly, as did the moment at which they were discussed. This was, for example, the case for the reform of the voting system, the future of Europe's foreign policy and the need for an explicit reference to the Union's supposed Christian roots. In addition, the newspapers rarely commented on the various positions put forward by the Member States in the Convention, and later on during the IGC. Often they merely stated that a particular politician was in favour or against something, but without mentioning the actual reason why.

In De Telegraaf 'personnel affairs', such as former Prime Minister Wim Kok not being appointed chair of the Convention (TEL 10.09.01), or the resignation of Hans van Mierlo as Dutch government representative in the Convention (TEL 27.09.02), offered an opportunity to discuss the EU's future, often with a more national twist - 
showing a rare overview of the diverging opinions between the Dutch parties as to the direction to take with Europe. ${ }^{132}$ In de Volkskrant there was also attention paid to national issues, but this was more focused on controversial themes than on individuals. This included Prime Minister Balkenende's support for the inclusion of a reference to Europe's Judeo-Christian heritage in the Constitution (VK 18.10.03). With the exception of its strong focus on the Stability and Growth Pact, attention to national issues was more limited in NRC Handelsblad compared to the other two Dutch newspapers analysed. It also paid more attention to discussions in other Member States and contained more articles about the contributions to the debate by important politicians such as Blair and Chirac. On 16 June 2000 commentator Sampiemon even provided an overview of the debate so far, based on contributions to various international newspaper, but without any reference to the Dutch position. ${ }^{133}$

In general we were less able to read about the positions of Dutch parties in the Dutch public sphere, than about German parties in the German public sphere especially the position of the CDU/CSU, which got plenty of media attention. CDU/CSU politicians had some specific demands, but generally supported the reform process, (e.g. FAZ 03.04.04; FR 13.05.03). In an opinion article in Frankfurter Allgemeine Zeitung, CDU MP Wolfgang Schäuble (08.06.00) even argued that many of Fischer's ideas were based on ideas previously put forward by the CDU/CSU and included in their election programme:

Joschka Fischer hat eine Rede zur Europapolitik gehalten. Neu war darin nichts wirklich.

The position of CDU/CSU also figured in Süddeutsche Zeitung (e.g. 13.05.03), but less prominently than in the other two German dailies. In fact, considerable attention was paid to what was happening in Brussels, just as in Frankfurter Allgemeine Zeitung. In Frankfurter Allgemeine Zeitung specific EU events such as the (in)formal meetings of the EU leaders or Foreign Affairs Ministers were sometimes discussed in several articles, unlike in the other five newspapers. This again suggests that this newspaper presented the most extensive coverage of all the six newspapers.

\footnotetext{
${ }^{132}$ In their analysis of the editorials of Dutch newspapers regarding a number of policy fields De Beus and Mak (2009, pp.118-9) also found that De Telegraaf focussed most on national affairs. For example, 49\% of the latter paper's editorials focussed purely on national issues, as compared to $37 \%$ of editorials published by De Volkskrant. Note that their study did not include NRC Handelsblad.

133 Incidentally, Sampiemon applauded the fact that the debate took place in public. The need for more public debate, for a European 'Öffentlichkeit', was addressed by MEPs Daniel Cohn-Bendit and François Bayrou (16.06.00) and by FDP parliamentary party leader Wolfgang Gerhardt (21.04.04) in Süddeutsche Zeitung, but also in an article about referendums and European integration in Frankfurter Rundschau (19.08.03).
} 


\section{The Process Dimension}

Two general observations are noticeable regarding the process dimension. First, previous episodes in the debates got less attention than current affairs and future events. Second, it was not always clear which actors or institutions were meant to take decisions and which procedures they were meant to follow. Table 3 displays the number of articles containing information regarding any element of the process dimension.

Table 3: The Process Dimension in Figures

\begin{tabular}{lcccc}
\hline & $\begin{array}{c}\text { What was the state of } \\
\text { affairs in the past? }\end{array}$ & $\begin{array}{c}\text { What is the current } \\
\text { state of affairs? }\end{array}$ & $\begin{array}{c}\text { What will happen } \\
\text { next? }\end{array}$ & $\begin{array}{c}\text { How is the policy } \\
\text { process shaped? }\end{array}$ \\
\hline FAZ (139) & 45 & 84 & 56 & 93 \\
\hline FR (48) & 13 & 27 & 23 & 27 \\
\hline SZ (76) & 28 & 49 & 34 & 55 \\
\hline TEL (16) & 5 & 14 & 10 & 11 \\
\hline VK (34) & 9 & 18 & 19 & 25 \\
\hline NRC (53) & 21 & 32 & 23 & 40 \\
\hline
\end{tabular}

NB In some cases articles contained more than one reference to the past, present and future, and/or the decision-making process. This table only records whether such pieces of information appeared in an article at all.

Sometimes articles did not refer to any temporal dimension, not even to the current state of affairs. This may be explained partly by the fact that the debate over Europe's future was sometimes of secondary importance in an article which, as has been noted previously, was quite often the case. Sometimes references to specific events remained unclear, such as to Fischer's speech (without explaining what he actually argued) or to Biarritz and Nice (FAZ 30.09.00) when it was not explained what would actually happen there on a practical level. Four newspapers contained more references to the decision-making process than to any of the three temporal dimensions. Nevertheless, the information provided on decision-making was often incorrect, incomplete or implicit.

Since media are in the business of providing news (a marketable commodity) it may not come as a huge surprise that newspapers predominantly focused on current affairs. Yet, some issues are difficult to understand without providing an insight into which events, decisions and procedures had led up to the current situation. Sometimes this was done, for instance, by pointing at the indecisive Amsterdam Treaty and the equally indecisive Nice Treaty. For example, on 8 June 2000 De Telegraaf referred to the 'loose ends' of the Amsterdam Treaty of 1996: the size of the Commission, the extension of majority voting and the voting weights of the Member States. Frankfurter Allgemeine Zeitung (03.07.00) included an article on 'the 
road to Nice' ('Weg nach Nizza'), which refers to the 1957 Treaties of Rome and every major treaty reform since. An article on the same day referred to the Amsterdam 'leftovers'. One could argue that just a single reference to the past would suffice, but considering that most people have little insight into EU affairs and the history of European integration, it may be that (each time) readers need to recap and grasp the background to the story. In fact, most references to the past referred to the recent past, such as to the rejection of the Nice Treaty by the Irish, or merely the current or previous treaty change, be it Amsterdam or Nice - in other words, not to other arguably more important treaty reform, such as the Maastricht Treaty.

Although references to current affairs were certainly more abundant, they were not necessarily clear at all times, such as regarding the current work of the Convention - but what work, which discussions? This ambiguity was most apparent when the EU's future was not the core topic of an article. If issues were topical, for example, Blair's announcement of the British referendum, then more details were presented. There was a similar lack of detail when it came to the next step in the policy process, though this may partly be explained by the fact that these steps (including dates) were not yet known to most actors involved. Clearly, it was difficult to predict when EU leaders would reach agreement, if at all. It was often reported that 'months of tough negotiations' (TEL 18.10.03) still lay ahead and while referendums were announced, the exact timing was much contested.

The elusiveness of the various procedures throughout the policy process was apparent at several stages. While it was clear that the agenda was set by Fischer's Humboldt speech and the ensuing reactions by other politicians, information about the policy-shaping phase was more ambiguous. In fact, it was sometimes suggested that bodies other than those tasked to act and decide would have the final say. As noted previously, the Convention was asked to lay down the foundations for a new treaty. Its proposals would then be discussed and decided upon in a traditional IGC. This was the gist of an article in Süddeutsche Zeitung (10.09.01; cf. 19.10.01), which, though mainly concerned with the Middle East peace process, noted that according to the Belgian Presidency a majority of Member States was in favour of setting up a Convention in order to prepare a new round of reforms. The article noted that so far treaties had only been negotiated and decided by governments during summits, before being put to parliament for ratification.

The unclear allocation of responsibilities was an important problem in both public spheres; readers were presented with a skewed image of the policy process. While all information taken together provided a more or less accurate overview of who did (or should have done) what, it is clear that throughout time there was a certain ambiguity as to the exact role of the Convention - does it decide, or just propose? This ambiguity was reflected in an article about the start of the Convention in de Volkskrant (02.03.02). On the one hand, this article claimed that the Convention had to succeed where government leaders had failed: to lay the founda- 
tions for an enlarged Europe that would be more democratic and more effective. This suggests that the Convention would indeed decide. On the other hand the article noted that the Convention would be 'putting forward ideas', but without clarifying the status of those ideas or who exactly would decide on them. This ambiguity was more prominent in the Dutch papers than the German ones, where it was more often noted that the Convention was drafting reform proposals. Nevertheless, it was also not always apparent here either who would subsequently decide on those proposals (e.g. SZ 26.06.02), and the Convention was often implicitly and explicitly accredited with more power than it actually had. For instance, when Frankfurter Rundschau (31.10.02) published the first draft skeleton of the Constitution, it wrote that the Convention had been established to reform the EU:

Der Konvent ist mit der Reform der EU beauftragt.

On 11 December 2002 Süddeutsche Zeitung wrote that the Convention had to finish what earlier governmental conferences had been unable to achieve: to prepare the EU for 25 and more members. This ambiguity remained throughout the lifetime of the Convention.

Moreover, with regard to the subsequent IGC - the first phase of the decisionmaking stage - it was not always clear who decides - the Member States, yes, but how? By (qualified) majority, informally by consensus, or formally by unanimity (e.g. SZ 13.05.03)? What exactly was an IGC anyway (e.g. FAZ 03.04.04)? It was usually reported that the Member States or EU leaders had reached an agreement of some kind (e.g. VK 06.07.04), which suggested consensus or unanimity, though this was rarely explicit. In a similar vain, it was often merely implicitly that the Member States would decide together, by referring to one country's position or that of several. Generally, the German newspapers more often referred to the IGC than the Dutch newspapers, except for NRC Handelsblad.

The precise nature of decision-making became more apparent as soon as discussions about the various referendums emerged, which were increasingly identified as being the key moments at which the decisions would be made. This was partly true, but the status of the referendums was not always clear and, of course, the majority of Member States would follow the parliamentary trajectory. It was, however, sometimes noted that ratification of the TECE needed the approval of all 25 Member States, which meant that one negative referendum outcome could halt the complete process (e.g. FAZ 12.11.04; NRC 21.04.04; TEL 21.04.04). In other cases, the status of a referendum, in terms of the overall (ratification) process, was not made crystal clear (e.g. TEL 25.11.03).

The process of ratification, in other words, the final phase of the decisionmaking stage in the policy-process, featured very prominently. In line with academic reflections about the influence of domestic issues on EU referendums and the cata- 
lyst effects of one (negative) referendum on another (e.g. Qvortrup, 2006; RobertsThomson, 2001), strategic issues played a very prominent role in the planning of referendums, as was reflected in the media. Should the Dutch referendum take place during spring instead of winter, to avoid citizens having to travel to the ballot box on slippery roads (VK 23.09.04)? Should the various referendums be coordinated so to convey their 'European character', as Dutch State Secretary for European Affairs Atzo Nicolaï argued (NRC 23.09.04)? There were attempts to coordinate the Dutch 'yes' campaign and produce a collective poster, but these were quite unsuccessful (NRC 27.04.05; VK 27.04.05). What about Blair's referendum U-turn? De Telegraaf (21.04.04; cf. FAZ 21.04.04; NRC 21.04.04) quoted an anonymous political analyst who argued that Blair's decision was a strategic one, aimed at making sure Europe would not become an issue during the forthcoming European and general elections. Frankfurter Allgemeine Zeitung (21.04.04) and NRC Handelsblad (21.04.04) recognised the role of the British tabloid press and media mogul Rubert Murdoch in this strategic game, illustrating Blair's (and his predecessors) precarious position when it came to European integration.

In both the Dutch and the German debate the prospect of a British referendum was seen as a serious blow to the chances of a European Constitution. Because of Blair's decision, the debate over a German referendum also intensified, with the FDP calling for a German referendum, and the CSU and Greens for a European-wide referendum (FAZ 21.04.04; FR 21.04.04; SZ 21.04.04). In Frankfurter Rundschau of 19 August 2003, the possibility of a German referendum is discussed both from a national and European perspective. The German government's reluctance about a popular vote - and the related arguments, including some which relate back to the establishment of modern-day Germany - were criticised by a commentator of Süddeutsche Zeitung (21.04.04), who argued that political fear of the citizens (masses) only exists when citizens are perceived to be too unintelligent, or when one is too idle to want to try to convince them. Yet, the commentator continued, the latter is indispensable for Europe:

Angst vor dem Volk muss Politik nur dann haben, wenn sie die Bürger für zu dumm hält oder wenn sie zu bequem ist, Überzeugungsarbeit zu leisten. Ohne solche Arbeit wird es Europa nicht geben.

These comments and debates concerning the various referendums show that it was clear in both public spheres what was at stake, certainly when taking into account previous, mixed experiences (cf. FR 19.08.03). An increasingly wary citizenry could put an end to the ratification process even before all Member States had had their say. Journalist Arie Elshout (VK 28.06.04) called the upcoming referendums an 'explosive element in the development of the EU'. And in De Telegraaf (21.04.04) Heather Grabbe of the London-based Centre for European Reform was quoted as 
saying that multiple referendums would denote the 'premature death of the EU Constitution'. Still, the nature of the various ratification procedures was not always clear. Some Member States would follow the parliamentary route, whereas others had opted for a referendum, but would these referendums be formally binding, or just consultative? And in case of the latter, could it still be de facto binding? Nonetheless, even if not often stated explicitly (for exceptions, see: FAZ 28.02.00; NRC 21.04.04), it was reported that only approval by all Member States would allow for the Constitutional Treaty to come into force. However, in advance of the French referendum, SPD MEP and former conventioneer, Klaus Hänsch, noted that a French 'non' would have a different political weight than that of, for example, a 'no' from Malta (FR 27.04.05). Previous experiences (the Danish 'Maastricht' referendums and the Irish 'Nice' referendums ${ }^{134}$ ) had indeed shown that, although all Member States are equal, some appear to be more equal than others.

While individually the six Dutch and German dailies provided a mixed picture of what was happening and who was responsible throughout the debate on the EU's future, together their general impression of events was fair. One may therefore argue that this represented an overview of how the issue was addressed in both public spheres. Still, when it comes to how the process and procedures were reported in the press, arguably it did not necessarily accurately reflect the way in which EU treaties in general, and the TECE in particular, were reformed in practice.

\section{The Actor Dimension}

The newspapers seemed to take their role as platforms for debate seriously. In both public spheres a variety of positions and actions of a whole set of different actors came to the fore. Thus, at first sight it appears they provided an extensive overview of the participants in the debate. Some articles mentioned as many as ten or more opinions including, not just political actors, but also other media and analysts, plus references to opinion polls (e.g. FAZ 03.07.00; FR 16.06.01; NRC 10.06.05; SZ 21.04.04; VK 31.10.02). At the beginning of the debate in particular this included the various visions on Europe's future by politicians such as Fischer, Juncker and Verhofstadt. As the debate proceeded, attention shifted first to the opinions aired in and about the Convention, and later to those of the Member States during the IGC, followed by opinions on the final version of the new treaty, and then the ratification process. Yet, even though the dailies referred to several actors and their positions, these positions were not always explained; in other words, why actors were in favour or against something did not always become clear.

A detailed look at the actor dimension provides more qualified conclusions (see Table 4). National and transnational actors were most prominent while suprana-

\footnotetext{
${ }^{134}$ And later of course again the Irish, in the context of the Lisbon Treaty.
} 
tional actors appear more often than non-EU actors. In fact, non-EU actors appear to have been virtually absent from the debate, with only the Pope's criticism on the absence of a reference to Europe's Christian roots from the Constitution's preamble, and American worries about a European defence policy appearing more than once. This may come as no surprise, since the debate about the EU's future is bound to attract predominantly EU actors from all kinds of levels, institutions and so on. In contrast, in his research regarding debates about the Turkish EU-bid Andreas Wimmel $(2004 ; 2005)$ found that non-EU actors also played an important role, with more than $27 \%$ of statements by British, French, German and EU actors aimed at American and Turkish actors. This too may be unsurprising given Turkey's strategic position as a NATO member and an important US ally, but it also shows that debates about EU affairs can and do attract non-EU actors.

Table 4: The Actor Dimension in Figures

\begin{tabular}{|c|c|c|c|c|c|}
\hline & National & Transnational & Supranational & Non-EU & Total \\
\hline FAZ & $58(27.10 \%)$ & $100(46.73 \%)$ & $53(24.77 \%)$ & $3(1.40 \%)$ & $214(100 \%)$ \\
\hline FR & 33 (29.46\%) & 55 (49.10\%) & 20 (17.86\%) & $4(3.57 \%)$ & $112(100 \%)$ \\
\hline$\overline{S Z}$ & $42(27.45 \%)$ & 75 (49.02\%) & 32 (20.92\%) & $4(2.61 \%)$ & $153(100 \%)$ \\
\hline NRC & 72 (43.90\%) & 65 (39.63\%) & 27 (16.46\%) & - & $164(100 \%)$ \\
\hline TEL & 17 (32.08\%) & 30 (56.60\%) & $5(10.50 \%)$ & 1 (1.89\%) & $53(100 \%)$ \\
\hline VK & 31 (38.27\%) & 38 (46.91\%) & $12(14.81 \%)$ & - & $81(100 \%)$ \\
\hline
\end{tabular}

NB To avoid recording actors multiple times, this table only mentions the totals per newspaper. Actors are only counted once, even when they occur more than once.

The examination of the actor dimension revealed two things. First, most actors involved in the debate were (individual) political leaders. Parliamentarians were sometimes also given a platform. Other media were mentioned quite regularly, but still only represented a fraction of the various actors, because they were often just the source of a story, and not presented as having their own opinion. Civil society representatives rarely took the stage - even politicians from the Länder were less prominent than expected. A second observation concerning the actor dimension is that most actors came from the Member States. Rather surprisingly, transnational actors (actors from other Member States) figured more prominently in the newspapers' coverage than Dutch politicians in the Dutch public sphere and German politicians in the German public sphere. Taken together, these two observations suggest that the debate was seen as one in which the Member States were the key actors (even if this was not always explicitly acknowledged in terms of the process dimension). With some exceptions, these were the big Member States: Britain, France and Germany. 
In general, supranational actors appeared in all newspapers, though only moderately in De Telegraaf. Frankfurter Allgemeine Zeitung presented the most diverse set of supranational actors (ranging from organised interests to EP party groups), with the other four newspapers located somewhere in between these two extremes. Generally, these actors appear to have had a slightly better chance (or were more successful at) getting a point across in the German public sphere. Commissioners got a platform to air their views on the debate, as did several MEPs (the EP as a whole was less prominent, as were the party groups). The Council of Ministers appeared as an actor only a few times, but the European Council more often, usually in the guise of 'EU leaders', or as the 'heads of state and government' in Frankfurter Allgemeine Zeitung. Pan-European media were absent from the debate, though the Financial Times was sometimes mentioned as a source - as we might expect, based on the discussions in Chapters 2 and 3.

Interventions in national debates were made by Commission President Prodi (1999-2004) who, in an opinion article, discussed the Irish rejection of the Nice Treaty and called upon all Europeans to participate in the debate about Europe's future (FAZ 25.06.01). Another example concerns the warnings about the breach of the Stability and Growth Pact by Pedro Solbes, Commissioner for Economic and Monetary Affairs in the Prodi Commission, in an opinion article in NRC Handelsblad (19.11.03):

One may question the need to adopt a new constitution next year, when governments are not willing to comply with the rules of existing treaties. ${ }^{135}$

The Commission and its representatives were mentioned less often than MEPs. Even the EP and its members figure little, though they were officially involved in the debate, especially during the policy formulation phase in the Convention. This may be expected based on the findings of other studies. For example, focusing on agenda-setters in European news in the year 2000, Trenz (2004, pp.300-1) found that the EP set the agenda in less than 50 articles, compared to more than 150 in case of the Commission and the Council of Ministers, and more than 200 in case of national governments (see, also: Voltmer \& Eilders, 2003, pp.187-8). Despite this, the apparently limited involvement of the EP and its members in this case would seem quite surprising, considering the fact that MEPs, in particular, played a key role in debating certain issues, especially during the initial stages of the Convention (Beach, 2008; Norman, 2003, pp.52-5). This is noteworthy because by inviting national parliamentarians as well as MEPs to cooperate, a more direct link between the Convention and the European citizens was effectively expected.

\footnotetext{
${ }^{135}$ Men kan zich afvragen wat voor nut het heeft volgend jaar een nieuwe grondwet aan te nemen wanneer de regeringen niet bereid zijn zich naar de regels in de huidige verdragen te voegen. (Own translation).
} 
In absolute numbers supranational actors may appear more prominent than one would expect (see, also: Kantner, 2006, p.156), but we should take into account that, in some cases, it was actually not clear what actors the papers were referring to (for example, anonymous 'diplomats in Brussels'); other supranational actors were only recorded once. In addition, national (and transnational) politicians seemed to be talking to one another or their audience, rather than addressing EU that is supranational - politicians, who themselves addressed citizens and decisionmakers in the Member States and in Brussels. This relative unimportance of the supranational institutions in both public spheres may reflect their perceived unimportance in the process of treaty reform (cf. Christiansen \& Reh, 2009).

Even though quite a number of different actors occurred in the newspaper articles, many of them were only found just once. The big Member States played a prominent role in the debate, whereas the smaller Member States were hardly ever mentioned. More precisely, debates in the three biggest Member States were referred to most often, especially France (referendum) and Britain (Blair's referendum U-turn). One way or another, Poland and Spain were identified as the main stumbling blocks for securing an agreement, though in the present sample they were not mentioned at all in De Telegraaf and Frankfurter Rundschau; Poland was not mentioned in de Volkskrant. Frankfurter Allgemeine Zeitung and NRC Handelsblad also provided (sporadic) information about other Member States and accession countries, most notably the Czech Republic, where ODS leader (and later President) Václav Klaus was identified as an influential opponent (FAZ 23.05.01; NRC 27.04.05) - which he remains today, as exemplified by his initial reluctance to sign the Lisbon Treaty.

All newspapers included vague references to 'smaller Member States' and/or 'accession countries' without explaining which these countries were. More explicit references usually either concerned governments, heads of government or ministers, though in the German newspapers attention was paid to political parties as well. Nevertheless, even when positions were discussed, this was often without much detail, merely noting (dis)agreements on a certain issue, not even the rationale behind such an opinion (as would be relevant to the issue dimension).

With the exception of De Telegraaf and Frankfurter Rundschau, room is also provided by newspapers for readers' opinions and - to a somewhat lesser degree to references to other media. Here Frankfurter Allgemeine Zeitung is most extensive as it contains a specific section on page two ('Stimmen der Anderen') devoted to printing literal excerpts from other national and international newspapers. Jessica Erbe $(2005$, p.84) explains that such press reviews have a long tradition in Germany, but only occur at times of special events in the Dutch press. In the set of articles examined, the only Dutch newspaper which printed an article that was a direct copy from another newspaper (Belgian newspaper De Standaard) was NRC Handelsblad, whereas Frankfurter Allgemeine Zeitung and Süddeutsche Zeitung each included 
several. Besides literal excerpts from other media, media in other countries were mostly referred to by Frankfurter Allgemeine Zeitung (e.g. FAZ 01.12.04) and NRC Handelsblad (e.g. NRC 16.06.00). In most other cases they are no more than a source which covers a certain event or presented information about debates and opinions in other countries (and hence were not recorded as an actor). Most references to debates and opinions in other countries were typically limited to the key players, such as Ministers of Foreign Affairs. Except for De Telegraaf, all newspapers included interviews with and/or reprinted opinion articles from actors in other Member States.

Surprisingly national actors do not seem to have been overrepresented as one might expect, on the basis of research that suggests national actors dominate public debates about EU affairs, and based on the assumption that national importance is a key selection criterion regarding EU affairs (cf. Kantner, 2006, p.156). For example, in their analysis of the news coverage of the 1999 and 2004 EP elections, De Vreese et al (2006) found that domestic political actors represented $83 \%$ of all actors in 1999. While this number was substantially lower in 2004, domestic actors were still more visible than EU actors. Here, however, only NRC Handelsblad referred to more national than transnational actors, but the differences between the two types of actors was minute. ${ }^{136}$ Vetters, Jentgens and Trenz (2009, pp.419-20) also recorded more transnational actors than national actors in the German debate (respectively over $50 \%$ compared to just $36 \%$ ), whereas in France national actors dominated (representing over $70 \%$ of all actors). The prominent role of transnational actors in the German debate could be explained by the virtual absence of differences of opinion between the main political parties. The authors explain the French case by pointing to the referendum debate, which became increasingly concerned with national issues. This has not been found in this study regarding the Dutch debate, but may be explained by the different selection methods used, as well as their specific focus on the ratification process.

The statement that transnational actors were more prominent than national actors needs some qualification. For one, in contrast to transnational actors, who tended to be named not more than once or twice, national actors often occurred several times (cf. Packham \& Osterhoff, 2001, pp.18-22). Moreover, the latter's opinions and actions were covered in a more detailed way, thus providing a better overview of their different positions - the manifestation in both public spheres of the French debate and, to a lesser extent, of Blair's announcement of a referendum, were the only instances of transnationalisation that come close. Finally, just because newspapers referred to transnational actors, does not mean there was a

\footnotetext{
${ }^{136}$ The case of NRC Handelsblad may appear contradictory. This was the Dutch newspaper that referred most to debates in other Member States. Yet, when this newspaper discussed national affairs it tended to present more diverse actors than the other two Dutch dailies, in particular national MPs (21 in total), which were barely mentioned in De Telegraaf (3) and De Volkskrant (4).
} 
transnational debate; in most cases, opinions or acts were just recorded, without any reaction or response from other actors. One of the few exceptions concerned the reactions to Fischer's Humboldt speech, as mentioned before.

In Germany Chancellor Schröder and Minister of Foreign Affairs, Fischer, were the most prominent figures in the debate, whereas in the Netherlands the Prime Minister, Balkenende, Minister of Foreign Affairs, Bot, and State Secretary for European Affairs, Nicolaï, were most prominent. The importance of the Stability and Growth Pact as an issue in the Dutch debates also meant that Finance Minister, Zalm, was mentioned a couple of times, though in absolute numbers not more often than his German counterpart, Eichel.

Finally, civil society organisations, whether of national or pan-European origin, were virtually absent. Only Frankfurter Allgemeine Zeitung and (26.06.02) and Süddeutsche Zeitung (26.06.02) referred to the Convention's hearings of civil society, and then only in general terms. In an article in NRC Handelsblad of 27 April 2005 it became clear that most Dutch organisations were in favour of the new treaty, but did not want to express it too openly, in order to still be able to criticise the Dutch government or the EU. As a Greenpeace spokesperson noted, "if Europe does something wrong in terms of the environment, we will resist it." ${ }^{137}$ Other studies have concluded that organised interests and civil society organisations did indeed play a less prominent role in the Dutch debate, often because they themselves were divided on the issue (Lucardie, 2005, p.115; Nijeboer, 2005, p.15-7). The limited visibility of organised interests in the debate about Europe's future was also recorded by Vetters, Jentgens \& Trenz $(2009$, p.421) as well as Helmut Gaisbauer and Markus Pausch (2009, pp.49-52), and corresponds to the findings of other studies, such as Koopmans (2007) mentioned in Chapter 1.

\section{Analysis}

As Anne Peters (2004, p.277-8) observes, previous treaty changes tended to go largely unnoticed in the public sphere, with debates often only taking place at the time of ratification (if at all), when the treaty texts had already been decided upon. The debate about Europe's future was intended to be as open as possible, in an attempt to involve the wider European citizenry at an early stage. It is questionable whether this aim was achieved. For example, some scholars argue that the Convention remained a predominantly elite endeavour, in which broader social participation was limited (Christiansen \& Reh, 2009, p.238; Lucarelli \& Radaelli, 2004). The same has been suggested with regard to the on- and offline influence of organised civil society (Monaghan, 2008; Wright, 2007). Others maintain, however, that at

137 “[A]ls Europa qua milieu iets fout doet, zullen wij ons daartegen verzetten.” (Own translation) 
least in terms of the quality of arguments, the Convention was a significant improvement compared to previous rounds of treaty change, because of its more inclusive set-up and the need for the participants to try to convince their fellow members of the lucidity of their arguments (Jopp \& Kleine, 2004, pp.255-6; Lucarelli \& Radaelli, 2004, p.15). This has been questioned too, however (Panke, 2006; cf. Christiansen \& Reh, 2009, pp.242-4).

In any case, subsequent negotiations during the IGC took place behind closed doors once again, thus limiting the chance for public scrutiny. In addition, Christiansen and Reh $(2009$, p.79, 257) argue that the route which later resulted in the Lisbon Treaty was intentionally 'de-democratized', in an attempt to prevent another failure. Treaty reform would once again be based on preparatory work in an IGC but with the overtly 'statist' discourse abandoned, as evidenced by the removal of references to EU symbols such as the flag and anthem.

Concerning wider public debate, David Allen (2004, p.22) writes that "the Convention fell well short of creating a genuine public space." Even though it created an elaborate website and established dialogues with organised civil society and Europe's youth, most citizens were unaware of the proceedings of the Convention. They did not engage in a wider public debate about the future of Europe during the early stages of the policy process. Only at the time of ratification did attention to the issue appear to increase. Hence, in this respect, the debate about the EU's future was not so different from previous rounds of treaty change after all.

Surveys regarding the Dutch rejection of the new treaty suggest that the absence of information about the EU in general, and the TECE in particular, played a role in opinion formation (Besselink, 2006, p.346). Considering the important role of national media as sources of political information, we may ask whether the lack of information raised by many citizens can be explained by the only moderate coverage of the debate throughout the policymaking process. Cornelia Bruell and Monika Mokre (2009, p.187) write that the media in several countries referred to an information deficit as being one reason for the gap between citizens and institutions, but they themselves seem to have been partly to blame.

Box 4 presents a summary of the main findings for each dimension. The analysis of the selected newspaper articles revealed temporal and content-related mismatches in both public spheres. As argued in Chapter 2, such deficiencies complicate the possibility to publicly scrutinise the policymaking process. As a consequence, citizens are presented with a distorted image of the policy process. The temporal mismatch in the current case concerned the moderate attention to specific phases of the policy process, in particular regarding the work of the Convention, which did most of the preparatory work, discussing ideas and drafting a first complete version of the TECE. Arguably there was attention paid to who would actually decide: the Member States in the IGC and later national parliaments and, in particular, citizens in those countries planning a referendum. Yet, even the IGC did 
not figure that prominently in the debates in the German and, even less so, Dutch newspapers. Moreover, much of the bargaining between the Member States took place outside the public limelight. The referendums seem to have been covered to a greater extent, but exerting any influence at this stage in the policy process was limited to a 'yes' or a 'no' vote. All in all, the process dimension reveals that little attention paid to important previous developments, thus maintaining an incomplete overview of all the phases in the policy process.

Box 4: Summary of the Three Dimensions

Issue Dimension

Several issues related to the debate on Europe's future were reported and discussed; sometimes at the same time, but also often at different times and to a different extent. Some issues were only discussed in one public sphere (and sometimes only in one newspaper); the Stability and Growth Pact was a particular issue in the Netherlands, the Kompetenzkatalog in Germany.

The future of Europe was also regularly referred to within the context of other issues - in other words, the background against which it was discussed was not always directly linked to the debate itself.

There were only a few references to the role the EU should or should not play; mostly regarding specific elements of the treaty (for instance, the possible reference to Europe's alleged Judeo-Christian tradition).

The relevance of treaty reform was mentioned only infrequently; mostly linked to the forthcoming Eastern Enlargement (though usually without explaining who it was relevant for); there was little discussion about the actual need for reform.

Process Dimension Emphasis was placed on the current state of affairs of the process, with less attention to what would happen next and even fewer references to past events limited attention was paid to the work of the Convention.

There were many references to who was taking the decisions; in four newspapers (FAZ, NRC, SZ and VK) this was even more prominent than any of the three temporal dimensions.

Information about the policy process and responsibilities were typically incorrect, incomplete or implicit (for example, concerning the role of the Convention).

Actor Dimension Many actors were mentioned, but typically without explaining their positions beyond 'in favour' or 'against'.

National and transnational actors featured most prominently, followed by supranational actors; non-EU actors were almost absent in the debates. It was sometimes difficult to establish who the actors actually were due to vague references (for example, 'diplomats in Brussels').

Surprisingly, there were more transnational actors mentioned than expected, yet these were recorded often just once or twice; less information was given about their positions than for national actors; there was little interaction across borders.

Most actors were national political leaders, ministers and authorities; actors from the three big Member States (Britain, France and Germany) were most common. 
The temporal mismatch identified in this study is in line with arguments put forward by John Erik Fossum and Hans-Jörg Trenz (2006; 2007; cf. Risse, 2010, pp.199-200; Vetters, Jentges \& Trenz, 2009, p.414), who have claimed that there was no (or little) interaction between the 'strong' and 'general' ('weak') publics (respectively, the Convention and the national public spheres) during the drafting process of the TECE. This also means that the text that was to be approved through national ratification, via the parliamentary channel and/or the referendum instrument, was actually publicly discussed in a different context to the one in which it was drafted. In fact, the referendums took place many months after agreement on the TECE in the IGC. This seems to confirm another point made in the previous chapters: EU affairs are often only debated during the decision-making stage or sometimes even later, whereas democratic decision-making requires the possibility to influence the policy process at an earlier stage.

The content-related mismatch was visible throughout the three dimensions, by way of incorrect, incomplete or implicit overviews of what was at stake, who was taking the decisions and how this was done. In the issue dimension, references to the reasons behind the treaty reform were limited, whereas in the process dimension references to previous steps were often missing, responsibility attributed to the wrong bodies (as in the case of the Convention) and decision-making procedures unclear. Even in the actor dimension, deficits existed in terms of merely partial explanations of the rationale behind actors' opinions. German newspaper coverage was more detailed than in the Netherlands, but the same deficiencies were found. As Risse (2010, pp.118-9) asserts, we need to be able to grasp the arguments of others in order for real debate to be possible, "[o]therwise, we will talk past each other." The articles analysed here did not always live up to this requirement.

Actors and newspapers provided only limited insight into previous treaty changes, into what happened during previous phases of the policy process, and into the reasons behind updating the existing treaty framework. This made it difficult to determine the broader context of the issue. It is clear - certainly in retrospect - that the whole exercise to draft a Constitutional Treaty was yet another step on the road to further European integration. The new treaty was in many ways the result of a gradual process, something that was often missing in the six newspapers. This may partly explain why for many Europeans it appeared as if the TECE were a huge leap ahead, whereas a large part of it consisted of elements of previous treaties, was based on ECJ case law or was already established informally during normal day-today politics in Brussels.

It was also often unclear which institutions and actors were responsible for which phases of the process. This was most visible with regard to the Convention: in both public spheres it was regularly suggested that the conventioneers would take the decisions, not the Member States or the EU leaders. In retrospect one could 
argue that, by focussing attention on the final decision, the present stage of policy formulation was emphasised with those who played at a key role at the time clearly identified (although more often as a collective - the Convention - than as individuals). It might have been possible to influence the drafting of the Convention by addressing them; the right actors were linked to the right phase, just not to the right extent of decision-making authority. Of course one problem with this interpretation is the limited attention paid to the Convention during most of its lifespan. As we have just seen, this is problematic too, since public debates only took place at a time when options to influence the process had become limited.

The actor dimension reveals that the newspapers all referred to many different actors, including representatives of the institutions and politicians from other (prospective) Member States. In the beginning of the debate especially, this included the visions on Europe's future by politicians such as Fischer, Juncker and Verhofstadt. As the debate proceeded, the attention first shifted to the opinions aired in the Convention, and later, to those of the Member States during the IGC. Civil society organisation and their representatives - be they national or not - rarely featured in the debates as reported in the Dutch and German press. As noted before, this finding corresponds to those of other studies. It has led several scholars to raise the question what this means in terms of the normative requirement that access to the public sphere should be equal for all interested parties (e.g. Kantner, 2006, p.158; Risse, 2010, p.161). ${ }^{138}$ While it may be unrealistic to assume everyone can have equal access, we might at least expect a more prominent role for organised civil society in the mediated European public sphere, if only because of their substantial role in European policymaking (e.g. Della Porta \& Caiani, 2009; Greenwood, 2007).

Even though references to actors, discussions and events in other Member States were present in all newspapers, they predominantly focussed on the three big Member States: Britain, France and Germany. As already noted, the debate in France - where disagreements about how to proceed with the integration process arose from the beginning - was an important focus in both public spheres. Another example is the announcement of the British referendum. Yet the German newspapers were apparently not interested in the debate in the Netherlands, and even though Fischer was identified as (one of) the core initiator(s) of the debate, no specific attention was paid to events in Germany in any of the three Dutch dailies. The moderate attention to the Dutch referendum in the German press may be the result of the selected constructed week (another constructed week for the first half of 2005 may have led to a different result), but references to events and actors in the Netherlands were virtually absent throughout the whole research period.

\footnotetext{
${ }^{138}$ Note that De Beus and Mak, as well as Risse, are quite optimistic regarding the politicisation of European affairs and the increased involvement of non-executive actors.
} 
The fact that (actors from) other countries were barely mentioned corresponds to the findings of other studies, which show an over-representation of references to the big three Member States and their representatives (e.g. Machill, Beiler \& Fischer, 2006, p.72; Sifft et al, 2007, p.144). These are the EU's most influential countries and (dis)agreement between them does to a large extent determine the course of further integration. Even though the focus on the big three Member States may not come as a surprise, it may become problematic if the positions of other countries are ignored. Their positions may be important for maintaining disagreements or for fostering agreement, and as such, crucial positions may go unnoticed.

Focussing on the debates of just a few Member States is not only important in terms of this particular case, but also directs our attention to the question of whether national public spheres can fuel transnational debates. Apparently these debates may actually not involve 27 national public spheres, but be limited to a few, even in cases where issues have EU-wide implications. This suggests that, while public spheres may intersect, they do not necessarily constitute a continuous process of interaction between all national spaces, but one which seems to be determined by the prominence of actors (individuals, institutions, Member States) and events (such as referendums). This seems to apply to most coverage of EU affairs (e.g. De Vreese, 2001; Wimmel, 2004).

The references to debates, events and actors in other Member States in this case did not usually involve many exchanges of opinions between public spheres, but rather the recording of what went on elsewhere. While this may be considered a form of transnationalisation of the coverage of EU affairs, it does not mean that there was a transnational debate (cf. Sifft et al, 2007, pp.130-1). Some scholars would argue that for a European public sphere to develop, exchange of opinions across borders is vital (e.g. Risse, 2010; Wimmel, 2005). Nevertheless, the fact that there was coverage by all six newspapers of what went on in other Member States can be seen as an important step in the development of a European public sphere it means that other opinions and positions are at least acknowledged (cf. Eder \& Kantner, 2000; Kantner, 2006).

In addition, we saw that the debate about Europe's future was also referred to in articles which primarily dealt with other issues, and that other topics were brought as a way of approaching commentaries on the treaty revision process. The importance of the EU and its future debate was apparently acknowledged, even though coverage remained limited, but also seen as important in terms of other national, European and international developments. In her study of quality newspapers' coverage of EU affairs in the year 2000 Kantner (2006, pp.151-2) also reports that European issues were raised in articles primarily dealing with, for example, national and sub-national topics. In fact, less than half of the articles analysed by Kantner primarily focussed on EU affairs. Trenz $(2004$, p.296) presents a similar 
finding in his study of the coverage of EU governance in quality newspapers from six Member States; between $40-50 \%$ of articles primarily focused on EU affairs. These are important observations when it comes to questioning the extent to which a European public sphere might materialise and, if so, what it might look like. It indicates that European affairs may potentially have a more pronounced effect on debates on all kinds of different issues.

In addition, there were issues which figured in both public spheres, in particular, the Danish 'no' to the Euro, the Irish rejection of the Nice Treaty and Blair's U-turn on a British referendum on the Constitution. Other less clear-cut common issues were the perceived gap between the EU and it citizens, and doubts over the significance of new treaty reform in light of the divisions over Iraq. The upcoming Eastern Enlargement was often reiterated as the main reason why a new treaty was necessary in the first place. This may not necessarily have signalled a transnationalisation of debates, but it does suggest there was some overlap in topics and frames of references.

These observations apply to both public spheres, but should not shroud the differences between the debates in the Dutch and German public spheres. The German dailies seem to have devoted more attention to the debate on the future of Europe and been (somewhat) more detailed in qualitative terms - especially Franfurter Allgemeine Zeitung. Of the Dutch papers, the coverage by NRC Handelsblad was most comprehensive and comparable to that of the German newspapers, whereas De Telegraaf by far provided the least detailed coverage of the debate and was less informative in terms of the three dimensions. For example, the De Telegraaf sample did not include any reprinted opinion articles by, or interviews with, politicians from other Member States. In contrast, Frankfurter Allgemeine Zeitung's daily section 'Stimmen der Anderen' assured the inclusion of regular excerpts from other national or non-national media. A broader variety of topics discussed in the Convention and the IGC were addressed in the German public sphere. Some issues had barely any prominence in one public sphere, whereas they did appear in the other, if not to a huge extent. The most prominent national concerns were the Stability and Growth Pact in the Netherlands, and the division of competences between the supranational and national (and sub-national) levels in Germany.

With some exceptions the newspaper coverage suggests that different issues were discussed at different times in the process. When similar issues were discussed, coverage regularly differed in terms of details. This limits the possibilities for transnational debates and overlapping national public spheres. Moreover, it should be noted that even within the Dutch and German public arenas the various media emphasised different issues at different times. This suggests that not only are there differences between national public spheres, but there apparently also are different discussions within these national spaces (cf. Kantner, 2006, p.153). However, as was explained in Chapter 2, these various platforms in national arenas tend to be linked, 
whereas this is not often the case when it comes to national arenas that should, in theory, form the basis of a European public sphere. In addition, as mentioned in the Introduction, the way in which newspapers - be they quality titles or not - cover EU affairs tends to be quite similar (e.g. Pfetsch, 2008, p.31; Pfetsch, Adam, Eschner, 2008, p.477).

In sum, if we assume that in a democratic polity it is important to be able to hold office holders, parliamentarians, officials and governments accountable, and influence their actions, citizens need to know who to address and when to do so (cf. Tsakatika, 2008). The debate about the future of Europe was apparently not controversial enough to gain more consistent media coverage, even though the press did pay attention to certain key moments during the process (in particular the referendums). The way in which the debate on Europe's future was presented in the public sphere obscured the development of the policy process, as well as the authority and responsibility of the EU. This means it was difficult, if not impossible, to influence the involved policymakers at the right moment and to hold them responsible. A minority of EU citizens, particularly Brussels 'insiders', may have known how best to keep well informed of the debate, but the average European citizen did not, as evidenced by several (Eurobarometer) surveys concerning the work of the Convention and the content of the TECE (e.g. European Commission 2005b). Taken together, the articles from both the Dutch and German newspapers presented some important elements of the debate. Yet, it is unlikely that any citizen read every article (on- or offline), listened to every radio programme or watched every current affairs programme dealing with Europe. Even if they did the national media differed in how they discussed the same topics, and the quality of coverage varied greatly, even within a single Member State.

\section{Conclusion}

The intensity of public debate about Europe's future was at most modest, certainly when taking a long-term perspective. It did not live up to the promises identified by Lucarelli and Radaelli (2004, p.4) and cited at the beginning of this chapter: to create a public sphere that would involve domestic publics and politics in the decisionmaking process, and promote deliberative, participatory governance. Findings in this chapter confirm what was asserted in Chapters 2 and 3, namely, that a debate cannot be created using a top-down approach - something that has also been highlighted by De Beus \& Mak (2009, pp.53-6) in their comments on this particular case. More importantly, the information which circulated in the Dutch and German public spheres showed discrepancies in terms of the rationale behind the reform process, its evolution, and the allocation of responsibilities. In addition to these contentrelated mismatches, this chapter also identified a temporal mismatch due to which 
part of the policy process - the debates in the Convention in particular - proceeded outside the public limelight. Previous treaty changes were at least partly ignored; public involvement only increased when the TECE had already been drafted and approved by the Member States. As discussed in the previous section, observations such as these raise questions about the quality of information available relating to EU affairs in national public spheres, but also the potential for transnational debates in Europe and their likely manifestations. 


\section{Ambient Air Quality: Tiny Particles, Major Consequences}

The previous chapter discussed an issue of high politics, the debate on Europe's future. This chapter will discuss a rather technocratic policy field, namely EU environmental policy and, in particular, the debates on air quality policies. In other words, this chapter will discuss legislation that originates from Brussels, whereas the last chapter dealt with a treaty about Brussels, indeed one intended to amend the rules and procedures by which those engaged in Brussels making legislation actually function. In recent decades the preservation of nature and the environment has become a widely accepted issue in the developed world, even though the state of the economy tends to have a negative effect on public support for environmental policies. Due to their cross-border nature and the lack of comprehensive knowledge, environmental problems are quite complex. Since they influence many sectors of society, multiple different actors try to influence policymaking, including various levels of government, international organisations, the business community and NGOs.

The EU is very active in the field of environmental policy and has become one of the main supporters of international agreements such as the 1997 Kyoto Protocol. The EU's body of environmental legislation tackles issues such as air and water quality, emission standards, biodiversity, recycling and so on. Due to the complex nature of environmental problems, most legislation is quite technical. As a result, EU policymaking in this field typically only receives modest attention in the wider public domain (e.g. Bijsmans \& Altides, 2007, pp.329-30), even though it may be hotly debated in the issue-specific and elite-supranational public spheres. Environmental policy legislation greatly influences the day-to-day life of European citizens, even though its implications and effects may not always be evident. 
This chapter will start by introducing EU environmental policy and EU ambient air quality policies in particular, and examine references to Dutch and German government positions regarding these issues. After that the empirical findings will be presented. This will then be followed by a discussion and a conclusion. This chapter will illustrate that mostly technical issues can become significant topics in public spheres, once their consequences become clear, and appear to directly affect people's life. It will, furthermore, illustrate that the way in which EU affairs figure in the public sphere is shaped by the issue at hand. It will be suggested that the phase in the policy process and the way in which European legislation has been transposed in national law are important too. Despite differences between the previous case and this one, it will become clear that similar mismatches apply.

\section{EU Environmental Policy: A Concise Overview}

The environment has been a concern for European policymakers since the 1950s, yet the nature of related legislation has changed over time. Originally there were no explicit environmental provisions in the treaties, but references to, for example, the harmonious development of the European market allowed for the adoption of several concrete pieces of legislation. These did not constitute a coherent policy, but rather a pragmatic approach. ${ }^{139}$

During the 1972 Paris summit, European leaders for the first time decided to establish a basis for a common environmental policy by asking the Commission to draw up an Environmental Action Programme (EAP). Ever since, EAPs have set the main political framework for the development of Europe's environmental policy, structuring it around specific themes and laying down the Commission's initiatives (Butt Philip 1998, p.257-61; Lenshow 2005, p.309). Gradually environmental policy became a distinct policy in its own right, no longer just a by-product of the development of a common market.

The 1986 SEA for the first time established a treaty basis for environmental policy and introduced majority voting (be it not as the rule) and the cooperation procedure. It also stated the objective to complete the internal market ('1992'), which would result in the (further) harmonisation of environmental standards (Hildebrand, 2005, p.34). The TEU established environmental protection as a core policy goal in the preamble of the treaty and introduced the principle of sustainability. QMV was adopted as the main decision-making procedure in the Council and co-decision was to apply to almost all aspects of environmental policymaking. The Amsterdam Treaty did not substantially alter the treaty provisions, although it did advance the application of the co-decision procedure and further strengthened the importance

\footnotetext{
139 The linkage between single market issues and environmental issues still occurs today (Butt Philip 1998; Lenschow 2005).
} 
of sustainable development (Jordan, 1998). Moreover, the Amsterdam Treaty required environmental considerations to be integrated into other policies and activities. The Nice Treaty did not present any novelties in the field of environmental policymaking (Jordan \& Fairbrass, 2005). The same may also be concluded regarding the Lisbon Treaty, though it does contain a number of rephrased provisions, for instance, regarding sustainable development (Art. 3 TEU). Moreover, modifications in other policy fields, such as new parliamentary powers concerning the CAP and the EU budget, as well as explicit mention of an EU energy policy, may influence environmental policy (Benson \& Jordan, 2008).

The Commission has the exclusive right of initiative and is responsible for implementation in environmental policy. As in most national capitals, its DG Environment competes with other departments, in particular DG Industry. Various other DGs such as Agriculture, Energy \& Transport $^{140}$ and Fisheries also play a prominent role (McCormick, 2001, pp.103-4; Peterson \& Bomberg, 1999, pp.190-2). QMV is the rule in the Council and co-decision applies to almost all aspects of environmental policy. ${ }^{141}$ The EP, through its Committee on Environment, Public Health and Food Safety (ENVI) often takes a rather 'green' position compared to the other institutions and is seen as the natural ally of DG Environment. Most legislation in the field takes the form of directives. The ECJ has issued some important rulings, for example, that common environmental objectives may prevail over the free movement of goods (Lenschow, 2005, p.317).

A number of business interests - such as BusinessEurope, which represents European employers' and industry organisations from more than thirty countries ${ }^{142}$ - and environmental groups - the most important being the European Environmental Bureau (EEB), a federation of over 140 national organisations - try to influence EU environmental policy. In addition, they provide the institutions, in particular the Commission and EP, with vital expertise (Greenwood, 2007, pp.129-32; Wurzel, 2002, pp.71-4). Finally, the European Environment Agency (EEA) - in cooperation with the European Environment Information and Observation Network (EIONET) - is responsible for the collection of relevant data and other information, for example, concerning air pollution. ${ }^{143}$

EU environmental policy has become increasingly important in terms of fostering shared perspectives and common approaches to environmental challenges, despite enduring differences in national traditions, ecological circumstances and regulatory styles (McCormick, 2001; cf. Wurzel, 2002, pp.4-36). Germany and the

\footnotetext{
${ }^{140}$ Recently split up into DG Energy and DG Mobility \& Transport.

${ }^{141}$ QMV does not apply to spatial planning, fiscal measures, energy and water resources (Art. 192 (2) TFEU).

${ }^{142}$ Formerly known as the Union of Industrial and Employers' Confederations in Europe (UNICE).

${ }^{143}$ The so-called European Air quality dataBase (AirBase) databank collects information about air quality across Europe. See: http://air-climate.eionet.europa.eu/databases/airbase/
} 
Netherlands have always been among the strongest supporters of a common European approach to environmental challenges (e.g. Andersen \& Liefferink, 1997; Hildebrand, 2005, p.28). ${ }^{144}$ They have also acted as leaders in drafting EU environmental policy, by pushing for new legislation and even threatening to 'go it alone', as in the case of air pollution (e.g. Hanf, 1997; Weale et al, 2000, chapter 11). Even so, Germany and the Netherlands remain substantial polluters and their leadership role in this policy field is not always evident; domestic political priorties and struggles for competences between ministries and different levels of government may present obstacles. Both countries have regularly labelled EU policies as too modest compared to their own policies, yet they have each had their fair share of infringement procedures launched against them (e.g. Liefferink, 1997, p.244; Pehle, 1997, pp.193, 196-7; Wurzel, 2002, pp.61-2).

The Ministry of Housing, Spatial Planning and the Environment (VROM) is responsible for Dutch environmental policy; its German counterpart is the Federal Ministry for the Environment, Nature Conservation and Nuclear Safety (BMU). In both countries other ministries are involved too, in particular those in charge of transport policy, industrial and economic policies and agricultural policy. The Federal Environmental Bureau (UBA) is one of the core bodies supporting the BMU. It is responsible for documentation and information, but also contributes to air pollution control through activities such as technical and scientific research (Pehle, 1997, p.177; Wurzel, 2002, p.62). In the Netherlands, the National Institute for Public Health and the Environment (RIVM) plays a key role in monitoring environmental quality (including air quality) and is responsible for drafting key reports, sometimes together with other organisations (Liefferink, 1997, p.222; Schenkel, 1998, pp.13943).

Other tiers of government, in particular the Länder and the Provinces, but also municipalities, are often responsible for the implementation of policies decided upon by central government (Hanf \& Van de Gronden, 1997, pp.172-3; Pehle \& Jansen, 1997, pp.102-4). Dutch sub-national administrations are sometimes either not interested or simply unable to cope with environmental policy, which can be especially problematic when it comes to implementation (Liefferink \& Van der Zouwen, 2004, pp.144-5). Even though the Länder have competences in the field and can issue their own legislation when the federal government has not acted, it is the latter which tends to determine the outline of German environmental policy by means of very detailed framework laws. The stipulation that equal living conditions should apply to the whole German territory (Art 72.2 GG) has been a particular incentive for the Bund to take action (Pehle, 1997, pp.169-70). Yet, it goes without saying that due to their more prominent role in German politics the Länder are a

\footnotetext{
${ }^{144}$ Since 1982 environmental protection is an explicit goal in the Dutch Constitution (Art. $21 \mathrm{GW}$ ); it was included in the German Basic Law in 1994 (Art. 20a GG).
} 
great deal more influential than the Provinces. The Bundesrat needs to approve environmental laws and the Länder actively guard their own competences - sometimes by refusing to cooperate when implementing EU environmental policy (Wurzel, 2004, p.109).

Public opinion has consistently supported a European environmental policy in light of the issue's inherent cross-border impact (Butt Philip, 1998, p.262). For example, a 2008 Eurobarometer survey dedicated to the environment revealed that $67 \%$ of respondents believed that protecting the environment should be a joint effort of the EU and its Member States, whereas only $28 \%$ held the opinion that it should be a purely national prerogative. Air pollution was the third main concern of European citizens, after climate change and water pollution. This Eurobarometer also revealed that $79 \%$ of the Dutch and $75 \%$ of Germans supported concerted efforts by the EU and its Member States to curb environmental problems. Air pollution was the fifth most important issue for German respondents, but the second core topic for Dutch respondents (European Commission, 2008a). The wider economic, political and social state of affairs also has an impact on public backing for environmental policy in Germany and the Netherlands, but generally attitudes have been supportive since the 1980 s.

\section{Clean Air For Europe}

Air quality has been a European policy focus since the early 1970s, but the first directive (Directive 80/779/EEC) was only adopted in $1980 .{ }^{145}$ At first the approach to this issue was rather fragmented, but since the 1990s a more strategic policy has emerged (McCormick, 2001, p.180). Stationary sources such as large combustion plants used to cause most air pollution, but their contribution to the problem has declined, especially since the 1980s. Today, traffic and transport are often identified as the main polluters, most notably with regard to nitrogen oxides (NOx) concentrations (Hanf, 1997, pp.126-31; Weale et al, 2000, pp.385, 397-8). These vehicle emissions are responsible for poor air quality in many European cities, despite continuing technological innovations; engines may generally have become cleaner, but they have also become more powerful; cars are now bigger and heavier and the number of road kilometres clocked up by drivers has increased (e.g. Braniš, 2009). The Dutch approach to combatting air pollution was initially mainly aimed at stationary sources, not at traffic (Schenkel, 1998, pp.169-71). As a transit country, the Dutch economy benefits from national and international traffic and transport. As one might expect, Germany's car producers have always resisted traffic-related EU policy measures (e.g. Wurzel, 2002, pp.83ff).

\footnotetext{
${ }^{145}$ For an overview of the most important legal documents and the full references, see Box 4 .
} 
EU air quality policy is unmistakably linked to other policies, for example, to issues such as climate change and sustainable energy sources, so any attempt to delineate it is somewhat artificial. Nevertheless, legislation on issues such as the introduction of bio-fuels has mainly developed within the domain of energy policy. Attempts to reduce aviation emissions are usually linked to climate change and economic measures, as reflected in the debates on whether or not this sector should become part of the EU's emission trading system. Even debates regarding car technology (such as the Auto-Oil programmes) have largely advanced in parallel to the development of the ambient air quality directives. The resulting pieces of legislation may have offered an opportunity for an integrated approach, but linkages have been mostly implicit (Wurzel, 2002, pp.84, 159).

John McCormick (2001, pp.29-31; cf. Hanf, 1997) explains that EU clean air policy is not straightforward, consisting of different approaches, including the establishment of emission limits and air quality standards. This chapter will explicitly focus on debates with regard to the latter: initiatives concerned with ambient air quality, which has been defined as 'outdoor air in the troposphere' in various directives (e.g. Directive 96/62/EC, Art. 2), and which is primarily concerned with setting so-called 'limit values' for the presence of pollutants in 'outdoor air' (McCormick, 2001, pp.185-6, 190). Efforts in other fields are aimed at safeguarding those limit values. Until the end of the 1990 s specific policies were pursued to deal with various aspects of air quality. Since then the focus has been on trying to establish a joint approach, with the aim of drafting a single legal document. Air pollution is one of seven thematic strategies of the Sixth EAP (EAP6), which runs until 2012 (European Commission, 2005c). ${ }^{146}$

While scholars have evaluated the EU's policy in the field of air pollution as being rather successful, despite its initial piecemeal nature, they have also noted that a poor record on compliance by the Member States has proved problematic (Lefevere, 1997, p.211; McCormick, 2001, pp.189-90). This has been a long-lasting issue in EU environmental policy, partly because implementation and monitoring are almost solely left to the Member States (e.g. Demmke, 2003). From EAP5 onwards the Commission has been trying to tackle this problem by focusing on air quality objectives instead of on strict standards, and by stressing transparency, information and partnership between public and private actors on the various levels of EU governance (Hanf, 1997, pp.144-6). Although the EEA plays a role in monitoring policies, the Member States are still responsible for transposing the directives, determining how they will realise quality objectives and collecting air quality data.

The ambient air quality framework directive (Directive 96/62/EC) was devised to improve the quality of air pollution legislation, and encourage better implemen-

\footnotetext{
${ }^{146}$ Decision No 1600/2002/EC of the European Parliament and of the Council of 22 July 2002 laying down the Sixth Community Environment Action Programme. OJ 2002, L242/1-15; see in particular Art. 7-2(f).
} 
tation by harmonising existing acts. It laid the basis for further developments in this area, including twelve daughter directives on various hazardous substances, such as particulate matter (PM), nitrogen oxide (NOx), nitrogen dioxide (NO2), sulphur dioxide (SO2), carbon monoxide ( $\mathrm{CO}$ ) and ozone (O3), and it incorporated new EU-wide quality objectives to improve compliance. The framework directive was criticised though, among other things for setting uniform objectives for the entire EU and for paying only moderate attention to cross-border pollution (Lefevere, 1997, pp.2134).

The first daughter directive (Directive 1999/30/EC) has been the most controversial. The directive's limit values gradually came into force from 1 January 2001 and would become even stricter from 2010. Member States - including Germany and the Netherlands - encountered substantial difficulties in meeting the limit values, in particular with regard to PM10 which applied from 1 January 2005.147 The NO2 limit values were also ambitious, but since they were only meant to apply generally from 2010 they were seen as less pressing. The limit values included in other directives proved to be much less challenging (González-Calatayud, 2007, p.266; Koelemeijer et al, 2005, p.15). As we will see below, this was clearly reflected in the debates in the Dutch and German public sphere. Hence, the rest of this chapter will predominantly be engaged with Directive 1999/30/EC.

The deadline for transposing the directive into national law was 19 June 2001. Germany did so in September 2002, in particular in the BundesImmissionsschutzgesetz (Federal Immission Control Act) and a related regulation (22. BImSchV). The Netherlands transposed the directive by means of the Besluit Luchtkwaliteit (Dutch Air Quality Order) in June 2001. While it voiced concerns about Commission proposals for this directive - including the likelihood that the objectives would not be met - at an early stage, the Netherlands did not object due to its concern not to be seen any longer as a forerunner and because a common approach to this cross-border issue was preferable (Rood, et al, 2005). Poor coordination between the national stakeholders involved was problematic, but the specific transposition and implemention of the directive in the Netherlands was even more so.

The countries where the limit value proved most challenging were not necessarily those where air quality was worst. The different ways of interpreting Directive 1999/30/EC partly explains why the issue became more controversial in some countries than in others. Comparative studies show that Germany and the Netherlands (as well as Sweden) followed a very strict implementation of the first daughter directive (Backes \& Van Nieuwerburgh, 2005; Backes, Van Nieuwerburgh and Koelemeijer, 2005; Koelemeijer et al, 2005). Both countries considered the limit values to

\footnotetext{
${ }^{147}$ A yearly average value of $40 \mu \mathrm{g} / \mathrm{m} 3$ air and a daily average value of $50 \mu \mathrm{g} / \mathrm{m} 3$ air which could not be exceeded more than thirty-five days per year.
} 
be absolute values that were not to be weighted against other interests. Dutch implementation was even stricter than in Germany, by not distinguishing between limit values for the protection of human health and values for vegetation, by making these values apply everywhere, by establishing a direct link between air quality and spatial planning, and by employing very detailed measuring and modelling techniques. In contrast, Germany allowed for the deterioration of air quality with new building projects, as long as the limit values were not exceeded by more than $3 \%$ and the best techniques were used to curb pollution.

EU air quality policy became a much contested issue in the Netherlands when it became clear it would have a strong impact on building plans and, potentially, on economic development. This occurred when the Council of State's Administrative Jurisdiction Division annulled several building plans in a number of high-profile rulings in 2004. In Germany problems started to occur when the limit values came into force in 2005 . This did not automatically lead to court cases, because instead Germany emphasised the need to draw up air quality plans to tackle the high concentrations of hazardous substances.

Directive 1999/30/EC was to be evaluated in 2003, but the establishment of the Clean Air for Europe (CAFE) programme altered the projected evaluation. The CAFE programme was intended to develop a 'long-term, strategic and integrated policy' (European Commission, 2001a, p.7). It was closely linked to the air pollution strategy drawn up within the framework of EAP6. One of the aims of this strategy was to simplify legislation and make it more effective, which first resulted in a Commission proposal for a new directive that would merge existing ambient air quality directives (European Commission, 2005d). Besides, new standards were to be introduced, above all for fine particulate matter (PM2.5), one of the most hazardous airborne substances. The strategy further proposed to improve implementation and monitoring and to broaden the application of EU air quality legislation to other sectors, such as transport. One of the outcomes of this policy process was the new Directive 2008/50/EC.

Box 5: Ambient Air Quality Legislation and Decisions: A Non-Exhaustive Overview

Directive 80/779/EEC of 15 July 1980 on air quality limit values and guide values for sulphur dioxide and suspended particulates, OJ 1980, L229/30-48.

Council Directive 96/62/EC of 27 September 1996 on ambient air quality assessment and management, OJ 1996, L296/55-63. (The Air Quality Framework Directive).

Council Decision 97/101/EC of 27 January 1997 establishing a reciprocal exchange of information and data from networks and individual stations measuring ambient air pollution within the Member States, OJ 1997, L035/14-22.

Council Directive 1999/30/EC of 22 April 1999 relating to limit values for sulphur dioxide, nitrogen dioxide and oxides of nitrogen, particulate matter and lead in ambient air, OJ 1999, L163/41-60. (The First Daughter Directive). 
Directive 2000/69/EC of the European Parliament and of the Council of 16 November 2000 relating to limit values for benzene and carbon monoxide in ambient air, OJ 2000, L313/12-21. (The Second Daughter Directive).

Directive 2002/3/EC of the European Parliament and of the Council of 12 February 2002 relating to ozone in ambient air, OJ 2002, L67/14-30 (The Third Daughter Directive).

2004/224/EC: Commission Decision of 20 February 2004 laying down arrangements for the submission of information on plans or programmes required under Council Directive 96/62/EC in relation to limit values for certain pollutants in ambient air, OJ 2004, L68/27-33.

2004/461/EC: Commission Decision of 29 April 2004 laying down a questionnaire to be used for annual reporting on ambient air quality assessment under Council Directives 96/62/EC and 1999/30/EC and under Directives 2000/69/EC and 2002/3/EC of the European Parliament and of the Council, OJ 2004, L156/78-125.

Directive 2004/107/EC of the European Parliament and of the Council of 15 December 2004 relating to arsenic, cadmium, mercury, nickel and polycyclic aromatic hydrocarbons in ambient air, OJ 2005, L23/316. (The Fourth Daughter Directive).

Directive 2008/50/EC of the European Parliament and of the Council of 21 May 2008 on ambient air quality and cleaner air for Europe, OJ 2008, L152/1-44.

Adopted and modified from http://ec.europa.eu/environment/air/legis.htm

\section{The Findings: A General Overview}

As in the last chapter, the presentation of the findings for this particular case study will start with a numerical overview and sketch of the debates in the Dutch and German newspapers. The time frame for this case was January 2000 to December 2005. For reasons of comparability, one could argue that the selection should be limited to the period from January 2000 to June 2005. However, given that the new thematic strategy and new draft directive were only published on 21 September 2005, the second part of 2005 has also been included. to allow for full coverage of the debate. Thus, this time frame covers a period in which there was a marked shift towards a more integrated air quality policy, even if it did not emerge as an issue in both public spheres. This period is also interesting because it spans several stages of the policy process: not only policy implementation, but also policy evaluation and agenda-setting. Moreover, the timeframe of the air quality case largely coincides with the debate on the future of Europe, thus enabling the comparability of both cases. The years during which the framework directive from 1996, and the first daughter directive from 1999, were drafted and approved are not analysed; an exploratory search for articles about EU air quality legislation in these earlier years yielded few of relevance, if any at all.

Articles were selected by searching for key terms appearing in the titles of the directives: the framework directive and the four daughter directives (Box 5). The articles had to refer to the EU's air quality policy and contain information regarding the policy process, as well as an opinion, act or statement related to it. The initial 
selection included articles which were eventually discarded, for instance, articles referring to cleaner air, limit values and other European policies, but without linking these issues in any meaningful way (e.g. FAZ 17.08.05; NRC 02.01.04). Others referred to air quality limit values, but without identifying them as European targets (e.g. FAZ 23.01.02; FR 29.04.05; NRC 09.02.04; SZ 04.04.05; TEL 21.09.05; VK 29.11.04). While negligible for the current case study, these examples confirm that the issue's importance was acknowledged. They illustrate how European policy is debated nationally, even if it is not specifically identified as being a 'European' matter.

Box 6: Search terms

\begin{tabular}{|c|c|c|}
\hline Dutch & English & German \\
\hline Luchtverontreiniging & Air Pollution & Luftverschmutzung \\
\hline Luchtkwaliteit & Air Quality & Luftqualität \\
\hline Arseen & Arsenic & Arsen \\
\hline Benzeen & Benzene & Benzol \\
\hline Cadmium & Cadmium & Cadmium/Kadmium \\
\hline Koolmonoxide & Carbon Monoxide & Kohlenmonoxid \\
\hline Schone Lucht & Clean Air & Saubere Luft/Luftreinhaltung \\
\hline Lood & Lead & Blei \\
\hline Kwik & Mercury & Quecksilber \\
\hline Nikkel & Nickel & Nickel \\
\hline Stikstofdioxide/-oxide & Nitrogen Dioxide/-oxide & Stickstoffdioxid/-oxide/Stickoxid \\
\hline Ozon & Ozone & Ozon \\
\hline Fijn Stof/Fijnstof* & Particle Matter & Feinstaub* \\
\hline Polycyclisch & Polycyclic & Polyzyklisch \\
\hline Roet & Soot & Ruß \\
\hline Zwavel & Sulphur & Schwefel \\
\hline
\end{tabular}

* NB: the Dutch version of Directive 1999/30/EC employs the term 'zwevende deeltjes', but this soon became known as 'fijnstof /'fijn stof'. A query only yielded articles that were already part of the set. The same applies to the German 'Partikel', the official term employed by the directive, though 'Staubpartikel' did yield some further results.

\section{Considering the Numbers}

Table 5 provides an overview of the number of articles studied for this particular case. Although this set included more articles than in the first case study, it should be noted that no further sampling method was used - in other words, all available articles from the research period that met the aforementioned criteria were included. 
Table 5: Number of Articles per Newspaper and per Year

\begin{tabular}{lccccccc}
\hline & FAZ & FR & SZ & NRC & TEL & VK & Total \\
\hline 2000 & 5 & 4 & 2 & 1 & - & - & 12 \\
\hline 2001 & 4 & 1 & 2 & 2 & 3 & 3 & 15 \\
\hline 2002 & 2 & 4 & 2 & 5 & 3 & 4 & 20 \\
\hline 2003 & 3 & 2 & 3 & 10 & 3 & 2 & 23 \\
\hline $\mathbf{2 0 0 4}$ & 6 & 8 & 6 & 15 & 3 & 11 & 49 \\
\hline Total & 50 & 64 & 73 & 68 & 32 & 34 & $\mathbf{3 2 1}$ \\
\hline
\end{tabular}

Not only did NRC Handelsblad cover the clean air debate more extensively than the other two Dutch newspapers but, based on this selection, it also paid more attention to the issue than the three German newspapers. In contrast to the previous case study, Frankfurter Allgemeine Zeitung is not overrepresented here. It may not be the most 'sensitive' of the three German newspapers when it comes to environmental issues, but in that respect it may be comparable with NRC Handelsblad (cf. Eilders, 2000). Besides more critical commentaries (e.g. FAZ 19.04.05), it too contained quite emphatic calls for policy action (e.g. FAZ 30.03.05). This suggests the widely shared image of the Frankfurter Allgemeine Zeitung as one of the key newspapers for EU affairs coverage does not necessarily apply to every topic or policy.

Figure 6: Annual Number of Articles per Newspaper

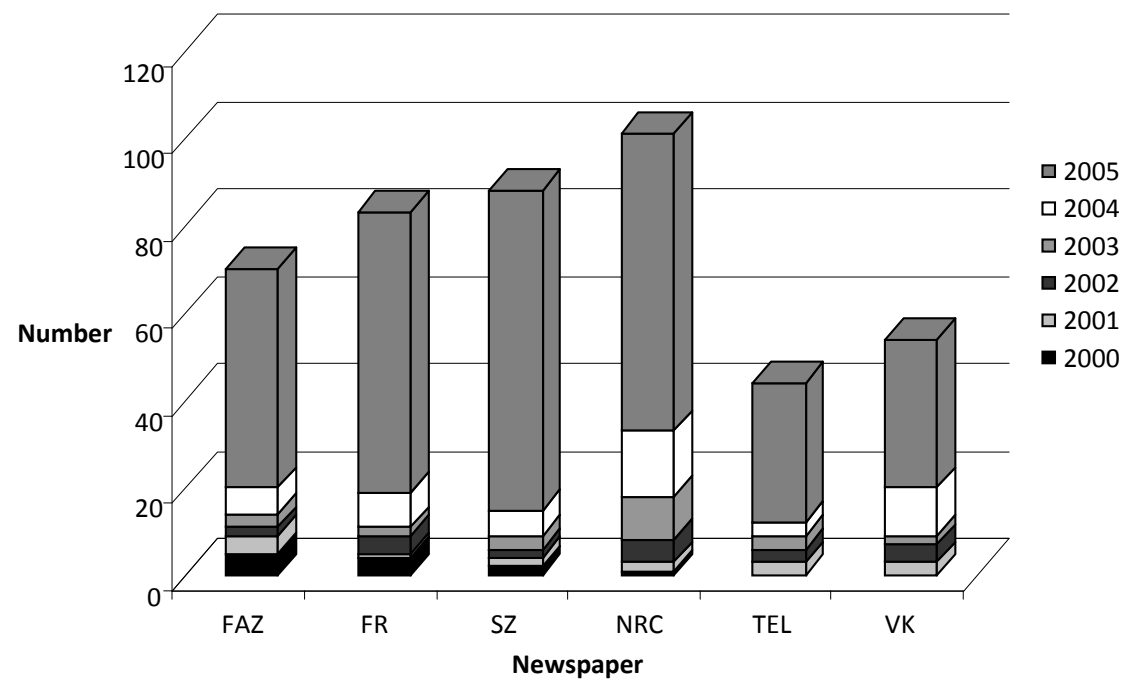


Figure 7 clearly indicates that at the outset Europe's air quality policy was barely an issue in either country, despite some early warnings that limit values potentially posed serious problems (e.g. FAZ 23.06.00; FR 19.07.01; NRC 04.11.02; SZ 06.02.01; TEL 24.07.01; VK 26.10.02). The Dutch debate only really got underway when the Council of State's Administrative Jurisdiction Division cancelled a number of construction plans in 2004 and 2005, and it subsequently became clear there were problems with the limit values set out in the EU directives. There was no such occurrence in Germany, though at the end of 2004 cities were becoming more apprehensive, considering the prospects of (partial) traffic-free zones and court cases that may be a consequence of not being able to meet the limit values.

Figure 7: Annual and Total Number of Articles per Newspaper

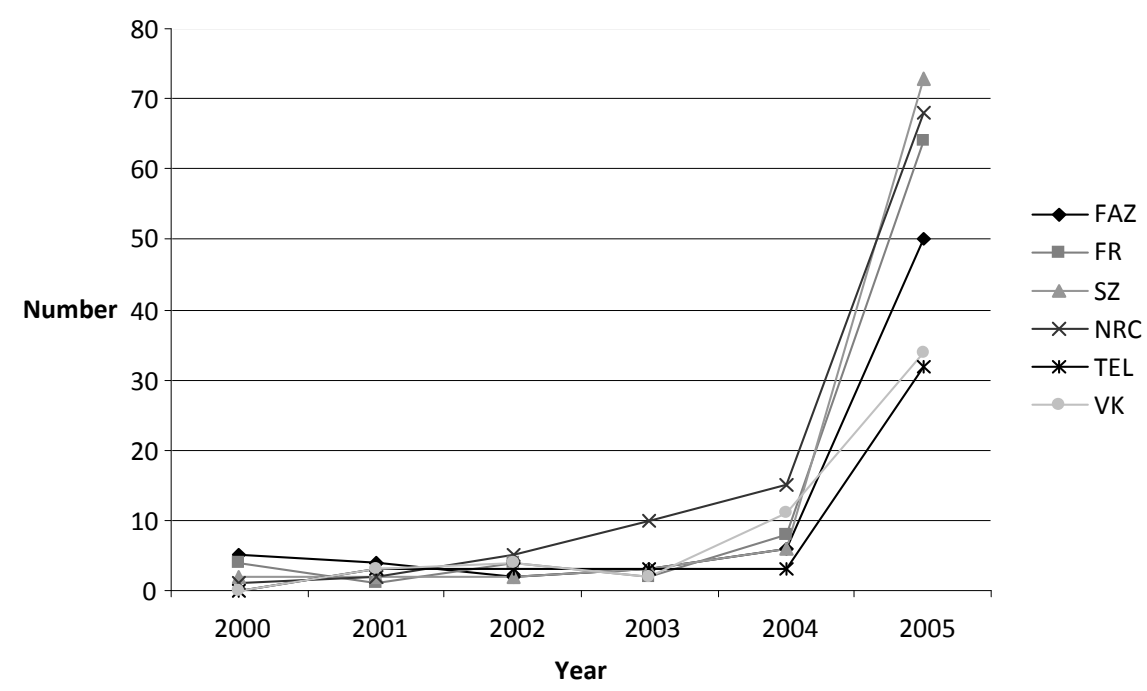

Analysis shows that many actors were surprised about the impact of the EU's legislation, which again suggests a temporal mismatch: initially, with the first daughter directive, the corresponding limit values and their transposition into national law did not feature as salient issues in the public spheres, but as soon as it was recognised that the limit values were creating problems, the debate really kicked off. The lack of early debates is also addressed below - an issue raised on several occasions by various actors. It should be noted that the debate over the implementation of the first daughter directive predominantly took place in a year in which the Commission was intending to present a wider revision of the existing body of air quality legislation. In 2003 a working group had already prepared preliminary proposals regarding $\mathrm{PM}$ which, among other things, focussed on a $\mathrm{PM}_{2.5}$ limit value and on the various sources of PM and their effects (González-Calatayud, 2005b, pp.260-61). In addition, the Commission had already published a review of Directive 1999/30/EC in 
early 2005 (González-Calatayud, 2007, p.266). According to a DG Environment official, the actual debates in the public spheres did not have a direct effect on the new proposals because Commission policymakers did not follow media reporting in the Member States on a daily basis. More important were early Dutch efforts to influence proposals that were then forthcoming. The issue was addressed by Dutch officials during several meetings even at the highest level. As the Netherlands was generally seen as a country with a good track record on environment and with significant technical and policy knowledge in the field, its concerns were taken seriously; the Commission believed that Dutch problems foreshadowed problems that other Member States would later encounter (Interview 16). The fact that the Commission was willing to grant the Member States more time to meet the target values - provided that they could show they had done everything in their powers to try to meet them so far - indicates the Commission was aware of difficulties encountered at the implementation stage.

\section{The Debate in the German Public Sphere}

When analysing the German newspapers, it becomes clear that EU air quality legislation did not receive much attention in the public sphere during the early years of the time period. Anxiety in Germany over air quality increased in late 2004. When the PM limit values came into force in 2005 , everyone was restlessly waiting to see what would follow: would the limit values be met, or would they end up being breached - and if so, when and where? What would the consequences be? On 4 January 2005 Frankfurter Rundschau described the mood by talking about day X the $36^{\text {th }}$ day that the daily average value would be exceeded, the day municipalities feared, the day environmentalists looked forward to because it presented them with the tools to demand tougher measures:

Der Tag $\mathrm{X}$ ist der 36. Tag. Umweltschützer lauern auf ihn, Kommunen fürchten ihn. Kommt er am 30. November in Berlin? Oder schon am 6. Juli in Frankfurt am Main? Seit Anfang des Jahres läuft der Count-Down und alle wissen: Der Tag wird kommen, an dem Umweltschützer "Luft-Alarm" auslösen und im Namen von Anwohnern stark verkehrsbelasteter Straßen ihre Stadt vor den Kadi ziehen. Ihr Anklagepunkt: krank machende, weil von Feinstäuben durchsetzte Luft.

It soon became clear that many cities were struggling to meet the limit values. On 27 March Munich became the first city to exceed the $50 \mu \mathrm{g} / \mathrm{m} 3 \mathrm{PM}$ limit value for more than the 35 days allowed by the directive, though it later became known that Stuttgart had actually breached it before Munich did.

The newspapers would regularly name those cities in the 'danger zone' and those which had already exceeded the limit value for more than 35 days - the 'league table' published by Frankfurter Allgemeine Zeitung on 30 March 2005 is an 
extreme example. The UBA usually provided the data regarding the number of days on which the daily limit value had been exceeded, but its staff - including UBA president Andreas Troge (e.g. SZ 22.03.05) - also played a more active role in the debate by providing background information on the limit values and nature of PM concentrations, and by commenting on possible solutions. Generally, the newspapers discussed PM as a major environmental issue. Road traffic (in particular diesel vehicles) was identified as the main source of pollution by many actors.

The debate in the newspapers focussed particularly on measures that needed to be taken to resolve the situation. In accordance with the framework directive and the daughter directive, Member States were obliged to draft action plans, which in practice was the responsibility of local and regional authorities. ${ }^{148}$ But what should be in those plans: (partial) traffic-free zones, congestion charges? Sometimes the nature of present-day mobility was even questioned, for example, by Thomas Schaller, head of the environment and consumer protection department in Augsburg, who argued that alternative transport solutions and new insights into city design, energy and location policy were needed (SZ 23.04.05). Another theme that surfaced in the articles was the question of responsibility and who exactly was tasked to address the problems that had arisen. Authorities on all levels pointed to each other. The Bundesregierung referred to municipalities and districts, but representatives of the German cities said they needed approval for their plans from the administrative regions (such as Oberbayern) or the Länder governments. Moreover, local authorities argued that the Bund and the Länder should set the legal framework to make certain measures possible. Minister Trittin (Environment) did not support calls for lowering the limit values or postponing them altogether, though, and dubbed these 'irresponsible' (e.g. FAZ 01.04.05). UBA official Axel Friedrich (SZ 31.03.05) even argued that everyone was responsible for the situation which had now arisen, because they had ignored what was heading their way. After all, the limit values were decided upon in 1999 and were transposed into German law in 2002, but what had been done since (FAZ 29.03.04)?

In an article in Süddeutsche Zeitung from 31 March 2005 - entitled 'The small dust of federalism' ('Der feine Staub des Föderalismus') - the debate over responsibilities was discussed within the framework of German federalism. SZ-journalist Ulrich Schäfer reported attempts to put into place an arrangement based on tax incentives that would encourage motorists to fit their diesel cars with soot filters. The Bundesregierung was in favour of such an arrangement, as were the Länder, but the latter demanded financial compensation because, while the Berlin government might decide to impose the new scheme, it would be up to the regional authorities to implement it. The Länder would also have to pay for it through road taxes, which they levied until mid-2009. As a result, they proposed that diesel cars without filters

${ }^{148} \S 47$ of the Federal Immission Control Act refers to 'competent authorities'. 
should be subject to higher taxes, but this was not accepted by the national government. $^{149}$

The debate about European car emission standards and soot filters for diesel cars was particular in the German newspapers, with dedicated, in-depth articles referring to the need to set new emission limits, or to the strategies for car manufacturers to be able live up to these targets, rather than engaging in the wider air quality debate. ${ }^{150}$ The presence of a sizeable automotive industry in Germany surely played a role here - German manufacturers were regularly considered to be technologically less advanced than French car builders, for instance, while industry representatives said they were just making different choices. In fact, sales of diesel cars were expected to decline due to uncertainty regarding the tax benefits for soot filters (e.g. FR 30.03.05).

The debate mainly took place within a national setting, with various stakeholders commenting on what was going on, including citizens and citizens' groups. Occasionally articles would discuss or refer to the situation in other Member States - mostly Italy. The Netherlands is rarely mentioned; when it is, it is purely within the context of those countries experiencing implementation problems, or which have decided to speed up the introduction of soot filters, but without any further coverage of the domestic debate (e.g. FAZ 22.09.05; FR 04.03.05). The PM-related health problems and numerous premature deaths - figures in the newspapers ranged from 10,000 (SZ 03.02.05) to 65,000 (FR 04.03.05) in Germany alone - were often referred to as important reasons to act, though retailers and others raised questions about the negative economic impact of the measures proposed to meet the limit values (for instance, closing off streets). The Commission's September 2005 proposals to update air quality policy and slightly relax the limit values were viewed positively by local administrators, but there was criticism too, even by the BMU (e.g. FR 23.09.05). Generally, supranational actors played but a minor role in the debate. The EU was sometimes the scapegoat for strict legislation, though gradually it was revealed that Germany had (of course) approved the directives and was ultimately responsible for their transposition into national law.

\section{The Debate in the Dutch Public Sphere}

The debate in the Dutch public sphere only really commenced after the Council of State started annulling construction plans that had either not been checked for their impact on ambient air quality, or would lead to a deterioration in ambient air quality. According to State Councillor Simons-Vinckx, member of the Council of State,

\footnotetext{
${ }^{149}$ Schäfer notes that a recent attempt to reform the tax system and make the Bund responsible for these road taxes, actually failed.

${ }^{150}$ The articles that also referred to Europe's ambient air quality policy were included in the analysis; those that did not were not taken into account.
} 
many construction plans were based on incomplete, incorrect, even seemingly manipulated calculations (NRC 26.09.05). In addition, air quality was becoming an ever heavier burden in areas located next to motorways, main roads and in urban areas. Problems were most urgent in the Randstad, the urbanised area in the west of the country, but others such as Maastricht, Nijmegen and Tilburg were encountering difficulties too (e.g. NRC 28.04.05; TEL 19.04.02; VK 06.04.05). Whereas the debate in the German newspapers mainly focussed on the 35-day threshold and the likely measures that would follow, the debate in the Dutch newspapers was equally concerned with the cancellation of building projects; the actual limit values were rarely mentioned. The particularly strict interpretation of the first daughter directive seems to be the reason for this.

The tangible effect of PM and NO2 limit values on actual building projects surely explains why this issue gained considerable attention in the newspapers, particularly when compared to the virtual absence of other limit values, which appeared to be less problematic. PM and, to a slightly lesser extent NO2, were identified as the main polluters - experts noted that PM was one of the most pressing contemporary environmental problems. Like in Germany, road traffic, diesel vehicles in particular, was identified as the core source of PM emissions, though this was questioned by some actors. The newspapers, local and national administrators, environmentalists and several other actors regularly pointed to the detrimental health effects and resulting premature deaths, often backed up with references to various national and international studies, for instance by the RIVM, whose researchers actively participated in the debate too, commenting on various plans (e.g. TEL 26.04.05).

The debate in the Dutch newspapers was mainly a national one, though it was noted that other countries were experiencing similar problems (e.g. VK 26.04.05), in particular cities in Germany (e.g. NRC 24.03.05; VK 02.04.05) ${ }^{151}$, but also in Italy. The domestic debate focused on the question of whether or not postponing various construction projects was a problem, but also on the appropriateness of EU targets. Local and national politicians, as well as representatives of the building sector and the Dutch motoring association (ANWB) were afraid the country would be shut down ('het land gaat op slot'). They considered EU limit values to be unrealistic and pointed at the impact of polluted air that blew in from abroad and the fact that natural substances such as sea salt were also included in the limit values (e.g. NRC 11.10.05; VK 03.11.05). The Dutch link between EU clean air targets and spatial planning came to be seen as the main reason for postponing building projects. In contrast, citizens and environmental organisations perceived EU legislation and Council of State rulings as an opportunity to fight for better air quality. They pointed at the many premature deaths caused by polluted air and PM in particular - more

\footnotetext{
${ }^{151}$ The problems in Germany were also discussed in an article in De Telegraaf on 28 March 2005, but since this article was published in the Sunday edition it was not recorded.
} 
than 10,000 per year in the Netherlands, according to several estimates (TEL 19.02.05; VK 11.05.05). Experts noted that the interpretation of the Council of State's Administrative Jurisdiction Division was correct (e.g. VK 25.09.04).

The theme of responsibility also surfaced in the Dutch dailies. The local and regional administrations demanded action from the national government, but the latter emphasised that the former could do more themselves. ${ }^{152}$ Hence, a plurality of potential solutions was presented by the various Dutch levels of government. These included reducing maximum road speeds, closing off certain streets, introducing soot filters for polluting vehicles, and introducing tax cuts or tax exemptions for cleaner cars (such as hybrid cars). At the same time it was widely acknowledged that the Netherlands might be unable to meet the limit values, at least not in the short term. The government even approached the Commission for an extension of the deadlines, but RIVM research indicated that the Netherlands would not even be able to meet such an extended deadline (NRC 25.04.05; 26.04.05). Meanwhile, experts called for more radical responses, with calls for a more stringent (European) source policy.

The EU was sometimes blamed for overly strict regulations, with references to the Commission now and again. Other institutions were barely mentioned in the newspapers; decision-making at the European level was mostly ignored. Sometimes articles informed the reader that Member States still had time to meet the limit values - for PM by 2005 and NO2 by 2010 - but generally, articles seemed to imply that the limit values were already in force. Considering the transition period included in the first daughter directive, this was not completely incorrect. In reality Council of State rulings foreshadowed the 2005 limit values, because most cases concerned building projects that would only be finished after 2005. Rarely did participants in the debate point out that the Netherlands had taken part in the negotiations on Europe's air quality policy and actually voted in favour of the resulting legislation. Yet, NRC Handelsblad in particular offered room for more nuances and clarification, pointing out that the issue was more complex, since problems may not have been the result of the legislation itself, but of the way in which it had been transposed into Dutch law - the aforementioned link between EU air quality limit values and spatial policy - or of the stringent interpretation of EU directives by the Council of State's Administrative Jurisdiction Division. The articles in De Telegraaf included less nuances and clarifications (for an exception, see: TEL 04.11.05). Even so, the fact that the papers reported it was the government intention to adapt the Besluit Luchtkwaliteit - most explicitly noted in NRC Handelsblad and de Volkskrant - indicated that the Dutch transposition of European air quality legislation impacted on Dutch society.

\footnotetext{
${ }^{152}$ It should be noted that in line with their more limited powers, the Dutch provinces were less prominent in the debate than the German Länder.
} 
The articles show that the Commission's plans for new legislation were viewed with some apprehension: on the one hand, because the Commission proposed new, tougher limit values, including new ones for $\mathrm{PM}_{2.5}$; on the other hand, because new legislation would potentially take into account the particular position of individual countries, while also allowing for certain temporary exemptions. Nonetheless, the number of references to the new thematic strategy and draft directive was limited (e.g. NRC 21.09.05; TEL 22.09.05; VK 22.09.05), though not much less than in the German newspapers.

\section{The Three Dimensions}

The period covered in this case includes a number of important moments in the development of EU air quality policy, including: the transposition of the first daughter directive into Dutch and German law; the agreement on and transposition of the second, third and fourth daughter directives; the coming into force of the PM limit values; and the presentation of Commission proposals to update and revise the existing legal framework. Some of these policy developments led to much debate in Brussels (see, for example: Catalayud, 2003, pp.375-7; Catalayud, 2006, pp.211-3; González-Calatayud, 2005a, pp.380, 387), yet in Germany and the Netherlands the focus was mostly on the first daughter directive and, in particular, on PM and NO2. This again illustrates that debates on EU policy take place in different contexts when the focus of 'weak' or 'strong' publics, and there may be no public resonance at all.

The other hazardous substances were barely mentioned in the newspapers; some never even turned up during the sampling of the articles. One exception concerns an article in Frankfurter Rundschau (04.01.05), which ends with an overview of the $\mathrm{SO} 2, \mathrm{CO}, \mathrm{NO} 2, \mathrm{PM}_{10}, \mathrm{O} 3$ and benzene $(\mathrm{C} 6 \mathrm{H} 6)$ targets. Nevertheless, the body text of the article almost exclusively dealt with the 2005 PM limit value. Another exception concerns an article in NRC Handelsblad (14.04.05) about a number of infringement cases, and one in particular that concerned the belated adaptation of rules regarding $\mathrm{CO}$ and $\mathrm{C} 6 \mathrm{H} 6$ limit values. The substances arsenic, cadmium, lead and nickel did turn up while compiling the set of articles, but predominantly in the context of other EU policies, for instance with regard to electronic waste or the composition of batteries. These articles were therefore excluded. $\mathrm{O} 3$ was the only hazardous substance that received more attention in the newspapers, mostly due to the warm summer of 2003, though the approval of the related directive by the Council was covered by Frankfurter Allgemeine Zeitung and Süddeutsche Zeitung, both on 11 October 2000.

In other words, besides the temporal mismatch, this case also displays a content-related mismatch, regarding the virtual absence of references to the other directives and process by which they were drafted, approved and transposed, but 
also regarding the depiction of the policy-process for Directive 1999/30/EC. This will be further explored in the following sections about the three content dimensions.

\section{The Issue Dimension}

Air quality policy may be a much more technical issue than the future of Europe essentially a political topic, concerning power and prestige. Yet, gradually the clean air debate also became a very political debate. While the PM limit values were increasingly viewed as difficult or even impossible to meet, the heterogenic group of actors that participated in the debate (see the actor dimension) got caught up in a debate that questioned the measures to be taken and who should be taking them, but also the appropriateness of the limit values (were they too strict?). Due to the fact that both debates were predominantly national affairs, only two events were discussed in all six newspapers, namely the Commission's internal debate about the costs versus benefits of environmental policy, and the Commission's presentation of the proposals for revised air quality legislation. De Volkskrant and De Telegraaf devoted attention to the first of these issues earlier than the other newspapers; both announced the forthcoming debate but did not refer to the outcome (at least not in the selected articles). There was some attention to PM-related challenges in other countries, but just by means of illustration, not as a way to exchange views and opinions. For example, Munich's struggle to meet the EU limit values was noted in both public spheres, as were the problems in Italian cities and London's congestion charge, mentioned as an example of an effective measure in all newspapers. In both debates certain national issues were discussed simultaneously, such as German plans to introduce coloured stickers in the German newspapers, and the revision of Dutch air quality legislation in the Dutch newspapers. Other topics were discussed at different times or were reported more prominently in some newspapers than in others - as was also the case in the debate about Europe's future.

Table 6: The Issue Dimension in Figures

\begin{tabular}{lcccc}
\hline & $\begin{array}{c}\text { Which issues are at } \\
\text { stake? }\end{array}$ & $\begin{array}{c}\text { What is the back- } \\
\text { ground/context? }\end{array}$ & $\begin{array}{c}\text { What role should the } \\
\text { EU play? }\end{array}$ & $\begin{array}{c}\text { What is the relevance } \\
\text { of the policy? }\end{array}$ \\
\hline FAZ (70) & 70 & 70 & - & 39 \\
\hline FR (83) & 83 & 83 & - & 56 \\
\hline SZ (88) & 88 & 88 & 5 & 64 \\
\hline NRC (101) & 101 & 101 & - & 80 \\
\hline TEL (44) & 44 & 44 & 1 & 42 \\
\hline VK (54) & 54 & 54 & 49
\end{tabular}

NB This table simply records whether information appears in an article at all. In a few cases an article contains more than one piece of information. 
As with the future of Europe, the debate surrounding the EU'S air quality legislation was the subject of articles not specifically dedicated to this issue. One might argue that this applies to most analysed articles, as many discussed national policy with references to EU policy, not EU policy in particular. However, the national implementation and enforcement of legislation is very much part of the EU policy process. We can deduce from this that EU affairs - in this case air quality policy - are seen to affect other policy areas, or are acknowledged as being important in national politics.

In a secondary context, the PM directive and its policy process were mentioned as an example of how EU affairs should not be conducted. It was compared with the policy processes for other EU policies, such as a directive on water quality (NRC 07.04.05) and the environmental noise directive (FAZ 20.04.05). In both cases, stakeholders warned that a situation could arise that presented challenges similar to those posed by the PM directive, if these new pieces of legislation were not taken seriously enough.

There were also references to air quality policy within the context of democratic decision-making and parliamentary control in EU affairs. On two occasions CSUleader and Bavarian Minister-President, Edmund Stoiber, was noted as saying that it was unacceptable that issues like the PM directive were being discussed in such a secretive manner in Brussels, without any prior open debate in parliament and in the public sphere. According to Stoiber, this not only resulted in the late recognition of what EU legislation actually entails, and what it means in practice, but may also led citizens to believe decisions are being made without engaging them:

\footnotetext{
"Was wir brauchen, ist eine wesentlich frühere beteiligung der Öffentlichkeit. (...) Sonst bekommt der Bürger das Gefühl, er werde mit wesentliche Entscheidungen in seiner Existenz betroffen, ohne dass er davon weiß." (SZ 15.04.05; see, also: FAZ 30.04.05)
}

During a British-Dutch conference about the role of national parliaments in the EU, several Dutch MPs referred to the PM directive as an example of national parliaments being completely unaware of the eventual consequences, including potential postponement of building plans by the Council of State (NRC 18.11.05). Just a couple of weeks later de Volkskrant (06.12.05) noted that a few months after the Dutch 'no' to the European Constitution, only four MPs attended the national parliament's session on the Commission's annual work plan. Yet, the paper continued, both current and future legislation (including European air quality limit values) were controversial in light of several building projects in the Randstad having been postponed. The press and public galleries were virtually empty too. ${ }^{153}$

\footnotetext{
${ }^{153}$ Incidentally, the air quality debate also turned up in a few other articles which principally dealt with the debate about the future of Europe (FR 02.06.05; NRC 28.04.05; SZ 02.05.05).
} 
As can be seen in Table 6, the majority of articles referred to the relevance of the policy - either what would happen if the limit values were exceeded (Commission cases, other court cases, Commission demands for action plans) or what the effect of the limit values themselves might be (that is to say health versus economy). In the Dutch newspapers references to the policy's relevance became gradually more concerned with the increasing amount of cancelled construction projects, so there was equal interest in the impact on planning as in the health risks of polluted air, the latter never completely absent from reporting. In the German newspaper the prospect of court cases brought by citizens and environmentalists, as well as the obligation to draft action plans, were often mentioned as the main relevance of policy; as in the Netherlands, the reference to health risks remained prominent throughout.

The traditional dispute between ecology and economy was an important theme in the air quality debate in both Germany and the Netherlands (cf. NRC 16.09.04; FAZ 13.04.05). As it was put in a commentary in Frankfurter Rundschau, 'the old game starts anew':

Das alte Spiel beginnt aufs Neue: Umweltschützer rufen nach Aktionen, packen die Folterwerkzeuge - Fahrverbote, City-Maut und Tempolimit - aus, fordern Rußfilter und Nachrüstung. Die Wirtschaft beschwört zu hohe Kosten, Untergang und Stillstand. Der Handel sieht sich von den Ökos in "Geiselhaft" genommen. (FR 29.03.05)

Retailers in city centres, construction companies, but also MPs, regional and local politicians expressed concern that the EU's clean air legislation might present too heavy a burden, given the postponement of construction projects and discussions by city councils as to which measures to take. They argued that introducing (partial) traffic-free zones would be at the expense of economic development and would result in deserted city centres, because consumers and suppliers would be unable to reach shops (e.g. SZ 13.08.05; TEL 23.11.05). As one might expect, this argument was countered by others, in particular, representatives of environmental organisations, but also politicians from several parties (e.g. FR 05.04.05; SZ 19.03.05; VK 21.11.05). Commissioner Dimas (Environment) noted that the debate about costs should not overlook the fact that human health was at stake. Moreover, the benefits from protecting public health, and the resulting reduction in rates of premature death and disease, would outweigh the costs of implementing the air quality policy (e.g. FR 24.05.05; see the actor dimension).

These differences of opinion were even noted at 'street level'. On 6 April 2005 de Volkskrant reported on the situation in two of the Netherlands' most polluted streets: the Stille Veerkade and the Amsterdamse Veerkade (both in The Hague). Some residents complained about traffic emissions and particles that dirtied their houses and the air they breathed, whereas others believed the situation was not that bad. One Turkish shop-owner summarised the challenge in only a few words: 
“De verontreiniging is ongezond, maar er moeten ook klanten komen."

To keep his food products healthy he kept his shop door closed as much as possible. The debate about the costs versus the benefits of EU environmental policy and clean air legislation was also played out inside the Commission, as will be discussed in the process dimension.

The debate during this particular period was very much occupied with the transposition, implementation and enforcement of EU policy and, in particular, the question of how to meet the PM limit values. The debate in Germany was more concerned with which measures had to be taken, though this issue was also relevant in the Dutch debate. In both countries measures were proposed by national (e.g. FAZ 10.08.05; VK 18.06.05), regional (e.g. SZ 06.04.05; TEL 18.05.05) and local administrations (e.g. FR 31.03.05; NRC 30.09.05), as well as by various other organisations (such as organisations promoting the use of natural gas: FR 21.05.05; TEL 14.05.05), and included spraying streets, (partial) traffic-free zones, lowering speed limits and introducing subsidies for cleaner cars. The fact that the Commission could eventually bring cases or that citizens and environmentalists might bring cases in national courts, was a constant threat, even though the Commission announced it would probably await the first annual reports before taking action; this effectively meant that no cases would be brought to court before 2006 (e.g. FAZ 30.03.05). Even so, all newspapers reported on (potential) Commission sanctions or infringement procedures regarding the transposition and implementation of several pieces of air quality legislation (all but De Telegraaf and de Volkskrant did on 23 January 2004). According to then Commissioner Wallström (Environment), the Member States' disregard was detrimental for citizens' health (FAZ 23.01.04; FR 23.01.04).

As previously mentioned, the implementation record in EU environmental policy is not very impressive. This latter observation was also the main focus of an article about the implementation of EU environmental policy in Frankfurter Rundschau (20.08.04), which even noted that clean air policy is one of three most problematic areas (see, also: NRC 24.01.04). Also, in an article in de Volkskrant primarily concerned with Council of State rulings on EU environmental legislation, such as the Habitats Directive ${ }^{155}$ and the PM directive, Jonathan Verschuuren, professor of European and International Law at Tilburg University, argued that such rulings are mainly the result of 'playing catch-up', when more attention is paid to European law:

"We hebben jarenlang onvoldoende oog gehad voor Europese regelgeving. Men is nu eindelijk waar men jaren geleden had moeten zijn." (VK 31.01.05)

\footnotetext{
154 "The pollution is unhealthy, but customers will have to come too." (Own translation).

${ }^{155}$ Council Directive 92/43/EEC of 21 May 1992 on the conservation of natural habitats and of wild fauna and flora, OJ 1992, L206/0007-0050.
} 
Besides the debate over the problems both countries were encountering with the limit values, the newspapers also focussed on the nature of those values and the possible effects of PM. ${ }^{156}$ Actors in the debate regularly referred to scientific studies as did background articles in the newspapers. As well as those by RIVM and UBA already mentioned, references included scientific studies by various organisations and universities from European and non-European countries, including the World Health Organisation (WHO) and the EU. In fact, WHO research was identified as an important source of information at the time when the EU limit values were determined (FAZ 29.03.05; NRC 26.10.05; SZ 30.11.04), which was indeed the case (Lefevere, 2000, p.379). Researchers, epidemiologists, politicians and representatives of environmental organisations in particular, such as Deutsche Umwelthilfe (German Environmental Aid) and Stichting Natuur en Milieu (the Netherlands Society for Nature and Environment) referred to varying numbers of premature deaths, but also potential PM-related health problems (including cancer, respiratory problems and vascular diseases).

There seemed to be widespread agreement that PM poses real problems - de Volkskrant (26.10.05) noted that even well-known environmental sceptics such as Björn Lomborg considered PM-related problems to be a major challenge. ${ }^{157}$ Yet, it was also noted the limit values were relative and arbitrary (e.g. SZ 23.03.05; 23.04.05). Epidemiology professor Bert Brunekreef of Utrecht University explained that even where the limit values were not exceeded, the air was still not clean and health problems could still arise:

\begin{abstract}
"De norm is een afspraak. Aan afspraken moet je je natuurlijk houden, maar zelfs als je onder die norm zit, wil dat nog niet zeggen dat de lucht schoon is. Juist de allerkleinste deeltjes, de nanopartikels die gevormd worden in het verkeer, zijn waarschijnlijk het gevaarlijkst en qua aantal veruit in de meerderheid. Het is dus de vraag, of de PM10 die de Europese regelgeving hanteert, wel de goede maat is. Maar het is nu eenmaal wel de norm waar we het voorlopig mee moeten doen." (NRC 28.04.05; cf. VK 26.04.05)
\end{abstract}

Brunekreef added that EU legislation at that point only concerned $\mathrm{PM}_{10}$, whereas smaller particles were probably even more harmful. In other words, the official EU limit values did not suffice (e.g. FAZ 28.01.04; SZ 21.03.05; VK 13.05.05). In this context, a few references were made to the US, where $\mathrm{PM}_{10}$ and $\mathrm{PM}_{2.5}$ limit values had already been in place for many years (NRC 18.06.05; SZ 06.02.01; VK 13.05.05). Researchers also pointed out that there was little knowledge of what exactly happens when PM enters the body and how health problems were arising (e.g. NRC 18.06.05; VK 14.12.02).

\footnotetext{
${ }^{156}$ This issue was least prominent in De Telegraaf.

${ }^{157}$ For an exception to this general consensus, see: NRC 01.11.05
} 
Another technical discussion concerned the sources of PM pollution. While road traffic and, in particular, diesel vehicles were generally identified as main source of pollution, this assumption was questioned or put into broader perspective (e.g. SZ 01.04.03; SZ 31.03.05). Some argued that the absolute contribution of road traffic was small compared to other sources, such as large combustion plants (e.g. FAZ 19.04.05; FAZ 26.04.05). Others however argued that the relative impact of road traffic was significant, as pollution was emitted in urban environments where more people could be affected (e.g. FAZ 13.04.05; NRC 01.02.03). Moreover, the composition of car emissions was felt to be more detrimental, due to the small particle size of diesel soot. Finally, the fact that PM consists of various types of substances, some of which are of natural origin, was also identified as an issue that EU legislation should focus on further (e.g. NRC 18.10.05).

While the nature of the limit values - were they too strict, too costly? - was subject to debate, it seems to have been generally accepted that air quality policy should be set on the European, not national, level. Sometimes sceptical opinions were expressed (e.g. NRC 13.10.05; FAZ 26.04.05) and it was not always clear that the Member States themselves were responsible for the limit values; at times it seemed as though 'the Commission' or 'the EU' had imposed them on the Member States (see below). Nevertheless, occasionally the Commission was explicitly credited for its efforts to combat a major health risk:

Der Europäische Kommission sei Dank, dass die Mitgliedsländer nun endlich Kenntnis nehmen von einer erheblichen Gesundheitsgefahr für die Bevölkerung. (SZ 02.04.05)

Gelukkig geeft Brussel meer om de gezondheid van de burgers. (NRC 08.04.05)

Seit Jahrzehnten gehört Ökologie auf die Habenseite einer sonst nicht nur positiven EU-Bilanz. Die friedlich zu Lande, zu Wasser und der Luft geschlagenen Schlachten bringen für alle Europäer mehr Lebensqualität. (FR 20.07.05)

When the role of the EU was discussed with a view to whether or not it should be involved in policymaking, the focus was mostly on the need for a more stringent source policy for cars or other major polluters (e.g. NRC 17.10.05).

\section{The Process Dimension}

As previously explained, the debates predominantly focussed on the PM limit values, the inability to meet them and the resulting discussion about, firstly, what would happen if the limit values were exceeded and, secondly, what the reaction from Brussels might be. The transposition of the first daughter directive did not receive particular attention (for an exception, see: FAZ 13.12.01). It did become an issue in 2005, however, when several commentators and actors noted that the 
agreement on, and transposition of, the first daughter directive had taken place way before the 2005 limit values actually came into force. The presentation of the new Commissions proposals was noted by all newspapers, as was the earlier discussion inside the Commission on the costs and benefits of environmental policy, both of which are discussed below.

As seen in Table 7, most attention was devoted to the current state of affairs. References to past and future events were more limited, tending to focus on events on the national level, rather than what had happened or was going to happen on the EU level. Such information was only present in predominantly backgroundrelated articles on: the limit values and how they came about, relevant debates in the Commission, or the new air quality plans. In other words, as for the previous case, the process dimension displays relatively little information about the initial development of EU air quality legislation. The focus is mostly on the present state of affairs, the existence of the PM limit values or - in the years up to 2005 - the imminent coming into force of the limit values.

Table 7: The Process Dimension in Figures

\begin{tabular}{lcccc}
\hline & $\begin{array}{c}\text { What was the state of } \\
\text { affairs in the past? }\end{array}$ & $\begin{array}{c}\text { What is the current } \\
\text { state of affairs? }\end{array}$ & $\begin{array}{c}\text { What will happen } \\
\text { next? }\end{array}$ & $\begin{array}{c}\text { How is the policy } \\
\text { process shaped? }\end{array}$ \\
\hline FAZ (70) & 21 & 64 & 21 & 60 \\
\hline FR (83) & 26 & 77 & 27 & 72 \\
\hline SZ (88) & 35 & 83 & 22 & 76 \\
\hline NRC (101) & 35 & 90 & 30 & 87 \\
\hline TEL (44) & 9 & 41 & 9 & 36 \\
\hline VK (54) & 8 & 51 & 18 & 49 \\
\hline
\end{tabular}

NB In some cases articles contained more than one reference to the past, present and future, and/or the decision-making process. This table only records whether such pieces of information appeared in an article at all.

References to past events were not absent. In 2005 it was noted increasingly that the limit values had been decided several years before coming into force, in the earlier stages of the policy process. Criticism was directed at the public authorities whom, allegedly, had not prepared thoroughly enough to cope with the coming into force of the limit values - in other words, the debates referred to notions of responsibility and accountability. The procedure by which the Member States had approved the limit values - consensus, unanimity or majority voting - was seldom made clear. Germany and the Netherlands were increasingly identified as having agreed to the limit values. For example, in de Volkskrant of 21 November 2005 Mirjam de Rijk, chair of Stichting Natuur en Milieu, wrote that the priorities of the 
Netherlands did not seem to be to combat pollution - the EU legislation was already six years old but the country had only started to act that year:

Al zes jaar is bekend dat de Nederlandse lucht op basis van Europese, door Nederland goedgekeurde milieuregels schoner moet. En dat luchtvervuiling de volksgezondheid flink schaadt, is nog langer bekend. Desondanks is Nederland pas dit jaar veel te laat dus - begonnen de vervuiling van de lucht met fijnstof aan te pakken.

A similar remark was made by FR-journalist Joachim Wille, in a commentary on 29 March 2005. Wille not only referred to the policymaking process in Brussels, but also to the transposition of the PM directive into German law in 2002:

Seit 1996 hat man die Feinstaub-Richtlinie in Brüssel und Straßburg beraten und vor rund drei Jahren in deutsches Recht genommen. Ebenso lange hatten Bundes- und Landespolitiker, Stadtverwaltungen, Spediteure und Autokonzerne Zeit, die Lage zu entschärfen. Doch passiert ist bis zum Stichtag 1. Januar 2005 praktisch nichts.

Only one article presented a more thorough synopsis of the policy process and that was published by Frankfurter Allgemeine Zeitung on 29 March 2005 - that is to say after the limit values came into force. The article explained that the air quality framework directive dated from 1996 and was worked out in three directives dealing with SO2, lead, PM and NOx (1999), on C6H6 and CO (2000), and on O3 (2002). ${ }^{158}$ It reported that the original proposals of the Commission from 1994 had been based on legislation dating back to the 1980s, and had even included stricter PM limit values than those in force, because the original proposals were weakened by the Member States. It informed the reader that the then current limit values (a daily average of $50 \mu \mathrm{g} / \mathrm{m} 3$ air that could not be exceeded more than 35 days, and a yearly average of $40 \mu \mathrm{g} / \mathrm{m} 3$ air) - which had gradually come into force from 1 January 2001, and been fully applied from January 2005 - were set to be tightened further in 2010 (when the daily average could only be exceeded seven days, and the yearly average halved to $20 \mu \mathrm{g} / \mathrm{m} 3$ air). The article continued to explain that while the directives did not call for traffic-free zones, they did oblige Member States to draft programmes to decrease the concentration of hazardous substances in the air. The Member States themselves would decide how to meet the limit values. The Commission would oversee the correct implementation of the air quality legislation and could go to the ECJ if Member States did not present convincing action plans. In short, the then current limit values were the result of a long, open policy process. In the words of Minister Trittin (Environment; Greens), everyone should have known what was heading their way:

\footnotetext{
${ }^{158}$ The article does not refer to the fourth daughter directive.
} 
Da kann man dem Umweltminister Trittin (Grüne) kaum widersprechen. "Jeder wußte, was da auf inn zukommt", hatte er den Ländern und Gemeinden entgegengehalten, als am vergangenen Donnerstag in München der neue Grenzwert für Feinstaub zum 35. Mal überschritten wurde.

As already briefly noted, this particular line of reasoning - that limit values were set years ago so those responsible should have been prepared - was a particular theme in the debate in 2005, at times even before (e.g. VK 25.09.04). Such reasoning was highlighted by the newspapers themselves, but also by several actors in the debate. The existence of air quality limit values seemed on some occasions to come as a surprise to many stakeholders in Germany and the Netherlands; in some articles parliament was criticised for having been 'asleep' when things were being settled in Brussels. Whether this was an attempt to 'shift blame', or the reflection of a profound lack of policy knowledge, analysis of this debate again shows how national debates often trail behind the policy process in Brussels.

Limited awareness of the process by which the values came about was also reflected in the allocation of responsibilities. Here, the Commission was regularly identified as the main decision-maker. Member States had to address to request an extension of the deadlines, or an exemption from existing rules in order to introduce mandatory soot filters ahead of time (as the Netherlands attempted). This is correct on the whole; the Commission is responsible for monitoring the implementation of EU legislation and, hence, can in theory start infringement cases. However, occasionally the Commission was depicted as the institution that had dictated those limit values (e.g. TEL 03.06.05) or insisted on them (e.g. SZ 19.02.05). These objectives had also been decreed or determined by 'the European Union' (e.g. FAZ 30.03.05; VK 16.10.04) or originated from 'Brussels' (e.g. FR 21.03.05; NRC 29.06.05).

In reality, the 1996 framework directive and the first daughter directive were the result of the cooperation procedure, whereas the other directives were based on co-decision. In other words, in all cases the Council and the Parliament had been involved, but were rarely referred to in the debate. The responsibilities of the individual Member States were mentioned more frequently (e.g. FAZ 29.03.05; FR 04.04.05; NRC 10.12.04; SZ 22.09.05; TEL 01.12.05; VK 22.09.05). Nevertheless, their role as decision-makers was less prominent than their role as implementers of existing legislation. Responsibility for taking the initial decisions was mostly only implicitly implied, by noting the approval of the existing air quality legislation by Germany and the Netherlands, which can be partly explained by focus of the debates on the challenges of implementation.

The EP and its members played little role in the debate. De Telegraaf did not refer to the EP and its members at all, while only one Dutch MEP, Jules Maaten (VVD), was interviewed by de Volkskrant, and then in the context of the 2004 EP elections 
(VK 21.05.04). NRC Handelsblad also referred to the EP only once, namely within the context of the internal Commission debate about the costs and the benefits of environmental policy, where it was noted that, in 2002 the Member States and the EP had asked the Commission to present new plans in various policy fields, including air quality (NRC 21.07.05). In Frankfurter Rundschau (22.09.05; 23.09.05) and Süddeutsche Zeitung (20.07.05; 22.09.05) MEPs reflected on the internal Commission debate and the new air quality proposals, but in Frankfurter Allgemeine Zeitung no individual MEPs are mentioned, just one reference to anonymous 'Europaabgeordneten' (FAZ 11.10.00). In the context of the launch of new air quality proposals, all three German papers noted the EP is fully involved in EU decision-making in the field of air quality regulation.

Despite its 'green' image, the EP - and its ENVI committee - figured little in the debates, which can probably be explained by the focus on implementation - those MEPs that did figure in the debate, tended to do so in the context of the new Commission proposals and the Commission's internal debate about the costs versus benefits of environmental policy. The latter foreshadowed the announcement of the new clean air strategy. This debate in July 2005 was picked up by all six newspapers, all of which presented it as a general debate about environmental policy and its compatibility with economic growth, with the exception of De Telegraaf (05.07.05), which restricted it to clean air policy. Commission President Barroso and Commissioners Mandelson (Trade), McCreevy (Internal Market) and Verheugen (Industry) reportedly wanted to make sure that the costs of environmental policy would not become disproportional. Frankfurter Rundschau $(05.07 .05 ; 21.07 .05)$ and NRC Handelsblad (21.07.05) both referred to a letter to Barroso by UNICE about the costs of air quality policy, which may well have influenced his decision to postpone new legislation until after the summer break. Yet, Environment Commissioner, Dimas, claimed the costs of this policy would be outweighed by the benefits of saving lives and serious illness (FR 20.07.05; NRC 21.07.05; SZ 20.07.05). This internal debate reflected the different preferences and priorities of the involved Commission DGs (see: González-Calatayud, 2007, p.270).

The redrafting of the existing legislation also received attention in the Dutch and German public spheres and was announced at an early stage in Frankfurter Rundschau (24.05.05) and Süddeutsche Zeitung (21.05.05). According to newspaper reports, the Commission was considering a number of changes that would affect the situation in both countries, such as the need to set limit values for even smaller particles, extended deadlines and the exclusion of natural PM sources from their calculations (e.g. FAZ 22.09.05; FR 22.09.05; NRC 21.09.05; SZ 22.09.05; TEL 22.09.05; VK 22.09.05). NRC Handelsblad (29.09.05; 03.12.05) and De Telegraaf (01.12.05) announced that for the first time the Council of Ministers would discuss Commissioner Dimas' proposals on 2 December. As seen previously, in both the Netherlands and Germany the debate over the implementation and enforcement of 
the existing limit values seemed to foreshadow the new 2005 proposals, though the exact impact is difficult to determine.

While some reactions to the Commission's proposals were unsurprising - representatives of companies and municipalities welcomed them, environmentalists criticised them - it is noteworthy that the governments of Germany and the Netherlands reacted differently. The BMU was reportedly not in favour of relaxing the limit values, because this would take place at the expense of public health: a BMU spokesperson called it a 'license to do nothing' ('Freibrief zum Nichtstun'; FR 23.09.05). In contrast, the Dutch State Secretary for Environment, Pieter van Geel, was apparently cautiously positive, but regretted the Commission did not pay more attention to the specific circumstances of the Member States. He further argued that instead of setting a new $\mathrm{PM}_{2.5}$ limit value, more emphasis should be put on determining a tough source policy for road traffic (NRC 21.09.05; TEL 22.09.05). In line with earlier remarks concerning the focus of the debate, the German newspapers noted that the proposals might allow municipalities more time to decide on the best way to combat air pollution, perhaps without having to resort to driving bans (FR 23.09.05) - though this threat would not disappear from the agenda, a representative of the German cities noted (FAZ 22.09.05). The Dutch newspapers recorded few other reactions to the Commission proposals. Yet, in NRC Handelsblad (24.09.05) Cor Lamers, mayor of Houten and chair of the environment committee of the organisation of Dutch municipalities, VNG, said he was quite satisfied. He was probably reflecting what many stakeholders thought. VNG had frequently called for measures to prevent the Netherlands from being 'shut down'. According to Lamers, Dimas presented the key to the lock that opened the door to the Netherlands:

"Dimas heeft ons het sleuteltje gegeven van het slot op Nederland"

Despite the fact that there were few or incomplete references to responsibility at the European level, there were many accounts of responsibility at the national level, from cities to district government (in Germany) to courts - in other words, reflecting the particular phase of the policy process (policy implementation). In both public spheres the authorities at several levels held each other responsible (e.g FR 21.03.05; NRC 15.04.05; VK 21.04.05; SZ 30.03.05), in what sometimes appeared as attempts to avoid having to take the blame for unpopular decisions (cf. FAZ 06.04.05). Many measures could have been decided upon at the local or regional level, but others required a decision at the national level or even EU approval. For example, to allow for traffic-free zones in the city centres of Germany, a colour sticker system was seen as an important tool to help distinguish between more and less polluting cars - the government in Berlin would have to draw up such a system (e.g. SZ 02.06.05). In the Netherlands there was widespread support for making diesel soot filters obligatory, but due to European competition rules Commission 
approval was required (e.g. NRC 16.11.05). The Commission signalled it would not support this measure, implying that it should permit an extension of the goals, MP Liesbeth Spies (CDA) argued (VK 04.11.05).

Tax incentives for fitting diesel cars with soot filter were also made available in the Netherlands; German politicians were strongly pushing for such incentives too. This required approval by the Bund and the Länder, but they disagreed about fundamental aspects of the system, in particular, about who should pay for it. Commission approval didn't seem to be an issue and was raised only once in the analysed articles, by the Land Nordrhein-Westfalen (SZ 31.03.05). In a debate hosted by Süddeutsche Zeitung a Ministry of Environment official noted that a soot filter obligation was never an option due to EU competition law (SZ 23.04.05).

In the Netherlands the debate about a new national law (Bes/uit Luchtkwaliteit) became an element in the discussion about responsibilities and, in particular, the idea to develop an 'on-balance approach' or 'saldobenadering' (e.g. NRC 21.07.05; TEL 21.07.05). It focussed, for example, on ways in which the Council of State's Administrative Jurisdiction Division's rulings could be prevented, by changing the application of the air quality legislation. Ever more experts claimed that the way in which the government had transposed the air quality legislation was needlessly strict, particularly with a view to the linkage between the limit values and spatial planning, which led to the cancellation of construction projects (e.g. NRC 26.04.05; VK 20.05.05). Other experts noted that the Netherlands had actually correctly interpreted the European legislation - other Member States would soon have to adapt their interpretation to the Dutch way of doing things (e.g. VK 25.09.04).

\section{The Actor Dimension}

Compared to the debate on the future of Europe, the actor dimension in this case displays two differences. First, the newspapers clearly referred to less transnational and supranational actors; the large majority of actors were domestic. Second, the air quality debate not only attracted politicians and political parties, but also various interest organisations, research centres and citizens' organisations - as is generally the case with regards to environmental policymaking (e.g. Cox, 2006, pp.20ff). The main similarity between the actor dimensions of both cases is that the newspapers offer room to different opinions within the various articles. In addition, again quite a few actors were only mentioned once, though overall the diversity of actors was much greater in this case than in the previous one.

Articles reported on debates in parliament, or presented synopses of other debates, such as the aforementioned debate hosted by Süddeutsche Zeitung (23.04.05), which brought together representatives from all domestic levels of government, and several interest organisations. In some cases, letters from representatives of these organisations or from readers referred to previous articles, letters or 
editorials. This was most clearly the case in a series of articles in NRC Handelsblad, in which several actors commented on each other, fuelled by an opinion piece of 17 October 2005 by State Secretary Van Geel (Environment) who himself partly reacted to articles in de Volkskrant and NRC Handelsblad. ${ }^{159}$ He argued against a decoupling of the link between spatial planning and environmental rules or relaxing limit values such as those regarding air quality. He expressed his support for creative, effective and feasible solutions. Several scholars, property developer Peter Noordanus, and the chair of environmental organisation Stichting Natuur en Milieu, Mirjam de Rijk, took part in this debate-in-the-debate, which featured many of the aforementioned characteristics and arguments: a heterogeneous set of domestic actors that discussed the postponement of building plans, the apparent detrimental health effects caused by PM, the possibility of adapting existing legislation - all of this accompanied by rather limited information about the way in which the limit values had come about and the role played by European and national legislators (NRC 18.10.05; 26.10.05; 27.10.05; 01.11.05; 17.11.05).

Table 8: The Actor Dimension in Figures

\begin{tabular}{|c|c|c|c|c|c|}
\hline & National & Transnational & Supranational & Non-EU & Total \\
\hline FAZ & $119(64.32 \%)$ & 37 (20.00\%) & $21(11.35 \%)$ & $8(4.32 \%)$ & $185(100 \%)$ \\
\hline FR & $171(70.66 \%)$ & 45 (18.60\%) & $20(8.26 \%)$ & $6(2.48 \%)$ & $242(100 \%)$ \\
\hline SZ & 195 (74.71\%) & $43(16.48 \%)$ & 17 (6.51\%) & $6(2.30 \%)$ & $261(100 \%)$ \\
\hline NRC & 149 (65.35\%) & $46(20.18 \%)$ & 18 (7.89\%) & 15 (6.58\%) & $228(100 \%)$ \\
\hline TEL & 74 (81.31\%) & $8 \quad(8.79 \%)$ & $6(6.59 \%)$ & $3(3.30 \%)$ & 91 (100\%) \\
\hline VK & 116 (67.84\%) & $36(21.05 \%)$ & $13(7.60 \%)$ & $6(3.51 \%)$ & $171(100 \%)$ \\
\hline
\end{tabular}

NB To avoid recording actors multiple times, this table only mentions the totals per newspaper. Actors are only counted once, even if they occur more than once.

Although the figures in Table 8 may suggest otherwise, transnational actors were not quoted extensively, but only figured in a few articles that reported on or referred to the PM-related problems other Member States were experiencing. Few of these actors addressed politicians in other countries or even European-level decision-makers: only, for example, in the context of the disagreement between Brussels and Austria with regards to transit traffic (e.g. FAZ 06.04.04; FR 02.08.03; SZ 31.08.02); to acknowledge that the UK was seeking an extension of the air quality deadlines (like the Netherlands (VK 01.10.04)); or to refer to administrators in Germany and Italy who had criticised the stringent EU limit values (e.g. NRC 06.04.05). In other words, even though related experiences (such as London's congestion

\footnotetext{
${ }^{159}$ Van Geel's article was unavailable in LexisNexis, but the digital archive of NRC Handelsblad still contained the article. Although an updated version, it was included in the analysis.
} 
charge or the threat of criminal law cases in Italy) were discussed, the relatively few articles that did refer to other Member States generally reflected on the national debates in those countries - there was no exchange of opinion across borders. Transnational actors included more anonymous bodies or stakeholders, such as cities, but also persons, such as Environment Minister, Trittin, in the Netherlands, London's mayor, Ken Livingstone, and some of his Italian colleagues in both public spheres. Dutch actors did not figure at all in the German debate, even though at the time the new Commission plans were presented the Netherlands was identified as another country struggling to meet the EU limit values (e.g. FAZ 22.09.05; FR 22.09.05).

As previously noted, research centres provided data and expertise about the limit values and health-related consequences of not being able to meet them. Several other actors referred to research centres to substantiate their arguments pro and contra the existing legislation. The research community was clearly presented as an international community; reference was often made to research from other countries or organisations, even outside Europe (e.g. FAZ 28.01.04). This was most clearly reflected by an article in NRC Handelsblad of 18 June 2005, which referred to several national and international (both European and non-European) studies. In fact, non-EU actors were only referred to in a few cases and these tended to be studies, as well as organisations or institutions that had presented relevant studies. American studies played a minor role in this respect and were only explicitly referred to in the Dutch debate (e.g. NRC 18.06.05; VK 26.10.02); WHO research was mentioned more frequently (e.g. FAZ 15.04.05; FR 15.04.05; NRC 01.02.03; SZ 02.06.05; VK 25.09.04). Other non-EU actors concerned countries considering similar legislation or where such legislation had already been implemented, including the US (California), Japan and China (e.g. FAZ 18.07.05; FR 20.07.05; NRC 18.06.05; VK 22.09.05).

National actors were represented most widely and included policymakers, citizens and citizens' organisations. Environmental organisations and citizen action groups figured prominently in all six newspapers and made use of the limit values to demand various measures from local, regional and/or national administrations (e.g. FAZ 25.10.05; VK 06.04.05). They also went to court to secure legal support for these demands - an article in de Volkskrant (02.04.05) noted that citizens in Germany and the Netherlands were preparing cases. As mentioned before, the Council of State's Administrative Jurisdiction Division supported many claims, but by the end of 2005 German (administrative) courts had only passed judgement in a few cases, with mixed results (SZ 02.06.05). ${ }^{160}$ Business associations, associations representing the building sector (in the Netherlands) and local and regional administra-

\footnotetext{
${ }^{160}$ The limited number of cases in Germany can probably be explained by more restricted options to go to court (Backes, 2006, pp.37ff).
} 
tions were most clearly opposed to the existing situation. Representatives from the car industry (individual companies as well as umbrella organisations) took part in both debates, but mostly in Germany (e.g. SZ 30.03.05; cf. VK 04.11.05).

In the Netherlands politicians and parties in the national parliament were slightly more engaged in the debate than in Germany, whereas in Germany politicians from the Länder played a very prominent role in the debate. This can probably be explained due to the prominent role of the Länder in German politics (Chapter 4) and their efforts to defend their prerogatives, also in environmental policy. Germany's regional politicians were important actors, responsible for (setting the criteria for) clean air action plans and agreeing to national policy proposals. Two of them were especially visible: Bavarian Minister of Environment Werner Schnappauf (e.g. FAZ 30.03.05; FR 04.02.05; SZ 30.03.05) and the Minister of Environment for Nordrhein-Westfalen, Bärbel Höhn (e.g. FAZ 30.03.05; FR 04.04.05; SZ 03.05.05). Besides, there was debate within the Länder. In the Netherlands the debate on provincial level received less attention, though proposals launched by regional authorities were reported. Dutch provincial politicians did have their say, but their more limited responsibilities also made them less important for the overall outcome of deliberations on Dutch clean air. Debates in the Dutch parliament, in particular regarding government plans to combat high PM concentrations or the new Besluit Luchtkwaliteit, were regularly covered and, in contrast to their German colleagues, Dutch MPs from all major parties were quoted several times (e.g. NRC 30.06.05; TEL 23.11.05; VK 26.04.05).

Local politicians, authorities and interest groups figured prominently in both public spheres, presenting solutions and demanding action from regional, national or European policy-makers. In both countries local debates, measures and examples played a role in the debate. Local politicians disagreed about the measures that needed to be taken, from Amsterdam (NRC 30.09.05; TEL 29.09.05) to Munich (FR 21.03.05; SZ 10.08.04) - should roads be closed off or should the city install trafficfree zones? In Frankfurter Rundschau and Süddeutsche Zeitung local politicians were even more prominent than in the other four newspapers. These were mostly politicians from the cities where these newspapers have their headquarters, respectively Frankfurt and Munich. As a result, local debates were covered in more detail in these two newspapers.

The responsible politicians in the national governments, Environment Minister, Jürgen Trittin, (Greens) in Germany and State Secretary for the Environment, Pieter Van Geel (CDA), in the Netherlands, played a prominent role in the debate, whereas other ministers, including Dutch Prime Minister Jan-Peter Balkenende and German Chancellor Gerhard Schröder, were less visible. Trittin and Van Geel presented proposals and reacted to opinions and calls from other local, regional, national and European political and non-political actors in the debate. In addition, both politicians often called on other authorities to act. In the German cabinet there was dis- 
agreement about certain proposals, especially regarding the tax benefits for soot filters and colour stickers, as a result of which the positions of some other ministers were mentioned too, in particular, Ministers Wolfgang Clement (Economic Affairs), Hans Eichel (Finance) and Otto Schily (Internal Affairs) (e.g. FAZ 04.04.05; FR 03.02.05; SZ 16.08.05). These disagreements reflected the high degree of ministerial autonomy, although this appears to have been less problematic in the Netherlands. In the Dutch newspapers, Van Geel's boss at VROM, Minister Sybilla Dekker, and Transport Minister, Carla Peijs were on occasions quoted in the context of Council of State rulings or discussions about measures to decrease PM concentrations (e.g. NRC 24.11.05; TEL 28.09.05; VK 21.11.05), but there was less disagreement about how to tackle such issues. Finally, it should be noted that Trittin and Van Geel mostly figured as national politicians, not as members of a European institution the Council of Ministers. ${ }^{161}$

In general the responsible institutions and actors at the European level did not figure very prominently in the debate. In Germany some MEPs also took part in it, but as mentioned, only on the occasion of the internal Commission debate during the summer of 2005 or the presentation of the new clean air proposals later that year. Commenting on the debate on the costs versus benefits of environmental policy, ENVI delegate Hiltrud Breyer (Greens) said that environmental policy is not a luxury that can only be pursued during good economic times (SZ 20.07.05) and warned that the Commission should not become an aid to industry (FR 20.07.05). Her colleague Karl-Heinz Florenz (CDU), chair of the ENVI committee, was in favour of cost-benefit analyses as long as they took into account the societal costs of not having legislation in place (SZ 20.07.05). Breyer again argued that the Commission bowed to industrial interests by loosening up the limit values (FR 22.09.05), though she welcomed plans to tackle ultra-fine particles (SZ 22.09.05). Another member of the ENVI committee, Dagmar Roth-Behrendt (SPD), noted that the EP and Council of Ministers would ultimately take the decisions (FR 23.09.05). Interviewed on the matter of the 2004 EP elections, Dutch MEP, Jules Maaten (VVD), argued that Europe should set targets to decrease pollution, but not determine how this should be done (VK 21.05.04).

Among the European institutions, the Commission appeared most often in the debate, in line with findings of other studies (e.g. Koopmans, 2007). Besides being (partly mistakenly) identified as the source of policy or the decision-maker, it was also addressed by other participants in the debate. Moreover, the Commission and, in particular Environment Commissioner, Stavros Dimas, defended the existing air quality legislation (e.g. SZ 21.05.05). The Commission highlighted that the costs resulting from the annulment of construction plans, or from measures such as traf-

${ }^{161}$ On one occasion Van Geel was recorded as the acting chair of the Council of Ministers (NRC 15.10.04), 
fic-free zones were less than the costs resulting from the premature death of citizens:

En vooral mag niet worden vergeten dat de maatregelen niet zijn bedoeld om de ontwikkeling van een lidstaat te frustreren, maar om de gezondheid van Europeanen te bevorderen. "Als bouwplannen niet doorgaan kost dat geld, maar als een deel van de eigen bevolking vroegtijdig sterft, kost dat nog veel meer", zo heet het. (NRC 24.09.05)

In an opinion article in Frankfurter Rundschau (24.05.05), Commissioner Dimas argued that the protection of the European citizens' health required a proper transposition of the existing legislation, as well as dedicated efforts to meet the limit values. This would be the responsibility of national, regional and municipal authorities - the Commission would not get involved in this discussion, but it would present a new clean air strategy later that year:

Wir müssen handeln, um unsere Bürger vor den Gefahren zu schützen. Erstes Ziel muss sein, die bisher verabschiedeten Gesetze vollständig umzusetzen und die Grenzwerte für Feinstaub - die sich auf PM10, Teilchen mit einem Durchmesser von 10 Mikrometer und darunter, beziehen - sowie eine Reihe weiterer Schadstoffe in der Luft einzuhalten. Das ist vor allem eine Aufgabe für die nationalen, Länder- und Kommunalbehörden, die in Deutschland nun über Verkehrseinschränkungen, CityMaut und Tempo 30 in den betroffenen Städten sowie Steuervorteile für Fahrzeuge mit Partikelfilter oder Gasantrieb nachdenken. Die Europäische Kommission wird sich in die Diskussion nicht einmischen, aber wir müssen auf Einhaltung der Grenzwerte und langfristigen Lösungen bestehen. (...) Doch das ist nicht genug - Feinstaub würde noch immer für tausende frühzeitige Todesfälle verantwortlich sein, was nicht akzeptabel ist. Die Europäische Kommission wird daher noch in diesem Jahr eine neue und umfassende EU-Strategie zur Luftreinhaltung vorstellen.

Besides institutions and their members or representatives, other supranational actors also appeared. These were mostly European level interest organisations. UNICE was previously mentioned; others included the European natural gas organisation ENGVA (TEL 14.05.05) and environmental organisations such as the Green $10^{162}$ (VK 05.07.05) and the EEB (SZ 22.09.05). It should, however, be noted that they mostly appeared in the context of European level events - the Commission's internal debate and the presentation of the new proposals - or generally, in the context of the PM-related problems. One exception concerned an interview with (former) EEB President Ralph Hallo in NRC Handelsblad (07.07.04). He argued that the Netherlands was increasingly lagging behind in implementing EU environmental legislation, such as regarding air quality. He also criticised the tendency of national

${ }^{162}$ A network of environmental NGOs active in Brussels. See: http://green10.org/ 
politicians to feign astonishment about new legislation from Brussels, even though the same national politicians were usually involved in drafting it from an early stage. The second exception concerned a call by the (former) secretary of the European Association of Craft, Small and Medium-Sized Enterprises (UEAPME), Hans-Werner Müller, for MEPs to pay more attention to the interests of SMEs when drafting EU legislation (FAZ 25.05.04). He raised this issue in the run up to the 2004 EP elections - air quality legislation was one of the examples he referred to. Note that Dutchman Hallo was interviewed by a Dutch newspaper and German Müller by a German newspaper. In fact, all individual MEPs mentioned in the newspapers were also either Dutch or German. This suggests that the nationality of European-level actors plays a role in their prominence in the public debate, which has been implied by other studies too, for example, regarding the day-to-day business of German reporters in Brussels (Leppik et al, 2007, pp.59-60, 69-70).

As with the debate on the future of Europe, this debate also enticed several readers and stakeholders to write letters to the newspapers. Readers supported EU clean air policy, refuted it as being 'tyrannical' (TEL 04.11.05), discussed potential measures and called upon politicians (and in Germany the car industry) to act. One reader argued that everyone's surprised reactions to the challenges caused by the PM directive might be explained by the media's failure to foster transparency with regard to this issue (SZ 05.04.05). Most readers' letters appeared in Süddeutsche Zeitung (the majority of them on 5 April 2005). Stakeholders also wrote more lengthy opinion pieces. These included representatives of environmental and consumer organisations (e.g. FR 05.04.05) as well as representatives of the business sector (e.g. VK 03.11.05). The issue was also important enough to be addressed in several commentaries and editorials. Finally, unlike in the debate on the future of Europe, opinions from newspapers in other countries were not reported, despite the fact that they sometimes acted as a source for stories, which again reflects the national focus of this debate.

\section{Analysis}

Studies that focus on (the development of) the European public sphere tend to focus on high-profile issues, such as European elections or, as in the last chapter, treaty reform. Yet, the core business of the EU - its day-to-day politics - often concerns issues which are more or less technocratic, ranging from internal market issues to environmental policy. This does not automatically imply that legislation in these fields develops outside of the public realm. For example, while concerning the rather technical issue of the internal market, the infamous services directive (also know as the 'Bolkestein directive') became a very contentious topic which became linked to issues such as 'social dumping' and so on. Even though this particular issue 
did not receive immediate attention, its controversial nature was still recognised at an early stage. In fact, this case shows that a technical topic can be picked up in the public sphere during early phases of the policy process. It additionally shows that protest and debate can have an influence on EU policymaking (e.g. Chang, Hanf \& Pelkmans, 2010; Crespy, 2010). Franz Seifert (2006) comes to similar conclusions in his study about the ways in which biotechnology was discussed in national public spheres - one of the few studies that focuses on the way in which a more technocratic has been publicly discussed. ${ }^{163}$

Of course, we may still ask to what extent such a technical issue as air quality policy should actually be discussed in the popular public sphere. After all, it seems unrealistic to expect people to understand such detailed legislation. Yet, the reasons behind it (to protect people's health) are evident, even though some may disagree when it comes to the extent to which environmental legislation should curb economic development, mobility and so on. As noted at the beginning of this chapter, the trade-off between environmental protection and public health on the one hand, and economic development and prosperity on the other, is a topic that often resurfaces in debates about environmental policy. EU air quality proved to be no different in this respect. The fact remains that other technical environmental issues such as acid rain or climate change have been discussed in the public sphere and these discussions regularly transcend national borders (e.g. Cox, 2006).

The analysis of the Dutch and German debates on EU air quality legislation reveals key elements of many EU-wide debates on environmental policy. Apart from the dispute between ecology and economy, the most prominent example was the participation of many different interested parties. The debates differed from those on the EU's future in a number of respects, most clearly in their focus on implementation. As such, the debates in both countries were predominantly national in character: the limit values needed to be met, but how, and what would the consequences be of not meeting them? The national focus was reflected in the issue dimension, by the emphasis on local and regional problems and the solutions needed to solve those problems. In the process dimension these national implementation challenges were reflected in a debate on responsibility, predominantly concerned with who should take the necessary decisions on the national, regional and local levels, and by references to various stages in the policy process that often concerned national events and decisions, instead of the past, present or future of the European policy process. In addition, the actor dimension revealed an overrepresentation of domestic (national, regional and local) actors.

\footnotetext{
${ }^{163}$ The Europub-project focused on a number of different policy fields, namely agriculture, monetary policy, retirement and pensions, education, troop deployment, immigration and European integration (e.g. Koopmans \& Pfetsch, 2006; Pfetsch, 2008). While the extent of integration differs in each field, arguably, all of them are considered to be contentious issues in terms of Member States' sovereignty, and thus tend to be much more political in nature than air quality policies or biotechnology.
} 
Box 7: Summary of the Three Dimensions

\begin{tabular}{|c|c|}
\hline Issue Dimension & $\begin{array}{l}\text { The emphasis was on national challenges, events, solutions, with only sporadic } \\
\text { attention to experiences in other Member States (by means of illustration, rather } \\
\text { than to exchange opinions). The only distinct EU topics were implementation } \\
\text { problems, the internal Commission debate and the policy review. In Germany the } \\
\text { 35-day threshold was more often mentioned than in the Netherlands, where the } \\
\text { focus was often on rulings by the Council of State's Administrative Jurisdiction } \\
\text { Division; in both countries attention was paid to the meaning of the limit values, } \\
\text { the sources of pollution, and what steps needed taking. }\end{array}$ \\
\hline
\end{tabular}

Air quality policy was also regularly referred to within the context of other issues in other words, the background against which it was discussed was not always directly linked to the policy itself.

There were only few references to the role the EU should or should not play there was general acceptance of policy having been devised at the EU level.

Policy relevance was often mentioned and concerned the consequences of not meeting the limit values and/or the effects of those limit values - regarding effects, the policy was seen as relevant for various groups, including the elderly or people in weak health.

Process Dimension The emphasis was on the current national state of affairs. Significantly less attention was paid to what had happened in the past and what would happen next the issue was most salient in 2005.

Many individuals and institutions were referred to regarding who should take action (or decide), particularly at the national level, yet there seemed to be uncertainty as to where responsibility ultimately lay.

Limited attention was paid to the policy process at the European level regarding limit values, they were merely acknowledged as the policy content - information about responsibilities and procedures was typically incorrect, incomplete or implicit (for example, 'the Commission has decided').

Actor Dimension Many actors were mentioned, but again quite a few just once or twice.

National actors featured most prominently; transnational, supranational and nonEU actors were under-represented. Transnational actors were typically mentioned in articles about experiences in other countries. The Commission and particularly Environment Commissioner Dimas were the main supranational actors.

An array of diverse actors was reported as being involved in the debates and the policies, including national and local politicians, other public authorities and implementing bodies, political parties, organised interests, researchers and research centres, citizens' organisations and, in Germany, the Länder.

Box 7 presents a summary of the main findings for each dimension. If we take a more detailed look at these dimensions we see that, in addition to the national focus, there were more similarities between debates in Germany and the Netherlands. In fact, there were fewer differences than in the previous case, even though the debates were for the most part national. In the issue dimension the focus was predominantly on the first daughter directive and, in particular, its PM limit values. 
Similar rationales were used to explain the need for such a policy, most prominently, the need to protect people's health by lowering PM concentrations. Another resemblance concerns the fact that in both public spheres the PM saga seems to have come as a surprise to many, leading to, at times, overstated worries about economic development ('het land gaat op slot'). The ongoing debate about who should do what, was a prominent shared theme in the process dimension, with politicians from all levels looking at each other for a way out of the current situation. In other words, responsibility was ambiguous, which can partly be explained by the fact that the implementing acts in both countries were not very clear or sufficiently detailed - they referred to 'competent authorities' only. In addition, air pollution does not stick to borders, so determining who should act can be a difficult task. In the actor dimension, a wide variety of actors contributed to the debates in both public spheres.

We have also seen differences between the debates in both countries. In the issue dimension this concerned the importance of the annulment of construction projects by the Council of State's Administrative Jurisdiction Division in the Dutch debate, versus the clear focus on the measures that had to be implemented to meet EU limit values in the German debate. This difference can be partly explained by the different ways in which Directive 1999/30/EC was transposed into national law. In other words, the way in which a country implements EU legislation (or is affected by it) seems to have an impact on the debate in the public sphere. It can be expected that this also plays a role in debates about other EU policies, maybe even to such an extent that policies that are controversial in some Member States, are not in others. In such cases, the 'transnationalisation' of public debates will not encompass all national public spheres.

In the process dimension a core difference concerned the competences of the Länder. Not only did they play a prominent role in drafting action plans, they were also involved in national initiatives, such as the introduction of tax benefits for the (retro)fitting of soot filters on diesel cars, which they were required to approve. In contrast, the Dutch Provinces played only a minor role in the debate, mostly focussing on implementation. The key role of the Länder also became clear in the actor dimension, where politicians from the Länder were often recorded. In the Dutch newspapers MPs were often quoted, but Bundestag delegates were almost absent from the German debate. Of course, this difference reflects variations in the political design of both countries: Länder politicians play a more decisive role in German politics than members of the Bundestag, but Dutch MPs are more important than provincial politicians. All newspapers referred to local actors, but these were especially visible in Frankfurter Rundschau and Süddeutsche Zeitung.

What is interesting to note in this respect is that elected politicians are generally considered poorly able to influence such a technical issue as EU environmental policy (e.g. Peterson \& Bomberg, 1999, p.194). The Bundestag is considered a weak 
player as regards environmental policy (Pehle, 1997, p.179). Dutch MPs acknowledge that the large majority of environmental targets is drafted on the European level; they find themselves discussing the desirability of certain norms even though they have already been approved in Brussels (Backes, 2007, pp.105-6). This corresponds to remarks in some of the earlier chapters regarding the limited involvement of national parliamentarians in EU affairs, in particular in Germany and the Netherlands, where elite support for European integration has long been taken for granted.

The national focus on the debate meant little attention was paid to experiences and debates in other Member States, notwithstanding the odd reference to London's congestion charge, Italian car-free days or problems in German cities. National actors from one Member State did not address their counterparts in other Member States, but European actors did address national actors and vice versa. Even so, a European perspective on the policy process was only offered by the infrequent references to previous decisions, the looming threat of infringement cases, and the presentation of the proposals for a revised air quality policy (and the postponement of these proposals in July 2005). Moderate attention to discussions and events in Brussels and other Member States was illustrated by the fact that, in contrast to the previous case, there were no opinion articles from, or interviews with, transnational or supranational actors.

Due to the nature of the implementation phase in the policy process, one may argue that the national focus is not surprising at all. Yet, it largely obscured the way in which the EU directive and the limit values came about, especially since the debate mainly took place in 2005 , after the limit values had come into force, following a transition period of a few years, and long after it was decided upon in Brussels and transposed by both national governments. In other words, here we see another example of how the debate in the 'weak' public sphere differed from the one in the 'strong' public sphere. This was also reflected in the fact that, as seen before, other air quality directives were not discussed, or were merely mentioned a few times, though usually not at a time when the directives had still to be approved or transposed into national law. Debates in Brussels were sometimes tense. For example, Alexandra Calatayud (2006, pp.211-213) explains that the fourth daughter directive was controversial enough to only get approved by a tight minority in the EP's ENVI committee, which apparently led the Council into starting negotiations with the EP before the plenary vote. The third daughter directive on ozone was mentioned at the time of approval by the Member States by Frankfurter Allgemeine Zeitung and Süddeutsche Zeitung, both on 11 October 2000.

Not only was there little information about the process in Brussels, but, interestingly, the transposition of Directive 1999/30/EC - in the Netherlands in 2001 and in Germany in 2002 - and the other directives did not receive significant atten- 
tion. ${ }^{164}$ We may argue that, in addition to the phases in the policy process that precede decision-making in Brussels, the transposition of EU directives offers a second chance for national politicians and publics to influence European policies. Even when national parliaments may have initially reacted, it was certainly not a real issue in the public domain. For example, while the Netherlands aired its concerns about the Commission proposals for Directive 1999/30/EC at an early stage, including the likelihood that the objectives would not be met, it still accepted the outcome of the drafting process. While this was not part of the time period analysed as part of this case study, the transposition of the directive was. What is interesting in this respect is that then Minister Jan Pronk (Environment) again acknowledged the problems that might result, in particular by the PM limit values. Yet, even at this stage there were few objections - at least, they were not discussed in public. Instead, the newspapers wrote that Pronk had asked the European Commission for an extension of the deadlines (NRC 15.02.01; TEL 24.07.01; VK 15.02.01). ${ }^{165}$ Again, the transposition of the third daughter directive was an exception, because it was recorded in Frankfurter Allgemeine Zeitung (20.06.03; 07.08.03). ${ }^{166}$ Even so, the context in which the public debate about the EU's air quality legislation took place was markedly different from the context in which the policy was drafted in Brussels, again displaying a temporal mismatch.

This case was also characterised by a content-related mismatch. European level responsibilities remained unclear, mostly due to the largely absent reference to this element in the debate. The way in which EU air quality legislation had evolved was never really clear - the Commission was sometimes even presented as the institution that had decided upon the limit values, even though the actual policy process looked quite different. Besides only occasionally being mentioned as the institution that actively took part in the policymaking process, the Council's members - the national ministers or state secretaries - were barely ever identified in this capacity. Only as the debate progressed did it become clear that they had approved the legislation and were largely responsible for its transposition into national law. Opinions from MEPs only occurred in the run up to, at the occasion of, or following, the Commission presenting its proposals to amend existing legislation. In addition, some actors not recorded as 'national' were actually Dutch or German (such as the MEPs). This suggests that the nationality of European-level actors plays a role in their

\footnotetext{
${ }^{164}$ Besides references to transposition in later articles, an article in Frankfurter Allgemeine Zeitung was the only one to note government approval of the transposition of what seems to be Directive 1999/30EC. Bundestag and Bundesrat still would have a say (FAZ 13.12.01).

${ }^{165}$ Moreover, since 2003 the Dutch parliament had actually been pushing for a different act (an Act of Parliament, instead of an Order) to enforce the directive and was still doing so in 2005 (Backes, 2007, pp.113-5; Verschuuren, 2005, p.631).Eventually a new Act of Parliament was proposed and approved in 2006.

${ }^{166}$ Two letters in Süddeutsche Zeitung $(13.08 .03 ; 23.09 .03)$ also referred to the transposition, but in terms of it having already been decided upon.
} 
prominence in the public debate, which is not surprising, since we have seen in Chapter 3 that nationality and importance on the national stage are important selection criteria for Brussels-based journalists. The limited number of references to European actors and the often unclear nature of national governments' contribution to the drafting of air quality legislation did not help to clarify which actors were involved in the policy process and who should ultimately be held accountable. In addition, some articles only referred to 'the EU' or 'Brussels', which meant the EU was presented as one big entity, not as a political organisation consisting of institutions with different roles in, and opinions on, EU affairs - this problem was signalled in earlier chapters and may relate to the recognised 'knowledge deficit'.

The temporal and content-related mismatches are important. Yet three points suggest there may also be potential for transnational debates about EU affairs of a more technical nature - or at least for national debates about such issues. First, there may not have been much attention to EU air quality legislation during the first couple of years, but this changed in 2005. This shows that EU affairs can become prominent in national public spheres, even when they are predominantly technical. In their study of the press coverage of another rather technical issue, trade, Jan Beyers and Bart Kerremans (2007) suggest that, among other things, activities of organised civil society may push a technical issue into the public limelight. As became clear during the analysis of the present case, such organisations certainly played an active role in the national public spheres. The general salience of environmental policy may have also played a role - for example, in the aforementioned Eurobarometer more than $90 \%$ of Dutch and German respondents considered environmental protection to be 'very important' or at least 'fairly important' (European Commission, 2008a, p.11). However, this influence is difficult to determine based on the current study. Alternatively, as was suggested by scholars and several actors in the debate (see above), the ways in which Directive 1999/30/EC in particular was implemented seems to have played a role, both in drawing attention to the topic in the first place and then regarding the content of debate. Adam (2007, p.414) suggests that national policy traditions ('long-standing, basic values within a policy field') may explain why certain issues are taken up in the public sphere, whereas others are not. In this case the generally positive stance towards stringent EU environment legislation of both countries, outlined above, may have played a role in this respect. We are of course unable to conclude that implementation matters on the basis of just one case, but it is an interesting suggestion nonetheless, which again indicates that national circumstances do play a role.

Second, what is even more interesting is that the debates developed in a synchronic way (be it synchronically late). There was not much interaction between different public spheres, but there were quite a few similarities in terms of development, focus and actors. In other words, different styles of transposition had an impact on debates, though this does not exclude the possibility that these debates 
could develop in similar ways. Seifert (2006) reached a largely comparable conclusion in his study. He argued that such a synchronous development of debates does not constitute a common public sphere or point to the existence of one European public. Yet we may still ask whether a European communicative network can exist without the interaction between national public spheres.

Third, like the future of the EU, air quality legislation was regularly mentioned in the context of other national or European topics, and during the article selection process it also became clear that even articles later excluded did refer to European legislation, even if it was not identified as such. This again suggests that European policy may be more prominent in the public sphere than often suggested. This is not altogether positive, however, because it again raises questions about responsibility and accountability. If it is not clear who drafted certain pieces of legislation, it is impossible to keep the right authorities and decision-makers responsible. The observation that debates only really occur after the impact of certain policies has become clear, enhances this challenge even further.

\section{Conclusion}

When viewed over a longer period, the debate on EU air quality policies was not really very prominent in the Dutch and the German public spheres. Yet, when the consequences of a particular piece of legislation - Directive 199/30/EC - became evident, media attention increased and national politicians and stakeholders became engaged in a debate that lasted throughout 2005. In this respect, both debates took place after the directive had been approved and after it had been transposed into national law. This again suggests a temporal mismatch, even though the debate in $\mathbf{2 0 0 5}$ may have had an impact on the plans proposed by the Commission in September that year, if not directly but by means of (in particular) Dutch lobbying efforts. In addition, the development of the policy process and allocation of responsibilities (even on the national level) were blurred once more, as such representing another mismatch in terms of content. In sum, while the way in which the topics of both case studies were discussed in the national public spheres differed, the conclusions of this chapter also show similarities with those of the previous one. At the same time, we have seen just how different a debate in the public sphere can be, depending on the issue (for example, treaty change versus air quality legislation) and on the phase in the policy process. Even the way European legislation is transposed into national law seems to matter. What this means in terms of the questions raised at the beginning of this study will be discussed in the next chapter, which will conclude this thesis. 



\section{7 \\ Conclusion: \\ A Public Sphere in the Making?}

The aim of this study was to expand our empirical knowledge about the European public sphere, which is still considered to be moderate (e.g. Gerhards, 2000, p.301; Machill, Beiler \& Fischer, 2006, p.59). It started by arguing that, notwithstanding the importance of other democratic challenges, the inadequate development of a European public sphere is a key problem for the EU. What such a 'European coffee house' should look like has been the topic of much debate. As we saw in Chapter 2, some scholars have argued that a European public sphere requires European intermediary organisations, including pan-European media. The fragmentation resulting from the existence of 27 national publics with their own customs and languages would hinder transnational discussions on Union affairs. Others have acknowledged the absence of pan-European media and the existence of these diverse public spheres, yet claimed this does not in itself prevent the evolution of pan-European discussions. Increased attention to EU affairs in - and interaction between - national public spheres might be a viable road towards opening up European politics to a broader public. Here it was argued that this latter position makes most sense, also when considering that national public spheres themselves are not homogeneous and static arenas. Instead, public spheres are shaped by the interplay between media, political actors and public. This means that, not only do they form constantly changing arenas, but such arenas may coexist and function parallel to each other, or they may interact. The previous chapters suggested that this is indeed the case.

The aim of this Conclusion is to go from the case-specific level to the general level in order to identify broader inferences about the European public sphere and, more specifically, about the potential contribution national arenas can make towards the enhancement of transnational public debates about EU affairs. This will 
be done by focussing on the three research questions outlined in the Introduction: To what extent do national public spheres act as a forum for debates on and provide information about EU affairs? Do these national public spheres interact and how? And can they establish a transnational European public sphere? At the end we will return to the graphical depiction of the European communicative network presented in Chapter 2 in order to present a more detailed sketch of the different ways in which national public spheres (can) play a role in EU policymaking. In addition, the likelihood and manifestations of the European public sphere will be discussed in light of questions about EU democracy.

\section{National Public Spheres and EU Affairs}

Throughout this study the focus was not so much on asking whether EU affairs are being discussed in the public sphere, but rather on the question how they are being discussed. As already mentioned, previous studies presented some cautiously optimistic conclusions, noting that EU affairs may already be becoming more prominent in several national public spheres (e.g. Kantner, 2006, p.155; Pfetsch, Adam \& Eschner, 2008; Seifert, 2006). The empirical research presented in Chapter 5 and 6 certainly shows that EU affairs are subject to discussion in national public spheres. Attention to the debate about the future of Europe was to be expected and it actually seems to have increased as the referendums drew nearer. Chapter 5 referred to other studies which confirmed this finding. More surprisingly, the politicisation of European policymaking appears to have occurred in such a technical policy field as air quality, once the impact of policies was made clear; when 'Europe hits home' (Börzel \& Risse, 2000) it may attract media attention. Chapter 6 illustrated that the impact of the limit values for hazardous substances led to a debate about how to deal with the situation that had arisen, but also to questions about the nature of these values and the ways in which they had been transposed into national law.

The two case studies showed that EU affairs are regularly discussed in the context of other, sometimes unrelated topics, and can play a role in national discussions, even without being explicitly identified as originating at the European level. In accordance with the selection criteria, articles that referred to EU legislation or issues, without identifying them as such, were excluded from the set of articles that has been analysed. This may be seen as a negative consequence of the way in which articles were selected, but content analysis requires some way of deciding on how to find and pick articles for analysis. The existence of articles that discuss EU affairs without explicitly marking them as such is nevertheless worth mentioning and might offer inspiration for different types of studies which could focus on this interesting phenomenon. Both these latter articles and those which discuss EU affairs in different settings suggest that the EU and its policies filter through into national public 
spheres more often than we normally assume (see, also: Kantner, 2006, pp.151-2; Trenz, 2004, p.296). This may not yet constitute a public sphere (let alone trigger transnational debates), but it does indicate that the problem may not be the $a b$ sence of references to what is happening in Brussels but rather the way in which this is accounted for in public spheres: only in passing and sometimes even without identifying the policy as being of European origin. Or, in other words, 'Europe' is being discussed in national public spheres, both explicitly and implicitly, even though the EU is not always depicted accurately and in full light, if at all.

This brings us to the question of what type of information is disseminated in national public spheres. In the introduction it was argued that it is important that the media cover facts, depict these facts accurately and provide a picture that is as complete as possible (McQuail, 1992). In Chapter 2, two issues were identified as being problematic in this respect: first, a mismatch in timing between debates in 'strong publics' (political bodies, such as the EP) and those in 'weak publics' (public spheres, such as represented by the media); second, a mismatch in content between the actual debates and processes in those strong publics and their representation in the media. These deficiencies have been identified in the coverage of national affairs and both problems surfaced in the two cases that were studied here. One of the most pressing problems with regard to debates about the EU is that they tend to take place after the key decisions have already been taken. Another problem concerns the fact that the representation of the European policy process in national public spheres often misrepresents the way things actually work in Brussels. This applies to both the general features of decision-making and the allocation of competences and responsibilities.

The Dutch and German debates about the future of Europe mostly took place after the core decisions had already been taken. For example, the preparatory work of the Convention received relatively little attention. In addition, responsibilities were unclear regarding the exact role of the Convention (regularly depicted as a decision-making body) or the way in which the Member States decided (by majority or by unanimity?). What is remarkable is the fact that transnational and even supranational actors were more prominent in the debate about the EU's future than is often suggested, thus implying some degree of interaction between different public spheres.

In contrast, the Dutch and German debates regarding EU air quality legislation were characterised by a national focus across all three dimensions. Yet, the analysis again showed that information regarding the process was deficient in terms of timing, the overview of the process and allocation of responsibilities. The Commission was regularly identified as the main decision-maker, while the role of the Member States in the policy process was unclear - even on the national level responsibility was not always obvious. The debates only really got going in 2005, many years after the directives had been agreed upon and transposed into national law. 
These temporal and content-related mismatches are problematic in terms of democratic EU governance, something which we will return to in more detail below. Yet, the observation that EU affairs can become subject to public debate both implicitly and explicitly in the case of both high-profile and seemingly more technocratic topics, is important. As such, more policies might be discussed in the public spheres if EU policymakers and stakeholders were more open about issues, options and preferences throughout the policymaking process. As we have seen in Chapter 3 this is often not the way in which EU affairs are communicated. Debates and events in Brussels are covered by several media, but the slow and incremental process of European policymaking does not always provide newsworthy items or events. Journalists in Brussels and in the Member States favour less technocratic language, more drama and personalisation, and more explanation as to how EU affairs affect particular Member States. A national angle is widely perceived as being important, but may not always be clear, and the topics that are deemed important by the European institutions may differ from those that the media are interested in (e.g. Bijsmans \& Altides, 2007; Trenz, 2004, p.303).

Whether recent attempts to streamline EU action in the field of communication policy can play a role in this respect is difficult to predict. As we saw in Chapter 3, the Commission, EP and (European) Council, as well as the Member States have made joint efforts to increase and improve communication about European policymaking, drafting new strategies on the European and the national level. The same chapter also identified potential problems which may not result in the envisaged outcome of such strategies, namely to tackle 'the inadequate development of a 'European public sphere" (European Commission, 2006a, p.4). For example, the debate about the future of Europe showed that a top-down approach to stimulating transnational debates was not successful. Furthermore, a concerted approach to communication as proposed by the Commission might conceal differences of opinion instead of bringing them into the open. The institutions and the Member States play distinct roles in the policymaking process and may have different opinions about the direction of EU policies. They also have to avoid accusations of propaganda.

\section{The Interaction Between National Public Spheres}

Discussions about EU affairs are not only shaped by institutional politics in Brussels, but also by national politics in the Member States. Chapter 4 provided a more detailed overview of the public spheres in Germany and the Netherlands. National public spheres typically vary due to different cultural, social and political traditions. In this respect, the consensus democracies of Germany and the Netherlands are characterised by some important similarities. In addition, their media systems share 
significant features and their stance towards European integration has broadly developed along comparable lines.

Interestingly, both cases showed similarities in terms of the quality of information available in the two public spheres. This seems to confirm the observation in Chapter 3 that media news values and selection criteria are comparable across Europe and that coverage of EU affairs shows many similarities (see, also, for example: De Beus \& mak, 2009, p.134). Therefore, Trenz (2008, p.299) correctly asks the question whether this may help to foster interaction between national public spheres. Yet, despite such similarities, interaction between the Dutch and German public spheres was mostly limited, in the first case to references to Fischer's Humboldt speech in the Dutch newspapers and, in the second case, references to problems in Dutch and German cities in, respectively, the German and Dutch newspapers. The fact that Germany and the Netherlands share certain characteristics when it comes to politics and the media, as well as a common history in, and vocation towards, the EU, does not result in the mutual coverage of national events and discussion. In other words, there is no automatic reference to events and discussions in comparable countries. There were more references to Germany in the Dutch media than vice versa, suggesting that the political influence of a Member State is more important than whether or not two Member States share similar features. Indeed, the first case study showed that news about other Member States was very much geared towards the big three Member States: Germany, France and the UK.

The few obvious differences between Germany and the Netherlands had an effect on some elements of the debate. The powerful influence of the Länder in German politics was especially evident in the air quality debate, where Länder politicians were identified as important actors. Some regional politicians, such as the influential (former) Bavarian Minister-President, Edmund Stoiber, and the Bundesrat representative in the Convention, (former) Baden-Württemberg MinisterPresident, Erwin Teufel, were also recorded as actors in the debate on Europe's future. In contrast, the weak provincial representatives in the Netherlands scarcely played a role in the air quality debate and were certainly absent from the debate on Europe's future. The importance of the Grundgesetz and the judiciary in Germany, which is reflected by the significance of judicial review, may have played a role in the German discussion about the future of Europe and appraisal of the Constitutional Treaty. This cannot be proven beyond doubt, though. Even so, in the Netherlands judicial review is impossible and the Dutch Grondwet is not allocated the same prominence. The idea of a European Constitutional Treaty was approached with some confusion, at least initially.

Beyond interaction between the Dutch and the German public spheres there was substantial attention paid to transnational and supranational actors that took part in the debate on Europe's future and there was also (limited) attention for 
problems related to air quality legislation in other countries. This would seem to indicate that some degree of interaction between different public spheres is not uncommon. Adam (2008) even reports that interaction in the French and German debates on the Constitutional Treaty involved European actors in over $80 \%$ of instances. Here, transnational and supranational actors were also more prominent in the debate on Europe's future than usually suggested (cf. Koopmans, 2007, p.205; Wimmel, 2004, p.20). The rather limited role of MEPs, while confirming previous studies in the field, does question the EP's possibility to represent European citizens and, to refer to Liebert (2007), as quoted in Chapter 3, to create publicity in fields that might otherwise stay outside the public limelight. We should also acknowledge that references to transnational and supranational actors and events mostly represented coverage of discussions in other countries, not an actual exchange of opinions across borders. In addition, it was not always apparent why transnational actors adopted particular positions.

Here it should be conceded that some of the more unusual findings might be due to the use of constructed week sampling as a method for studying the debate on Europe's future. The samples gave the impression that the German dailies did not refer to the debate on the future of Europe in the Netherlands or the identification of a significant number of transnational and even supranational actors. However, employing constructed weeks sampling also means that one will not always be able to capture all aspects of a debate. For example, it might have seemed as if the Dutch newspapers did not refer to the hearings of civil society organisations and the gathering of the Youth Convention, but NRC Handelsblad actually did refer to the Youth Convention on 12 July 2002. ${ }^{167}$ The fact that it is an evening newspaper might have played a role here, because all three German morning newspapers referred to this event a day later (13 July 2002) - this day was part of a constructed week.

Despite this, constructed week sampling allows for a long-term analysis, which can actually provide for a much better overview of the whole debate, compared to a focus on particular events or the use of random sampling. For example, analysing the debates on the referendums about the Constitutional Treaty would almost certainly have identified more national actors due to the particular stage in the debate (national ratification). For instance, in their study of the debates about the future of Europe between the 2004 IGC and September 2005 Gaisbauer and Pausch (2009, pp.49-52) found that national actors appeared most frequently. This means that the period on which European public sphere research focuses has an unmistakable impact on the findings. In other words, to get a more complete insight into what constitutes the European public sphere, future research should not just focus on key events, as is often the case, but also to other phases of the policy process, to the whole policy cycle that is.

\footnotetext{
${ }^{167}$ Politici in spe hebben Europa geen dromen te bieden, NRC Handelsblad, 12 July 2002.
} 
Incidentally, while horizontal interaction across national borders was often limited to coverage of what was happening in other Member States, vertical interaction between the national and the European level involved more direct exchanges of opinions, with European officials intervening in national debates and national politicians commenting on proposals made by the Commission.

\section{Transnational Public Debates}

The fact that events and discussions in other Member States do not go unnoticed does not mean that we can automatically discern transnational debates. In fact, compared to the debate on Europe's future, the debate on the EU's air quality legislation was mostly a national affair, which implies that the stage of the policy process as well as the nature of the topic at hand has an impact on debates about European affairs, both in terms of the intensity of the debate and the communicative exchanges between public spheres. Additionally, mismatches in timing, the overview of the policymaking processes and the allocation of responsibilities present a problem in terms of the development of a European public sphere. Citizens are presented with a skewed overview of EU affairs, often at the wrong moment, namely after policies have been decided upon.

The representation and discussion of EU affairs in the public sphere may differ depending on the issue in question, but also on national differences, ranging from characteristics of the political systems to the way in which European legislation has been transposed in national legislation. Particular dissimilarities included the involvement of distinct actors (the prominence of Länder politicians in Germany) or the emphasis on different aspects of policies (the postponement of building projects in the Netherlands). Differences such as these do not, however, exclude similarities between the debates in different public spheres. Even the aforementioned mismatches were present in both cases and in the debates in both Germany and the Netherlands. This suggests that there actually is some degree of comparability between debates in national public spheres.

The coexistence of differences and similarities was most clearly seen in the second case study on EU air quality legislation, in which different means of transposition played a role in terms of the legislation's domestic consequences, but in which responsibility was a key issue in both public spheres, as was the balancing of public health versus economic development. In addition, an element of surprise among actors could be discerned in the debates in the Dutch and the German newspapers. The issue became highly salient at about the same time (too late), and although the focus was slightly different (in particular, the postponement of building plans versus 'Tag $X$ ' and the limit values), there was simultaneous debate. In other words, despite their predominantly national focus, the debates developed along parallel lines 
in terms of timing, themes and - with the exception of the role of regional authorities - even actors (organised interests, citizens' organisations, local governments and so on).

As noted in Chapter 6, Seifert (2006) also found that while there was little interaction between national debates about biotechnology, those debates developed along the same lines, engaging similar types of actors to discuss comparable themes. While the issue was not prominent in all national public spheres, Seifert describes how it was controversial in countries such as Austria and Britain. He even argues that these debates had an impact on the European policy-process, because national politicians tended to transfer domestic worries about, and arguments against, biotechnology to the European level. To some extent this seems to have been the case with regard to the Dutch debate. In the section about democracy and the European public sphere, we will discuss the extent to which these 'synchronised national publics' can contribute to democratising EU governance. They may certainly form a stepping stone for transnational debates.

Transnational debates may also be possible because of two aforementioned points. First, the fact that there were several references to events, discussions and actors in other Member States, in particular in the debate on the future of Europe, would suggest that there is potential for transnational debates, not just coverage of events elsewhere. It shows that issues are not always placed within a domestic context, even though national perspectives and peculiarities may play a role. Second, implicit references to EU policies and articles in which EU affairs were only a secondary issue were found in both public spheres, and have also been identified by Trenz (2004) and Kantner (2006). These references show another type of similarity between the ways in which EU affairs become part of national public spheres. For Kantner (ibid, pp.157-8) this is one of the reasons for claiming that the political horizon in EU Member States is (at least partly) shifting towards the European level.

In sum, there are reasons to believe that national public spheres can form a transnational arena for debate (see, also: Van de Steeg, 2006). Yet, this assessment should not be equated with arguing that national arenas will always offer opportunities for transnationalisation (cf. Pfetsch, 2008, p.36). The European public sphere is certainly not completely fragmented, as references to debates and events in other Member States are not uncommon. Nevertheless, those linkages between national spaces may be brief or very superficial, as was sometimes the case in the debate on Europe's future, where some Member States and transnational actors were only referred to once. In other words, it will be difficult to continuously maintain transnational debates. This also raises questions concerning the extent to which debates in and patters of interaction between national public spheres need to be similar; questions that have so far remained unanswered in the existing literature and that can also not be answered here (see, also: Risse, 2010, p.155). It is certainly imaginable that debates might regularly remain confined to domestic settings - in 
fact, Sifft et al (2007) argue that while the 'monitoring' of EU affairs has increased since the 1980s, the interaction between national public spheres has not. Again, the question we should ask, is to what extent this is problematic or not. We will return to that question below.

\section{Europe's Communicative Network: A Multifaceted Public Sphere}

What we have seen so far is that debates about EU affairs and European policies are covered both implicitly and explicitly by the national media. Moreover, a certain degree of interaction between national public spheres does exist; there are even indications that the transnationalisation of debates is possible. We have also seen that the nature and characteristics of national debates can differ according to the topic (history-making decision versus technocratic policy), timing (prior to decisions or following transposition) and Member State (due to certain political traits or due to the way in which policies have been transposed into national law).

The two cases studied showed differences in terms of what was discussed, who participated in the discussion and when things were discussed. There were differences both between and within the cases. For example, the air quality case showed an emphasis in the debate in Germany on the limit values and possible consequences in the event of them being breached. While this issue was picked up in the Dutch debate, the main focus was on the postponement of construction projects. In the German discussions on the future of Europe the division of competences was an important issue, as opposed to the Stability and Growth Pact in the Netherlands.

There were also differences in terms of who participated. When comparing both cases, it is clear that the debates about the future of Europe included many more references to transnational and supranational actors than the debates about the air quality legislation. Moreover, the virtual absence of organised interests in the future of Europe case contrasted with their active part in the discussions about air quality legislation. Finally, the importance of Länder in German politics is reflected by the fact that their policies and positions were very much part of the debates in Germany, in particular, regarding air quality legislation. Non-EU actors were almost completely absent in both cases.

In terms of timing there were differences too, although generally both debates were sparked at the wrong time, only intensifying when policy formulation could no longer be influenced. Of course, the Dutch and French referendums were still important moments in the policy process, because they represented additional instances of decision-making (even though the choice was limited to 'yes'/'no') and especially because the ratification process turned out to be more problematic than many had hoped. In contrast, EU air quality legislation was apparently not discussed in public in advance of Council approval, nor was it an important issue before the 
transposition of the directive(s); implementation would still have offered an additional opportunity to influence the impact of a policy already decided upon in Brussels, but that still needed to be transferred to the national level.

There were differences between the ways in which both policies were discussed and sometimes also between the ways in which these policies were discussed in the two public spheres. In addition, there were differences between the newspapers. All newspapers showed discrepancies in the ways in which they reflected upon EU affairs, but overall Frankfurter Allgemeine Zeitung provided most information and was also often more precise, whereas the opposite holds for De Telegraaf. Interestingly, while, of the Dutch newspapers, NRC Handelsblad devoted most attention to both cases, of the German dailies Frankfurter Allgemeine Zeitung paid most attention to the debate on the future of Europe and Süddeutsche Zeitung to the debate on air quality legislation. This implies that the weight attached to EU affairs is important for the extent of coverage media are willing to provide, but so is the particular topic that is being discussed. The special attention to local PM-related discussions in Frankfurter Rundschau and Süddeutsche Zeitung can be seen as an example of the latter.

In addition, while the newspapers sometimes discussed similar issues (for example, the reform of CFSP in relation to the war in Iraq), they also focused on different topics. In both cases certain national issues were discussed at the same time, such as the German plans to introduce coloured stickers in the German newspapers and the revision of Dutch air quality legislation in the Dutch newspapers. Yet, other topics were discussed at different times or were reported more prominently in some newspapers than in others. This will also apply to other media. In fact, there may be more overlap between the debates in certain types of media or media with a certain profile (cf. Van de Steeg, 2006, pp.626, 628). This idea has not been explored further here, but some studies have suggested that ideological differences do not seem to matter much when newspapers report on EU affairs (e.g. De Beus \& Mak, 2009, p.118; Pfetsch, 2008, p.35). Paul Statham (2007, p.470) has argued that this may just be the case for EU affairs, where pressures from owners, affiliated political parties and citizens has so far mattered less than with regard to national politics. Perhaps such differences become more pronounced in debates about EU affairs that take place mainly within a national context. For example, De Telegraaf's reporting on air quality was less nuanced and more in line with its perceived editorial stance, than that of the other two Dutch newspapers. In any case, the existence of differences in focus and topics within the national public spheres does raise questions about the assumptions of those who would argue in favour of a single European public sphere. Even on the national level unified spaces can only be formed when the media cover similar issues, and refer and connect to each other.

These observations suggest that there are at least three aspects which have an impact on the likelihood and manifestations of a transnational European public 
sphere. First, there may be some or no interaction between the national spaces. This interaction may be limited to the mere coverage of events, debates and experiences in other Member States. Ideally interaction would also consist of exchanges of opinions across borders (e.g. Risse, 2002; Wimmel 2004; 2005). Yet, coverage of what happened or is going on elsewhere can already help to increase awareness of the European dimension of certain issues (e.g. Voltmer \& Eilders, 2003, pp.189-90). Moreover, even without actual debates crossing borders, opinions in one Member States may still serve as reference points in other national discussions.

Second, debates may or may not take place synchronously. Synchronism entails parallel discussions about EU affairs that take place at about the same time, refer to comparable problems and arguments and involve similar actors. As we have seen before, synchronous debates can take place without interaction between public spheres. Seifert's (2006) research suggests that this does not exclude the possibility of these debates having an effect on EU policymaking. Debates may also not be synchronous. They may take place during different phases of the policy process, for example ahead of decisions in the Council and the EP or while legislation is being implemented. They may also focus on different problems or elements of the policy, or include different actors.

Third, debates can take place in many Member States, but also in only a few. Ideally, we might assume that the more citizens that take part, the better the democratic quality of decision-making. Yet we could also imagine situations in which only a few Member States are affected by or involved in policies. In her previously mentioned study, Kantner (2006, pp.155-6) describes how certain issues may be more important for some countries than for others and how in some countries the importance of an issue may be recognised earlier than in others. For example, she mentions ECB policies or the threat of separatist movements. Seifert's (2006) account of the biotechnology debate in Europe also attests to this argument. Another example is foreign policy, where Member States' interests sometimes diverge and may even be absent (Keukeleire \& MacNaughtan, 2008, pp.136-7). European officials involved in communicating the affairs of the Commission and the EP have even considered taking such differences into account, as was mentioned in Chapter 3. Perhaps debates about EU affairs could even be limited to just one Member State (cf. Kantner, 2006, p.149; J.H. Meyer, 2004, p.210). In this case, there will be no horizontal interaction, just vertical. Such a situation may, for example, arise when the Commission targets one particular country with regard to a directive, which is only controversial there or with regard to the specific features of a certain domestic sector. $^{168}$

\footnotetext{
${ }^{168}$ For example, the Commission has recently argued that the Dutch social housing sector does not comply with EU state aid rules. The housing corporations have objected to this interpretation, which also led to some debate in the Netherlands, especially regarding the competences of the Commission. See, for example: http://www.europa-nu.nl/id/vievfu1bxmxs/nieuws/woningcorporaties_in_verzet_tegen?ctx=vha4p0rx1qv1
} 
Such debates do take place and therefore this situation forms one extreme on a scale of possible contributions by national public spheres to a transnational European public sphere - even though this option may not constitute a European public sphere, but rather just a national arena which features supranational actors. To the other extreme is a setting in which all 27 public spheres are synchronously debating an EU topic, and interacting in a way that comments, opinions and arguments cross borders. This would be the ultimate example of a transnational European public sphere, even if this is a very unlikely development.

Between these two extremes we can distinguish a number of settings. Thus, we would still talk of a transnational European public sphere when many (but not all) Member States are involved in a synchronous and interactive debate. In a case where only a few Member States are involved, a situation of restricted transnationalism would arise. ${ }^{169}$ Another setting would consist of EU affairs only being discussed in a few national public spheres, without any interaction or synchronism. This would amount to Risse's fragmented European public sphere, as referred to in Chapter 2 - different spaces existing independently from each another. This situation could also involve many Member States. Nevertheless, in both scenarios national public spheres could contain lively discussions about EU affairs, even when limited to national reflections and vertical linkages.

In other cases there may be no interaction between national public spheres, even though European issues are discussed in the Member States - Sifft et al (2007) have called this 'segmentation'. Debates could, however, still develop synchronously. If they only take place in a few Member States, the European public sphere would be segmented and restricted; if they take place in many, only segmentation would apply. We have seen in the second case that some degree of interaction could still occur when debates are predominantly segmented. It is even possible to imagine cases in which there are no synchronous debates, but a degree of interaction nonetheless. EU affairs may be discussed at different times, but with references to previous experiences or debates in other Member States (cf. Seifert, 2006). For example, the Dutch might discuss the way in which EU legislation was transposed into Dutch national law, while referring to how it was transposed in German. Such discussions could also take place in a few or in many Member States, which we could respectively call a restricted trans-temporal European public sphere and a trans-temporal European public sphere. Of course, when debates take place at different times the opportunities for direct cross-border communication become limited, but these debates do not have to remain strictly national (see, also: Risse, 2010, pp.116-7, 169-71).

\footnotetext{
${ }^{169}$ As just noted, there is as yet no yardstick for the minimum level of interaction between or synchronicity of debates in national public spheres that is needed.
} 
The different manifestations of the (European) public sphere just described are displayed in Table 9. Clearly, as noted throughout this research, there is no such thing as the public sphere; rather, as we saw in Chapters 2 and 3 , it is a multifaceted, ever-changing construct. Europe may be discussed in national public spheres, but these debates are not always transnational, nor is Europe always indentified as the source of legislation. National public spheres may reflect upon EU affairs individually, or together in a concerted way. They might also do so for a longer period, but engagement with EU affairs can also be accidental, incidental and implicit. In other words, engagement with European policymaking may be weak or strong, ranging from national public spheres that merely monitor policymaking to the establishment of a truly transnational European public sphere. These considerations imply that the graphical representation of Europe's communicative network that was presented at the end of Chapter 2 does not cover its full complexity. One single graphical depiction of this network of public spheres would become too complex, simply because of the fact that it is constantly changing.

Table 9: Possible Manifestations of the Public Sphere in EU Affairs

\begin{tabular}{lccc}
\hline & Interaction & Synchronism & Member States \\
\hline National Public Sphere & No & No & One \\
\hline Fragmented European Public Sphere & No & No & Few/Many \\
\hline $\begin{array}{l}\text { Restricted Trans-Temporal European Public } \\
\text { Sphere }\end{array}$ & Yes & No & Few \\
\hline Trans-Temporal European Public Sphere & Yes & No & Many \\
\hline $\begin{array}{l}\text { Restricted and Segmented European Public } \\
\text { Sphere }\end{array}$ & No & Yes & Few \\
\hline Segmented European Public Sphere & No & Yes & Many \\
\hline $\begin{array}{l}\text { Restricted Transnational European Public } \\
\text { Sphere }\end{array}$ & Yes & Yes & Few \\
\hline Transnational European Public Sphere & Yes & Yes & Many/27 \\
\hline
\end{tabular}

In fact, besides the national public spheres and transnational arenas that may emerge when they interact, we should not forget that two further manifestations of the European public sphere were identified - namely the elite, European-level public sphere and the issue-specific public spheres. Both bring together politicians, officials, scholars, students and journalists with a particular interest in EU affairs. While the elite, European-level public sphere and the issue-specific public spheres may not be able to reach out to the general public, they do play a key role in the European communicative network by acting as platforms for specialised discussions. After all, the very nature of many technical issues means that one should not expect them to be subject to wider public debates - arguably this would not be useful for citizens or bring any value-added to policymaking. In addition, these two manifesta- 
tions of the European public sphere influence the Brussels agenda, but can also transmit debates and events in the Brussels micro-cosmos to national public spheres through national correspondents based in the EU's capital (e.g. Kopper et al, 2007, p.86). ${ }^{170}$ As such, there may still be vertical interaction, despite the absence of horizontal interaction.

\section{EU Democracy and the 'European Coffee House'}

In the Introduction it was explained that coffee houses have played a pivotal role in the development of democratic societies, but what democratic contribution may we reasonably expect from a multifaceted 'European coffee house'? And to what extent could the different involvement of national public spheres affect decisionmaking in Brussels?

We have seen in Chapter 3 that the policy process in Brussels tends to differ from what most citizens are used to in national politics. The need to establish compromises, package deals and qualified majorities, as well as the involvement of many different actors and levels make it a very complicated and often wary process for citizens and media to grasp. In addition, there is no clear government-opposition dichotomy and the system of checks and balances works different from that in most Member States. It can be expected that the way in which the EU is governed will have an impact on the way in which it figures in the public sphere and on the likelihood of transnational public debates (cf. Giorgi, Crowley and Ney, 2001). For example, due to its complexity the EU sometimes appears to be one single body, as was also seen in the debate on air quality legislation, where newspapers articles regularly referred to 'the EU' or 'Brussels'. Also, the long and complicated policy processes and the diffusion of power and influence can obscure responsibilities at the expense of accountability.

Writing about the Convention, Anne Peters (2004, p.281) uses the term 'Komplexitätsfalle' ('complexity trap') to cover the complexity of the issues and the enormous number of participants that took part in the proceedings, both which made it very difficult for average citizens to follow the discussions. Arguably, we could apply this term to the day-to-day politics of European policymaking and its deficient coverage in the national media. Many of the issues that are discussed in Brussels are very complex and policymaking is characterised by the involvement of many different actors. This makes it hard to follow what is going on in the EU, even for journalists expected to act as intermediaries between national arenas and the Brussels micro-cosmos. Consequently, we should probably not expect citizens to be willing and/or able to get involved in every debate on EU affairs. Actually, as was

\footnotetext{
${ }^{170}$ In fact, counter-public spheres may also form a starting point for further discussions (see, for example: Della Porta \& Caiani, 2009).
} 
explained in Chapter 2, most citizens only get involved when they believe they will be directly affected by a particular policy or issue - once again, this questions topdown attempts to create a European public sphere.

In other words, the idea of a public sphere in which all citizens should be able to participate could still function as a normative benchmark, but we should except that complex issues require different types of involvement, for example, by experts in EU committees (e.g. Joerges \& Neyer, 1997; see, also, Statham, 2007, p.475), but also that there are issues which do not concern all (cf. Schmitter, 2000). For example, in the case of air quality legislation, the establishment of limit values could be left to experts. Involvement of the wider citizenry could be limited to the general direction of policies, for instance regarding the question of to what extent EU air quality legislation should limit construction projects. ${ }^{171}$ Here we could again refer to the fact that the transposition of EU legislation offers an additional opportunity to influence the impact of a policy. As such, purely national debates could still have an impact on EU affairs.

Interaction between national public spheres already occurs, and transnational debates could evolve. We might also ask whether synchronous national debates can act as channels by which to democratise EU governance. Arguably, citizens can only decide on their position vis-à-vis certain policies when they have an overview of other opinions (such as those held by citizens from other Member States), and only then solutions to common problems can be identified. This is why, as explained in Chapter 2, views differ as to what extent the dominance of national perspectives, actors and issues are problematic in terms of the development of a European public sphere. Opinions also differ over whether or not communicative interaction across borders is a necessary element for a European public sphere, but it certainly adds an extra dimension to it. In that respect Risse's (2010, p.126) recent emphasis on different degrees of engagement with European affairs by national public spheres makes sense and is in line with what has been argued in previous sections. The fact that even simple coverage of EU affairs may help citizens acknowledge the existence of the EU and enable basic, comprehensible (if not necessarily comprehensive) communication on EU affairs should be valued positively. ${ }^{172}$ We might also add that, as explained in Chapter 3, national governments represent their citizens in Brussels. This way opinions and preferences that materialise in national public spheres may actually be relayed to the European level, as seems to have been the case with regard to air quality legislation. This has also been suggested by Seifert (2006) in his study about debates on biotechnology in national public spheres. Such synchronous

\footnotetext{
${ }^{171}$ Some would argue that people are not interested in EU affairs, but both case studies indicated that the public can become involved when something is at stake. This may not always be the case, as consequences will not always be as clear as for example regarding air quality.

172 Naturally, a public sphere requires more than just coverage of EU affairs, namely debate between different actors which represent different opinions.
} 
debates do not in themselves constitute a transnational public sphere, yet the fact that they remain segmented does not mean that EU policymaking remains largely void of democratic input either.

What if debates focus on the same EU policies, but without interaction and with regard to different themes and at different times? While synchronised publics still offer an opportunity to influence EU affairs at similar times, such a fragmented European public sphere would mean national publics getting involved at different times, with some maybe able to influence the policy process at an early stage, with others focussing on transposition debates or perhaps involved even later. This may also apply to restricted and trans-temporal European public spheres.

Debates may only serve as a way to explain and legitimise decisions that have already been taken. In cases in which Member States and their publics see no incentive to get involved, this may not be problematic at all. Yet, for people to be able to get involved in policymaking, timing is of the essence. In this respect, both cases displayed a temporal mismatch regarding the moment at which EU affairs were covered in the national public spheres. The focus on events may add an extra layer to this problem, although in his study of the debates on the Turkish EU-bid, Wimmel $(2004$, p.30) rightly argues that it indicates that public debates about EU affairs do take place - another reason to refute the idea that a European public sphere cannot exist. Even so, the focus on events is problematic because it often means that a large part of the policy process takes place outside the public realm. As was already noted, news coverage of EU affairs tends to be limited to the phase of decisionmaking or even only to implementation problems, as clear from the analysis of the air quality debates. If Europeans only become aware of the existence of legislation at this stage, there is no real possibility to influence the results and consequences.

In addition, a content-related mismatch proved to be present too, in particular with regard to the coverage of the policy process and responsibilities. The misrepresentation of the European policy process in the national public spheres leads to at least two important problems (cf. Tsakatika, 2008). First, it makes it difficult if not impossible to hold the right people responsible for pieces of legislation or certain decisions - belated attention for EU affairs only aggravates this problem. Second, those who are responsible may have an easier job to shift the blame (the so-called 'blame game' as referred to in Chapter 3). For example, national politicians can claim that 'the Commission made me do it' (M.P. Smith, 2000), which provides them with the possibility to agree on unpopular decisions in Brussels, without being held responsible by their electorates at home. The fact that the origin of policies (namely, the EU institutions) is not always clear, as was also observed while selecting articles for this study, is problematic too in this respect (e.g. Adam, 2008, p.94).

Even if debates remain largely national for at least the foreseeable future, a good overview of the policy process and who to address (and at which time) is nonetheless required. This is also why qualitative studies into the European public 
sphere are needed, because they offer a better possibility to identify mismatches such as those previously discussed and to show how the mass media paint a political 'reality' of Europe that does not necessarily correspond with the actual functioning of the European Union (e.g. Trenz, 2008, p.303). Even so, there is still the question of what exactly adequate information constitutes. ${ }^{173}$ In both cases information was available in all newspapers - and sometimes more than expected, for example, regarding transnational actors in the debate on Europe's future - but on several aspects of the policy process, the mismatches in timing and content were problematic. Of course, we cannot expect the media to cover or repeat everything, but it is with regard to these deficiencies that citizens get a distorted insight into the debate. In this context it should therefore also be noted that while national perspectives in such debates may help to bring EU affairs out into the open, they also partly explain why mismatches occur (cf. Adam, 2007, p.412; Sifft et al, 2007, p.137).

In order to investigate the type of information available in national public spheres and to find out if and how these public spheres interact, this research has relied upon newspapers as its sources. Newspapers are still important in the modern media age, providing a good overview of what information is publicly disseminated. These conclusions are therefore considered to be representative of the public sphere (and other media) as a whole. This does not imply, however, that other types of media are unimportant, as was already explained in the Introduction. It is also reasonable to expect that, in the near future, further technological and social developments will continue altering our perception of the European public sphere. Undoubtedly Internet-based news sources, as well as online social networks will become ever-more important in stimulating political participation and democratic debate, as witnessed at the time of Barack Obama's election campaign to become President of the US. European politicians and institutions are also making increasing use of the Internet. Some have Facebook pages, such as the European Parliament (150,726 people 'like this' as of 19 March 2011) and Commissioner for Digital Agenda Neelie Kroes (3,314 friends), others write blogs or are active on Twitter, such as EP President Jerzy Buzek. ${ }^{174}$ Citizens can find information and opinions online, on the Europa website or other sites dedicated to EU affairs, and might even 'chat' with their representatives online. For the average citizen, however, this has so far not been the customary way of finding out information about European (and national) affairs. Despite the rapid growth of new media, the role of traditional mass media such as newspapers in providing lucid and comprehensive coverage of social, political and economic issues, remains fundamental. Without such media coverage

\footnotetext{
${ }^{173}$ The same applies to how much coverage of EU affairs is required, a question which has so far been left unanswered. For example, De Beus and Mak $(2009$, p.46) suggest a 50/50 yardstick as far as the inclusion of transnational and supranational actors are concerned, but do not provide a rationale for this suggestion.

${ }^{174}$ http://twitter.com/jerzybuzek
} 
citizens will arguably not have the option to engage in public debates and, thus, be limited in their ability to influence policymakers.

\section{A Public Deficit?}

Like other studies of the European public sphere, this study only provided a snapshot of this, as yet largely unknown, phenomenon. What it did show is that EU affairs are being discussed in national public spheres and that there are chances of debates crossing borders. Therefore, scholars such as Eder (2000), who have argued that debates about EU affairs do take place and do cross borders, have a point when they argue that we should focus on what the European public sphere might look like, not on whether or not such debates take place. After all, the latter has already been confirmed, even though this development may not yet be one-dimensional, linear or even across Member States. By focussing on two different case studies in two similar countries, this study has also confirmed that discussions about EU affairs vary according to the topic at hand, as argued by others, and even according to policymaking phase. It has shown that discussions can develop along similar lines in different Member States, but that differences between them can have an effect on these discussions. By adopting this particular approach, this study has been able to move beyond some of the traditional assumptions about the European public sphere, for example regarding the dominance of national actors, and has identified the European public sphere as a multifaceted, ever-changing construct.

In terms of democracy, this multifaceted image of the European public sphere may pose problems when people are excluded from debates, but at the same time it also takes into account the fact that the EU consists of different Member States with different priorities. The conclusion that EU affairs are discussed in national public spheres, be it explicit or implicit, should at least make us cautious of jumping to quick conclusions about the existence of a public deficit, at least in terms of the amount of coverage. What seems more problematic is the quality of coverage: reports about EU affairs tend to be published too late and the information provided by our national media tends to display discrepancies with regard to factual processes and responsibilities at the European level.

Of course, there are still other discussions in Brussels that either go unnoticed or are monitored too late. In some cases this may be problematic, in others it may not. Yet, more awareness about EU affairs is still needed and this requires moving beyond the prevailing impressions that 'Europe happens somewhere else' and that 'there is no alternative' for the political choices that are being made in Brussels (Best, 2002, pp.113-5). Some kind of politicisation of EU affairs and a different approach to communication therefore seem to be essential. While some have argued that this process is already underway, it may not always be easily achievable due to 
institutional habits, but also due to the EU's specific set-up and its day-to-day functioning. Besides, we should bear in mind that better communication and more publicity do not form a panacea, because "there is no guarantee that people will actually like what they see more clearly" (ibid, 2002, p.93) and it "might even increase the probability of rejection" (Fossum \& Trenz, 2006, p.18). But then again, that is the essence of democracy. 



\section{Annex 1: Codebook}

A codebook determines the structure for content analysis, explaining procedures and definitions and clarifying the coding form. The latter is sometimes also called a protocol: "a list of questions, items, categories, or variables that guide data collection from documents." (Altheide, 1996, p.26) According to Fred Wester (2006, p.27) a qualitative approach normally does not use a very elaborate coding scheme. However, elsewhere he notes that coding is indispensable for a systematic analysis (Wester \& Peters, 2004, p.93). Although this might appear contradictory, what in fact seems to be the point is that we should be careful not to end up with a too rigid scheme that will ignore other possible meanings and findings (see: Silverman, 2001, pp.123-4; cf. Altheide, 1996, p.27).

To minimise the room for error and misinterpretation a codebook offers a standard, a checklist. This way, categories will be applied consistently and uniformly. Some discussions of qualitative research seem to downplay the importance of reliability and validity (e.g. Denzin \& Lincoln, 2003), but others do stress the need to take this into account (e.g. Silverman, 2001; see, also: Krippendorff, 2004, p.158). After all, we should be able to justify our choices and interpretations (Wester \& Peters, 2004, pp.22-3).

The structure of a codebook should relate to the structure of the material that will be coded and the logic of observation. It also provides information on the project, the texts that are analysed and the categories and dimensions and how they should be applied. Wester, Pleijter and Renckstorf (2006, pp.196-201) have proposed eight steps along which to structure the work. Slightly adapted to the current research project these steps are: 
1. Read the series of articles about a topic for each newspaper to get familiar with the subject matter and to get a first overview of the relevant dimensions.

2. Shortly describe the rough general storyline and context of the complete set of articles from each newspaper.

3. Provide a first summary of the series.

4. Read each text (article) and highlight relevant passages.

5. Compile a list of headlines and relevant fragments for each series of articles.

6. Phrase the relevant themes for each series.

7. Compare the different series of newspaper articles - in this study, the six series corresponding with the selected Dutch and German newspapers.

8. Compare the representation of the different topics - in other words, the two cases.

These eight steps resulted in a number of concrete documents that were used to study the cases and subsequently draft the relevant chapters:

- Lists of all the selected articles for each series, including short summaries of the articles' contents;

- Lists containing a detailed overview of the information provided by the articles of each series, based on the three content dimensions;

- Summaries of all six series;

- Summaries of the debates in the two public spheres.

\section{General Instructions}

Articles were selected from the article databases mentioned in the Introduction, using the key terms listed in Box 3 (Chapter 5) and Box 5 (Chapter 6). To be included in the analysis, articles had to:

- Refer to the debate on Europe's future, respectively the debate on EU air quality legislation;

- Provide an implicit or explicit indication of one of five stages of an average policy cycle, being agenda-setting, policy-shaping, decision-making, implementation and evaluation (e.g. Versluis, Van Keulen \& Stephenson, 2011);

- Mention an opinion, act or other type of statement relating to the process or the policy itself. 
Based on these criteria the selection process was quite straightforward in most instances. In cases where doubts remained, articles were included as it was expected that this would not impair the overall findings of this qualitative study (cf. Wester, Pleijter \& Renckstorf, 2006, p.205). In some cases the application of the selection criteria meant that an article on a similar issue may be excluded from the analysis of one newspaper, while being included in the next. For example, in both the Dutch and the German newspapers the rejection of the TECE was later linked to the installation of a new French government and to falling Euro exchange rates. Most of these articles were excluded, but for an exception see: FAZ 10.06.05. Finally, sometimes the databases returned articles from local and regional editions. Since this study focused on the national debate, these articles were excluded.

Articles that continued on another page were counted as one when it was explicitly mentioned to be a follow-up. Short first-page announcements of articles that figured on the inside pages were also not counted separately, unless they contained different information. Full length articles that referred to other articles were included separately. In practice this was not always that straightforward. For example, the FAZ-database in particular contained files that already presented two parts of an article together. Even though such occurrences may have had an impact on the quantity of articles, they did not distort the actual quality of the information.

The articles were manually coded, using different colours to mark the three dimensions: black for the issue dimension, blue for the process dimension and red for the actor dimension. ${ }^{175}$ The analysis of those articles in which the two topics were of secondary importance only focussed on the relevant information regarding the topics; other information was not recorded. For example, only those actors that referred to the Union's future or to EU air quality legislation were recorded.

\section{The Coding Form}

While the coding form was not actually filled out for each article, it was used to ask the relevant questions to each article. These questions concerned general information, as well as the three content dimensions. The 'answers' were used to compile the lists with article titles and summaries and the forms which were used to record the information. The instructions and the coding form provided here represent modified versions, because along the process it became clear that some questions or categories were not practical.

\footnotetext{
${ }^{175}$ Originally the aim was to use Atlas.ti, but in practice this programme did not always prove to be helpful.
} 


\section{General Information}

NAME OF THE NeWSPAPER: de Volkskrant (VK), NRC Handelsblad (NRC), De Telegraaf (TEL), Frankfurter Rundschau (FR), Süddeutsche Zeitung (SZ), Frankfurter Allgemeine Zeitung (FAZ)

\section{ARTICLE TITLE: main- and, when applicable, subtitle}

DATE: day.month.year (for example, FAZ 29.03.05) - this is also the way in which references to articles have been included in the two empirical chapters.

AUTHOR: authors were recorded as actors in case of columns/letters/editorials/opinion articles. In case of editorials, the newspaper in which they appeared were recorded as an actor.

TYPE OF ARTICLE: regularly, the article databases did not display page-numbers or sections, so this was not specifically recorded. What was more important for the analyses was the type of article. Again, this was not always clear, but a distinction between three general categories was made: news/background/analysis articles presented the news and related information, columns/letters/editorials/opinion articles were specific contributions to the debate and interviews were discussions between (usually) (a) journalist(s) and one or more interviewees.

EU PRIMARY OR SECONDARY: this refers to the prominence of the EU or its policies in the texts. A primary focus applied when an article's key topic was related to the topic of case study in question - in other words, the debate on Europe's future or the debate on EU air quality legislation. In case of a secondary focus the topic of the case study was not the main concern of the article.

\section{Three Content Dimensions}

The presence of the following three dimensions in political communications can increase the visibility of policies, show who can be held accountable and stimulate public debates (Meyer, 1999, pp.622-3). Since these dimensions cannot always be discerned in the coverage of national affairs, they were not used to mirror some kind of idealistic situation, but as analytical tools to study the content of the selected articles. In both case studies, information was provided by the newspapers themselves, but also by the actors they quoted. Likewise, actors were directly cited or contributed via opinion articles, but they were also indirectly mentioned by other actors or by the newspapers. 
ISSUE DIMENSION: this dimension deals with the actual content of the policies.

- What issues are at stake? What problem is addressed? For example, specific air quality norms proposed by the Commission.

- What is the background/context of the issues? Naturally, all articles referred to a certain background, whether or not specifically related to the issue at stake. This question was used to see in which other contexts the policies were discussed (for example, the war against Iraq or democratic decision-making in the EU).

- What role should the EU play? This could both mean that the EU should do something or that it should not. For example, both positions were recorded regarding the possible inclusion of a reference to Europe's supposedly JudeoChristina heritage in the Constitutional Treaty.

- What is the relevance of the policy? Who benefits from or is affected by certain policies? The latter could only be recorded in the second case study and just a few times (for example, 'PM pollution is especially detrimental for people with asthma').

PROCESS DIMENSION: this dimension focuses on the policy process; on past, present and future steps, but also on who is involved in the process. Past present and future steps may each refer to the five stages mentioned previously.

- What was the state of affairs in the past? For example, Fischer's Humboldt speech in May 2000 or the transposition of Directive 1999/30/EC by Germany (in 2002) or the Netherlands (in 2001).

- What is the current state of affairs? For example, meetings of institutions, but also very recent events, such as 'last week's proposals' - they still shape the current state of affairs.

- What will happen next? The future state of affairs, such as when the European Council will meet or when air quality limit values will come into force.

- How is the policy process shaped? This indicates who is believed to be responsible and who is not. It may also hold information about how decisions are being made, for example based on QMV.

ACTOR DIMENSION: this dimension is concerned with the involvement of the various actors and their actions and positions. In this dimension the focus was on the present. Hence, actors who had done something in the past were not recorded as con- 
tributing to the current debate. Actors included politicians, but also interest organisations, companies or citizens' groups and individual citizens. In general, personalisation provides news with a face and clarifies responsibilities. In some cases references were very specific (for example, 'Commissioner Wallström calls upon Member States to implement legislation'), in others they were descriptive (e.g. 'Brussels has decided that...'). Spokespersons of institutions and ministries were not mentioned separately since they represented their organisations or for example individual Commissioners. Similarly, Commission delegations or EP delegations in the Member States were recorded under their respective institutions.

- National actors: in Dutch papers, Dutch actors; in German papers, German actors.

- Transnational actors: actors from other EU Member States or the Accession Countries. The latter for example contributed actively to the debates in the Convention or were in the process of implementing EU air quality legislation. In a few instances actors could not be located (for example, 'diplomats' or 'scientists'), in which case they were recorded as transnational. In the context of articles about for example Commission proposals, interest organisations were always recorded as European, even when the article only read 'environmentalists'. This did however not apply to for example 'diplomats', because they tend to be national officials, not European.

- Supranational actors: EU actors including national MEPs (in other words, Dutch and German MEPs), organised interests' umbrella organisations, European think tanks such as the Centre for European Reform (CER) and the Centre for European Policy Studies (CEPS), pan-European media such as the European Voice but also the Financial Times - a British newspaper, but generally regarded as the only true European newspaper (e.g. Grefe, 2001). When the EU leaders or ministers sat together in the (European) Council and acted as such, they were also recorded as a supranational actor. The newspapers sporadically referred to 'European citizens', but these were counted as transnational actors.

- Non-EU actors: other countries in Europe or outside, such as the US, and other organisations such as the UN, the WHO or organised interests such as Greenpeace (unless referred to as Greenpeace Europe) or Friends of the Earth (unless referred to as for example Friends of the Earth Netherlands, Milieudefensie). 


\section{Annex 2:}

\section{The Constructed Weeks}

\begin{tabular}{|c|c|}
\hline 2000 & \\
\hline $1^{\text {st }}$ Half & $2^{\text {nd }}$ Half \\
\hline Monday 28 February & Monday 3 July \\
\hline Tuesday 22 February & Tuesday 17 October \\
\hline Wednesday 8 March & Wednesday 2 August \\
\hline Thursday 8 June & Thursday 27 July \\
\hline Friday 16 June & Friday 22 September \\
\hline Saturday 4 March & Saturday 30 September \\
\hline 2001 & \\
\hline $1^{\text {st }}$ Half & $2^{\text {nd }}$ Half \\
\hline Monday 25 June & Monday 10 September \\
\hline Tuesday 5 June & Tuesday 4 December \\
\hline Wednesday 23 May & Wednesday 29 August \\
\hline Thursday 17 May & Thursday 27 December \\
\hline Friday 27 April & Friday 19 October \\
\hline Saturday 16 June & Saturday 17 November \\
\hline 2002 & \\
\hline $1^{\text {st }}$ Half & $2^{\text {nd }}$ Half \\
\hline Monday 10 June & Monday 26 August \\
\hline Tuesday 16 April & Tuesday 20 August \\
\hline Wednesday 26 June & Wednesday 11 December \\
\hline Thursday 16 May & Thursday 31 October \\
\hline Friday 15 March & Friday 27 September \\
\hline Saturday 2 March & Saturday 13 July \\
\hline
\end{tabular}




\begin{tabular}{|c|c|}
\hline 2003 & \\
\hline $1^{\text {st }}$ Half & $2^{\text {nd }}$ Half \\
\hline Monday 17 February & Monday 25 November \\
\hline Tuesday 13 May & Tuesday 19 August \\
\hline Wednesday 5 March & Wednesday 19 November \\
\hline Thursday 27 March & Thursday 18 December \\
\hline Friday 14 February & Friday 5 September \\
\hline Saturday 4 January & Saturday 18 October \\
\hline 2004 & \\
\hline$\overline{1^{\text {st }} \text { Half }}$ & $2^{\text {nd }}$ Half \\
\hline Monday 28 June & Monday 20 December \\
\hline Tuesday 11 May & Tuesday 6 July \\
\hline Wednesday 21 April & Wednesday 1 December \\
\hline Thursday 27 May & Thursday 23 September \\
\hline Friday 6 February & Friday 12 November \\
\hline Saturday 3 April & Saturday 4 December \\
\hline 2005 & \\
\hline $1^{\text {st }}$ Half & $2^{\text {nd }}$ Half \\
\hline Monday 18 January & \\
\hline Tuesday 8 February & \\
\hline Wednesday 27 April & \\
\hline Thursday 10 February & \\
\hline Friday 10 June & \\
\hline Saturday 29 January & \\
\hline
\end{tabular}




\section{Interviews}

\begin{tabular}{|c|c|c|}
\hline 1 & Official, DG Communication, European Parliament & 17 January 2007, Strasbourg \\
\hline 2 & $\begin{array}{l}\text { European affairs journalist, representative International Press } \\
\text { Association (API-IPA) }\end{array}$ & 2 July 2007, Brussels \\
\hline 3 & Official, Press Service, European Parliament & $\begin{array}{l}3 \text { July 2007, Brussels and } 14 \text { April } \\
2008, \text { Brussels }\end{array}$ \\
\hline 4 & Public affairs member of staff, Weber Shandwick & 3 July 2007, Brussels \\
\hline 5 & Official, Press Service, European Parliament & 14 April 2008, Brussels \\
\hline 6 & $\begin{array}{l}\text { Former German journalist (ARD, RTL); now at the European Jour- } \\
\text { nalism Centre }\end{array}$ & 15 April 2008, Maastricht \\
\hline 7 & $\begin{array}{l}\text { Former Finnish TV journalist; now at the European Journalism } \\
\text { Centre }\end{array}$ & 15 April 2008, Maastricht \\
\hline 8 & $\begin{array}{l}\text { Official EU Unit, Information and Communication Department, } \\
\text { Dutch Ministry of Foreign Affairs }\end{array}$ & 28 April 2008, The Hague \\
\hline 9 & Official, European Parliament Information Office, the Netherlands & 14 May 2008, The Hague \\
\hline 10 & Official, European Commission Representation, the Netherlands & 14 May 2008, The Hague \\
\hline & Official, DG Communication, European Parliament & 5 June 2008, Brussels \\
\hline & Official, DG Communication, European Commission & 23 May 2008, Brussels \\
\hline & $\begin{array}{l}\text { Former press officer Finnish Permanent Representation; former } \\
\text { official DG F, Council Secretariat; now at the European Journalism } \\
\text { Centre }\end{array}$ & 23 May 2008, Brussels \\
\hline & $\begin{array}{l}\text { Double interview official Press Unit and official Communication } \\
\text { Unit, DG F, Council Secretariat }\end{array}$ & 10 June 2008 , Brussels \\
\hline & Spokesperson Dutch Permanent Representation & 10 July 2008 , Brussels \\
\hline & Official, DG E & $\begin{array}{l}31 \text { August 2010, telephone } \\
\text { interview }\end{array}$ \\
\hline
\end{tabular}

NB This list only contains the formal interviews that are explicitly referred to in the text. To safeguard anonymity specific information about the levels of the officials has been omitted. 



\section{References}

Aarts, K. \& Thomassen, J. (2000) Belangstelling voor Politiek en Politiek Zelfvertrouwen, in: Thomassen, J., Aarts, K. \& Van der Kolk, H. (eds.) Politieke Veranderingen in Nederland 1971-1998. Kiezers en de Smalle Marges van de Politiek (Nijmegen: Sdu Uitgevers), pp.35-55.

Abbott, D. (2002) The Media's Contribution to Democracy, in: Deckmyn, V. (ed.) Increasing Transparency in the European Union? (Maastricht: EIPA), pp.243-7.

Adam, S. (2007) Domestic Adaptations of Europe: A Comparative Study of the Debates on EU Enlargement and a Common Constitution in the German and French Quality Press, International Journal of Public Opinion Research, 19 (4), pp.409-33.

Adam, S. (2008) Do Mass Media Portray Europe as a Community? German and French Debates on EU Enlargement and a Common Constitution, Javnost - The Public, 15 (1), pp.91-112.

Adam, S. (2009) Euroscepticism and the Mass Media. An Analysis of the Form of Contention in the German and French Debates on a European Constitution, in: Fuchs, D., Magni-Berton, R. \& Roger, A (eds.) Euroscepticism. Images of Europe among Mass Publics and Political Elites (Opladen [etc.]: Barbara Budrich Publishers), pp.193-211.

Agacinski, S. (2001) Stages of Democracy, in: Hénaff, M. \& Strong, T.B. (eds.) Public Space and Democracy (Minneapolis [etc.]: University of Minnesota Press), pp.129-43.

Allen, D. (2004) The Convention and the Draft Constitutional Treaty, in: Cameron, F. (ed.) The Future of Europe. Integration and Enlargement (London [etc.]: Routledge), pp.18-34.

Altheide, D.L. (1996) Qualitative Media Analysis (Qualitative Research Methods Vol.38) (Thousand Oaks [etc.]: SAGE Publications).

Andersen, M.K. \& Liefferink, D. (1997) Introduction: The Impact of Pioneers on EU Environmental Policy, in: Andersen, M.K. \& Liefferink, D. (eds.) European Environmental Policy. The Pioneers (Manchester [etc.]: Manchester University Press), pp.1-39.

Anderson, B. (1983) Imagined Communities. Reflections on the Origins and Spread of Nationalism (London [etc.]: Verso).

Anderson, P.J. \& McLeod, A. (2004) The Great Non-Communicator? The Mass Communication Deficit of the European Parliament and its Press Directorate, Journal of Common Market Studies, 42 (5), pp.897-917.

Anderson, P.J. \& Price, J. (2008) An Evaluation of the Press and Communication Reforms of the Prodi Commission of 1999-2004. With Particular Reference to UK Europhile and Eurosceptic Journalists' Perceptions of their Impact, European Journal of Communication, 23 (1), pp.29-46.

Anderson, P.J. \& Weymouth, T. (1999) Insulting the Public? The British Press and the European Union (London [etc.]: Longman). 
Andeweg, R.B. \& Irwin, G.A. (2002) Governance and Politics of the Netherlands (Basingstoke [etc.]: Palgrave Macmillan).

Ansell, C., Maxwell, R. \& Sicurelli, D. (2006) Protesting Food: NGOs and Political Mobilization in Europe, in: Ansell, C. \& Vogel, D. (eds.) What's the Beef? The Contested Governance of European Food Safety (Cambridge, Mass. [etc.]: MIT Press), pp.97-122.

Arnull, A. \& Wincott, D. (eds.) (2002) Accountability and Legitimacy in the European Union (Oxford [etc.]: Oxford University Press).

Auberger, T. \& Iszkowski, K. (2007) Democratic Theory and the European Union: Focusing on 'Interest' or 'Reason'? Journal of European Integration, 29 (3), pp.271-84.

Backes, Ch. W. (2006) Internationale Vergelijking Implementatie EU Richtlijnen Luchtkwaliteit (Utrecht: Centrum voor Omgevingsrecht en Beleid/NILOS, Universiteit Utrecht).

Backes, Ch. (2007) Juridische Institutionalisering van het Mileubeleid, in: Driessen P. \& Leroy, P. (eds.). Milieubeleid. Analyse en Perspectief (Bussum: Uitgeverij Coutinho), pp.101-28

Backes, Ch.W. \& Van Nieuwerburgh, T. (2005) Transformatie van Richtlijn 1999/30/EG in het Recht van Enkele EG Landen en -regio's en Toepassing van de Grenswaarden voor NO2 en $\mathrm{PM}_{10}$ in de Praktijk (Utrecht: Centrum voor Omgevingsrecht en Beleid/NILOS, Universiteit Utrecht).

Backes, Ch.W., Van Nieuwerburgh, T. \& Koelemeijer, R.B.A. (2005) Transformation of the First Daughter Directive on Air Quality in Several EU Member States and its Application in Practice, European Environmental Law Review, 14 (6), pp.157-64.

Baisnée, O. (2002) Can Political Journalism Exist at the EU Level? in: Kuhn, R. \& Neveu, E. (eds.) Political Journalism. New Challenges, New Practices (London [etc.]: Routledge), pp.108-28.

Baisnée, O. (2004) The Politics of The Commission as an Information Source, in: Smith, A. (ed.) Politics and the European Commission. Actors, Interdependence, Legitimacy (London [etc.]: Routledge), pp.134-155.

Baisnée, O. (2007a) Understanding EU News Production Logics: Norms, Channels and Structures of Reporting Europe from Brussels, in: AIM Research Consortium (ed.) Reporting and Managing European News. Final Report of the Project "Adequate Information Management in Europe" 2004-2007 (Bochum [etc.]: Projekt Verlag), pp.25-43.

Baisnée, O. (2007b) The European Public Sphere does not Exist (At Least it is Worth Wondering...), European Journal of Communication, 22 (4), pp.493-503.

Bakker, P. \& Vasterman, P. (2007) The Dutch Media Landscape, in: Terzis, G. (ed.) European Media Governance. National and Regional Dimensions (Bristol [etc.]: Intellect), pp.145-55.

Balčytienè, A., Raeymaeckers, K., De Bens, E., Vinciūnienè, A. \& Schröder, R. (2007) Understanding the Complexity of EU Communication: The Spokespersons' Perspective, in: AIM Research Consortium (ed.) Understanding the Logic of EU Reporting in Brussels. Analysis of Interviews with EU Correspondents and Spokespersons (Bochum [etc.]: Projekt Verlag), pp.151-66.

Bale, T. (2005) European Politics. A Comparative Introduction (Basingstoke [etc.]: Palgrave Macmillan).

Balvanes, M., Donald, S.H. \& Shoesmith, B. (2009) Media Theories and Approaches. A Global Perspective (Basingstoke [etc.]: Palgrave Macmillan).

Bardoel, J. (2002) Het Einde van de Journalistiek? Nieuwe Verhoudingen tussen Professie en Publiek, in: Bardoel, J., Vos, C., Van Vree, F. \& Wijfjes, H. (ed.) Journalistieke Cultuur in Nederland (Amsterdam: Amsterdam University Press), pp.357-71.

Bardoel, J. \& d'Haenens, L. (2004) Media Meet the Citizen. Beyond Market Mechanisms and Government Regulations, European Journal of Communication, 19 (2), pp.165-94.

Barnett, C. (2004) Media, Democracy and Representation: Disembodying the Public, in: Barnett, C. \& Low, M. (eds.) Spaces of Democracy. Geographical Perspectives on Citizenship, Participation and Representation (London [etc.]: SAGE Publications), pp.185-206.

Beach, D. (2008) A new Pragmatism: The Role and Impact of the European Parliament in the Constitutional Treaty Negotiations, in: Laursen, F. (ed.) The Rise and Fall of the EU's Constitutional Treaty (Leiden [etc.]: Martinus Nijhoff Publishers), pp.145-59. 
Becker, P. \& Leiße, O. (2005) Die Zukunft Europas. Der Konvent zur Zukunft der Europäischen Union (Wiesbaden: VS Verlag für Sozialwissenschaften).

Beierwaltes, A. (2002) Demokratie und Medien. Der Begriff der Öffentlichkeit und seine Bedeutung für die Demokratie in Europa. (Baden-Baden: Nomos Verlagsgesellschaft, $2^{\text {nd }}$ edn.).

Benhabib, S. (1992) Models of Public Space: Hannah Arendt, the Liberal Tradition, and Jürgen Habermas, in: Calhoun, C. (ed). Habermas and the Public Sphere (Cambridge, Mass. [etc.]: MIT Press), pp.73-98.

Benhabib, S. (1996) Toward a Deliberative Model of Democratic Legitimacy, in: Benhabib, S. (ed.) Democracy and Difference. Contesting the Boundaries of the Political (Princeton, NJ [etc.]: Princeton University Press), pp.67-94.

Bennett, W.L. \& Entman, R.M. (2001) Mediated Politics: An Introduction, in: Bennett, W.L. \& Entman, R.M. (eds.) Mediated Politics. Communication in the Future of Democracy (Cambridge [etc.]: Cambridge University Press), pp.1-29.

Bennett, W.L. \& Manheim, J.B. (2001) The Big Spin: Strategic Communication and the Transformation of Pluralist Democracy, in: Bennett, W.L. \& Entman, R.M. (eds.) Mediated Politics. Communication in the Future of Democracy (Cambridge [etc.]: Cambridge University Press), pp.279-98.

Benson, D. \& Jordan, A. (2008) A Grand Bargain or an "Incomplete Contract"? European Union Environmental Policy after the Lisbon Treaty, European Energy and Environmental Law Review, 17 (5), pp.280-90.

Benz, A. (2003) Demokratie in der Europäischen Union, in: Katenhusen, I. \& Lamping, W. (eds.) Demokratien in Europa. Der Einfluss der europäischen Integration auf Institutionenwandel und neue Konturen des demokratischen Verfassungsstaate (Opladen: Leske + Budrich), pp.157-80.

Benz, A. (2006) Policy-Making and Accountability in EU Multilevel Governance, in: Benz, A. \& Papadopoulos, Y. (eds.) Governance and Democracy. Comparing National, European and International Experiences (London/New York: Routledge), pp.99-114.

Benz, A. \& Papadopoulos, Y. (2006) Introduction. Governance and Democracy: Concepts and Key Issues, in: Benz, A. \& Papadopoulos, Y. (eds.) Governance and Democracy. Comparing National, European and International Experiences (London [etc.]: Routledge), pp.1-26.

Berezin, M. (2003) Territory, Emotion, and Identity: Spatial Recalibration in a New Europe, in: Berezin, M. \& Schain, M. (eds.) Europe without Borders. Remapping Territory, Citizenship, and Identity in a Transnational Age (Baltimore [etc.]: The Johns Hopkins University Press), pp.1-30.

Besselink, L.F.M. (2006) The Netherlands. Double Dutch: The Referendum on the European Constitution, European Public Law, 12 (3), pp.345-51.

Best, E. (2002) Transparency and European Governance: Clearly Not a Simple Matter, in: in: Deckmyn, V. (ed.) Increasing Transparency in the European Union? (Maastricht: EIPA), pp.91-117.

Best, E., Christiansen, T. \& Settembri, P. (eds.) (2008) The Institutions of the Enlarged European Union. Continuity and Change (Cheltenham [etc.]: Edward Elgar).

Beuter, R. (1994) Germany and the Ratification of the Maastricht Treaty, in: Laursen, F. \& Vanhoonacker, S. (eds.) The Ratification of the Maastricht Treaty (Maastricht: EIPA), pp.87-112.

Beuter, R. (2002) Germany: Safeguarding the EMU and the Interests of the Länder, in: Laursen, F. (ed.) National Preference Formation, Interstate Bargaining and Outcome (Odense: Odense University Press), pp.93-120.

Beyers, J. \& Kerremans, B. (2007) The Press Coverage of Trade Issues: A Comparative Analysis of Public Agenda-Setting and Trade Politics, Journal of European Public Policy, 14 (2), pp.269-92.

Bijsmans, P. (2009) Parlez-Vous Européen? Europadebat en Communicatiebeleid, Bestuurskunde, 18 (2), pp.43-52.

Bijsmans, P. \& Altides, C. (2007) 'Bridging the Gap' between EU Politics and Citizens? The European Commission, National Media and EU Affairs in the Public Sphere, Journal of European Integration, 29 (3), pp.323-40.

Birza, L. (2000) Government Communication and European Integration, in: Katus, J. \& Volmer, W.F. (eds.) Government Communication in the Netherlands. Background, Principles and Functions (The Hague: Sdu Publishers, $2^{\text {nd }}$ edn), pp.117-122. 
Blom, T. (2001) Europa is Geen Natie. Naar een Postparlementaire Democratie?, Krisis, 2 (1), pp.24-42. Blumler, J.G. \& Gurevitch, M. (1995) The Crisis of Public Communication (London [etc.]: Routledge).

Blumler, J.G. \& Kavanagh, D. (1999) The Third Age of Political Communication: Influences and Features, Political Communication, 16 (3), pp.209-30.

Boomgaarden, H.G., Vliegenthart, R., De Vreese, C.H. \& Schuck, A.R.T. (2010) News on the Move: Exogenous Events and News Coverage of the European Union, Journal of European Public Policy, 17 (4), pp.506-526.

Börzel, T.A. \& Risse, T (2000) When Europe hits Home: Europeanization and Domestic Change, European Integration online Papers, 4 (15), Available Online: http://eiop.or.at/eiop/pdf/2000-015.pdf

Börzel, T.A. \& Risse, T. (2003) Conceptualizing the Domestic Impact of Europe, in: Featherstone, K. \& Radaelli, C.M. (eds.) The Politics of Europeanization (Oxford [etc.]: Oxford University Press), pp.5780.

Braniš, M. (2009) Air Quality of Prague: Traffic as a Main Pollution Source, Environmental Monitoring and Assessment, 156 (1-4), pp.377-90.

Brants, K. (2002a) Opgejaagd door Cerberus. De Moeizame Mediatisering van de Politieke Communicatie, in: Bardoel, J., Vos, C., Van Vree, F. \& Wijfjes, H. (eds.) Journalistieke Cultuur in Nederland (Amsterdam: Amsterdam University Press), pp.85-99.

Brants, K. (2002b) Naar een Mediacratie?, in: Van Holsteyn, J. \& Mudde, C. (eds.) Democratie in Verval (Amsterdam: Boom), pp.151-64.

Bruell, C. \& Mokre, M. (2009) Conclusions: Agonism in the European Public Sphere, in: Bruell, C., Mokre, M. \& Pausch, M. (eds.) Democracy Needs Dispute. The Debate on the European Constitution (Frankfurt [etc.]: Campus Verlag), pp.182-93.

Brüggemann, M. (2005) How the EU constructs the European Public Sphere. Seven Strategies of Information Policy, Javnost - The Public, 12 (2), pp.57-74.

Brüggemann, M., Kleinen-v. Königslöw, K. \& Sifft, S. (2004) EU Democracy and the Transnationalization of Public Spheres (Paper presented at the Second Pan-European Conference of the ECPR Standing Group on EU Politics on "Implications of A Wider Europe: Politics, Institutions and Diversity", Bologna 24-26 June 2004).

Burnham, P., Gilland Lutz, K., Grant, W. \& Layton-Henry, Z. (2008) Research Methods in Politics (Basingstoke [etc.]: Palgrave Macmillan, $2^{\text {nd }}$ edn.).

Busch, K. \& Knelangen, W. (2004) German Euroscepticism, in: Harmsen, R. \& Spiering, M. (eds.) Euroscepticism: Party Politics, National Identity and European Integration. (European Studies. An Interdisciplinary Series in European Culture, History and Politics. Vol. 20) (Amsterdam [etc.]: Rodopi), pp.83-98.

Butt Philip, A. (1998) The European Union: Environmental Policy and the Prospects for Sustainable Development, in: Hanf, K. \& Jansen, A-I. (eds.) Governance and Environment in Western Europe. Politics, Policy and Administration (Harlon [etc.]: Longman), pp.253-76.

Calatayud, A. (2006) Atmospheric Pollution, in: Etty, T.F.M. \& Somsen, H. (eds.) The Yearbook of European Environmental Law. Volume 6 (Oxford [etc.]: Oxford University Press), pp.211-24.

Calhoun, C. (ed.) (1992) Habermas and the Public Sphere (Cambridge, Mass. [etc.]: MIT Press).

Calhoun, C. (1993) Civil Society and the Public Sphere, Public Culture, 5 (2), pp.267-80.

Calhoun, C. (2003) The Democratic Integration of Europe. Interests, Identity, and the Public Sphere, in: Berezin, M. \& Schain, M.A. (eds.) Europe without Borders. Remapping Territory, Citizenship, and Identity in a Transnational Age (Baltimore [etc.]: The Johns Hopkins University Press), pp.243-74.

Campbell, A. \& Stott, R. (eds.) (2007) The Blair Years. Extracts from the Alastair Campbell Diaries (London: Hutchinson).

Catalayud, A. (2003) Atmospheric Pollution, in: Somsen, H. (ed.) The Yearbook of European Environmental Law. Volume 3 (Oxford [etc.]: Oxford University Press), pp.355-79.

Cederman, L-E. \& Kraus, P.A. (2005) Transnational Communication and the European Demos, in: Latham, R. \& Sassen, S. (eds.) Digital Formations: Information Technology and New Architectures in the Global Realm (Princeton [etc.]: Princeton University Press), pp.283-311. 
Chang, M., Hanf, D. \& Pelkmans, J. (2010) The Services Directive: Trojan Horse or White Night?, Journal of European Integration, 32 (1), pp.97-114.

Christiansen, T. (2008) The Institutional Politics of the European Union. An Analysis of Administrative Governance and Constitutional Reform in the EU (PhD Thesis, Maastricht University).

Christiansen, T. \& Reh, C. (2009) Constitutionalizing the European Union (Basingstoke [etc.]: Palgrave Macmillan).

Chryssochoou, D.N. (2003) EU Democracy and the Democratic Deficit, in: Cini, M. (ed.) European Union Politics (Oxford: Oxford University Press), pp.365-82.

Colomer, J.M. (2008) Introduction, in: Colomer, J.M. (ed.) Comparative European Politics (London [etc.]: Routledge, $3^{\text {rd }}$ edn.), pp.1-16.

Corbett, R., Jacobs, F. \& Shackleton, M. (2007) The European Parliament (London: John Harper Publishing, $7^{\text {th }}$ edn.).

Costa, O., Jabko, N., Lequesne, C. \& Magnette, P. (2003) Introduction: Diffuse Control Mechanisms in the European Union: Towards a New Democracy?, Journal of European Public Policy, 10 (5), pp.666-76.

Coultrap, J. (1999) From Parliamentarism to Pluralism. Models of Democracy and the European Union's 'Democratic Deficit', Journal of Theoretical Politics, 11 (1), pp.107-35.

Council of the European Union (2006a) Evaluation Report on Member States' Activities during the Reflection Period - Questionnaire, 6199/06 (Brussels, 9 February 2006).

Council of the European Union (2006b) Report on Member Sates' Information and Communication Activities during the Reflection Period, 9701/1/06 REV 1 (Brussels, 24 May 2006).

Cox, R. (2006) Environmental Communication and the Public Sphere (Thousand Oaks [etc.]: SAGE Publications).

Crespy, A. (2010) When 'Bolkestein' is Trapped by the French Anti-Liberal Discourse: A DiscursiveInstitutionalist Account of Preference Formation in the Realm of European Union Multi-Level Politics, Journal of European Public Policy, 17 (8), pp.1253-1270.

Crowley, J. \& Giorgi, L. (2006) Introduction: The Political Sociology of the European Public Sphere, in: Giorgi, L., Von Homeyer, I. \& Parsons, W. (eds.) Democracy in the European Union: Towards the Emergence of a Public Sphere (London [etc.]: Routledge), pp.1-23.

Crum, B. (2009) Accountability and Personalisation of the European Council Presidency, Journal of European Integration, 31 (6), pp.685-701.

Cumberbatch, G. (1998) Effects. Media Effects: The Continuing Controversy, in: Briggs, A. \& Cobley, P. (eds.) The Media: An Introduction (Harlow [etc.]: Longman), pp.262-74.

Curran, J. (1998) Newspapers and the Press. Newspapers: Beyond Political Economy, in: Briggs, A. \& Cobley, P. (eds.) The Media: An Introduction (Harlow [etc.]: Longman), pp.81-96.

Curran, J. (2000) Rethinking Media and Democracy, in: Curran, J. \& Gurevitch, M. (eds.) Mass Media and Society (London [etc.]: Arnold, $3^{\text {rd }}$ edn.), pp.120-54.

Curtin, D.M. (1997) Postnational Democracy. The European Union in Search of a Political Philosophy (The Hague [etc.]: Kluwer Law International).

Curtin, D. (2006) Framing Public Deliberation and Democratic Legitimacy in the European Union, in: Besson, S. \& Marti, J.L. (eds.) Deliberative Democracy and its Discontents (Aldershot [etc.]: Ashgate), pp.133-56.

Curtin, D. (2007) Transparency, Audiences and the Evolving Role of the EU Council of Ministers, in: Fossum, J.E. \& Schlesinger, P. (eds.) The European Union and the Public Sphere. A Communicative Space in the Making? (London [etc.]: Routledge), pp.246-58.

Dahl, R.A. (1989) Democracy and its Critics (New Haven, CT [etc.]: Yale University Press).

Dahl, R.A. (1994) A Democratic Dilemma: System Effectiveness versus Citizen Participation, Political Science Quarterly, 109 (1), pp23-34.

Dahl, R.A. (1999) Can International Organizations be Democratic? A Skeptic's View, in: Shapiro, I. \& Hacker-Cordón, C. (eds.) Democracy's Edges (Cambridge [etc.]: Cambridge University Press), pp.1936. 
Dalton, R.J. (1999) Political Support in Advanced Industrial Democracies, in: Norris, P. (ed.) Critical Citizens. Global Support for Democratic Governance (Oxford [etc.]: Oxford University Press), (pp.57-77).

Davies, Norman (1997) Europe. A History (London [etc.]: Pimlico).

Davies, Nick (2008) Flat Earth News (London: Chatto \& Windus).

De Backer, W. (2002) How Information Technology can Further Transparency: Euractiv.com, in: Deckmyn, V. (ed.) Increasing Transparency in the European Union? (Maastricht: EIPA), pp.241-2.

De Beus, J. \& Mak, J. (2009) De Kwestie Europa. Hoe de EU tot de Nederlandse Politiek Doordringt (Amsterdam: Amsterdam University Press).

Decker, F. \& Hartleb, F. (2007) Populism on Difficult Terrain: The Right- and Left-Wing Challenger Parties in the Federal Republic of Germany, German Politics, 16 (4), pp.434-54.

Della Porta, D. \& Caiani, M. (2006) The Europeanization of Public Discourse in Italy. A Top-Down Process?, European Union Politics, 7 (1), pp.77-112.

Della Porta, D. \& Caiani, M. (2009) Social Movements and Europeanization (Oxford [etc]: Oxford University Press).

Denzin, N.K. \& Lincoln, Y.S. (2003) Introduction. The Discipline and Practice of Qualitative Research, in: Denzin, N.K. \& Lincoln, Y.S. (eds.) Collecting and Interpreting Qualitative Materials (Thousand Oaks [etc.]: SAGE Publications, $2^{\text {nd }}$ edn.), pp.1-45.

Delanty, G. \& Rumford, C. (2005) Rethinking Europe. Social Theory and the Implications of Europeanization (London [etc.]: Routledge).

Delicath, J.W. \& Deluca, K.M. (2003) Image Events, the Public Sphere, and Argumentative Practice: The Case of Radical Environmental Groups, Argumentation, 17 (3), pp.315-33.

Delli Carpini, M.X. \& Williams, B.A. (2001) Let Us Infotain You: Politics in the New Media Environment, in: Bennett, W.L. \& Entman, R.M. (eds.) Mediated Politics. Communication in the Future of Democracy (Cambridge [etc.]: Cambridge University Press), pp.160-81.

Demmke, C. (2003) Trends in European Environmental Regulation: Issues of Implementation and Enforcement, in: Somsen, H. (ed.) The Yearbook of European Environmental Law. Volume 3 (Oxford [etc.]: Oxford University Press), pp.329-54.

Den Hartog, A. (1994) The Netherlands and the Ratification of the Maastricht Treaty, in: Laursen, F. \& Vanhoonacker, S. (eds.) The Ratification of the Maastricht Treaty (Maastricht: EIPA), pp.213-29.

De Schutter, O. (2002) Europe in Search of its Civil Society, European Law Journal, 8 (2), pp.198-217.

De Vreese, C. (2001) 'Europe' in the News. A Cross-National Comparative Study of the News Coverage of Key EU Events, European Union Politics, 2 (3), pp.283-307.

De Vreese, C. (2003) Communicating Europe (London: The Foreign Policy Centre), Available Online: http://fpc.org.uk/fsblob/89.pdf

De Vreese, C.H., Banducci, S.A., Semetko, H.A. \& Boomgaarden, H.G. (2006) The News Coverage of the 2004 European Parliamentary Election Campaign in 25 Countries, European Union Politics, 7 (4), pp.477-504.

Díez Medrano, J. (2003) Qualitätspresse und europäische Integration, in: Klein, A., Koopmans, R., Trenz, H-J., Klein, L., Lahusen, C. \& Rucht, D. (eds.) Bürgerschaft, Öfferntlichkeit und Demokratie in Europa (Opladen: Leske + Budrich), pp.191-212.

Dinan, D. (1999) Ever Closer Union. An Introduction to European Integration (Basingstoke [etc.]: Macmillan, $2^{\text {nd }}$ edn.).

Dinan, D. (2002) Institutions and Governance 2001-02: Debating the EU's Future, Journal of Common Market Studies, 40 (Annual Review), pp.29-43.

Dinan, D. (2003) Governance and Institutions: Anticipating the Impact of Enlargement, Journal of Common Market Studies, 41 (Annual Review), pp.27-43.

Dinan, D. (2004) Governance and Institutions: The Convention and the Intergovernmental Conference, Journal of Common Market Studies, 42 (Annual Review), pp.27-42.

Dinan, D. (2005) Governance and Institutions: A New Constitution and a New Commission, Journal of Common Market Studies, 43 (Annual Review), pp.37-54.

Dougal, J. (2003) Living with Press Eurotrash, British Journalism Review, 14 (2), pp.29-34. 
Downey, J. \& Fenton, N. (2003) New Media, Counter Publicity and the Public Sphere, New Media \& Society, 5 (2), pp.185-202.

Duff, A. (2001) From Amsterdam Left-Overs to Nice Hangovers, The International Spectator, XXXVI (1), pp.13-9.

Dyrberg, P. (2002) Accountability and Legitimacy: What is the Contribution of Transparency? in: Arnull, A \& Wincott, D. (eds.) Accountability and Legitimacy in the European Union (Oxford [etc.]: Oxford University Press), pp.81-96.

Eberl, O. (2004) Die Normalität des Referendums. Europäische Verfassung und deutscher Sonderweg, Blätter für deustche und internationale Politik, 11/2004, pp.1364-74.

Eder, K. (2000) Zur Transformation nationalstaatlicher Öffentlichkeit in Europa. Von der Sprachgemeinschaft zur issuespezifischen Kommunikationsgemeinschaft, Berliner Journal Für Soziologie, 10(2), pp.167-184.

Eder, K. (2003) Öffentlichkeit und Demokratie, in: Jachtenfuchs, M. \& Kohler-Koch, B. (Hrsg.) Europäische Integration (Opladen: Leske + Budrich, $2^{\text {nd }}$ edn.), pp.85-120.

Eder, K., Hellmann, K-U. \& Trenz, H-J. (1998) Regieren in Europa jenseits öffentlicher Legitimation? Eine Untersuchung zur Rolle von politischer Öffentlichkeit in Europa, in: Kohler-Koch, B. (ed.) Regieren in entgrenzten Räumen. (Politische Vierteljahresschrift, Sonderheft 29) (Opladen [etc.]: Westdeutscher Verlag), pp. 321-44.

Eder, K. \& Kantner, C. (2000) Transnationale Resonanzstrukturen in Europa. Eine Kritik der Rede vom Öffentlichkeitsdefizit, in: Bach, M. (ed.) Die europäisierung nationaler Gesellschaften (Kölner Zeitschrift für Soziologie und Sozialpsychologie, Sonderheft 40) (Wiesbaden: Westdeutscher Verlag), pp.306-31.

Edwards, M. (2004) Civil Society (Cambridge [etc.]: Cambridge University Press).

Eilders, C. (2000) Media as Political Actors? Issue Focusing and Selective Emphasis in the German Quality press, German Politics, 9 (3), pp.181-206.

Eilders, C. (2002) Conflict and Consonance in Media Opinion: Political Positions of Five German Quality Newspapers, European Journal of Communication, 17 (1), pp.25-63.

Eilders, C., Degenhardt, K., Herrmann, P. \& Von der Lippe, M. (2004) Surfing the Tide: An Analysis of Party and Issue Coverage in the National Election Campaign 2002, German Politics, 13 (2), pp.218-42.

Eising, R. (2003) Europäisierung und Integration. Konzepte in der EU-Forschung, in: Jachtenfuchs, M. \& Kohler-Koch, B. (eds.) Europäische Integration (Opladen: Leske + Budrich, $2^{\text {nd }}$ edn.), pp.387-416.

Ellis, M. (2004) The Coffee House. A Cultural History (London: Weidenfeld \& Nicolson).

Engel, C. (2006) Germany: A Story of Saving Face, in: Laursen, F. (ed.) The Treaty of Nice. Actor Preferences, Bargaining and Institutional Choice (Leiden [etc.]: Martinus Nijhoff Publishers), pp.83-116.

Erbe, J. (2005) "What do the Papers say?" How Press Reviews link National Media Arenas in Europe, Javnost - The Public, 12 (2), pp.75-92.

Eriksen, E.O. (2007) Conceptualising European Public Spheres. General, Segmented and Strong Publics, in: Fossum, J.E. \& Schlesinger, P. (eds.) The European Union and the Public Sphere. A Communicative Sphere in the Making? (London [etc.]: Routledge), pp.23-43.

Eriksen, E.O. \& Fossum, J.E. (2002) Democracy through Strong Publics in the European Union?, Journal of Common Market Studies, 40 (3), pp.401-24.

Escher, H. (1998) Ländermitwirkung und der Ausschuß der Ständigen Vertreter (AStV), in: Borkenhagen, F.H.U. (ed.) Europapolitik der deutschen Länder: Bilanz und Perspektiven nach der Gipfel von Amsterdam (Opladen: Leske + Budrich), pp.51-68.

Esser, A. (2002) The Transnationalization of European Television, Journal of European Area Studies, 10 (1), pp.13-29.

European Commission (1994) Information. Communication. Openness (Luxembourg: Office for Official Publications of the European Communities).

European Commission (2001a) Communication from the Commission. The Clean Air for Europe (CAFE) Programme: Towards a Thematic Strategy for Air Quality, COM (2001) 245 final (Brussels, 04.05.2001). 
European Commission (2001b) European Governance. A White Paper, COM (2001) 428 final (Brussels, 25.7.2001).

European Commission (2002) Communication from the Commission to the Council the European Parliament, the European Economic and Social Committee and the Committee of the Regions on an Information and Communication Strategy for the European Union, COM (2002) 350 final/2 (Brussels 2.10.2002).

European Commission (2005a) Action Plan to Improve Communicating Europe by the Commission, SEC (2005) 985 (Brussels, 20.07.2005).

European Commission (2005b) Eurobarometer 63. Public Opinion in the European Union (Brussels).

European Commission (2005c) Communication from the Commission to the Council and the European Parliament. Thematic Strategy on Air Pollution, COM (2005) 446 final (Brussels, 21.9.2005).

European Commission (2005d) Proposal for a Directive of the European Parliament and the Council on Ambient Air quality and Cleaner Air for Europe, COM (2005) 447 final (Brussels, 21.9.2005).

European Commission (2005e) Communication from the Commission to the Council, the European Parliament, the European Economic and Social Committee and the Committee of the Regions. The Commission's Contribution to the Period of Reflection and Beyond: Plan-D for Democracy, Dialogue and Debate, COM (2005) 494 final (Brussels, 13.10.2005).

European Commission (2006a) White Paper on a European Communication Policy, COM (2006) 35 final (Brussels, 1.2.2006).

European Commission (2006b) Communication from the Commission to the European Council. The Period of Reflection and Plan D, COM (2006) 212 final (Brussels, 10.05.2006).

European Commission (2006c) Plan D: Elargir et Approfonir le Debat en Europe. Note d'Information de Mme Wallström, SEC (2006) 1553 (Brussels, 24.11.2006).

European Commission (2007a) Communication from the Commission to the Council, the European Parliament, the European Economic and Social Committee and the Committee of the Regions. Communicating Europe in Partnership, COM (2007) 568 final (Brussels, 3.10.2007).

European Commission (2007b) Commission Working Document. Proposal for an Inter-Institutional Agreement on Communicating Europe in Partnership, COM (2007) 569 final (Brussels, 03.10.2007).

European Commission (2008a) Attitudes of European Citizens towards the Environment. Report (Special Eurobarometer 295/ Wave 68.2) (Brussels).

European Commission (2008b) Communication from the Commission to the European Parliament, the Council, the European Economic and Social Committee and the Committee of the Regions. Debate Europe - Building on the Experience of Plan D for Democracy Dialogue, and Debate, COM (2008) 158/4 (Brussels).

European Commission (2008c) Communication from the Commission. European Transparency Initiative. A Framework for Relations with Interest Representatives (Register and Code of Conduct), COM (2008) 323 final (Brussels, 27.05.08).

European Council (2001) Presidency Conclusions European Council Meeting in Laeken, 14 and 15 December 2001, SN 300/1/01 REV 1.

European Council (2003) A Secure Europe in a Better World. European Security Strategy (Brussels, 12.12.2003).

European Council (2006) Brussels European Council, 15/16 June 2006, Presidency Conclusions, 10633/1/06 REV 1 (Brussels, 17.07.2006).

European Council (2007) Brussels European Council, 21/22 June 2007, Presidency Conclusions, 11177/1/07 REV 1 (Brussels, 20.07.2007).

European Parliament (2005) Report on the Period of Reflection: The Structure, Subjects and Context for an assessment of the debate on the European Union, A6-0414/2005 (16.12.2005).

European Parliament (2006) Report on the White Paper on a European Communication Policy, A60365/2006 (16.10.2006). 
Falter, J.W. (2002) Politik als Inszenierung. Ein Essay über die Problematik der Mediendemokratie in 24 Punkten, in: Von Alemann, U. \& Marschall, S. (eds.) Parteien in der Mediendemokratie (Wiesbaden: Westdeutscher Verlag), pp.420-30.

Featherstone, K. (2003) Introduction: In the Name of Europe, in: Featherstone, K. \& Radaelli, C.M. (eds.) The Politics of Europeanization (Oxford [etc.\}: Oxford University Press), pp.3-26.

Fischer, J. (2000) Vom Staatenverbund zur Föderation: Gedanken über die Finalität der europäischen Integration (Humboldt-Universität, Berlin, 12-05-2000). Retrieved on 20 March 2007 from: http://www.jeanmonnetprogram.org/papers/00/joschka_fischer_ge.rtf

Follesdal, A. \& Hix, S. (2005) Why there is a Democratic Deficit in the EU: A Response to Majone and Moravcsik, European Governance Papers (EUROGOV), No. C-05-02. Available Online: http://www.connex-network.org/eurogov/pdf/egp-connex-C-05-02

Foret, F. (2004) Advertising Europe. The Production of Public Information by the Commission, in: Smith, A. (ed.) Politics and the European Commission. Actors, Interdependence, Legitimacy (London [etc.]: Routledge), pp.156-69.

Fossum, J.E. \& Schlesinger, P. (2007) The European Union and the Public Sphere: a Communicative Sphere in the Making?, in: Fossum, J.E. \& Schlesinger, P. (eds.) The European Union and the Public Sphere. A Communicative Sphere in the Making? (London [etc.]: Routledge), pp.1-19.

Fossum, J.E. \& Trenz, H.J. (2006) When the People come in: Constitution-Making and the Belated Politicisation of the European Union, European Governance Papers (EUROGOV), No. C-06-03. Available Online: http://www.connex-network.org/eurogov/pdf/egp-connex-C-06-03.pdf

Fossum, J.E. \& Trenz, H.J. (2007) The Public Sphere in European Constitution-Making, in: Fossum, J.E. \& Schlesinger, P. (eds.) The European Union and the Public Sphere. A Communicative Sphere in the Making? (London [etc.]: Routledge), pp.206-21

Franklin, B. (2004) Packaging Politics. Political Communications in Britain's Media Democracy (London: Arnold, $2^{\text {nd }}$ edn.).

Franklin, M., Van der Eijk, C. \& Marsh, M. (1996) Conclusions: The Electoral Connection and the Democratic Deficit, in: Van der Eijck, C. \& Franklin, M.N. (eds.) Choosing Europe? The European Electorate and National Politics in the Face of Union (Ann Arbor: The University of Michigan Press), pp.366-88.

Fraser, N. (1992) Rethinking the Public Sphere: A Contribution to the Critique of Actually Existing Democracy, in: Calhoun, C. (ed). Habermas and the Public Sphere (Cambridge, Mass. [etc.]: MIT Press), pp. 109-42.

Freijser, C. (2002) Buitenlandse Opinies Verrijken het Debat, De Journalist, 107 (4), pp.35-6.

Friends of Europe et al (2004) Can EU hear me? How to Get the EU's Message Across (Brussels: Friends of Europe).

Gabriel, O.W. (2007) Bürger und Demokratie im vereinigten Deutschland, Politische Vierteljahresschrift, 48 (3), pp.540-52.

Gaffney, J. (1999) Political Rhetoric and the Legitimation of the European Union, in: Banchoff, T. \& Smith, M.P. (eds.) Legitimacy and the European Union. The Contested Polity (London [etc.]: Routledge), pp.199-211.

Gaisbauer, H.P. (2009) Debating the Skandalon: Cuases and Consequences of the French "Non" and the Dutch “Nee", in: Bruell, C., Mokre, M. \& Pausch, M. (eds.) Democracy Needs Dispute. The Debate on the European Constitution (Frankfurt [etc.]: Campus Verlag), pp.163-81.

Gaisbauer, H.P. \& Pausch, M. (2009) The Gap Between Elites and Citizens in European Media Discourses, in: Bruell, C., Mokre, M. \& Pausch, M. (eds.) Democracy Needs Dispute. The Debate on the European Constitution (Frankfurt [etc.]: Campus Verlag), pp.44-68.

Galloway, D. (2001) The Treaty of Nice and Beyond. Realities and Illusions of Power in the EU (Sheffield: Sheffield Academic Press).

Gandy, O.H. (2001) Dividing Practices: Segmentation and Targeting in the Emerging Public Sphere, in: Bennett, W.L. \& Entman, R.M. (eds.) Mediated Politics. Communication in the Future of Democracy (Cambridge [etc.]: Cambridge University Press), pp.141-59. 
Gargarella, R. (2000) Demanding Public Deliberation. The Council of Ministers: Some Lessons from the Anglo-American History, in: Eriksen, E.O. \& Fossum, J.E. (eds.) Democracy in the European Union. Integration through Deliberation (London [etc.]: Routledge), pp.189-205.

Garnham, N. (1992) The Media and the Public Sphere, in: Calhoun, C. (ed). Habermas and the Public Sphere (Cambridge, Mass. [etc.]: MIT Press), pp.359-76.

Gavin, N.T. (2001) British Journalists in the Spotlight. Europe and Media Research, Journalism: Theory, Practice and Criticism, 2 (3), pp.299-314.

Gellner, E. (1983) Nations and Nationalism (Oxford: Blackwell).

Gellner, W. \& Strohmeier, G. (2002) The 'Double' Public: Germany After Unification, German Politics, 11 (3), pp.59-82.

Gerhards, J. (2000) Europäisierung von Ökonomie und Politik und die Trägheit der Entstehung einer europäischen Öffentlichkeit, in: Bach, M. (ed.) Die europäisierung nationaler Gesellschaften. (Kölner Zeitschrift für Soziologie und Sozialpsychologie, Sonderheft 40) (Wiesbaden: Westdeutscher Verlag), pp.277-305.

Giddens, A. (1990) The Consequences of Modernity (Cambridge: Polity Press).

Giorgi, L., Crowley, J. \& Ney, S. (2001) Surveying the European Public Space - A Political and Research Agenda, Innovation, 14 (1), 73-83.

Glaab, M. \& Kießling, A. (2001) Legitimation und Partizipation, in: Korte, K-R. \& Weidenfeld, W. (eds.) Deutschland-Trendbuch. Fakten und Orientierungen (Bonn: Bundeszentrale für politische Bildung), pp.571-611.

Gleissner, M. \& De Vreese, C. H. (2005) News about the EU Constitution. Journalistic challenges and media portrayal of the European Union Constitution, Journalism: Theory, Practice and Criticism, 6(2), pp. 221-242.

Goldhagen, D.J. (1996) Hitler's Willing Executioners. Ordinary Germans and the Holocaust (New York: Vintage Books, this edition 1997).

González-Calatayud, A. (2005a) Atmospheric Pollution, in: Etty, T.F.M. \& Somsen, H. (eds.) The Yearbook of European Environmental Law. Volume 4 (Oxford [etc.]: Oxford University Press), pp.377-94.

González-Calatayud, A. (2005b) Atmospheric Pollution, in: Etty, T.F.M. \& Somsen, H. (eds.) The Yearbook of European Environmental Law. Volume 5 (Oxford [etc.]: Oxford University Press), pp.253-63.

González-Calatayud, A. (2007) Atmospheric Pollution, in: Etty, T.F.M. \& Somsen, H. (eds.) The Yearbook of European Environmental Law. Volume 7 (Oxford [etc.]: Oxford University Press), pp.257-70.

Gray, M. (2000) Negotiating EU Treaties: The Case for a New Approach, in: Best, E., Gray, M. \& Stubb, A. (eds.) Rethinking the European Union. IGC 2000 and Beyond (Maastricht: EIPA), pp.263-80.

Green, S., Hough, D., Miskimmon, A. \& Timmins, G. (2008) The Politics of the New Germany (London [etc.]: Routledge).

Greenwood, J. (2007) Interest Representation in the European Union (Basingstoke [etc.]: Palgrave Macmillan, $2^{\text {nd }}$ edn.).

Grefe, C. (2001) Mächtig, trocken, rosa, Die Zeit, 2001/29.

Grimm, D. (1995) Does Europe Need a Constitution? European Law Journal, 1 (3), pp.282-302.

Grondwet voor het Koninkrijk der Nederlanden (2008) (Staatsblad 2008, 348).

Group 1a (2001) Report of Working Group on Broadening an Enriching the Public Debate on European Matters (Brussels, June 2001). Available Online: http://ec.europa.eu/governance/areas/group1/report_en.pdf

Grundgesetz für die Bundesrepublik Deutschland (2002) (Bonn: Bundeszentrale für politische Bildung).

Grundmann, R. (1999) The European Public Sphere and the Deficit of Democracy, in: Smith, D. \& Wright, S. (eds.) Whose Europe? The Turn to Democracy (Oxford [etc.]: Blackwell Publishers), pp. 125-46.

Gurevitch, M. \& Blumler, J.G. (1990) Political Communication Systems and Democratic Values, in: Lichtenberg, J. (ed.) Democracy and the Media. A Collection of Essays (Cambridge [etc.]: Cambridge University Press), pp.269-89. 
Gutmann, A. \& Thompson, D. (1996) Democracy and Disagreement. Why Moral Conflict cannot be Avoided in Politics, and What should be Done About It (Cambridge, Mass. [etc.]: The Belknap Press of Harvard University Press).

Habermas, J. (1990 [1962]) Strukturwandel der Öffentlichkeit. Untersuchungen zu einer Kategorie der bürgerlichen Gesellschaft (Frankfurt am Main: Suhrkamp Verlag).

Habermas, J. (1995) Remarks on Dieter Grimm's 'Does Europe Need a Constitution?' European Law Journal, 1 (3), pp.303-7.

Habermas, J. (1996) Between Facts and Norms. Contributions to a Discourse Theory of Law and Democracy (Cambridge, Mass. [etc.]: MIT Press).

Hallin, D.C. \& Mancini, P. (2004) Comparing Media Systems. Three Models of Media and Politics (Cambridge [etc.]: Cambridge University Press).

Hallin, D. \& Mancini, P. (2007) The North Atlantic or Liberal Media Model Countries. Introduction, Terzis, G. (ed.) European Media Governance. National and Regional Dimensions (Bristol [etc.]: Intellect), pp.27-32.

Hanf, K. (1997) Air Pollution Policy in the European Union, in: Baker, R. (ed.) Environmental Law and Policy in the European Union and the United States (Westport, CT [etc.]: Praeger), pp.125-46.

Hanf, K. \& Van de Gronden, E. (1997) The Netherlands: Joint Regulation and Sustainable Development, in: Hanf, K. \& Jansen, A-I. (eds.) Governance and Environment in Western Europe. Politics, Policy and Administration (Harlon [etc.]: Longman), pp.152-80.

Harden, I. (2002) The European Ombudsman's Efforts to Increase Openness in the Union, in: Deckmyn, V. (ed.) Increasing Transparency in the European Union? (Maastricht: EIPA), pp.123-45.

Hardy, J. (2008) Western Media Systems (London [etc.]: Routledge).

Harmsen, R. (2004) Euroscepticism in the Netherlands: Stirrings of Dissent, in: Harmsen, R. \& Spiering, M. (eds.) Euroscepticism: Party Politics, National Identity and European Integration (European Studies. An Interdisciplinary Series in European Culture, History and Politics. Vol. 20) (Amsterdam [etc.]: Rodopi), pp.99-126.

Harmsen, R. (2005) The Dutch Referendum on the Ratification of the European Constitutional Treaty, 1 June 2005, Referendum Briefing Paper No.13 (Sussex: European Parties Elections and Referendums Network).

Hartley, J. (1992) The Politics of Pictures. The Creation of the Public in the Age of Popular Media (London [etc.]: Routledge).

Hayes-Renshaw, F. \& Wallace, H. (2006) The Council of Ministers (Basingstoke [etc.]: Palgrave Macmillan, $2^{\text {nd }}$ edn.).

Heikkilä, H. (2007) Beyond 'Insofar as' Questions. Contingent Social Imaginaries of the European Public Sphere, European Journal of Communication, 22 (4), pp.427-41.

Heise, U. (1987) Kaffee und Kaffeehaus. Eine Kulturgeschichte (Hildesheim [etc.]: Olms Presse).

Held, D. (1999) The Transformation of Political Community: Rethinking Democracy in the Context of Globalization, in: Shapiro, I. \& Hacker-Cordón, C. (eds.) Democracy's Edges (Cambridge [etc.]: Cambridge University Press), pp.84-111.

Held, D. (2006) Models of Democracy (Cambridge [etc.]: Polity Press, $3^{\text {rd }}$ edn.).

Hellemans, L. (2007) Het Debat over de Ethologie in de Jaren Zestig en Zeventig van de 20e Eeuw, in: Meijman, F.J., Snelders, S. \& De Wit, O. (eds.). Leonardo voor het Publiek. Een Geschiedenis van de Wetenschaps- en Techniekcommunicatie (Amsterdam: VU University Press/Da Vinci Institute), pp.189-201.

Hénaff, M. \& Strong, T.B. (2001) Introduction. The Conditions of Public Space: Vision, Speech, and Theatricality, in: Hénaff, M. \& Strong, T.B. (eds.) Public Space and Democracy (Minneapolis [etc.]: University of Minnesota Press), pp.1-31.

Hendriks, F. (2001) Polder Politics in the Netherlands: The 'Viscous State' Revisited, in: Hendriks, F. \& Toonen, T.A.J. (eds.) Polder Politics. The Re-Invention of Consensus Democracy in the Netherlands (Aldershot [etc.]: Ashgate), pp.21-40. 
Herdegen, M. (1994) Maastricht and the German Constitutional Court: Constitutional Restraints for an "Ever Closer Union", Common Market Law Review, 31, pp.235-49.

Herdegen, M. (1995) After the TV Judgment of the German Constitutional Court: Decision-Making within the EU Council and the German Länder, Common Market Law Review, 32 (6), pp.1369-84.

Heringa, A.W. \& Kiiver, Ph. (2009) Constitutions Compared. An Introduction to Comparative Constitutional Law (Antwerp [etc.]: Intersentia, $2^{\text {nd }}$ edn.).

Heywood, A. (2002) Politics (Basingstoke [etc.]: Palgrave, $2^{\text {nd }}$ edn.).

Heywood, A. (2004) Political Theory. An Introduction (Basingstoke [etc.]: Palgrave Macmillan, $3^{\text {rd }}$ edn.).

Hildebrand, P.M. (2005) The European Community's Environmental Policy, 1957 to '1992': From Incidental Measures to an International Regime, in: Jordan, A. (ed.) Environmental Policy in the European Union (London [etc.]: Earthscan, $2^{\text {nd }}$ edn.), pp.19-41.

Hodess, R.B. (1997) The Role of News Media in European Integration: A Framework of Analysis for Political Science, Res Publica, 39 (2), pp.215-228.

Hoetjes, B.J.S. (2001) The parliament of the Netherlands and the European Union: Early Starter, Slow Mover, in: Maurer, A. \& Wessels, W. (eds.) National Parliaments on their Ways to Europe: Losers or Latecomers? (Baden-Baden: Nomos Verlagsgesellschaft), pp.337-58.

Hoetjes, B.J.S. (2003) The Netherlands: A Former Founding Father in Search of Control, in: Wessels, W., Maurer, A. \& Mittag, J. (eds.) Fifteen into One? The European Union and its Member States (Manchester [etc.]: Manchester University Press), pp.315-36.

Hoffmann, L. \& Shaw, J. (2004) Constitutionalism and Federalism in the 'Future of Europe' Debate: The German Dimension, German Politics, 13 (4), pp.625-44.

Hohendahl, P.U., Berman, R.A., Kenkel, K \& Strum, A. (2000) Öffentlichkeit - Geschichte eines kritischen Begriffs (Stuttgart [etc.]: Metzler).

Holtz-Bacha, C. (2002) Parteien und Massenmedien im Wahlkampf, in: Von Alemann, U. \& Marschall, S. (eds.) Parteien in der Mediendemokratie (Wiesbaden: Westdeutscher Verlag), pp.42-56.

Hrbek, R. (1999) The Effects of EU Integration on German Federalism, in: Jeffery, C. (ed.) Recasting German Federalism. The Legacies of Unification (London [etc.]: Pinter), pp.217-33.

Hrbek, R. (2001) Die deutschen Länder und das Vertragswerk von Nizza, Integration, 24 (2), pp.102-13.

Hrbek, R. (2003) Die deutschen Länder und der Verfassungsentwurf des Konvents, Integration, 26 (4), pp.357-70.

Hüller, T. (2007) Assessing EU Strategies for Publicity, Journal of European Public Policy, 14 (4), pp.56381.

Illner, M., Čermák, D., Kosteleckŷ, T. \& Stachová, J. (2006) EU Accession and the Public Sphere in New Member States: The Case of the Czech Republic, in: Giorgi, L., Von Homeyer, I. \& Parsons, W. (eds.) Democracy in the European Union: Towards the Emergence of a Public Sphere (London [etc.]: Routledge), pp.157-79.

Imhof, K. (1996) "Öffentlichkeit" als historische Kategorie und als Kategorie der Historie, Schweizerische Zeitschrift für Geschichte, 46 (1), pp.3-25.

Imhof, K. (2003) Öffentlichkeitstheorien, in: Bentele, G., Brosius, H-B. \& Jarren, O. (eds.) Öffentliche Kommunikation. Handbuch Kommunikations- und Medienwissenschaft (Wiesbaden: Westdeutscher Verlag), pp.193-209.

Imig, D. \& Tarrow, S. (eds.) (2001) Contentious Europeans. Protest and Politics in an Emerging Polity (Lanham [etc.]: Rowman \& Littlefield), pp.3-26.

Ismayr, W. (2003) Das politische System Deutschlands, in: Ismayr, W. (ed.) Die politische Systeme Westeuropas (Opladen: Leske + Budrich, $3^{\text {rd }}$ edn.), pp.445-86.

Jakubowicz, K. (2007) The Eastern European/Post-Communist Media Model Countries. Introduction, in: Terzis, G. (ed.) European Media Governance. National and Regional Dimensions (Bristol [etc.]: Intellect), pp.303-13.

Janssen, J. (2001) Publieke Steun voor de Europese Unie. Analyse van de Publieke Opinie in 12 Lidstaten, 1952-1998. 
Jansen van Galen, J. (2001) Praten met de Buren is Moeilijker dan je Denkt, De Journalist, 106 (13), pp.38-9.

Jeffery, C. (1997a) Farewell to the Third Level? The German Länder and the European Policy Process, in: Jeffery, C. (ed.) The Regional Dimension of the European Union. Towards a Third Level in Europe? (London [etc.]: Frank Cass), pp.56-75.

Jeffery, C. (1997b) Regional Offices in Brussels and Multi-Level Governance in the EU: A UK-Germany Comparison, in: Jeffery, C. (ed.) The Regional Dimension of the European Union. Towards a Third Level in Europe? (London [etc.]: Frank Cass), pp.183-203.

Jeffery, C. (2004) Regions and the Constitution for Europe: German and British Impacts, German Politics, $13(4)$, pp.605-24.

Joerges, C. \& Neyer, J. (1997) From Intergovernmental Bargaining to Deliberative Political Processes: The Constitutionalisation of Comitology, European Law Journal, 3 (3), pp.274-300.

Jopp, M. \& Kleine, M. (2004) Multiplikatoren europäischer Öffentlichkeit: Die Rolle der europäischen Institutionen, in: Franzius, C. \& Preuß, U.K. (eds.) Europäische Öffentlichkeit (Baden-Baden: Nomos Verlagsgesellschaft), pp.249-60.

Jordan, A. (1998) Step Change or Stasis? EC Environmental Policy after the Amsterdam Treaty, Environmental Politics, 7 (1), pp.227-36.

Jordan, A. \& Fairbrass, J. (2005) European Union Environmental Policy after the Nice Summit, in: Jordan, A. (ed.) Environmental Policy in the European Union (London [etc.]: Earthscan, $2^{\text {nd }}$ edn.), pp.42-6.

Kaase, M. (2000) Germany: A Society and a Media System in Transition, in: Gunther, R. \& Mughan, A. (eds.) Democracy and the Media. A Comparative Perspective (Oxford [etc.]: Oxford University Press), pp.375-401.

Kaelble, H. (2002) The Historical Rise of a European Public Sphere? Journal of European Integration History, 8 (2), pp.9-22.

Kaiser, W. \& Starie, P. (2005) The European Union as a Transnational Political Space. Introduction, in: Kaiser, W. \& Starie, P. (eds.) Transnational Europe. Towards a Common Political Space (London [etc.] Routledge), pp.1-14.

Kantner, C. (2003) Öffentliche politische Kommunikation in der EU. Eine hermeneutisch-pragmatische Perspektive, in: Klein, A., Koopmans, R., Trenz, H-J., Klein, L., Lahusen, C. \& Rucht, D. (eds.) Bürgerschaft, Öffentlichkeit und Demokratie in Europa (Opladen: Leske + Budrich), pp.213-29.

Kantner, C. (2006) Die thematische Verschränkung nationaler Öffentlichkeiten in Europa und die Qualität transnationaler politischer Kommunikation, in: Imhof, K., Blum, R., Bonfadelli, H. \& Jarren, O. (eds.) Demokratie in der Mediengesellschaft (Wiesbaden: VS Verlag für Sozialwissenschaften), pp.145-60.

Keane, J. (1995) Structural Transformations of the Public Sphere, The Communication Review, 1 (1), pp.122.

Keane, J. (1998) Civil Society: Old Images, New Visions (Cambridge [etc.]: Polity Press).

Keane, J. (2003) Global Civil Society? (Cambridge [etc.]: Cambridge University Press).

Keman, H. (2008) The Low Countries. Confrontation and Coalition in Segmented Societies, in: Colomer, J.M. (ed.) Comparative European Politics (London [etc.]: Routledge, $3^{\text {rd }}$ edn.), pp.208-45).

Keohane, D. (2005) A French Lesson for Europe? A Guide to the Referenda on the EU Constitutional Treaty, CER Briefing Note (London: Centre for European Reform, $3^{\text {rd }}$ Version).

Keukeleire, S. \& MacNaughtan, J. (2008) The Foreign Policy of the European Union (Basingstoke [etc.]: Palgrave Macmillan).

Kevin, D. (2001) Coverage of the European Parliament Elections of 1999: National Public Spheres and European Debates, Javnost - The Public, 8(1), pp.21-38.

Kevin, D. (2003) Europe in the Media. A Comparison of Reporting, Representation, and Rhetoric in National Media Systems in Europe (Mahwah, NJ [etc.]: Lawrence Erlbaum Associates).

Kevin, D. (2007) Conclusion: Making the News in Brussels, in: AIM Research Consortium (ed.) Understanding the Logic of EU Reporting in Brussels. Analysis of Interviews with EU Correspondents and Spokespersons (Bochum [etc.]: Projekt Verlag), pp.197-203. 
Kielmannsegg, P. Graf. (2003) Integration und Demokratie, in: Jachtenfuchs, M. \& Kohler-Koch, B. (eds.) Europäische Integration (Opladen: Leske + Budrich, $2^{\text {nd }}$ edn.), pp.49-83.

Kjær, A.M. (2004) Governance (Cambridge [etc.]: Polity Press).

Kleinnijenhuis, J. \& Oegema, D. (1995) De Media: Debat op Drift, in: Van Kersbergen, K. \& Pröpper, I.M.A.M. (eds.) Publiek Debat en Democratie (Den Haag: Sdu Uitgeverij), pp.175-193.

Kleinnijenhuis, J., Oegema, D., De Ridder, J.A. \& Ruigrok, P.C. (1998) Paarse Polarisatie. De Slag om de Kiezer in de Media (Alphen aan den Rijn: Samsom).

Kleinnijenhuis, J., Takens, J. \& Van Atteveldt, W.H. (2005) Toen Europa de Dagbladen ging vullen, in: Aarts, K. \& Van der Kolk, H. (eds.) Nederlanders en Europa. Het Referendum over de Europese Grondwet (Amsterdam: Uitgeverij Bert Bakker), pp.123-44.

Kleinstüber, H.J. (2001) Habermas and the Public Sphere: From a German to a European Perspective, Javnost - The Public, 8 (1), pp.95-108.

Kleinsteuber, H.J. \& Thomass, B. (2007) The German Media Landscape, in: Terzis, G. (ed.) European Media Governance: National and Regional Dimensions (Bristol [etc.]: Intellect), pp.111-23.

Koelemeijer, R.B.A., Backes, Ch.W., Blom, W.F., Bouwman, A.A. \& Hammingh, P. (2005) Consequenties van de EU-Luchtkwaliteitsrichtlijnen voor Ruimtelijke Ontwikkelingsplannen in Verschillende EULanden (Bilhoven: Milieu- en Natuurplanbureau).

Kohler-Koch, B. \& Rittberger, B. (eds.) (2007a) Debating the Democratic Legitimacy of the European Union (Lanham [etc.]: Rowman \& Littlefield).

Kohler-Koch, B. \& Rittberger, B. (2007b) Charting Crowded Territory: Debating the Democratic Legitimacy of the European Union, in: Kohler-Koch, B. \& Rittberger, B. (eds.) Debating the Democratic Legitimacy of the European Union (Lanham [etc.]: Rowman \& Littlefield), pp.1-29.

Kömeçoglu, U. (2005) The Publicness and Sociabilities of the Ottoman Coffeehouse, Javnost - The Public, $12(2)$, pp.5-22.

Koopmans, R. (2007) Who Inhabits the European Public Sphere? Winners and Losers, Supporters and Opponents in Europeanised Political Debate, European Journal of Political Research, 46 (2), pp.183210.

Koopmans, R. \& Erbe, J. (2004) Towards a European Public Sphere? Vertical and Horizontal Dimensions of Europeanized Political Communication, Innovation, 17 (2), pp.97-118.

Koopmans, R., Neidhardt, F. \& Pfetsch, B. (2000) Conditions for the Constitution of a European Public Sphere (Paper presented at the Euroconference 'Democracy beyond the Nation State', Athens, 5-7 October 2000).

Koopmans, R. \& Pfetsch, B. (2006) Obstacles or Motors of Europeanization? German Media and the Transnationalization of Public Debate, Communications, 31 (2), pp.115-38.

Kopper, G.G., De Bens, E., Frinault, T., Ionescu, L., Lauristin, M., Păun, M. \& Raeymaekers, K. (2007) News Management Processes of the European Union: Reconstructing Problem Areas, in: AIM Research Consortium (red.), Reporting and Managing European News. Final Report of the Project "Adequate Information Management in Europe" 2004-2007 (Bochum [etc.]: Projekt Verlag), pp.79-115.

Korte, K-R. (2001) Regieren, in: Korte, K-R. \& Weidenfeld, W. (eds.) Deutschland-Trendbuch. Fakten und Orientierungen (Bonn: Bundeszentrale für politische Bildung), pp.515-46.

Krause, P.A. (2008) A Union of Diversity. Language, Identity and Polity-Building in Europe (Cambridge [etc.]: Cambridge University Press).

Kriesi, H. (1994) Akteure - Medien - Publikum. Die Herausforderung direkter Demokratie durch die Transformation der Öffentlichkeit, in: Neidhardt, F. (ed.) Öffentlichkeit, öffentliche Meinung, soziale Bewegungen (Kölner Zeitschrift für Soziologie und Sozialpsychologie, Sonderheft 34/1994) (Opladen/Wiesbaden: Westdeutscher Verlag), pp.234-60.

Krippendorff, K. (2004) Content Analysis. An Introduction to Its Methodology (Thousand Oakes [etc.]: SAGE Publications, $2^{\text {nd }}$ edn).

Krouwel, A. \& Lucardie, P. (2008) Waiting in the Wings: New Parties in the Netherlands, Acta Politica, 43 (2-3), pp.278-307. 
Kunelius, R. \& Heikkilä, H. (2007) Mainstream Journalism: Problems and Potential of a European Public Sphere, in: AIM Research Consortium (ed.) Reporting and Managing European News. Final Report of the Project "Adequate Information Management in Europe" 2004-2007 (Bochum [etc.]: Projekt Verlag), pp.45-77.

Kurpas, S., Brüggemann, M. \& Meyer, C. (2006) The Commission White Paper on Communication. Mapping a Way to a European Public Sphere (CEPS Policy Brief, No. 101) (Brussels: Centre for European Policy Studies).

Lacy, S., Riffe, D., Stoddard, S., Martin H. \& Chang, K-K. (2001) Sample Size for Newspaper Content Analysis in Multi-Year Studies, Journalism and Mass Communication Quarterly, 78 (4), pp.836-45.

Laffan, B. (1996) The Politics of Identity and Political Order in Europe, Journal of Common Market Studies, 34 (1), pp.81-102.

Lafont, C. (2006) Is the Ideal of Deliberative Democracy Coherent? in: Besson, S. \& Marti, J.L. (eds.) Deliberative Democracy and its Discontents (Aldershot [etc.]: Ashgate), pp.1-25.

Langendoen, M. \& Pijpers, A. (2002) The Netherlands: The Mixed Fruits of Pragmatism, in: Laursen, F. (ed.) The Amsterdam Treaty. National Preference Formation, Interstate Bargaining and Outcome (Odense: Odense University Press), pp.267-89.

Lanting, B. (2005) Brusselse Regels. Het 'Officiële Orgaan' van de Commissie is Roze, de Volkskrant, 8.6.2005.

Lefevere, J. (1997) The New Directive on Ambient Air Quality Assessment and Management, European Environmental Law Review, 6 (7), pp.210-4.

Lefevere, J. (2000) Atmospheric Pollution, in: Somsen, H. (ed.) Yearbook of European Environmental Law. Volume 1 (Oxford [etc.]: Oxford University Press), pp.361-382.

Lenschow, A. (2005) Environmental Policy. Contending Dynamics of Policy Change, in: Wallace H., Wallace, W. \& Pollack, M.A. (eds.). Policy-Making in the European Union (Oxford [etc.]: Oxford University Press, $5^{\text {th }}$ edn.), pp.305-27.

Leppik,T., Lönnendonker, J., Nitz. P., Hahn, O. \& Schröder, R. (2007) The Case of Germany, in: AIM Research Consortium (ed.) Understanding the Logic of EU Reporting in Brussels. Analysis of Interviews with EU Correspondents and Spokespersons (Bochum [etc.]: Projekt Verlag), pp.57-75.

Lepszy, N. (2003) Das politische System der Niederlands, in: Ismayr, W. (ed.) Die politische Systeme Westeuropas (Opladen: Leske + Budrich, $3^{\text {rd }}$ edn.), pp.349-87.

Liebert, U. (2007) Transnationalising the Public Sphere? The European Parliament, Promises and Anticipations, in: Fossum, J.E. \& Schlesinger, P. (eds.) The European Union and the Public Sphere. A Communicative Space in the Making? (London [etc.]: Routledge), pp.259-78.

Liefferink, D. (1997) The Netherlands: A Net Exporter of Environmental Policy Concepts, in: Andersen, M.K. \& Liefferink, D. (eds.) European Environmental Policy. The Pioneers (Manchester [etc.]: Manchester University Press), pp.210-50.

Liefferink, D. \& Van der Zouwen, M. (2004) The Netherlands. The Advantage of Being 'Mr Average, in: Jordan, A. \& Liefferink, D. (eds.) Environmental Policy in Europe. The Europeanization of National Environmental Policy (London [etc.]: Routledge), pp.'136-53.

Lijphart, A. (1999) Patterns of Democracy. Government Forms and Performance in Thirty-Six Countries (New Haven [etc.]: Yale University Press).

Livingstone, S. (2003a) The Changing Nature of Audiences. From the Mass Audience to the Interactive Media User, in: Valdivia, A.N. (ed.) A Companion to Media Studies (Malden, Mass. [etc]: Blackwell), pp.337-59.

Livingstone, S. (2003b) On the Challenges of Cross-National Comparative Media Research, European Journal of Communication, 18 (4), pp.477-500.

Llobera, J.R. (2001) What unites Europeans?, in: Guibernau, M. (ed.) Governing European Diversity (London [etc.]: SAGE Publications), pp.169-94.

Lodge, J. (1994) Transparency and Democratic Legitimacy, Journal of Common Market Studies, 32 (3), pp.343-68.

Lord, C. (1998) Democracy in the European Union (Sheffield: Sheffield University Press). 
Lord, C. \& Harris, E. (2006) Democracy in the New Europe (Basingstoke [etc.]: Palgrave Macmillan).

Lucardie, P. (2005) De Campagne: David tegen Goliath?, in: Aarts, K. \& Van der Kolk, H. (eds.) Nederlanders en Europa. Het Referendum over de Europese Grondwet (Amsterdam: Uitgeverij Bert Bakker), pp.104-122.

Lucarelli, S. \& Radaelli, C.M. (2004) The European Convention: A Process of Mobilization?, South European Society and Politics, 9 (1), pp.1-23.

Luitwieler, S. \& Pijpers, A. (2006) The Netherlands: From Principles to Pragmatism, in: Laursen, F. (ed.) The Treaty of Nice. Actor Preferences, Bargaining and Institutional Choice (Leiden [etc.]: Martinus Nijhoff Publishers), pp.228-46.

Luyendijk, J. (2006) Het zijn net Mensen. Beelden uit het Midden-Oosten (Amsterdam: Podium).

Machill, M. (1998) Euronews: The First European News Channel as a Case Study for Media Industry Development in Europe and for Spectra of Transnational Journalism Research, Media, Culture \& Society, 20 (3), pp.427-50.

Machill, M., Beiler, M. \& Fischer, C. (2006) Europe-Topics in Europe's Media. The Debate about the European Public Sphere: A Meta-Analysis of Media Content Analyses, European Journal of Communication, 21 (1), pp.57-88.

Magnette, P. (2003) European Governance and Civic Participation: Beyond Elitist Citizenship?, Political Studies, 51 (1), pp.144-60.

Majone, G. (1998) Europe's 'Democratic Deficit': The Question of Standards, European Law Journal, 4 (1), pp.5-28.

Mak, G. (2005) No Europe without a European Coffee House, in: Von der Gablentz, O. et al, Europe as a Cultural Project. Final Report of the Reflection Group of the European Cultural Foundation (20022004) (Amsterdam: European Cultural Foundation), pp.53-56.

Mak, G. (2007) In Europe. Travels through the Twentieth Century (London: Harvill Secker).

Mancini, P., Allern, S., Baisnée, O., Balčytienė, A., Hahn, O., Lazar, M. \& Raudsaar, M. (2007) Context, News Values and Relationships with Sources - Three Factors Determining Professional Practices of Media Reporting on European Matters, in: AIM Research Consortium (red.), Reporting and Managing European News. Final Report of the Project "Adequate Information Management in Europe" 2004-2007 (Bochum [etc.]: Projekt Verlag), pp.117-53.

Mansbridge, J. (1999) Everyday Talk in the Deliberative System, in: Macedo, S. (ed.) Deliberative Politics. Essays on Democracy and Disagreement (Oxford [etc.]: Oxford University Press), pp.211-39.

Mardell, M. (2005) Why I'm Taking on Europe, British Journalism Review, 16 (3), pp.31-5.

Marhold, H. (2006) Deutsche Europapolitik nach dem Regierungswechsel 2005, Integration, 29 (1), pp.322.

Marquand, D. (1979) Parliament for Europe (London: Jonathan Cape).

Mason, J. (2002) Qualitative Interviewing: Asking, Listening and Interpreting, in: May, T. (ed.) Qualitative Research in Action (London [etc.]: SAGE Publications), pp. 225-41.

Maurer, A. (2003) Germany: Fragmented Structures in a Complex System, in: Wessels, W., Maurer, A. \& Mittag, J. (eds.) Fifteen into One? The European Union and Its Member States (Manchester [etc.]: Manchester University Press), pp.115-49.

Mautner, G. (2008) Analyzing Newspapers, Magazines and Other Print Media, in: Wodak, R. \& Krzyżanowski, M. (eds.) Qualitative Discourse Analysis in the Social Sciences (Basingstoke [etc.]: Palgrave Macmillan), pp.30-53.

McCormick, J. (2001) Environmental Policy in the European Union (Basingstoke [etc.]: Palgrave Macmillan).

McCormick, J. (2008) Understanding the European Union. A Concise Introduction (Basingstoke [etc.]: Palgrave Macmillan, $4^{\text {th }}$ edn.).

McGrew, A. (1997) Globalization and Territorial Democracy: An Introduction, in: McGrew, A. (ed.) The Transformation of Democracy? Globalization and Territorial Democracy (Cambridge [etc.]: Polity Press), pp.1-24.

McKee, A. (2005) The Public Sphere: An Introduction (Cambridge [etc.]: Cambridge University Press). 
McNair, B. (2000) Journalism and Democracy. An Evaluation of the Political Public Sphere (London [etc.]: Routledge).

McNair, B. (2003) An Introduction to Political Communication (London [etc.]: Routledge, $3^{\text {rd }}$ edn.).

McQuail, D. (1992) Media Performance. Mass Communication and the Public Interest (London [etc.]: SAGE Publications).

McQuail, D. (2000) McQuail's Mass Communication Theory (London [etc.]: SAGE Publications, $4^{\text {th }}$ edn.).

McQuail, D. (2001) The Media in Europe, in: Guibernau, M. (ed.) Governing European Diversity (London [etc.]: SAGE Publications), pp.195-228.

Meijer, A., Grimmelikhuijsen, S. \& Brandsma, G.J. (2009) Transparantie. Verbreedt en verstrekt Openbaarmaking de Publieke Verantwoording?, in: Bovens, M. \& Schillemans, T. (eds.) Handboek Publieke Verantwoording (The Hague: Uitgeverij LEMMA), pp.205-27.

Meyer, C. (1999) Political Legitimacy and the Invisibility of Politics: Exploring the European Union's Communication Deficit, Journal of Common Market Studies, 37 (4), pp.617-39.

Meyer, C. (2003) Die Wächterfunktion von europäischer Öffentlichkeit. Das Brüsseler Pressecorps und der Rücktritt der EU-Kommission, in: Klein, A., Koopmans, R., Trenz, H-J., Klein, L., Lahusen, C. \& Rucht, D. (eds.) Bürgerschaft, Öffentlichkeit und Demokratie in Europa (Opladen: Leske + Budrich), pp.231-45.

Meyer, C.O. (2005) The Europeanization of Media Discourse: A Study of Quality Press Coverage of Economic Policy Co-ordination since Amsterdam, Journal of Common Market Studies, 43 (1), pp.121-48.

Meyer, C.O. (2009) Does European Union Politics become Mediatized? The Case of the European Commission, Journal of European Public Policy, 16 (7), pp.1047-64.

Meyer, J-H. (2004) Europäische Öffentlichkeit aus historischer Sicht, in: Franzius, C. \& Preuß, U.K. (eds.) Europäische Öffentlichkeit (Baden-Baden: Nomos Verlagsgesellschaft), pp.209-27.

Meyer, T. (2001) Inszenierte Politik und politische Rationalität, in: Korte, K-R. \& Weidenfeld, W. (eds.) Deutschland-Trendbuch. Fakten und Orientierungen (Bonn: Bundeszentrale für politische Bildung), pp.547-70.

Milner, S. (2000) Introduction: A Healthy Scepticism?, Journal of European Integration, 22 (1), pp.1-13.

Moeller, R. (1996) The German Social Democrats, in: Gaffney, J. (ed.) Political Parties and the European Union (London [etc.]: Routledge), pp.33-52.

Möller, A. (2008) From Idealism to Pragmatism: Germany and the Constitutional Treaty, in: Laursen, F. (ed.) The Rise and Fall of the EU's Constitutional Treaty (Leiden [etc.]: Martinus Nijhoff Publishers), pp.145-59.

Monaghan, E. (2008) 'Communicating Europe': The Role of Organised Civil Society, Journal of Contemporary European Research, 4 (1), pp.18-31.

Moore, C., Jacoby, W. \& Gunlicks, A.B. (2008) Introduction: German Federalism in Transition, German Politics, 17 (4), pp.393-407.

Moravcsik, A. (2002) In Defence of the Democratic Deficit: Reassessing Legitimacy in the European Union, Journal of Common Market Studies, 40 (4), pp.603-24.

Morgan, D. (1995) British Media and European Union News. The Brussels News Beat and Its Problems, European Journal of Communication, 10 (3), pp.321-43.

Morgan, D. (1999) The European Parliament, Mass Media and the Search for Power and Influence (Aldershot [etc.]: Ashgate).

Mughan, A. \& Gunther, R. (2000) The Media in Democratic and Nondemocratic Regimes: A Multilevel Perspective, in: Gunther, R. \& Mughan, A. (eds.) Democracy and the Media. A Comparative Perspective (Cambridge [etc.]: Cambridge University Press), pp.1-27.

Munnichs, G. (2000) Publiek Ongenoegen en Politieke Geloofwaardigheid. Democratische Legitimiteit in een Ontzuilde Samenleving (Assen: Van Gorcum).

Nanz, P. \& Steffek, J. (2004) Global Governance, Participation and the Public Sphere, Government and Opposition, 39 (2), pp.314-35. 
Naômé, C. (2002) The Case-Law of the Court of Justice and the Court of First Instance of the European Communities on Transparency: From Carvel to Hautala II (1995-2001), in: Deckmyn, V. (ed.) Increasing Transparency in the European Union? (Maastricht: EIPA), pp.147-97.

Neelen, G.H.J.M., Rutgers, M.R. \& Tuurenhout, M.E. (eds.) (2003) De Bestuurlijke Kaart van Nederland. Het Openbaar Bestuur en Zijn Omgeving in Nationaal en Internationaal Perspectief (Bussum: Uitgeverij Coutinho, $3^{\text {rd }}$ edn.).

Negrine, R. (1996) The Communication of Politics (London [etc.]: SAGE Publications).

Negrine, R. \& Stanyer, J. (eds.) (2007) The Political Communication Reader (London [etc.]: Routledge).

Neidhardt, F. (1994) Öffentlichkeit, öffentliche Meinung, soziale Bewegungen, in: Neidhardt, F. (ed.) Öffentlichkeit, öffentliche Meinung, soziale Bewegungen (Kölner Zeitschrift für Soziologie und Sozialpsychologie, Sonderheft 34) (Opladen: Westdeutscher Verlag), pp.7-41.

Neveu, E. (2002) Europe as an 'un-imaginable community'? The Failure of French News-Magazine L'Européen (March-July 1998), Journal of European Area Studies, 10 (2), pp.283-300.

Newman, M. (2001) Democracy and Accountability in the EU, in: Richardson, J. (ed.) European Union. Power and Policy-Making (London [etc.]: Routledge, $2^{\text {nd }}$ edn.), pp.357-74.

Newsom, D. (2007) Bridging the Gaps in Global Communication (Malden, MA [etc.]: Blackwell Publishing). Nijeboer, A. (2005) The First Dutch Referendum. A Pre-Ballot Assessment, Policy Paper (Paris: Notre Europe).

Nijhuis, T. \& Blom, T. (2002) Leiderschap tegen Wil en Dank. Schröders Nieuwe Europa-Politiek, S \& D, 59 (2), pp.14-24.

Norman, P. (2003) The Accidental Constitution. The Story of the European Convention (Brussels: EuroComment).

Norman, P. (2004) Germany and the UK from Convention to the IGC, German Politics, 13 (4), pp.569-80.

Norton, P. (ed.) (1996) National Parliaments and the European Union (London [etc.]: Frank Cass).

Nugent, N. (2006) The Government and Politics of the European Union (Basingstoke [etc.]: Palgrave Macmillan, $6^{\text {th }}$ edn.).

O’Brennan, J. (2004) Ireland's National Forum on Europe: Elite Deliberation Meets Popular Participation, Journal of European Integration, 26 (2), pp.171-89.

Olsen, J. (2007) The Merger of the PDS and WASG: From Eastern German Regional Party to National Radical Left Party?, German Politics, 16 (2), pp.205-21.

Oppenhuis, E. (1996) The Netherlands: Small Party Evolution, in: Van der Eijk, C. \& Franklin, M.N. (eds.) Choosing Europe? The European Electorate and National Politics in the Face of Union (Ann Arbor: The University of Michigan Press), pp.209-26.

Outhwaite, W. (2008) European Society (Cambridge [etc.]: Polity).

Packham, K. \& Osterhoff, M. (2001) Europeanisation and National Public Spheres: The Issue of the Nice IGC 2000 in British, German, Spanish and Austrian Press, CEuS Working Paper 2001/9 (Bremen: Jean Monnet Centre for European Studies).

Palmer, J. (1998) News Production. News Values, in: Briggs, A. \& Cobley, P. (eds.) The Media: An Introduction (Harlow [etc.]: Longman), pp.377-391.

Panke, D. (2006) More Arguing Than Bargaining? The Institutional Design of the European Convention and Intergovernmental Conventions Compared, Journal of European Integration, 28 (4), pp.357-79.

Papadopoulos, Y. \& Magnette, P. (2010) On the Politicisation of the European Union: Lessons from Consociational National Polities, West European Politics, 33 (4), pp.711-29.

Papathanassopoulos, S. (2007) The Mediterranean/Polarized Pluralist Media Model Countries. Introduction, in: Terzis, G. (ed.) European Media Governance. National and Regional Dimensions (Bristol [etc.]: Intellect), pp.191-200.

Parsons, C. (2009) Competing Vision of European Union, in: Rumford, C. (ed.) The SAGE Handbook of European Studies (London [etc.]: SAGE Publications), pp.191-208.

Paterson, W. (1996) The German Christian Democrats, in: Gaffney, J. (ed.) Political Parties and the European Union (London [etc.]: Routledge), pp.53-70. 
Paterson, W.E. (2003) Germany and Europe, in: Padgett, S., Paterson, W.E. \& Smith, G. (eds.) Developments in German Politics 3 (Basingstoke [etc.]: Palgrave Macmillan), pp.206-26.

Pauw Sanders Zeilstra Van Spaendonck (2004) Waar halen ze het vandaan? Tweede-Kamervragen in het jaar 2003/2004 (Den Haag).

Peers, S. (2002) From Maastricht to Laeken: The Political Agenda of Openness and Transparency in the European Union, in: Deckmyn, V. (ed.) Increasing Transparency in the European Union? (Maastricht: EIPA), pp.7-32.

Pehle, H. (1997) Germany: Domestic Obstacles to an International Forerunner, in: Andersen, M.K. \& Liefferink, D. (eds.) European Environmental Policy. The Pioneers (Manchester [etc.]: Manchester University Press), pp.161-209.

Pehle, H. \& Jansen, A-I. (1997) Germany: The Engine in European Environmental Policy, in: Hanf, K. \& Jansen, A-I. (eds.) Governance and Environment in Western Europe. Politics, Policy and Administration (Harlon [etc.]: Longman), pp.82-109.

Pelkmans, J.L.M., Sie Dhian Ho, M., Limonard, B.R. \& Vazquez Muñoz, A. (2003) De Nederlandse Stem in de Europese Conventie: Een Impuls voor het Debat over het Eindspel, in: Pelkmans, J.L.M., Sie Dhian Ho, M. \& Limonard, B.R. (eds.) Nederland en de Europese Grondwet (WRR Verkenningen) (Amsterdam: Amsterdam University Press), pp.193-256.

Peters, A. (2004) Europäische Öffentlichkeit im europäischen Verfassungsprozess, in: Franzius, C. \& Preuß, U.K. (eds.) Europäische Öffentlichkeit (Baden-Baden: Nomos Verlagsgesellschaft), pp.271-88.

Peters, B.G. (1998) Comparative Politics. Theory and Methods (Basingstoke [etc.]: Macmillan).

Peterson, J. (2009) Policy Networks, in: Wiener, A. \& Diez, T. (eds.) European Integration Theory (Oxford [etc.]: Oxford University Press, $2^{\text {nd }}$ edn.), pp.105-24.

Peterson, J. \& Bomberg, E. (1999) Decision-Making in the European Union (Basingstoke [etc.]: Macmillan).

Pfetsch, B. (2001) Political Communication Culture in the United States and Germany, Press/Politics, 6 (1), pp.46-67.

Pfetsch, B. (2004) From Political Culture to Political Communication Culture. A Theoretical Approach to Comparative Analysis, in: Esser, F. \& Pfetsch, B. (eds.) Comparing Political Communication. Theories, Cases and Challenges (Cambridge [etc.]: Cambridge University Press), pp.344-66.

Pfetsch, B. (2008) Agents of Transnational Debate across Europe. The Press in Emerging European Public Sphere, Javnost - The Public, 15 (4), pp.21-40.

Pfetsch, B, Adam, S. \& Eschner, B. (2008) The Contribution of the Press to Europeanization of Public Debates. A Comparative Study of Issue Salience and Conflict Lines of European Integration, Journalism. Theory, Practice \& Criticism, 9 (4), pp.465-492.

Piepenschneider, M. (2004) Die Rolle der europäischen Parteien, in: Franzius, C. \& Preuß, U.K. (eds.) Europäische Öffentlichkeit (Baden-Baden: Nomos Verlagsgesellschaft), pp.237-47.

Pritchard, G. (1996) National Identity in a United and Divided Germany, in: Bideleux, R. \& Taylor, R. (eds.) European Integration and Disintegration. East and West (London [etc.]: Routledge), pp.154-73.

Pröpper, I.M.A.M. \& Witteveen, W.J. (1995) Goede en Slechte Debatten, in: Van Kersbergen, K. \& Pröpper, I.M.A.M. (eds.) Publiek Debat en Democratie (Den Haag: Sdu Uitgeverij), pp.13-30.

Pross, H. (2000) Zeitungsreport. Deutsche Presse im 20. Jahrhundert (Weimar: Verlag Hermann Böhlaus Nachfolger).

Qvortrup, M. (2006) The Three Referendums on the European Constitution Treaty in 2005, The Political Quarterly, 77 (1), pp.89-97.

Raunio, T. \& Wiberg, M. (2000) Does Support lead to Ignorance? National Parliaments and the Legitimacy of EU Governance, Acta Politica, 35 (2), pp.146-68.

Rawls, J. (1997) The Idea of Public Reason, in: Bohman, J. \& Regh, W. (eds.) Deliberative Democracy. Essays on Reason and Politics (Cambridge, Mass. [etc.]: MIT Press), pp.93-141.

Renfordt, S. (2007) Do Europeans Speak With One Another in Time of War? Results of a Media Analysis on the 2003 Iraq War (RECON Online Working Paper 2007/17), Available Online: http://www.reconproject.eu/main.php/RECON_wp_0717.pdf?fileitem=16662535 
Riffe, D., Aust, C.F. \& Lacy, S.R. (1993) The Effectiveness of Random, Consecutive Day and Constructed Week Sampling in Newspaper Content Analysis, Journalism Quarterly, 70 (1), pp.133-9.

Risse, T. (2002) How do We Know a European Public Sphere When We see One? Theoretical Clarifications and Empirical Indicators (Prepared for IDNET Workshop "Europeanization and the Public Sphere", European University Institute Florence, February 20-21, 2002).

Risse, T. (2009) Social Constructivism and European Integration, in: Wiener, A. \& Diez, T. (eds.) European Integration Theory (Oxford [etc.]: Oxford University Press, $2^{\text {nd }}$ edn.), pp.144-60.

Risse, T. (2010) A Community of Europeans? Transnational Identities and Public Spheres (Ithaca [etc.] Cornell University Press).

Roberts, G.K. (2000) German Politics Today (Manchester [etc.]: Manchester University Press).

Roberts-Thomson, P. (2001) EU Treaty Referendums and the European Union, Journal of European Integration, 23 (2), pp.105-37.

Rometsch, D. (1996) The Federal Republic of Germany, in Rometsch, D. \& Wessels, W. (eds.) The European Union and Member States. Towards Institutional Fusion? (Manchester [etc.]: Manchester University Press), pp.61-104.

Rood, J., Van Keulen, M., Nollen, S. \& Arts, G. (2005) Nederland en de Totstandkoming van EUMilieurichtlijnen. Eindrapport (The Hague: Netherlands Institute of International Relations 'Clingendael').

Rooijendijk, C. (2005) That City is Mine! Urban Ideal Images in Public Debates and City Plans, Amsterdam \& Rotterdam 1945-1995 (Amsterdam: Vossiuspers).

Rosamond, B. (2000) Theories of European Integration (Basingstoke [etc.]: Palgrave Macmillan).

Rose, R. (2008) Political Communication in a European Public Space: Language, the Internet and Understanding as Soft Power, Journal of Common Market Studies, 46 (2), pp.451-75.

Rüdig, W. (1996) Green Parties and the European Union, in: Gaffney, J. (ed.) Political Parties and the European Union (London [etc.]: Routledge), pp.254-72.

Rumford, C. (2002) The European Union. A Political Sociology (Malden, MA [etc.]: Blackwell).

Rumford, C. (2006) Introduction. Rethinking European Spaces: Territory, Borders, Governance, Comparative European Politics, 4 (2/3), pp.127-40.

Russ-Mohl, S. (2003) Towards a European Journalism? - Limits, Opportunities, Challenges, Studies in Communication Science, 3 (2), pp.203-16.

Saalfeld, T. (1996) The German Houses of Parliament and European Legislation, in: Norton, Ph. (ed.) National Parliaments and the European Union (London [etc.]: Routledge), pp.12-34.

Saalfeld, T. (2003 [2000]) Germany. Stable Parties, Chancellor Democracy, and the Art of Informal Settlement, in: Müller, W.C. \& Strøm, K. (eds.) Coalition Governments in Western Europe (Oxford [etc.]: Oxford University Press), pp.32-85.

Sanders, K. (2009) Communicating Politics in the Twenty-First Century (Basingstoke [etc.]: Palgrave Macmillan).

Sassatelli, M. (2002) Imagined Europe. The Shaping of a European Cultural Identity through EU Cultural Policy, European Journal of Social Theory, 5 (4), pp.435-51.

Savigny, H. (2002) Public Opinion, Political Communication and the Internet, Politics, 22 (1), pp.1-8.

Scheffer, P. (2001) Meningen moeten Reizen, De Journalist, 106 (12), pp.25-7.

Schenkel, W. (1998) From Clean Air to Climate Policy in the Netherlands and Switzerland - Same Problems, Different Strategies? (Bern [etc.]: Peter Lang).

Scherer, H. \& Vesper, S. (2004) Was schreiben die Anderen? Ausländische Pressestimmen als Vorform paneuropäischer Öffentlichkeit - Eine Inhaltsanalyse deutscher Qualitätszeitungen, in: Hagen, L.M. (ed.) Europäische Union und mediale Öffentlichkeit. Theoretische Perspektiven und Empirische Befunde zur Rolle der Medien im europäischen Einigungsprozess (Köln: Halem), pp.13-28.

Schermaier, M.J. (2006) German Law, in: Smits, J.M. (ed.) Elgar Encyclopedia of Comparative Law (Cheltenham [etc.]: Edward Elgar), pp.273-88.

Schlesinger, P.R. (1995) Europeanisation and the Media: National Identity and the Public Sphere, ARENA Working Paper No. 7/95 (Oslo: Arena). 
Schlesinger, P. (1999) Changing Spaces of Political Communication: The Case of the European Union, Political Communication, 16 (3), pp.263-279.

Schlesinger, P. \& Kevin, D. (2000) Can the European Union become a Sphere of Publics? in: Eriksen, E.O. \& Fossum, J.E. (eds.) Democracy in the European Union. Integration through Deliberation (London [etc.]: Routledge), pp.206-229.

Schmidt, M.G. (2000) Demokratietheorien. Eine Einführung (Opladen: Leske + Budrich, $3^{\text {rd }}$ edn.).

Schmidt, M.G. (2003) Political Institutions in the Federal Republic of Germany (Oxford [etc.]: Oxford University Press).

Schmidt, M.G. (2008) Germany. The Grand Coalition State, in: Colomer, J.M. (ed.) Comparative European Politics (London [etc.]: Routledge, $3^{\text {rd }}$ edn.), pp.58-93.

Schmitt, H. (1996) Germany: A Bored Electorate, in: Van der Eijk, C. \& Franklin, M.N. (eds.) Choosing Europe? The European Electorate and National Politics in the Face of Union (Ann Arbor: The University of Michigan Press), pp.137-56.

Schmitter, P.C. (2000) How to Democratize the European Union...and Why Bother? (Lanham [etc.]: Rowman \& Littlefield Publishers).

Schoenbach, K. (1996) The "Americanization" of German Election Campaigns: Any Impact on the Voters?, in: Swanson, D.L. \& Mancini, P. (eds.) Politics, Media, and Modern Democracy. An International Study of Innovations in Electoral Campaigning and Their Consequences (Westport, CT [etc.]: Praeger), pp.91-104.

Scholten, O. \& Kleinnijenhuis, J. (1999) Landelijke Dagbladen, Politieke Partijen en Kiezers 1972-1998, in: Van Cuilenburg, J., Neijens, P. \& Scholten, O. (ed.) Media in Overvloed (Amsterdam: Amsterdam University Press), pp.83-100.

Seifert, F. (2006) Synchronised National Publics as Functional Equivalent of an Integrated European public. The Case of Biotechnology, European Integration online Papers, 10 (6), Available Online: http://eiop.or.at/eiop/texte/2006-008a.htm

Semetko, H.A., De Vreese, C.H. \& Peter, J. (2000) Europeanised politics - Europeanised media? European Integration and Political Communication, West European Politics, 23 (4), pp.121-41.

Shackleton, M. (2007) Communicating Europe: Why so Controversial? The Parliament's WebTV Project (Paper Presented at the EUSA Biennial Conference, Montreal, 17-19 May 2007).

Shaw, M. (2000) Media and Public Sphere without Borders? News Coverage and Power from Kurdistan to Kosovo, in: Nacos, B.L., Shapiro, R.Y. \& Isernia, P. (eds.) Decisionmaking in a Glass House. Mass Media, Public Opinion, and American and European Foreign Policy in the $21^{\text {st }}$ Century (Lanham [etc.]: Rowman \& Littlefield), pp.27-40.

Shore, C. (2000) Building Europe. The Cultural Politics of European Integration (London [etc.]: Routledge).

Sifft, S., Brüggemann, M., Kleinen-v. Königslöw, K., Peters, B. \& Wimmel, A. (2007) Segmented Europeanization: Exploring the Legitimacy of the European Union from a Public Discourse Perspective, Journal of Common Market Studies, 45 (1), pp.127-45.

Silverman, D. (2001) Interpreting Qualitative Data. Methods for Analysing Talk, Text and Interaction (London [etc.]: SAGE Publications, $2^{\text {nd }}$ edn.)

Sinnott, R. (1997) European Public Opinion and the European Union. The Knowledge Gap (ICPS Working Paper 126/1997) (Barcelona: Institut de Ciències Polítiques i Socials).

Smith, A.D. (1992) National Identity and the Idea of European Unity, International Affairs, 68 (1), pp.5576.

Smith, A. (2007) European Commissioners and the Prospects of a European Public Sphere. Information, Representation and Legitimacy, in: Fossum, J.E. \& Schlesinger, P. (eds.) The European Union and the Public Sphere. A Communicative Space in the Making? (London [etc.]: Routledge), pp.227-45.

Smith, M.P. (2000) 'The Commission Made Me Do It': The European Commission as a Strategic Asset in Domestic Politics, in: Nugent, N. (ed.) At the Heart of the Union. Studies of the European Commission (Basingstoke [etc.]: Macmillan, $2^{\text {nd }}$ edn.), pp.170-89.

Smits, J.M. (2006) The Netherlands, in: Smits, J.M. (ed.) Elgar Encyclopedia of Comparative Law (Cheltenham [etc.]: Edward Elgar), pp.493-6. 
Sneijder, P. (2008) Doolhof Europa, in: Van Hoogstraten, M. \& E. Jinek (ed.) Het Maakbare Nieuws. Antwoord op Joris Luyendijk - Buitenlandcorrespondenten over hun Werk (Balans: Amsterdam), pp.97107.

Soetendorp, B. \& Hanf, K. (1998) The Netherlands: Growing Doubts of a Loyal Member, in: Hanf, K. \& Soetendorp, B. (eds.) Adapting to European Integration. Small States and the European Union (London [etc.]: Longman), pp.36-51.

Soysal, Y.N. (2002) Locating Europe, European Societies, 4 (3), pp.265-84.

Sprungk, C. (2007) The French Assembleé Nationale and the German Bundestag in the European Union. Towards Convergence in the 'Old' Europe?, in: O'Brennan, J. \& Raunio, T. (eds.) National Parliaments Within the Enlarged European Union. From 'Victims' of Integration to Competitive Actors? (London [etc.]: Routledge), pp.132-62.

Sprungk, C. \& Von Oppeln, S. (2005) Die europäische Verfassungsdebatte in Deutschland und Frankreich, in: Franzke, J. (ed.) Europa in der Denkpause. Wege aus der Verfassungskrise (Potsdam: Brandenburgische Landeszentrale für politische Bildung), pp.76-86.

Stabenow, M. (2004) Zwischen europäischem Rock und nationalem Hemd - EU-Berichterstattung aus Brüsseler Sicht, in: Franzius, C. \& Preuß, U.K. (eds.) Europäische Öffentlichkeit (Baden-Baden: Nomos Verlagsgesellschaft), pp.230-6.

Staeheli, L.A. \& Mitchell, D. (2004) Spaces of Public and Private: Locating Politics, in: Barnett, C. \& Low, M. (eds.) Spaces of Democracy. Geographical Perspectives on Citizenship, Participation and Representation (London [etc.]: SAGE Publications), pp.147-60.

Statham, P. (2007) Journalists as Commentators on European Politics. Educators, Partisans or Ideologues?, European Journal of Communication, 22 (4), pp.461-477.

Stråth, B. (2002) A European Identity. To the Historical Limits of a Concept, European Journal of Social Theory, 5 (4), pp.387-401.

Street, J. (2001) Mass Media, Politics and Democracy (Basingstoke [etc.]: Palgrave).

Sturm, R. \& Pehle, H. (2001) Das neue deutsche Regierungssytem. Die Europäisierung von Institutionen, Entscheidungsprozessen und Politikfeldern in der Bundesrepublik Deutschland (Opladen: Leske + Budrich).

Swift, A. (2006) Political Philosophy. A Beginners' Guide for Students and Politicians (Cambridge [etc.]: Polity).

Taggart, P. (2006) Keynote Article: Questions of Europe - The Domestic Politics of the French and Dutch Referendums and their Challenge for the Study of European Integration, Journal of Common Market Studies, 44 (Annual Review), pp.7-25.

Taylor, C. (1995) Liberal Politics and the Public Sphere, in: Etzioni, A. (ed.) New Communitarian Thinking. Persons, Virtues Institutions and Communities (Charlottesville [etc.]: University Press of Virginia), pp.183-217.

Taylor, P.M. (1997) Global Communications, International Affairs and the Media since 1945 (London/New York: Routledge).

Ter Horst, G. (2008) Grondwet moet veel meer Bezielen. Een Juridische Tekst of een Document dat Allen verbindt?, NRC Handelsblad, 27.2.2008.

Terzis, G. (ed.) (2008) European Media Governance. The Brussels Dimension (Bristol [etc.]: Intellect Books).

Teschner, J. (2000) No Longer Europe's Europhiles? Euroscepticism in Germany in the 1990s, Journal of European Integration, 22 (1), pp.59-86.

The European Convention (2003) Report from the Presidency of the Convention to the President of the European Council, CONV851/03 (Brussels, 18 July 2003).

Tilly, C. (1995) Democracy is a Lake, in: Andrews, G.R. \& Chapman, H. (eds.) The Social Construction of Democracy 1870 - 1990 (New York: New York University Press), pp.365-87.

Timmermans, A. \& Andeweg, R.B. (2003) The Netherlands. Still the Politics of Accommodation?, in: Müller, W.C. \& Strøm, K. (eds.). Coalition Governments in Western Europe (Oxford [etc.]: Oxford University Press), pp.356-98. 
Trenz, H-J. (2003) Einführung: Auf der Suche nach einer europäischen Öffentlichkeit, in: Klein, A., Koopmans, R., Trenz, H-J., Klein, L., Lahusen, C. \& Rucht, D. (eds.) Bürgerschaft, Öffentlichkeit und Demokratie in Europa (Opladen: Leske + Budrich), pp.161-8.

Trenz, H-J. (2004) Media Coverage on European Governance. Exploring the European Public Sphere in National Quality Newspapers, European Journal of Communication, 19 (3), pp.291-319.

Trenz, H.J. (2008) Understanding Media Impact on European Integration: Enhancing or Restricting the Scope of Legitimacy of the EU?, Journal of European Integration, 30 (2), pp.291-309.

Trenz, H-J. \& Eder, K. (2004) The Democratizing Dynamics of a European Public Sphere. Towards a Theory of Democratic Functionalism, European Journal of Social Theory, 7 (1), pp.5-25.

Triandafyllidou, A. (2009) The Mohammed Cartoons Crisis in the British and Greek Press. A European Matter?, Journalism Studies, 10 (1), pp.36-53.

Tsakatika, M. (2008) Political Responsibility and the European Union (Manchester [etc.]: Manchester University Press).

Tumber, H. (1995) Marketing Maastricht: the EU and News Management, Media, Culture \& Society, 17 (3), pp.511-19.

Van Cuilenburg, J.J. (1993) De Maatschappelijke Informatievoorziening, in: Van Deth, J.W. (ed.) Handboek Politicologie (Assen: Van Gorcum), pp.308-28.

Van der Eijk, C. (2000) The Netherlands: Media and Politics between Segmented Pluralism and Market Forces, in: Gunther, R. \& Mughan, A. (eds.) Democracy and the Media. A Comparative Perspective (Oxford [etc.]: Oxford University Press), pp.303-42.

Van der Eijck, C. \& Franklin, M.N. (2004) Potential for Contestation on European Matters at National Elections in Europe, in: Marks, G. \& Steenbergen, M.R. (eds.) European Integration and Political Conflict (Cambridge [etc.]: Cambridge University Press), pp.32-50.

Van der Harst, J. (2003) De Verdwenen Voorspelbaarheid. Het Nederlandse Europabeleid tijdens en na de Koude Oorlog; een Vergelijking, in: De Graaf, B., Hellema, D. \& Van der Zwan, B. (ed.) De Nederlandse Buitenlandse Politiek in de Twintigste Eeuw (Amsterdam: Boom), pp.131-54.

Van der Kolk, H. \& Aarts, K. (2005) Inleiding, in: Aarts, K. \& Van der Kolk, H. (eds.) Nederlanders en Europa. Het Referendum over de Europese Grondwet (Amsterdam: Uitgeverij Bert Bakker), pp.9-18.

Van de Steeg, M. (2002) Rethinking the Conditions for a Public Sphere in the European Union, European Journal of Social Theory, 5 (4), pp.499-519.

Van de Steeg, M. (2003) Bedingungen für die Entstehung von Öffentlichkeit in der EU, in: Klein, A., Koopmans, R., Trenz, H-J., Klein, L., Lahusen, C. \& Rucht, D. (eds.) Bürgerschaft, Öffentlichkeit und Demokratie in Europa (Opladen: Leske + Budrich), pp.169-90.

Van de Steeg, M. (2006) Does a Public Sphere Exist in the European Union? An Analysis of the Content of the Debate on the Haider Case, European Journal of Political Research, 45 (4), 609-34.

Van Hoogstraten, M. \& Jinek, E. (eds.) (2008) Het Maakbare Nieuws. Antwoord op Joris Luyendijk - Buitenlandcorrespondenten over hun Werk (Amsterdam: Balans).

Van Praag, P. (2003) The Winners and Losers in a Turbulent Political Year, Acta Politica, 38 (1), pp.5-22.

Van Praag, P. \& Brants, K. (2000) Politieke Communicatie in een Consensusdemocratie, in: Van Praag, P. \& Brants, K. (eds.) Tussen Beeld en Inhoud. Politiek en Media in de Verkiezingen van 1998 (Amsterdam: Het Spinhuis), pp.242-57.

Van Schendelen, M.P.C.M. (1996) The Netherlands: From Founding Father to Mounding Baby, in: Norton, Ph. (ed.) National Parliaments and the European Union (London [etc.]: Routledge), pp.60-74.

Van Vree, F. (2000) De Politiek van de Openbaarheid. Journalistiek en Publieke Sfeer (Groningen: Historische Uitgeverij).

Verhoeven, I. (2004) Veranderend Politiek Burgerschap en Democratie, in: Engelen, E.R. \& Sie Dhian Ho, M. (eds.) De Staat van de Democratie. Democratie voorbij de Staat (WRR Verkenningen 4) (Amsterdam: Amsterdam University Press), pp.55-77.

Verschuuren, J. (2005) The Netherlands, in: Etty, T.F.M. \& Somsen, H. (eds.) The Yearbook of European Environmental Law. Volume 4 (Oxford [etc.]: Oxford University Press), pp.629-38. 
Versluis, E., Van Keulen, M. \& Stephenson, P. (2011) Analyzing the EU Policy Process (Basingstoke [etc.]: Palgrave Macmillan).

Vetters, R., Jentges, E. \& Trenz, H-J. (2009) Whose Project is It? Media Debates on the Ratification of the EU Constitutional Treaty, Journal of European Public Policy, 16 (3), pp.412-30.

Vink, E. (2007) Multi-Level Democracy: Deliberative or Agnostic? The Search for Appropriate Normative Standards, Journal of European Integration, 29 (3), pp.303-22.

Voltmer, K. \& Eilders, C. (2003) The Media Agenda: The Marginalization and Domestication of Europe, in: Dyson, K.H.F. \& Goetz, K.H. (eds.) Germany, Europe and the Politics of Constraints. (Proceedings of the British Academy, 119) (Oxford [etc.]: Oxford University Press), pp.173-97.

Von Alemann, U. \& Marschall, S. (2002) Parteien in der Mediendemokratie - Medien in der Parteiendemokratie, in: Von Alemann, U. \& Marschall, S. (eds.) Parteien in der Mediendemokratie (Wiesbaden: Westdeutscher Verlag), pp.15-41.

Wallace, H. (2007) Adapting to Enlargement of the European Union: Institutional Practice since May 2004 (Brussels: Trans European Policy Studies Association).

Wallace, W. \& Smith, J. (1995) Democracy or Technocracy? European Integration and the Problem of Popular Consent, West European Politics, 18 (3), pp.137-57.

Ward, D. (2004) The European Union Democratic Deficit and the Public Sphere. An Evaluation of EU Media Policy (Amsterdam [etc.]: IOS Press).

Warleigh, A. (2003) Democracy and the European Union. Theory, Practice and Reform (London [etc.]: SAGE Publications).

Weale, A., Pridham, G., Cini, M., Konstadakopulos, D., Porter, M. \& Flynn, B. (2000) Environmental Governance in Europe. An Ever Closer Ecological Union? (Oxford [etc.]: Oxford University Press).

Weiler, J.H.H. (1997) To be a European Citizen - Eros and Civilisation, Journal of European Public Policy, 4 (4), pp.495-519.

Weiss, R.S. (1994) Learning from Strangers. The Art and Method of Qualitative Interview Studies (New York: The Free Press).

Wennekers, C. (2009) Welk Europa voor de Nederlanders, Bestuurskunde, 18 (2), pp.35-42.

Weibull, L. (2007) The Northern European/Democratic Corporatist Media Model Countries. Introduction, in: Terzis, G. (ed.) European Media Governance. National and Regional Dimensions (Bristol [etc.]: Intellect), pp.55-62.

Wessler, H. (2004) Europa als Kommunikationsnetzwerk. Theoretische Überlegungen zur Europäisierung von Öffentlichkeit, in: Hagen, L.M. (ed.) Europäische Union und mediale Öffentlichkeit. Theoretische Perspektiven und Empirische Befunde zur Rolle der Medien im europäischen Einigungsprozess (Köln: Halem), pp.13-28.

Wester, F. (2006) Inhoudsanalyse als Onderzoeksontwerp, in: Wester, F. (ed.) Inhoudsanalyse: Theorie en Praktijk (Alphen a/d Rijn: Kluwer), pp.11-44.

Wester, F. \& Peters, V. (2004) Kwalitatieve Analyse. Uitgangspunten en Procedures (Bussum: Uitgeverij Coutinho).

Wester, F., Pleijter, A. \& Renckstorf, K. (2006) Interpretatieve Inhoudsanalyse; Nederlanders en Duitsers in de Krant, in: Wester, F. (ed.) Inhoudsanalyse: Theorie en Praktijk (Alphen a/d Rijn: Kluwer), pp.191-205.

Wimmel, A. (2004) Transnationale Diskurse. Zur Analyse politischer Kommunikation in der europäischen Medienöffentlichkeit, Zeitschrift für Internationale Beziehungen, 11 (1), pp.7-25.

Wimmel, A. (2005) Transnationale Diskurs in der europäischen Medienöffentlichkeit: Die Debatte zum EU-Beitritt der Türkei, Politische Vierteljahresschrift, 46 (3), pp.459-83.

Wimmer, J. (2005) Counter-Public Spheres and the Revival of the European Public Sphere, Javnost - The Public, 12 (2), pp.93-110.

Wolinetz, S.B. (2008) Trimming the Sails: The Dutch and the EU Constitution after the Referendum, in: Laursen, F. (ed.) The Rise and Fall of the EU's Constitutional Treaty (Leiden [etc.]: Martinus Nijhoff Publishers), pp.181-200. 
Wright, S. (2007) A Virtual European Public Sphere? The Futurum Discussion Forum, Journal of European Public Policy, 14 (8), pp.1167-85.

Wurzel, R.K.W. (2002) Environmental Policy-Making in Britain, Germany and the European Union. The Europeanisation of Air and Water Pollution Control (Manchester [etc.]: Manchester University Press).

Wurzel, R.K.W. (2004) Germany. From Environmental Leadership to Partial Mismatch, in: Jordan, A. \& Liefferink, D. (eds.) Environmental Policy in Europe. The Europeanization of National Environmental Policy (London [etc.]: Routledge), pp.99-117.

Zürn, M. (2000) Democratic Governance beyond the Nation-State: The EU and other International Institutions, European Journal of International Relations, 6 (2), pp.183-221.

Zürn, M. (2006) Zur Politisierung der Europäischen Union, Politische Vierteljahresschrift, 47 (2), pp.24251. 



\section{Samenvatting}

Sinds de start van de Europese integratie in de jaren vijftig van de vorige eeuw zijn er vanuit de samenleving regelmatig vragen gesteld over het democratische gehalte van de Europese samenwerking. Sinds het Verdrag van Maastricht zijn de zorgen hierover alleen maar toegenomen en is het democratische gehalte van de Europese Unie een nog prominentere rol gaan spelen in politieke en wetenschappelijke discussies. Door dit verdrag nam de invloed van de Europese Unie op sommige terreinen flink toe, terwijl de Unie op tal van andere terreinen voor het eerst een rol kreeg toebedeeld. Oplossingen die de revue zijn gepasseerd, zijn onder andere het versterken van de rol van het direct gekozen Europees Parlement, het versterken van de rol van nationale parlementen en het introduceren van direct-democratische elementen zoals referendums. Deze oplossingen zijn ook deels toegepast, maar over de effectiviteit ervan zijn de meningen verdeeld.

Vanaf ongeveer midden jaren negentig zijn academici in deze context ook steeds meer aandacht gaan besteden aan wat de Nederlands schrijver Geert Mak in zijn in 2004 verschenen In Europa een 'Europees koffiehuis' noemt. Hij doelt hierbij op wat in het Nederlands vaak de 'openbaarheid' wordt genoemd en in het Duits en het Engels tegenwoordig veelal bekend is als respectievelijk 'die Öffentlichkeit' en 'the public sphere': de 'ruimte' waarin debat en opinievorming over maatschappelijke thema's mogelijk wordt gemaakt en wordt gestimuleerd. Er wordt vaak aangenomen dat deze ruimte - die vooral bouwt op de interactie tussen politiek, burgers en media, maar die bijvoorbeeld ook ontstaat door protesten op straat - op nationaal niveau beter functioneert dan op Europees niveau. Doelend op de veronderstelde beperkte publieke discussies over de besluitvorming in de Europese Unie, spreekt men dan ook wel eens van een Europees publiek tekort. Voor veel burgers zijn de media echter de belangrijkste informatiebron over politieke besluitvorming. 
Daarbij dient te worden aangetekend dat niet iedereen even positief oordeelt over de nationale openbaarheden. Zo wordt vaak gewezen op de pogingen van politici om politieke verslaggeving te beïnvloeden, of op de commercialisering van de media die ten koste zou gaan van feitelijke verslaggeving. Hier wordt echter betoogd dat zulke processen niet alleen nadelige zijn geweest, maar ook positieve gevolgen hebben doordat politieke besluitvorming opener en begrijpelijker is geworden. Critici verwijzen vaak naar de openbaarheid van vroeger die kwalitatief veel beter zou zijn geweest dan de huidige, maar er mag niet worden voorbijgegaan aan het feit dat politiek toen veel meer een elitaire bezigheid was. De openbaarheid dient juist open te zijn voor iedereen die denkt dat haar of zijn belangen daarbij gediend zijn.

Nationale en Europese politici hebben geprobeerd om de Europese openbaarheid te bevorderen door het ontwikkelen van communicatiestrategieën, het organiseren van publieksdebatten en het inrichten van hun instellingen op informatieverstrekking en communicatie met burgers en de media. Tot nu toe hebben die van bovenaf gestuurde initiatieven echter weinig effect gesorteerd. Dat valt deels ook te verklaren doordat de politieke logica in Brussel niet altijd past binnen de logica van de media. Zo is de besluitvorming soms traag, zijn onderwerpen vaak zeer technisch en zijn er maar weinig aansprekende politici in de belangrijke instellingen. Correspondenten in Brussel hebben bovendien geen eenvoudige taak, want zij moeten schrijven over een organisatie die enorm veel beleidsterreinen bestrijkt. Daarbij worden journalisten door allerlei betrokkenen met informatie bestookt, met als gevolg een informatieoverschot. Regelmatig missen ze daarbij ook de nationale invalshoek, die juist de interesse voor Europees beleid zou kunnen doen toenemen. Het feit dat correspondenten in Brussel vaak ook de verslaggeving over de NoordAtlantische Verdragsorganisatie en over Belgische, Luxemburgse en soms ook Nederlandse politiek voor hun rekening moeten nemen, maakt de verslaggeving over Europese besluitvorming er niet eenvoudiger op.

Ondanks het feit dat er academici zijn die vinden dat een Europese openbaarheid alleen dan kan bestaan wanneer er overkoepelende Europese media zijn (maar ook Europese partijen en één Europees volk), lijkt de meerderheid van hen van mening dat nationale media een belangrijke rol kunnen spelen. Daarbij wordt wel vaak gewezen op het belang van gelijktijdige debatten, die op vergelijkbare manieren over dezelfde thema's zouden moeten gaan. Idealiter zou daarbij ook aandacht moeten worden besteed aan debatten in andere lidstaten. Sommige academici voegen daaraan toe dat zulke debatten ook grensoverschrijdend moeten zijn, bijvoorbeeld doordat politici uit andere lidstaten niet alleen worden aangehaald in nationale media, maar ook dat er op de meningen van deze politici wordt gereageerd - dat er interactie is over grenzen heen. Deze dissertatie richt zich op zulke thema's en dan specifiek op de volgende drie vragen: in welke mate vormen nationale openbaarheden een forum voor debat en voor de uitwisseling van informatie 
over Europese politiek? Vindt er interactie plaats tussen deze openbaarheden en, zo ja, hoe ziet die eruit? En kan als gevolg hiervan een transnationale Europese openbaarheid ontstaan?

Dergelijke thema's zijn vaak bekeken vanuit een kwantitatief onderzoekskader. Hier wordt echter gesteld dat om een goed overzicht te krijgen van hoe Europa wordt gerepresenteerd in nationale openbaarheden en van een eventuele wisselwerking tussen die openbaarheden, een kwalitatieve benadering van belang is. Omdat deze keuze belangrijke beperkingen met zich meebrengt, is er voor gekozen aandacht te besteden aan twee landen die op de belangrijke vlakken politiek, media en houding ten aanzien van Europa veel gemeen hebben, namelijk Duitsland en Nederland. Daarnaast richt het onderzoek zich op twee specifieke casussen, één politiek gevoelig thema - het debat over de toekomst van Europa en het Europees Grondwettelijk Verdrag - en één meer technisch onderwerp - Europese wetgeving op het terrein van luchtkwaliteit. Veel onderzoek naar de Europese openbaarheid heeft zich gericht op politiek gevoelige onderwerpen, maar de manier waarop technocratisch beleid wordt besproken in openbaarheden is tot nu toe onderbelicht gebleven.

Om een zo goed mogelijk beeld te krijgen van de manier waarop beide thema's in de Duitse en Nederlandse openbaarheden ter sprake kwamen, worden hier artikelen uit een zestal kranten geanalyseerd, drie per land. Hoewel kranten niet meer de leidende media zijn in termen van consumptief gebruik, spelen zij in Duitsland en Nederland nog steeds een belangrijke rol. Dagbladen zoals NRC Handelsblad en Frankfurter Allgemeine Zeitung bieden een belangrijk platform voor debat en bepalen regelmatig de politieke agenda en de agenda van andere media. Hier wordt daarom aangenomen dat een analyse van kranten het beste overzicht geeft van de manier waarop de Europese politiek wordt besproken in nationale openbaarheden.

De analyse richt zich in beide gevallen op de periode 2000-2005, waarbij in het geval van de eerste casus slechts de eerste helft van 2005 is meegenomen. Artikelen zijn daarbij geselecteerd aan de hand van een vast stramien. De analyse besteedt aandacht aan drie dimensies. De issue dimension heeft betrekking op het besproken onderwerp, de achtergrond ervan, het belang van het onderwerp en de rol van de Europese Unie op dat terrein. De process dimension behandelt het besluitvormingsproces en richt zich op de bestaande situatie, op wat daaraan vooraf is gegaan en op wat er in de toekomst eventueel staat te gebeuren. De actor dimension gaat over de actoren die in het debat optreden en op wat zij doen en zeggen. Hierbij wordt een onderscheid gemaakt tussen nationale, transnationale (uit andere lidstaten), supranationale (van de Europese instellingen) en niet aan de Europese Unie gelieerde actoren. Actoren zijn in alle gevallen zowel politici als burgers, maar ook bijvoorbeeld media.

Uit de analyse van de eerste casus blijkt dat de toekomst van Europa en de besluitvorming betreffende het Grondwettelijk Verdrag in beide nationale openbaar- 
heden onderwerp van debat waren en dat daarbij regelmatig dezelfde onderwerpen gelijktijdig ter sprake kwamen. Maar er werden ook vaak verschillende deelonderwerpen besproken en discussies vonden zeker niet altijd gelijktijdig plaats. Er werd ook veel aandacht besteed aan gebeurtenissen in Brussel en in andere lidstaten en er werd niet alleen naar nationale politici verwezen; supranationale en vooral transnationale actoren kwamen vaak voor in het debat (niet-Europese actoren waren vrijwel afwezig). De nadruk lag daarbij wel op regeringsfunctionarissen en in mindere mate parlementariërs, terwijl het maatschappelijk middenveld nauwelijks deel lijkt te hebben genomen aan het debat. Wat betreft de informatievoorziening was er sprake van twee belangrijke tekortkomingen. Enerzijds wat betreft de timing van het publieke debat dat grotendeels werd gevoerd nadat de belangrijke discussies hadden plaatsgevonden en besluiten waren genomen. Hierdoor vond het publieke debat plaats in een andere context en was er nauwelijks nog ruimte om het besluitvormingsproces te beïnvloeden. Anderzijds waren er tekortkomingen wat betreft de inhoud en de informatievoorziening. Het betrof hierbij vooral de manier waarop de besluitvorming plaatsvond en wie daarin de doorslaggevende stem hadden (en dus verantwoordelijk zouden kunnen worden gehouden). Zulke verwijzingen waren regelmatig incorrect of slechts expliciet. Er werd ook zelden aandacht besteed aan wat er voorafging aan het debat over de toekomst van Europa. Ook was het niet altijd duidelijk waarom deze nieuwe verdragswijziging van belang was, of waarom en hoe een bepaald deelonderwerp in het verdrag moest worden opgenomen. Deze bevindingen hebben betrekking op beide openbaarheden, maar in het algemeen was er in de Duitse openbaarheid iets meer aandacht voor zulke zaken.

De analyse van de manier waarop de Europese wetgeving op het gebied van luchtkwaliteit in de Duitse en Nederlandse openbaarheden ter sprake kwam, laat vergelijkbare tekortkomingen zien. Ook hier was er soms sprake van intensief debat. Maar ook hier vond het publieke debat vooral pas plaats nadat de belangrijkste besluiten waren genomen en was het vaak onduidelijk waarop die besluiten waren gebaseerd, hoe ze tot stand waren gekomen en wie ze had genomen. Als deze zaken al ter sprake kwamen dan betrof het vooral wie er op nationaal, regionaal of lokaal niveau verantwoordelijk waren. Wel was er veel aandacht voor het belang van dit beleid, waarbij argumenten betrekking hadden op de volksgezondheid en ook economische overwegingen een rol speelden. De Europese rol op dit terrein werd echter zelden in twijfel getrokken. Een groot verschil tussen deze casus en de vorige was verder dat het debat over de luchtkwaliteit vooral een nationaal karakter had, wat deels te verklaren is door het feit dat het vooral plaatvond toen bleek dat de implementatie van het beleid tot grote problemen leidde. Bovendien was er een aantal verschillen tussen de manier waarop Duitsland en Nederland de betreffende richtlijnen in nationale wetgeving hadden omgezet, waardoor er ook andere accenten werden gelegd. Opvallend genoeg verliepen beide debatten wel synchroon en werd er in beide gevallen wel gewezen op de verantwoordelijkheid van Europese en 
nationale politici. Aandacht voor andere lidstaten was echter veelal beperkt tot het beschrijven van gebeurtenissen aldaar en behelsde maar zelden de uitwisseling van meningen - nationale actoren domineerden dan ook het debat. Belangrijk is dat in deze casus het maatschappelijk middenveld wel degelijk deelnam aan het debat. Het betrof hierbij bijvoorbeeld milieuorganisaties, maar ook vertegenwoordigers van het bedrijfsleven.

Wat opvalt is, dat beide onderwerpen in de Duitse en Nederlandse openbaarheden vaak ook ter sprake kwamen in artikelen die over iets heel anders gingen. Tijdens de selectie van de artikelen viel het zelfs op dat er soms feitelijk werd gesproken over Europees beleid, zonder dat duidelijk te maken - deze artikelen maakten uiteindelijk geen deel uit van de gedetailleerde analyse. Beide constateringen laten zien dat Europa vaak een belangrijkere rol lijkt te spelen in nationale debatten dan normaal wordt gesuggereerd, al is het natuurlijk problematisch dat de Europese invloed niet altijd wordt geëxpliceerd waardoor burgers een verkeerd beeld kunnen krijgen van wat er zich in Brussel afspeelt. Het feit dat nationale overheden vaak belang hebben bij die onduidelijkheid en soms onterecht successen claimen, dan wel 'Brussel' de schuld geven van beleid waarmee ze zelf hebben ingestemd, helpt hierbij niet.

De analyse van beide casussen laat verder ook zien dat de openbaarheid allerminst een statische ruimte is, maar vooral een dynamische, gevormd door interactie tussen politieke actoren, publiek en media. Daarbij speelt het onderwerp dat wordt besproken een belangrijke rol, net zoals het moment in het beleidsproces waarop publiek debat plaatsvindt. Wat betreft het luchtkwaliteitsbeleid weten we verder dat dit in sommige landen veel minder een thema was dan in andere landen. Dit suggereert dat sommige Europese thema's slechts in een aantal lidstaten zal worden opgepikt (of wellicht zelfs in slechts één lidstaat). Zelfs wanneer beleid in meerdere nationale openbaarheden ter sprake komt, dan nog hoeft dat debat niet gelijktijdig plaats te vinden, laat staan grensoverschrijdend te zijn. Voor de Europese openbaarheid betekent dit dat deze zich op verschillende manieren manifesteert.

Tot slot is het belangrijk erop te wijzen dat het veronderstelde Europees publiek tekort veel meer een kwestie lijkt te zijn van kwalitatieve gebreken dan van te weinig aandacht voor de besluitvorming in de Europese Unie. Natuurlijk zijn er belangrijke thema's die nog steeds onderbelicht blijven, maar er zijn ook zaken die wel in de openbaarheid besproken worden, zoals de toekomst van Europa en wetgeving op het gebied van luchtkwaliteit. Hierbij is het, zoals hiervoor aangegeven niet altijd duidelijk, hoe de besluitvorming verloopt. Voor het democratische gehalte van de Europese Unie vormt dit echter een probleem. Daarmee is niet gezegd dat meer en betere communicatie en discussies tot meer instemming met Europees beleid leiden, maar dat is ook niet de essentie van democratie. Het kan er wel toe leiden dat dit beleid op een meer democratische wijze tot stand komt. 



\section{Curriculum Vitae}

Patrick Bijsmans (1977) studied Arts and Culture (specialisation Political Culture) at Maastricht University. After graduating in summer 2002, he started teaching on the university's new Bachelor in European Studies in September 2002. From January to April 2003 he worked as research assistant at the Duitsland Instituut Amsterdam of the University of Amsterdam.

Bijsmans returned to teach European Studies at Maastricht University before embarking on his PhD in September 2003, which was jointly financed by Maastricht University's Faculty of Arts and Social Sciences and the aforementioned Duitsland Instituut Amsterdam. He has participated in the Graduiertenkolleg of the Duitsland Instituut Amsterdam and in the European Research Colloquium 'Democracy and the European Union', organised by the Netherlands Institute of Government (NIG) and the CONNEX (Connecting Excellence on European Governance) network.

Throughout his doctoral research Bijsmans was active in teaching, both at the Bachelor and Master level. In addition, he was a member of several academic advisory and administrative bodies, including the Programme Committee of the Master in European Public Affairs and the NIG's PhD Council, as well as acting as Maastricht's graduate representative for the European Consortium for Political Research (ECPR).

From January to May 2009 Bijsmans was acting Director of Studies of the BacheIor in European Studies and since September 2010 has assumed the full-time role of Director of Studies. He has been a member of the ECPR, the NIG and the Specialist Group on Media and Communication in Europe of the University Association for Contemporary European Studies (UACES). Since September 2010 Bijsmans is coeditor of the book reviews section of the Journal of Common Market Studies. 